


DANGEROUS MARINE ANIMALS 




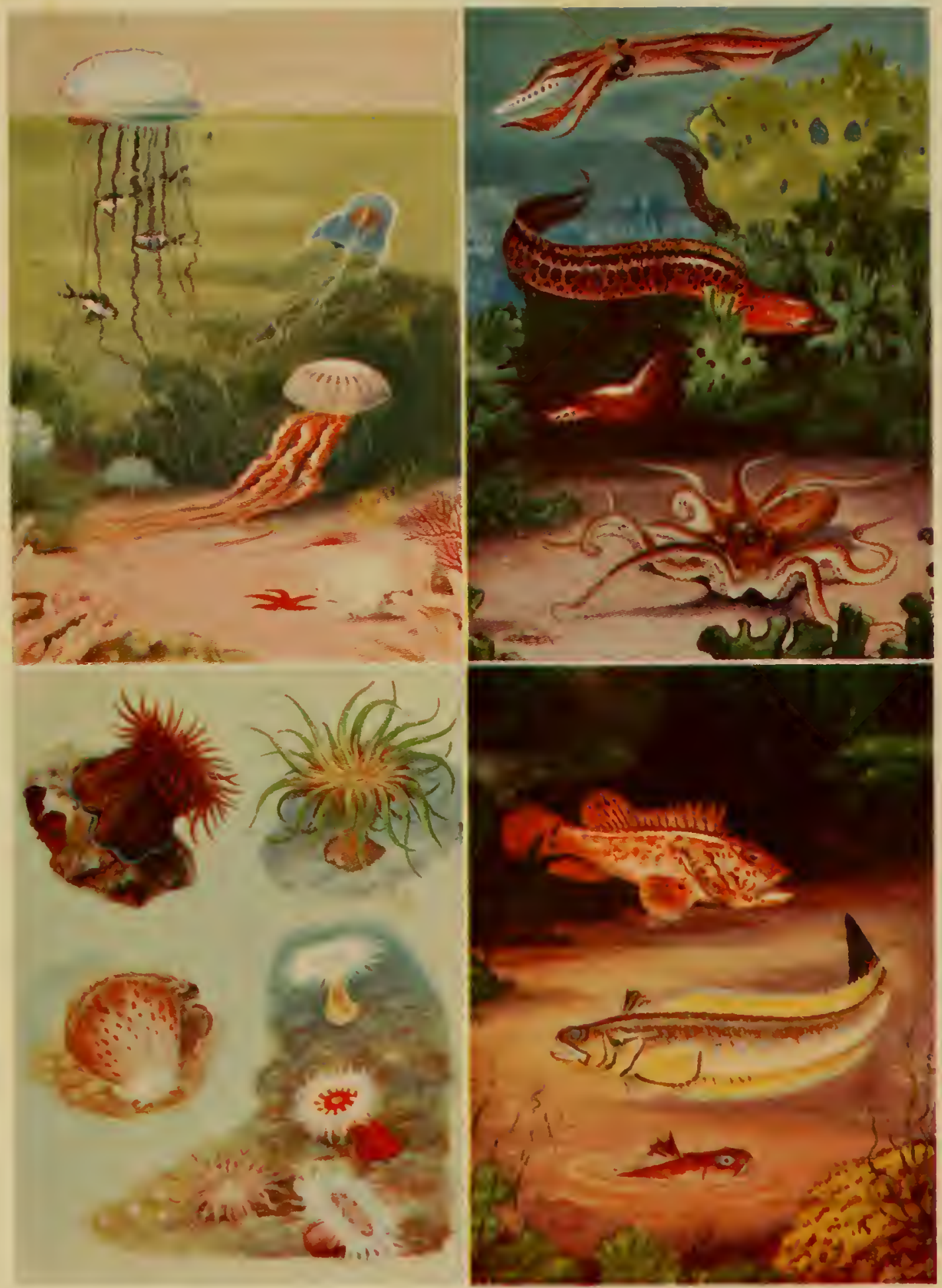

Top Left: Portuguese Man-o'-War, Sea Wasp and Sea Nettle. Top Right: Moray Eel, Stinging Coral, Squid and Octopus. Bottom Left: Stinging Sea Anemones. Bottom Right: Scorpionfish and Weeverfish. 


\section{Dangerous \\ Marine Animals}

BRUCE W. HALSTEAD, M.D.

Director, World Life Research Institute

Lieutenant Commander, United States Novol Reserve, Department of the Novy, Formerly Instructor in Tropical Medicine, Division of Preventive Medicine, U.S. Naval Medicol School, National Navol Medical Center, Bethesda, Maryland.
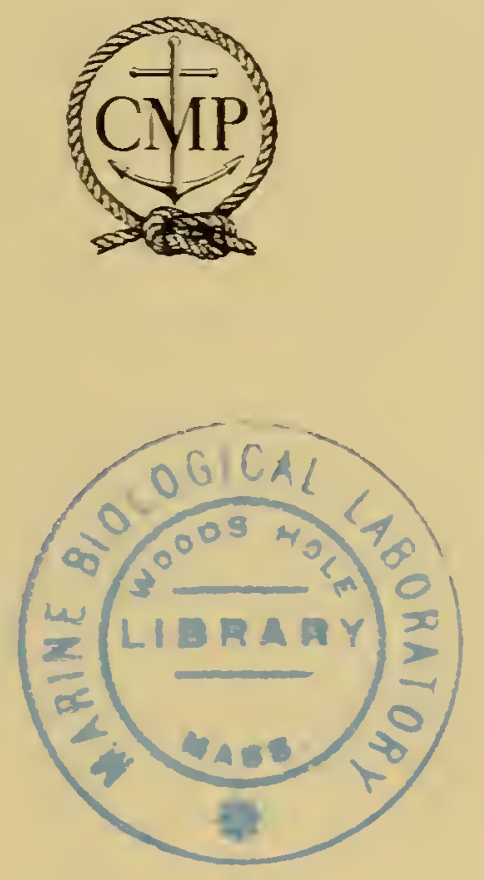

CORNELL MARITIME PRESS

CAMBRIDGE, MARYLAND

1959 
(C) 1959 by Cornell Maritime Press

Cambridge, Maryland

Library of Congress Catalog Card Number: 58-59799 Manufactured in the United States of America 


\section{PREFACE}

The sea-inspiration to the poet and writer, challenge to the scientist, battleground of militarists, adventureland of sportsmen-continues as one of the last great frontier's for man to conquer. The sea has taken on new meaning as a military medium, with the introduction of nuclear-powered submarines as launchers of guided missiles. The development of new underwater detection mechanisms has brought the importance of marine organisms and their sounds into sharp focus. The detonation of thermonuclear weapons and the dumping of radioactive materials has brought man into a new and more intricate relationship with ocean currents, and with the flora and fauna of the sea. The minute phytoplankton of the sea, formerly of interest only to the bespectacled academician, threatens to invade the domain of the politician in the new era of radioactive uptake. The rapid expansion in human population, presently on an upward spiral of more than $43,000,000$ additional persons each year, demands that the nutritionist re-examine man's protein larder. The Food and Agriculture Organization of the United Nations officially has declared that fisheries' products must be increased by nearly 90 per cent if we are adequately to feed the world's future population. In the quest for new chemical agents, pharmacologists and chemists are beginning to turn their attention to the vast untapped resources of the sea. Even the sportsman has turned to the underwater world with renewed interest and vigor. Yes, the ocean is becoming of increasing importance to the health and welfare of mankind. However, with the greater effort to penetrate the ocean depths, to pry into the secrets of its creatures, and to harness its mighty resources will come new problems which, all too frequently, are accompanied by pain and death.

One area of activity which has brought man into closer contact with marine organisms in their natural environment than probably any other is that of skin diving-be it professional, or merely for pleasure. Skin diving has become one of the world's fastest growing sports. It is estimated that there are more than one million skin divers in the United States alone, and still the field continues to grow. Numerous deaths have resulted from diving-many of which might have been prevented by adequate technical training. Although skin diving can be considered as a sport, like flying, it requires education, skill, and experience.

Stories concerning dangerous marine organisms are legion. While these hair-raising tales may be useful in holding an audience spell- 
bound, a diver at a depth of 100 feet, who suddenly finds himself surrounded by a hungry-looking school of sharks, soon becomes more interested in facts than in fantasy. The bluff of being big and tough wears mighty thin when you mistakenly place your hand into the gaping mouth of a toothy moray eel. Human death-times for even some of the "toughies" reads three to eight minutes, when stung by the deadly sea wasp! However, it is not the purpose of this manual to throw needless scares into the skin diving populace, but rather to point out some known facts regarding dangerous marine organisms, and to show what to do about the situation, if worse comes to worse. This is a facet of medicine where the old adage of "an ounce of prevention is worth a pound of cure" certainly holds true.

This present volume is an outgrowth of some fourteen years of medical research on dangerous marine organisms, particularly those which are poisonous and venomous to man. The bulk of this research has been conducted for the Armed Forces of the United States, and has been published in technical journals with limited distribution. A comprehensive treatise on toxic marine organisms will be published in the near future, entitled "Poisonous and Venomous Marine Animals of the World", and will provide full documentation for the individual who is interested in the scientific aspects of this subject. Although personal field research in many of the tropical seas of the world has increased my appreciation of the problem of dangerous marine animals, and has pointed out the need for the present volume, this work is by no means limited to the experience of a single person, but rather, is based on the medical histories of literally thousands of individuals over a period of several hundred years.

The purpose of this volume is to provide persons, encountering dangerous marine animals, with a ready source of information regarding the identification, geographical distribution, habits, and noxious characteristics of these animals. Sufficient data have been included to be of value to the first-aid worker and to the physician, alike. Technical discussions regarding the chemistry and pharmacology of these poisons, most of which are unknown, have been purposely eliminated. Every effort has been made to keep unnecessary technical details to a minimum, in order to be of practical value to the layman. If this little volume can contribute in a small way to the health and happiness of those working with marine organisms in their native habitats, it will have fulfilled its mission.

Bruce W. Halstead 


\section{ACKNOWLEDGMENTS}

The material presented in this handbook is an outgrowth of years of research conducted at the School of Tropical and Preventive Medicine, College of Medical Evangelists, Loma Linda, California, under the sponsorship of the Departments of the Air Force, Navy, and Army, the U. S. Coast Guard, National Institutes of Health of the U. S. Public Health Service, American Philosophical Society, National Science Foundation, U. S. Fish and Wildlife Service, Williams-Waterman Fund of the Research Corporation of America, American Medical Association, and the Alumni Research Foundation of the College of Medical Evangelists. In addition, certain art and photographic facilities were provided by the U. S. Naval Medical School, National Naval Medical Center.

Numerous foreign scientific groups were helpful in providing medical data of great value. Particularly outstanding among these groups were Dr. Claro Martin, Philippine Bureau of Fisheries, Japanese National Ministry of Welfare and Health, Dr. Tokiharu Abe, Central Fisheries Agency, Japanese Ministry of Agriculture and Forestry, Dr. Yoshio Hiyama, College of Agriculture, Tokyo University, Dr. Gilbert Whitley, Australian Museum, and Dr. V. M. Coppleson of Sydney, Australia.

Members of the staffs of the Smithsonian Institution, Edward Rhodes Stitt Library at the National Naval Medical Center, and the National Library of Medicine were most helpful in documenting data. Special thanks are due Drs. Leonard P. Schultz, Charles Cutress, Jr., Fenner A. Chace, David H. Johnson, and Harold A. Rehder.

I am indebted to Dr. George Llano and Mr. Stewart Springer for their helpful comments on sharks.

Most of the original art work used in this handbook was done by Messrs. Mitsuo Shirao, Shigeru Arita, Robert Kreusinger, George Coates, Harry Baerg, and O. Hon.

Most of the foreign source materials utilized in this research were prepared by the Translation Units of the National Institutes of Health and the Naval Medical Center, thanks to the cooperative efforts of Miss Rosemary Roberts and Miss Tatiana Boldyreff.

Finally, I wish to express my deep appreciation to Miss Frances $\mathrm{H}$. Atkinson for her critical typing of the manuscript and to Dr. Carl L. Hubbs for his valuable criticism.

B.W.H. 



\title{
DEDICATION
}

\author{
To my wife, Joy, \\ and children, Linda,
}

Sandy, David

and Larry 



\section{CONTENTS}

Frontispiece

Preface .............................

Acknowledgments ...................... vii

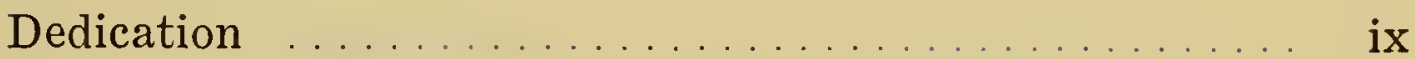

I. Dangerous Marine Animals_Our Knowledge of the Past. . 1

II. Marine Animals That Bite . . . . . . . . . . . . . 9

III. Marine Animals That Sting . . . . . . . . . . . . . . . . 32

IV. Marine Animals That Are Poisonous to Eat......... 100

Selected Bibliography . . . . . . . . . . . . . . . . . . 137

Index $\ldots \ldots \ldots \ldots \ldots \ldots \ldots \ldots \ldots \ldots \ldots$

80942

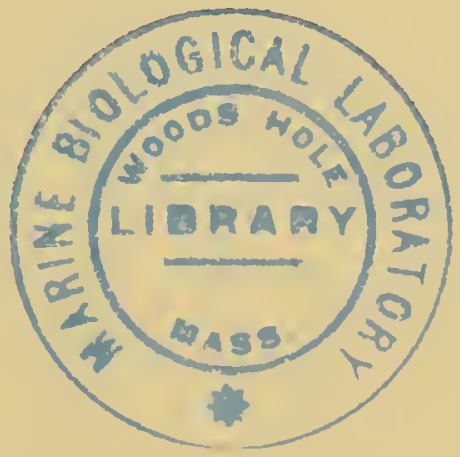



DANGEROUS MARINE ANIMALS 



\section{DANGEROUS MARINE ANIMALS-OUR KNOWLEDGE OF THE PAST}

The development of the aqualung by the great French diver, M. Jacques Yvez Cousteau, and his colleagues, has given birth to a new area of activity for mankind-skin diving. A new environment has been opened to man; this Cousteau has termed the "silent world". Indeed it is a seemingly silent world, enshrouded in mystery, intrigue, and beauty beyond description. Tropical reefs offer a submarine world of colors that seem to vibrate and sparkle. But with the beauty there is always found the beast. In multiplied instances beauty of form, gracefulness of carriage, lavishness of color seem to go hand in hand with disease and death. Hidden within the delicate lacy fins of the magnificent zebrafish are the needle-like hollow spines that convey the deadly venom. The dangers inherent in certain types of marine life are sufficiently great to behoove one to develop an intelligent appreciation of them.

From time immemorial man has depended upon the sea for food, medicine, clothing and, in recent times, for many of his industrial and military needs. Man has peered into its depths and speculated as to its contents. What man has been unable to observe with his eyes he has generously conceived in myth and fable with his imagination. The abysms of the sea and its little-known animal life have served well the interests of the fictionist. However, as it has been repeatedly shown in the past, much of this folklore is based on elements of fact. At any rate, it is of interest to see the manner in which our knowledge of dangerous marine organisms has evolved. And thus, through a study of the past, we are better able to understand the present.

Sharks and their attacks upon man have stimulated the imagination of writers from antiquity. Probably the earliest reference to man's encounters with sharks is by Pliny the Elder, who wrote during the first century of the "cruel combat that sponge fishermen must maintain against the dogfish. ..." He then went on to point out that dogfish attack the groins, the heels and all of the white portions of the body. Pliny recommended that to get rid of the dogfish it is best to swim straight for them and you will frighten them off. He also believed that the danger from shark attacks was increased as the diver neared the surface of the water rather than 
at a deeper level. It is rather interesting to note that many of these observations of Pliny are accepted facts in some diving circles today.

Rondelet, the famous French physician and naturalist of the Rennaissance, frequently lacked facts, but never originality. He describes a footman whom he reportedly "observed" running down the beach pursued by a dogfish hot at his heels. Fortunately, he struck at the beast with his foot and killed it. The dogfish in those days must have been real marathon runners! It was Rondelet who also contended that Jonah of the Scriptures was swallowed by a shark rather than a whale.

One of the earliest references to a shark actually attacking a man was published by Olaus Magnus in Rome in his Septentrionalibus, written about 1555 . Included in this work is a drawing of several sharks attacking a bather, who is in the process of being rescued by a "kindly" ray.

In 1623, the Dutch navigator, Carstenszoon, recorded sharks and swordfishes and other "unnatural monsters" from the waters near Cape York, Queensland, and alluded to some of their dangers.

According to Dr. Paul Budker, a modern French scholar on sharks, these beasts were regarded with great fear by sailors working in the Mediterranean during the 18th Century. The sailors believed that a shark would not attack except in hunger, in which case, they would have to throw the monster a loaf of bread. If this did not suffice, a sailor would have to be lowered by a rope to the surface of the water and look menacingly at the shark-otherwise the shark would grab the vessel with its teeth and devour it. Well, such was life in the good old days!

Probably the greatest number of shark attacks have taken place in Australian waters. The first recorded shark tragedy in that region is by Tench in 1793 in The Narrative of the Expedition to Botany Bay. He refers to a female aboriginal, who was bitten in half by a shark in New South Wales several years before. Francois Peron, the naturalist for the Baudin expedition, described a shark attack which occurred at Faure Island, Hamelin Harbour, Western Australia, in 1803.

The question as to whether sharks prefer dark or light-skinned victims is a favorite topic for argument among old salts. This is a question which appears to have originated with Count Bernard Lacépède, the famous French naturalist, who vigorously debated the subject with some of his colleagues during the early 1800's. Lacépède was of the firm opinion that sharks were attracted more 
to negroes because of their "more odorous emanations." Modern research has shown that the truth of the matter is more likely to be in the reverse direction, since sharks seem to be more readily attracted to light-colored objects.

Paul Budker points out in his book, La Vie des Requins that the old slave ships did much to encourage the anthropophagic tastes of sharks. Negro slaves were transported in ships under the most primitive, unhygienic and revolting conditions imaginable. Disease and death were rampant under these circumstances. Trailing in the wake of these vessels of "man's inhumanity to man" were schools of sharks which seemed to await with ghoulish delight their daily ration of human corpses, which were tossed over the side. After one severe storm on a run between Mozambique and Bourbon, France, more than fifty slaves suffocated because of the necessity of closing the hatches. The log of the vessel read: "What a windfall for the sharks!"

Strange to say, little has been written in modern times of an authoritative nature on sharks and their relationship to man. The best reference to Australian sharks is by Dr. Gilbert P. Whitley of the Australian Museum in Sydney, in his book on Australian fishes entitled, Sharks, Rays, etc. (1939). His book contains a great deal of valuable and interesting information regarding the habits, identification, and folklore connected with sharks. He also includes a list of all of the reported shark attacks in Australia up to the time of publication.

The increased loss of surface vessels and aircraft and the resulting high incidence of shark attacks during World War II pointed up the need for an effective shark repellent. Through the combined efforts of the U. S. Office of Scientific Research and Development, U. S. Navy and Army Air Corps, the National Research Council, and various civilian organizations, such as the American Museum of Natural History, Woods Hole Oceanographic Institution, Scripps Institute of Oceanography, Marine Studios, Inc., New York Zoological Society, University of Florida, and the Calco Chemical Corporation, an intensive search was made for a satisfactory deterrent. Experiments were conducted feeding shark bait with the various chemicals to be tested. Controls were also run feeding them bait without the repellent, and the results of the two tests were then compared. After testing more than 70 different chemical compounds, it was found that no more than four were deserving of further attention. These were: decomposing shark meat, maleic acid, copper sulphate, and copper acetate. It was sub- 
sequently shown that the potent factor in the decomposing meat was ammonium acetate. It was later decided that a dye should be added in order to hide the swimmer from view. Finally a chemical packet was developed which combined a nigrosine dye with copper acetate. This compound was later given the popular but somewhat misleading name, shark chaser. According to the research reports conducted at that time, this compound was said to be highly effective under normal feeding conditions of the shark. There are varying opinions as to the effectiveness of the repellent in the field under "mob feeding" conditions. At any rate, it is the best repellent available at present, and is currently used on life preservers for the U.S. Armed Forces. The material is commercially produced by the Shark Chaser Chemical Company, San Pedro, California.

About the time that the American researchers were conducting their investigations on shark repellents, similar studies were going on in Australia under the auspices of the Commonwealth Scientific and Industrial Research Organization. Their conclusions were essentially the same as those of the American workers.

Because of the high incidence of shark attacks along the coast of New South Wales, the local government instituted a Shark Menace Advisory Committee to investigate methods of protecting bathers from shark attacks. As a result of their studies, a program in meshing was begun, consisting of laying a long rope net overnight near the beach and removing it by trawler in the morning. This technique has proved to be highly efficacious and is still employed.

The leading Australian medical authority on shark attacks is Dr. V. M. Coppleson, who is currently preparing a book on the subject.

Dr. George Llano, formerly of the Arctic, Desert, Tropic, Information Center, Department of the Air Force, Maxwell Air Force Base, Alabama, is probably the best American authority on the subject of shark attacks. For many years he has been compiling data on this problem with the hope of preparing a treatise on shark attacks at some future date. The habits and biology of sharks have been studied intensively by Mr. Stewart Springer of the Fish and Wildlife Service, Department of Interior, Washington, D. C.

One of the most recent and valuable scientific works on the identification and biology of sharks is by Bigelow and Schroeder in their series on the Fishes of the Western North Atlantic (1948). 


\section{Stinging Marine Animals}

Our knowledge of stinging marine animals dates back to the days of classical antiquity. Aristotle, who wrote during the period from 348 to 322 B.C., made reference to the stinging ability of stingrays. Nicander, a Greek poet and physician of the second century B.C., reported the sting of the stingray to cause "gangrene of the wounded flesh." Pliny really got carried away with his subject when he reported that the deadly stingray, called Trygon, was able to kill a tree by driving its sting into one of the roots! He also mentions the serious wounds produced by the weeverfish.

Numerous scientific and popular reports are to be found in the early literature relative to the dangers of stings from venomous fishes, but serious scientific research on the subject was not conducted until the time of Dr. A. Bottard, a French scientist, who wrote the first monograph on the venom organs of venomous fishes, entitled, "Les Poissons Venimeux", published in 1889. Several scientists had worked previously on the venom organs of weeverfishes, but Bottard was the first to approach the subject in a more or less organized manner.

One of the earliest known occupational illnesses of divers caused by a biological hazard is the so-called sponge fisherman's disease. This disease is frequently manifested by a severe burning skin rash with areas of painful ulcerations. For many years it was believed that the disease was due to the handling of sponges. Finally, Dr. S. G. Zervos demonstrated in a series of scientific articles published in France in 1903, 1934, and 1938, that the disease was not due directly to sponges, but rather by coming in contact with the stinging tentacles of small sea anemones adhering to the sponges.

We are largely indebted to Dr. H. Muir Evans, an English surgeon, for our knowledge of the venom apparatus of the stingray. Much of Dr. Evans' medical practice was concerned with taking care of fishermen in Lowestoft, England, who came to him complaining of wounds which they had received from weevers, spiny dogfish, and stingrays. The stimulus received from these patients goaded Dr. Evans into studying the venomous nature of these fishes on a more scientific basis. Thus was opened a new horizon in medicine for Dr. Evans, which he describes in an interesting manner in his book, Stingfish and Seafarer (1943). Those of us who have engaged in research on venomous fishes here in America owe much to the challenge provided by the writings of this fine old surgeon of Lowestoft. 
Serious students interested in stinging marine organisms will receive much benefit from the outstanding volumes of Dr. Marie Phisalix, "Animaux Venimeux et Venins" (1922), and the brilliant writings of Dr. E. N. Pawlowsky, "Gifttiere und Giftigkeit" (1927). Despite his age, now in his 80's, Dr. Pawlowsky continues as the distinguished head of the Academy of Sciences in Leningrad, Russia. There are no recently published books on the subject of venomous marine animals. However, such a work is now in preparation in this country, written by the author of this present volume.

\section{Marine Animals Poisonous to Eat}

The danger of eating poisonous marine organisms dates back to the time of the Pharaohs of ancient Egypt, to the Toltec civilization, and to the days when Moses led the children of Israel out of the land of Egypt with the warning ... "and whatsoever hath not fins and scales ye may not eat; it is unclean unto you." (Deut. 14:9-10). This advice is still recommended in modern American military survival manuals.

The emperors of ancient Japan forbade their soldiers to indulge in the most poisonous of all fishes, the deadly puffer, called in Japan, the fugu. Those who were caught eating this scaleless delicate morsel lost their entire inheritance. Similar prohibitions were issued by Alexander the Great to his soldiers.

Peter Martyr, the great historian of the West Indies, specifically refers to the danger of the ciguatera type of fish poisoning. This form of poisoning supposedly developed in fishes as a result of their eating the poisonous machineel berry-a theory which continues to persist today, but is without scientific foundation.

Captain Cook almost terminated his famous world voyage in 1776 as a result of eating poisonous fishes which were sold to him by friendly savages in New Caledonia.

Down through the centuries hundreds of articles have been published by explorers, missionaries, physicians, naturalists and scientists about the dangers of eating molluscs, fishes and other marine organisms at certain seasons of the year under certain circumstances. The French, Russian, Japanese, and American navies have called attention to the medical importance of these organisms. It is estimated that during World War II more than 400 Japanese military personnel lost their lives in Micronesia from the eating of fresh tropical reef fishes. A most unusual piece of toxicological research was conducted by the Japanese scientist, Dr. Yoshio 
Hiyama, on the poisonous fishes of Micronesia. Visiting the Marshall and Saipan Islands under the most trying of circumstances he found that large numbers of the reef fishes of these islands were deadly for humans to eat. It was the research of Dr. Hiyama that served as a basis for much of the subsequent research on poisonous fishes that has been conducted in the United States and elsewhere.

The origin of fish poisons-that is, the type that are eaten, rather than those injected-has always been a mystery. Scientific interest in this age-old problem underwent another revival with the remarkable sequence of poisonings which took place between February 1946 and April 1947 at Fanning Island in the Line Islands-a small group of coral islands lying along an almost straight line between the Territory of Hawaii and the Equator. During this period there were 95 cases of fish poisoning among a population of 224 persons caused by eating the same fish species they had always eaten with impunity! Investigation of the incident has since revealed that a startling change in the edibility of the shore fishes began about 1943, involving the islands of Midway, Johnston, Kingman Reef, Palmyra, Fanning, and Christmas Island. These poisonings reached a peak about 1947 , and have since undergone some decline; but nevertheless have continued until the present time. Strange to say, the fishes of most of the Hawaiian Islands and Washington Island have remained unaffected and without any change in their edibility.

For centuries it has been known that a fish species may be edible in one area and violently poisonous in another. Toxicity in a fish seems to develop without rhyme or reason, but this is undoubtedly only because we do not understand the mechanisms involved.

The most recent surge of poisonings caused by the eating of marine organisms, namely, squid, octopus and certain types of oceanic fishes, took place in Japan, the Philippines and elsewhere in the Indo-Pacific region. It has been estimated that more than 40,000 persons were involved in the 1955-1956 outbreaks. The cause is the big question for the underwater medical researchers of the future to answer. At present, no one knows. If mankind is to continue to utilize the resources of the sea, greater efforts must be expended in attempting to unravel the mysteries hidden in its depths.

\section{What of the Future?}

As we glance back at the dimly lit pages of the past, we are once again reminded of the debt of gratitude that the scientific com- 
munity has to scientists of yesterday. These old musty archives continue to contribute valuable medical data to the men who go down into the depths of the sea today. Our applied knowledge regarding most of these marine creatures is still very meager. Moreover, it will continue to remain so until basic medical and marine biological research is permitted to join hands in pushing back the frontiers of ignorance.

The reader should keep in mind, as he enters the sea and matches wits with these death-dealing creatures, that there is an ever-increasing amount of scientific evidence that these noxious organisms and their poisons may serve as sources of the life-giving antibiotics, anti-cancer, and other indispensable therapeutic agents of tomorrow. These organisms must be considered as more than mere marine biological hazards - they are the vast chemical reserves of the future.

But now for the cold realities of today-dangerous marine organisms-their noxious effects, treatment, or better yet, how to avoid them! 


\section{CHAPTER II}

\section{MARINE ANIMALS THAT BITE}

\section{SHARKS}

Probably the marine animals most generally feared by swimmers and skin divers are sharks. Despite the vast amount of fiction, legend, horror tales, and wishful thinking written about the subject, there are few facts available regarding the relationship of sharks to man. Public opinion concerning shark attacks seems to range all the way from "most species are dangerous", to "none of them are noxious" to man. Scientific evidence and military and civilian medical records lead one to believe that the facts of the matter probably are to be found somewhere between these equally untenable attitudes.

The swimmer in shark-infested waters is confronted with four important questions, namely: (1) which species of sharks are most likely to attack, (2) how do you recognize them, (3) what are their habits, and (4) what can be done to ward off an attack, if such were to take place?

General. There are about 350 known kinds of sharks, but probably a score or less are believed to attack man. Sharks range in size from the small scyliorhinids and triakids, which mature at a length of only 18 inches, to the giant whale shark, which may attain a length greater than 50 feet. It is consoling to know that this huge monster feeds exclusively on small marine organisms. All sharks are carnivorous, but most species are too small, inadequately armed, or inhabit depths too great to be dangerous to man. The natural food of the larger and more effectively armed sharks consists of large fishes, other sharks, seals, and a variety of marine organisms. If one is forced to generalize regarding the dietary habits of sharks, it is safest to assume that if the shark is more than four feet in length, adequately armed, and there is blood and food in the water, it is potentially dangerous to man.

A favorite topic of discussion among fishermen is the number of series of teeth in a shark that are in actual use at any given time (Fig. 1, Top). The number varies from four to five, depending upon the species of shark and the part of the jaw concerned. In addition, there are several reserve series in each jaw, with their points in the reverse position, undergoing development. In this latter instance they are covered over by a fold of mucous membrane and must be 

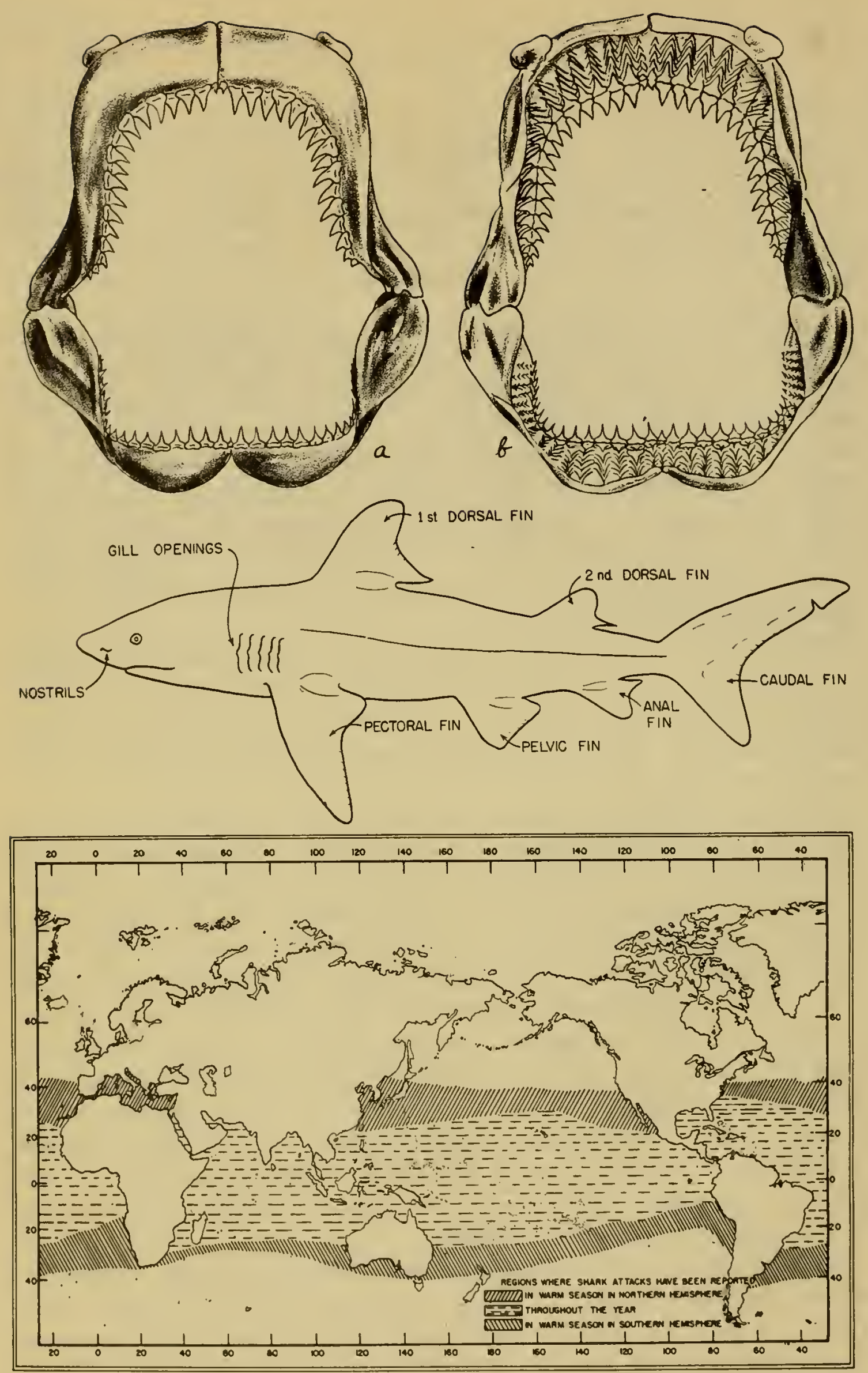

Fig. 1. Top: Jaws of a Carcharinid shark, Eulamnia, showing arrangement of teeth. a. Front view. b. View from behind, showing rows of teeth. (Baergh) Center: External anatomy of a typical shark. (Hon) Bottom: Map showing areas where shark attacks have been reported. (After Burden) 
dissected before they are seen. When functional teeth are lost, those of the next younger series move up to take their place. This process of tooth replacement continues throughout the life of the shark. Teeth may be replaced singly in some shark species, or as an entire series in others. A series of teeth which form a continuous cutting edge are generally replaced as an entire series. The replacement process usually requires several days to a week or more.

The means employed by sharks to detect food and injured animals in the water is a subject that has been of considerable interest to physiologists for many years. Although the intelligence of a shark is probably of a low order and their visual acuity is notoriously poor, their ability to detect food is phenomenal. Food detection is believed to be accomplished by their highly developed olfactory organs, and a lateral line system that is extremely sensitive to low frequency vibrations in the water. The auditory nerves undoubtedly serve as a further aid in locating sources of unusual underwater noises. The ability of sharks to detect a disabled or wounded animal, at great distances, is almost uncanny. Some workers are of the opinion that food detection may be further aided by special gustatory organs. Figure 1, center, shows the external anatomy of a typical shark.

The feeding habits of sharks appear to fall into two general categories: (1) The individual feeding pattern, which occurs when a single, or several, sharks are normally in quest of food. In most instances, the movements of the shark are relatively slow and determined, when making its approach, but at times may be somewhat sudden and swift. The swimming pattern, approach and the final attack seem to vary with the species and the circumstances. (2) In the event of a catastrophic situation, such as might be caused by the sinking of a vessel, the crash of a plane into the water, or an explosion, in which large quantities of food and blood suddenly appear in the water, the entire feeding characteristics of sharks may suddenly revert to a frenzied state which is frequently referred to as the mob feeding pattern. This form of feeding has been commonly observed in some of the carcharhinid sharks. Under these conditions, sharks have been observed swimming vertically from the bottom, straight to the surface, breaking the water, and snapping savagely at anything in sight. It is during periods such as this that the greatest danger is encountered, and almost all repellent devices appear to be useless. Cannabalism was observed, in one instance, when a large school of sharks was feeding, in an excited state, on a school of snappers which had been killed in an underwater blast. While one large shark was feeding on a snapper 


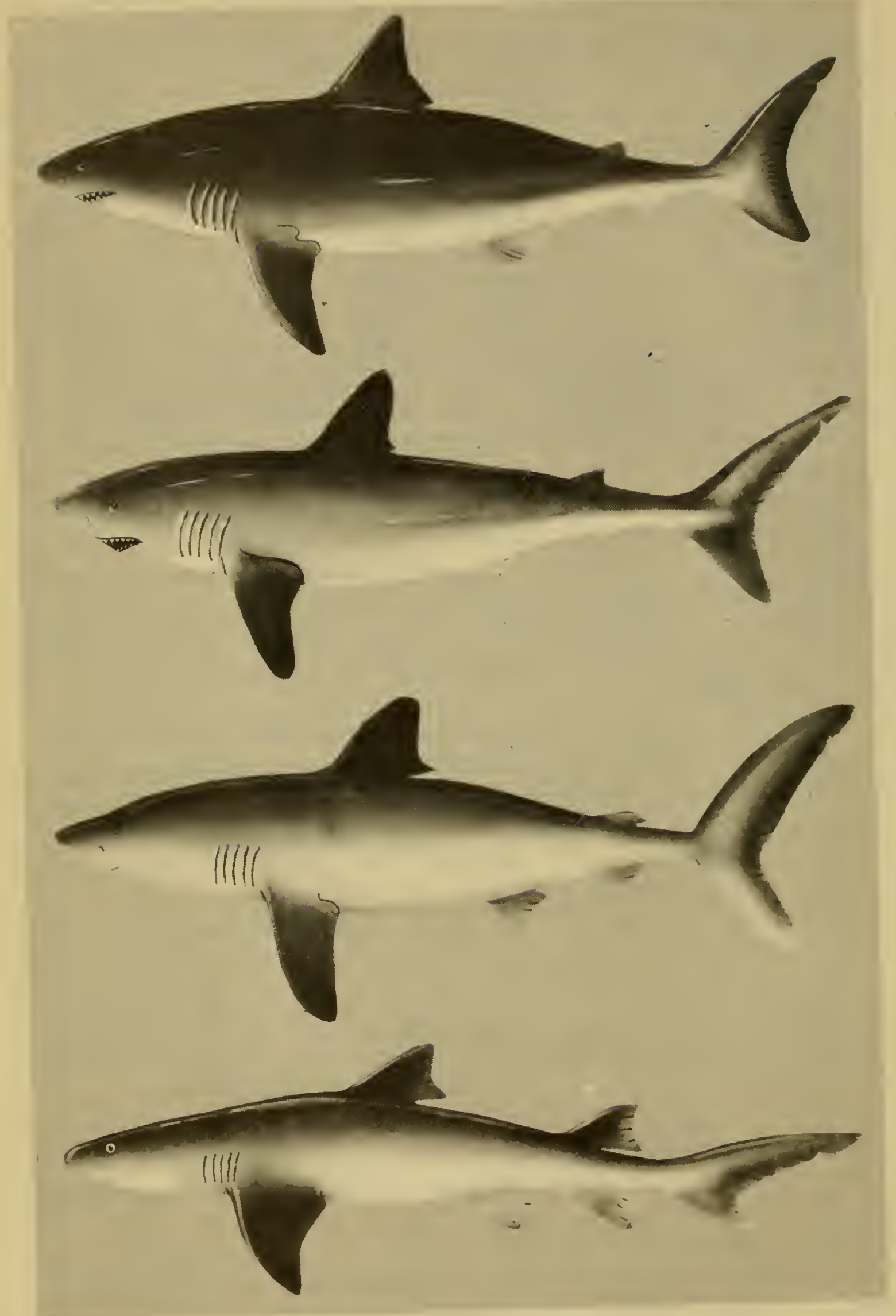

Fig. 2. Top to Bottom: White Shark, Carcharodon carcharias (Linnaeus). Sharp-nosed Mackerel or Mako Shark, Isurus oxyrinchus Rafinesque. Mackerel
or Porbeagle Shark, Lamna nasus (Bonnaterre). Lemon Shark, Negaprion brevirostris (Poey). 

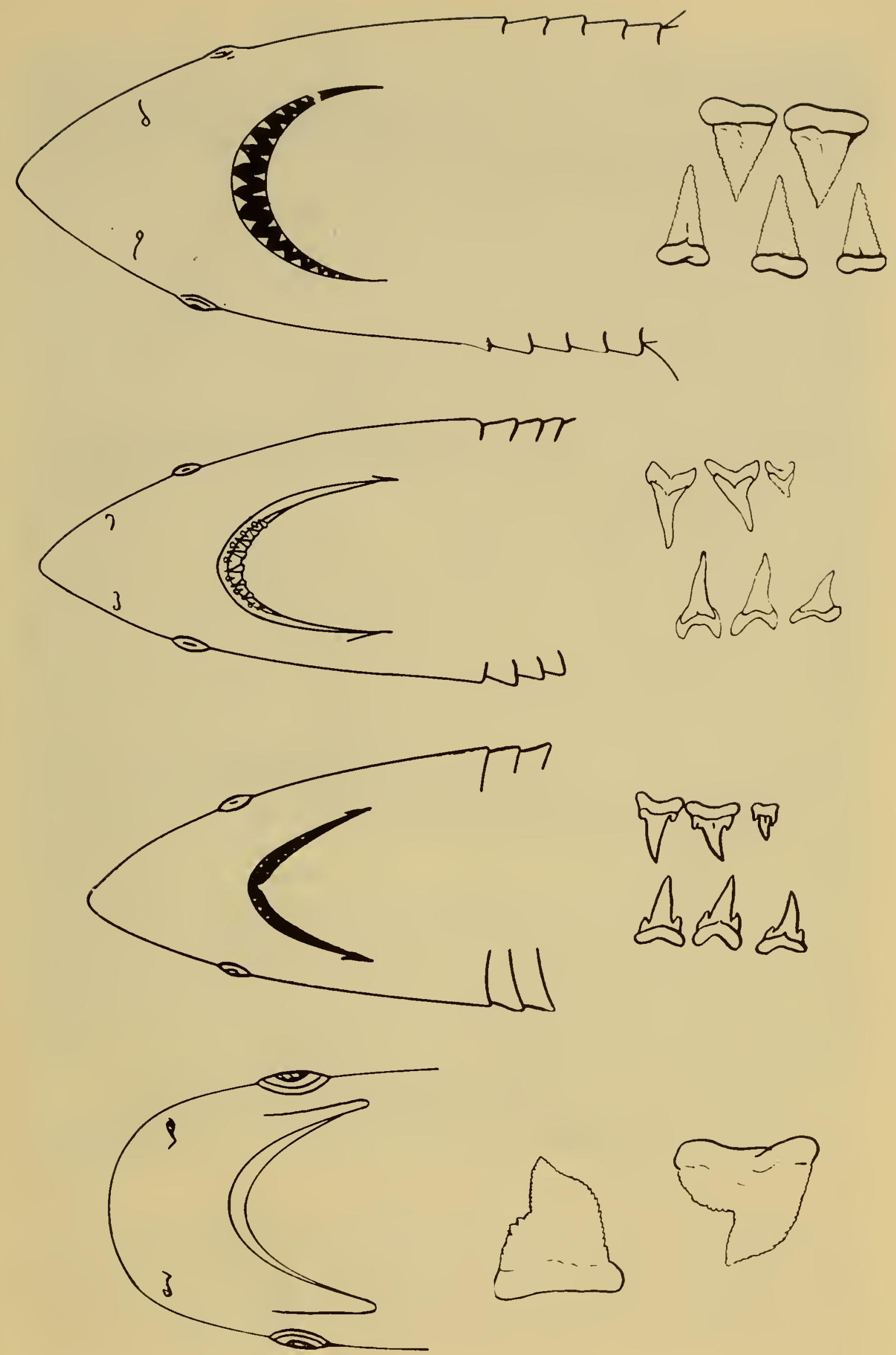

Fig. 2A. Jaws and teeth of sharks. Top to bottom: Carcharodon carcharias (Linnaeus). Isurus oxyrinchus Rafinesque. Lamna nasus (Bonnaterre). Galeocerdo cuvier (Lesueur). 
that had been caught in a coral crevice, a second shark moved into the scene and, in one gulp, ripped out the belly of the first shark. Within a few moments, the hapless shark was completely devoured by additional members of the pack, which joined the killing.

Sharks will frequently single out an individual in a crowd of swimmers and will attack that one person, ignoring all others, including those who attempt to rescue him. This phenomenon has been observed on a number of occasions in various regions. On the other hand, divers who have had the most experience with sharks contend that "you cannot predict their actions".

The danger of shark attacks is greatest in tropical and subtropical seas, between $30^{\circ} \mathrm{N}$. by $30^{\circ} \mathrm{S}$. of the Equator (Fig. 1, Bottom). Although temperate waters are generally considered to be free of shark attacks, they are not completely exempt, as shark attack records from both California and the eastern seaboard of the United States clearly attest. Apparently, certain species of man-eaters migrate periodically into cooler waters in quest of food, and at such times attacks have occurred. Particularly dangerous areas are Queensland, Australia, and South Africa. Despite the lack of published scientific records, numerous attacks have also been known to occur on the Pacific side of Panama.

Most attacks have occurred when the temperature of the water was greater than $70^{\circ} \mathrm{F}$., although fatalities have taken place in temperatures of $60^{\circ} \mathrm{F}$., or less. The peak month of attacks is January, and the period of greatest risk is between 1500 and 1600 . However, sharks feed at all hours, and particularly so at night.

Species of Sharks Known to be Dangerous to Man: The sharks believed to be of greatest concern to the diver are members of four families. These families are listed according to what is believed to be their order of greatest danger to man, namely:

Isuridae - the Mackerel, or Man-eaters

Carcharhinidae-The Requiem Sharks

Carchariidae-the Sand Sharks

Sphyrnidae-the Hammerhead Sharks

\section{MaCKerel or MaN-EATER SHARK FAmily (ISURIDAE)}

White Shark, Carcharodon carcharias (Linnaeus). (Fig. 2, Top). This shark is reputed to be one of the most dangerous of its kind. It is savage, aggressive, fast-swimming, and has been known to attack boats. Numerous human attacks are accorded to this species. The distinctive characters of this shark are the strongly lunate caudal fin and large, coarsely serrate teeth. The color of the shark 


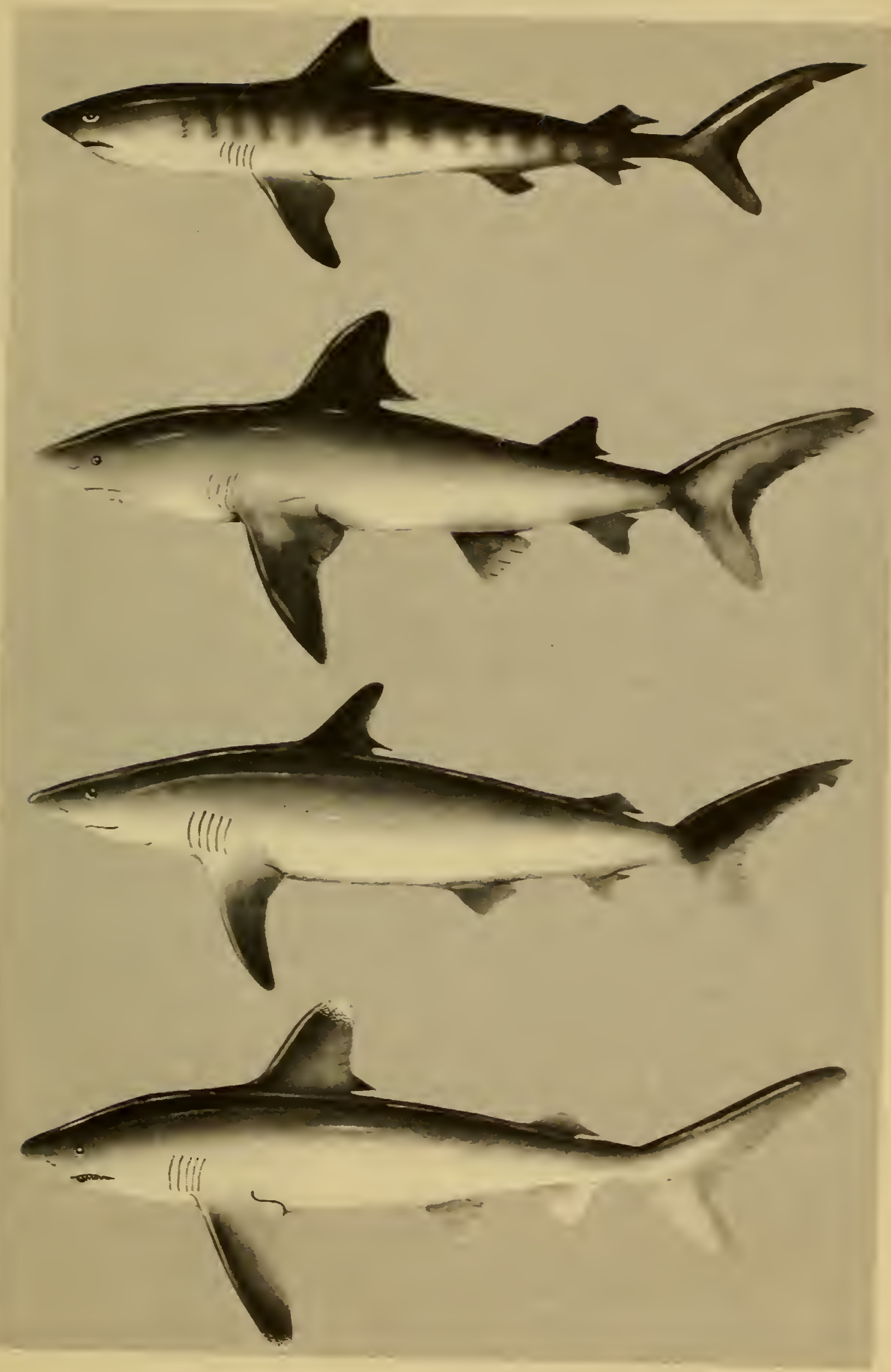

Fig. 3. Top to Bottom: Tiger Shark, Galeocerdo cuvieri (Lesueur). (Hon) Lake Nicaragua Shark, Carcharhinus nicaraguensis (Gill and Bransford). Dusky Shark, Carcharhinus obscurus Lesueur. White-tipped Shark, Pterolamiops longimanus (Poey). (Hon) 

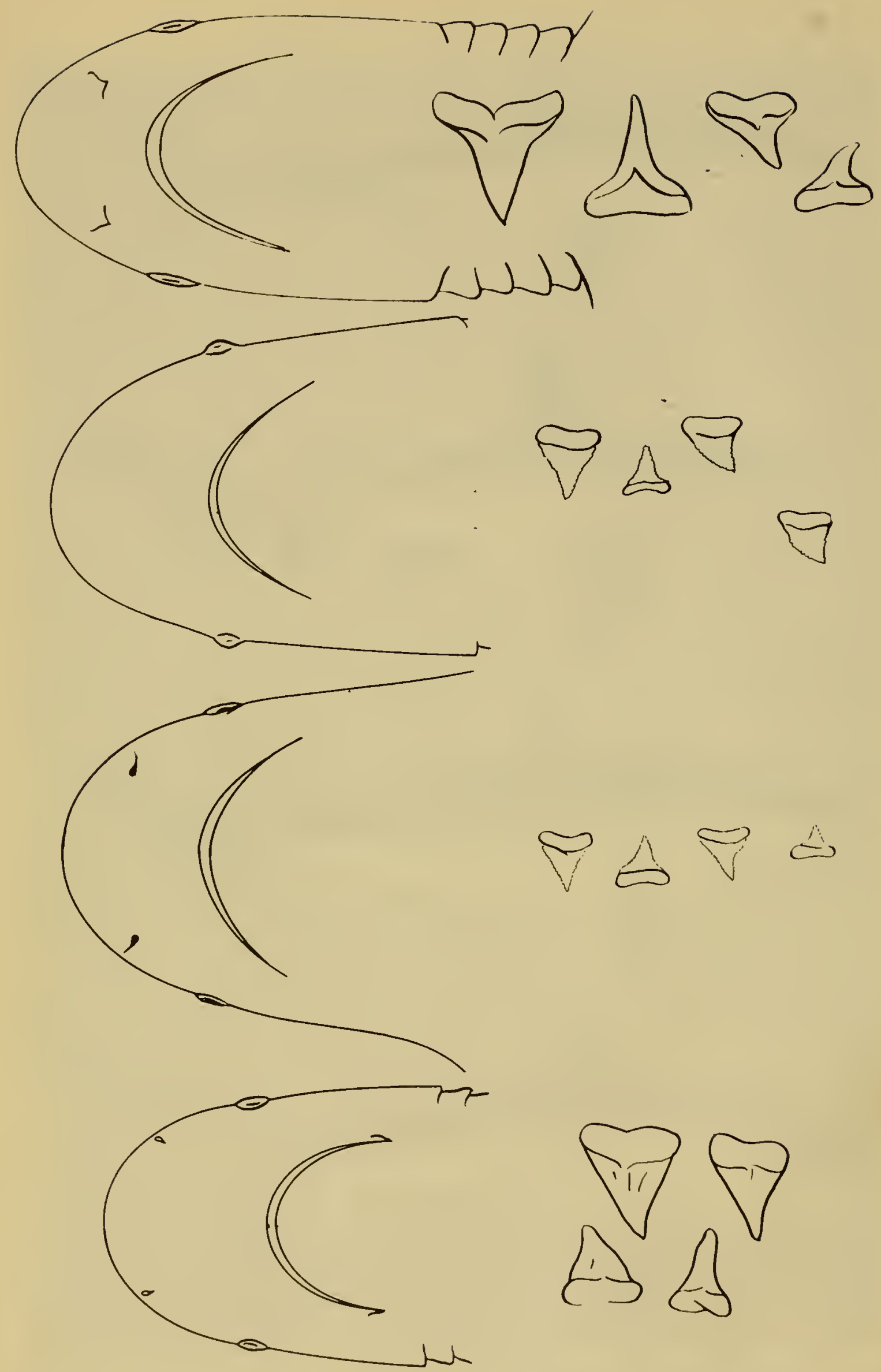

Fig. 3A. Top to bottom: Negaprion brevirostris (Poey). Carcharhinus nicaraguensis (Gill and Bransford). Carcharhinus obscurus Lesueur. Ptcrolamiops longimanus (Poey). 
is slaty-brown, dull, slate-blue, leaden gray, or almost black above, shading more or less abruptly to dirty white on the lower surface with a black spot on the axil of the pectoral; the tips of the pectorals also black, usually with some adjacent black spots; the dorsals and caudal dark along rear edges. Large specimens may be dun-colored above or even leaden-white. The white shark may attain a length of $30 \mathrm{ft}$. or more. Distribution is oceanic, widespread in tropical, subtropical and warm temperate belts of all oceans. More numerous in Australian waters, but nowhere is it abundant.

Sharp-nosed Mackerel or Mako Shark, Isurus oxyrinchus Rafinesque. (Fig. 2, Next to Top). This shark has a reputation of being savage, dangerous, and has been known to attack boats. The mako is a fast swimmer, may leap out of the water, and is classed as a game fish. The mako is distinguished by its teeth, slender form, and by the relative position of the second dorsal and anal fins. Its color is deep blue-gray, cobalt, or ultramarine blue above, and snow-white below. Attains a length of $13 \mathrm{ft}$. This is an oceanic species of tropical and warm-temperate Atlantic. It is replaced in the Pacific by $I$. glaucus, and in India by $I$. guntheri.

Mackerel or Porbeagle Shark, Lamna nasus (Bonnaterre). (Fig. 2, Next to Bottom). This is said to be an active and strong-swimming species when in pursuit of prey, but otherwise considered to be rather sluggish. The distinctive characters of this species are the teeth and relative positions of the second dorsal and anal fins. The color is dark bluish-gray above, changing abruptly on the lower sides to white. The pectorals are dusky on the outer half or third. Anal fin white or slightly dusky. Said to attain a length of $12 \mathrm{ft}$. This species inhabits continental waters of the northern North Atlantic, ranging from the Mediterranean and northwestern Africa to the North Sea, Scotland, Orkneys, and southern Scandinavia, on the eastern side; less common north to Iceland, northern Norway and the Murman Coast; from the Newfoundland Banks and Gulf of St. Lawrence in the west, south to South Carolina. Represented by closely allied forms in the North Pacific, Alaska, Kamchatka, Japan, Australia and New Zealand.

\section{Requiem Shark Family (CARChaRhiNidae)}

Tiger Shark, Galeocerdo cuvieri (Lesueur). (Fig. 3, Top). Unless in pursuit of food, the tiger shark is usually sluggish, but under the proper stimulation can be a vigorous and powerful swimmer. A number of human attacks have been credited to this species. 
The tiger shark tends to be somewhat of a scavenger in its eating habits. The distinctive characters of this species are the teeth, a very short snout, and a sharply pointed tail. The color is gray or grayish brown, darker above than on sides and belly. The oblique or transverse bars on the sides and fins are usually present only in the smaller specimens. Said to attain a length of $30 \mathrm{ft}$., but the largest recorded specimen was $18 \mathrm{ft}$. The tiger shark is widespread in the tropical and subtropical belts of all oceans, inshore and offshore alike. Said to be the commonest large shark in the tropics.

Lemon Shark, Negaprion brevirostris (Poey). (Fig. 2, Bottom). Little is known of its habits. The lemon shark is commonly found in saltwater creeks, bays and sounds, and around docks. It is believed to be the cause of a number of attacks on humans in South Carolina waters. Distinctive characters are the second dorsal fin that is nearly as large as the first, broadly rounded snout, and its teeth. Attains a length of about $11 \mathrm{ft}$. Color yellowish brown above or dark bluish gray, sides and belly yellow or olivaceous. Inshore, western Atlantic, northern Brazil to North Carolina, tropical West Africa.

Lake Nicaragua Shark, Carcharinus nicaraguensis (Gill and Bransford). (Fig. 3, Next to Top). Little is known of the habits of this shark, except that is comes commonly into very shallow water, although it is seldom seen at the surface. A number of well-authenticated human attacks are credited to this shark. Color is dark gray above, very light below. Said to attain a length of $10 \mathrm{ft}$., but usually smaller. This is a freshwater species and is confined to the freshwaters of Lake Nicaragua, its tributaries and outlet.

Dusky Shark, Carcharhinus obscurus (Lesueur). (Fig. 3, Next to Bottom). Little is known of the habits of this shark. Frequently found in shallow water. Back and upper sides, bluish or leaden gray, sometimes pale, lower parts white. Lower surfaces of pectorals grayish and sooty toward tips. Attains a length up to $14 \mathrm{ft}$. Tropical and warm-temperate waters on both sides of the Atlantic.

White-tipped Shark, Pterolamiops longimanus (Poey). (Fig. 3, Bottom). This shark has been accused of being a man-eater by reliable authorities. It is definitely known to be almost indifferent and fearless in its contacts with man. The white-tipped shark is a relatively slow-swimming and sluggish species. The distinctive characteristics of this shark are the broadly rounded apex of the first dorsal fin, the convexity of the pesterior outline of the lower caudal lobe, and a very short snout in front of the nostrils. The shark is light gray or pale brown to slaty blue above and yellowish 
or dirty white below. Pelvics and lower surface of pectorals are spotted with gray and the tips of dorsals, grayish white. In some instances, the pelvics, caudal lobes and pectorals are white-tipped. This shark inhabits the tropical and subtropical Atlantic, and is common in the Mediterranean and along the Iberian Peninsula. It is a pelagic species, and is generally found in deep offshore waters. Little is known about its habits. It is said to attain a length of 13 ft. or more.

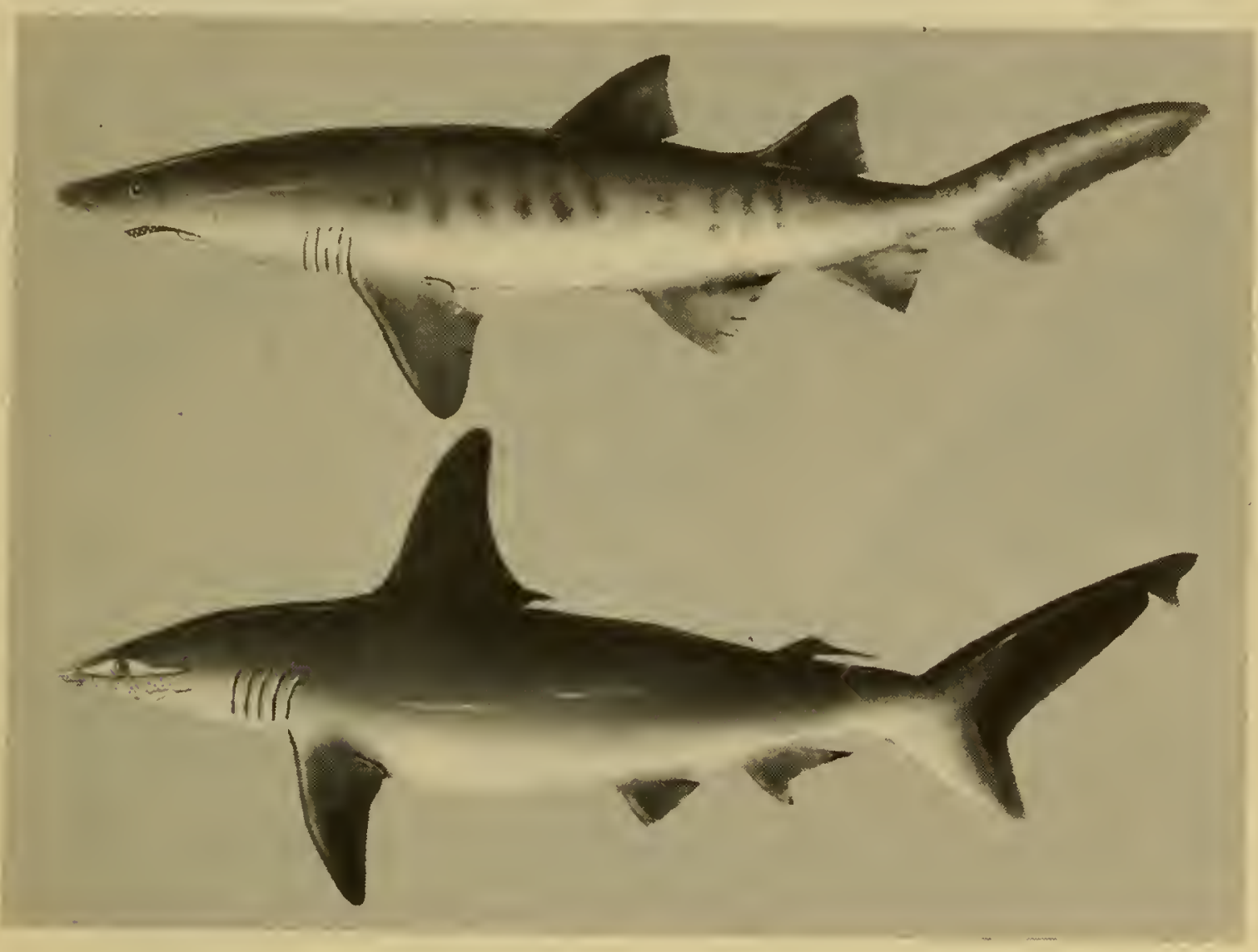

Fig. 4. Top: Sand Shark, Carcharias taurus Rafinesque. Bottom: Hammerhead Shark, Sphyrna diplana Springer. (Hon)

\section{SAND SHARK FAMILY (CARChaRIIDAE)}

Sand Shark, Carcharias taurus Rafinesque. (Fig. 4, Top). A comparatively sluggish shark, having a voracious appetite, living mostly on, or close to, the bottom. It is a shore species. Its relatives in East Indian waters have a bad reputation, but this is not true of the North American species. Its distinctive characteristics are the five gill openings in front of the pectorals, the second dorsal about as large as the first, the position of the first dorsal entirely in front of the pelvics, and the teeth. Color is bright, gray-brown above, darkest along back, snout, and on upper sides of pectorals, paling on sides to grayish white on belly and on lower sides of fins. Body 

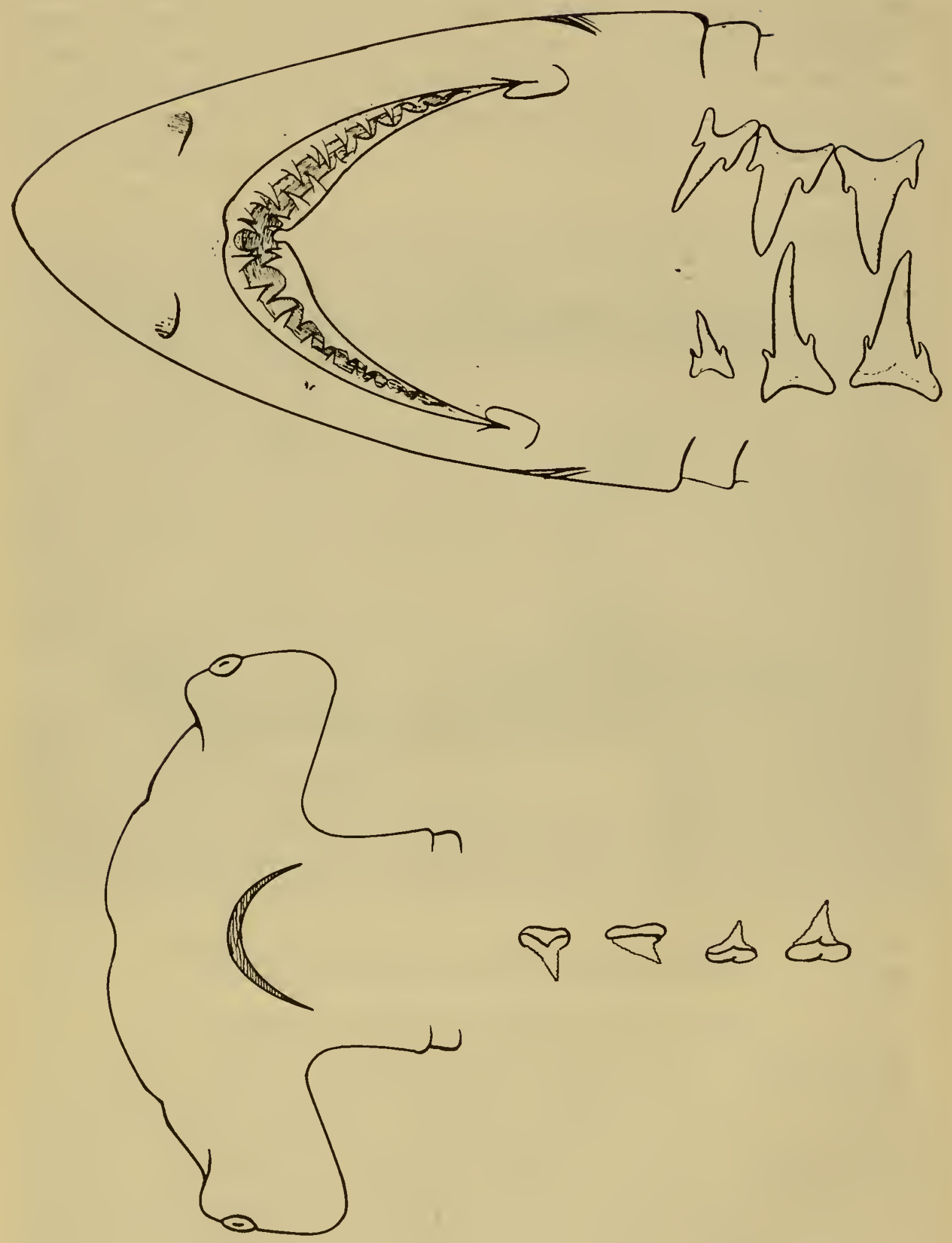

$\forall \Leftrightarrow \Leftrightarrow$

Fig. 4A. Top to bottom: Carcharias taurus Rafinesque. Sphyrna diplana Springer. 


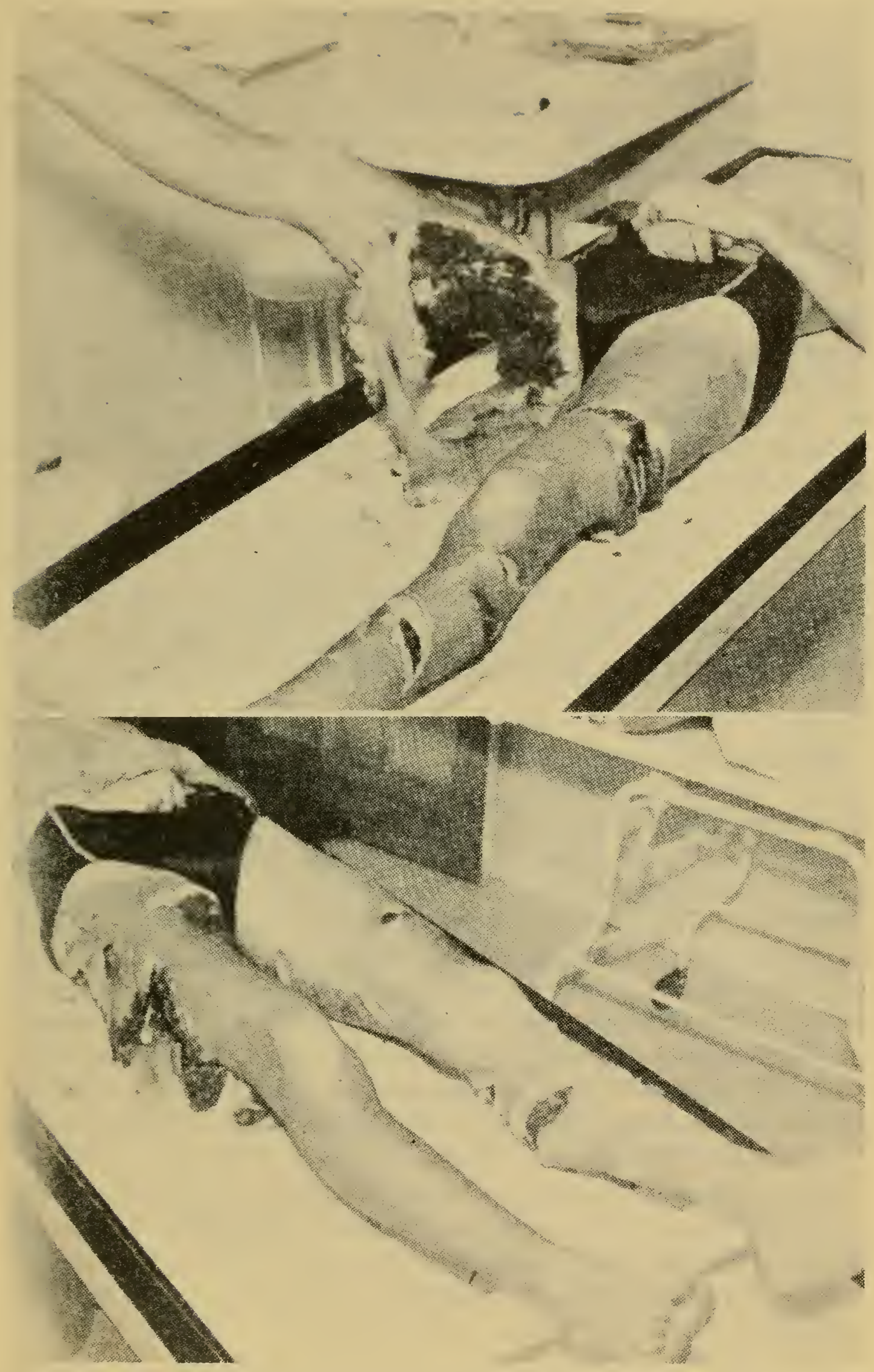

Fig. 5. Swimmer wounded by a Carcharodon shark in Monterey Bay, California. Note massive tissue loss which resulted in the death of the victim. (From Bolin) 
rearward from pectorals marked with round to oval spots, varying in color from yellowish brown to ochre yellow. Attains a length of $10 \mathrm{ft}$. Inhabits the Mediterranean, tropical West Africa, Canaries and the Cape Verdes in the eastern Atlantic, South Africa; western Atlantic from the Gulf of Maine to Florida and southern Brazil ; represented in Argentine waters and in the Indo-Pacific by close allies.

Gray Nurse Shark, Carcharias arenarius Ogilby. (Not pictured: similar to Fig. 4, Top). This shark is said to be swift and savage in making its attacks. It inhabits both coastal areas and the open sea. This shark is characterized by the size and position of the dorsal fins, and teeth. Color varies from pale gray to dirty pale brown above, dull white below. Attains a length of $9 \mathrm{ft}$. or more. Inhabits waters about Australia.

Ganges River Shark, Carcharias gangeticus Müller and Henle. (Not pictured: similar to Fig. 4, Top). Little is known about its habits. Reputed to be a ferocious shark, attacking many bathers. Color is gray above, dull white below. Attains a length of $7 \mathrm{ft}$. Indian Ocean to Japan, ascending freshwater rivers.

\section{HAM MERHEAD SHARK FAMILY (SPHYRNIDAE)}

Hammerhead Shark, Sphyrna diplana Springer. (Fig. 4, Bottom). This shark is a powerful swimmer, and may be found far out at sea or close inshore, frequently seen swimming at the surface. Human remains have been found in the stomachs of hammerheads, and they are definitely known to attack man. Color is ashen-gray above, fading to white below. Hammerheads are readily distinguished by the peculiar shape of the head which is much flattened dorso-ventrally and very widely expanded laterally in "hammer" or "bonnet" form, with the eyes at its outer edges. Hammerheads may attain a length of $15 \mathrm{ft}$. or more. S. diplana is representative of a complex of closely related species which are distributed throughout tropical and warm temperate zones of all oceans, including the Mediterranean Sea.

Medical Aspects. Bites from sharks are severe, and death is due to massive hemorrhage and shock. The fatality rate from reported shark attacks has been variously estimated from 50 to 80 percent. Severe skin abrasions may be suffered by brushing up against the skin of sharks.

Treatment. Shark bites generally result in a loss of large amounts of tissue and massive hemorrhage (Fig. 5). Therefore, the first aid management of shark bites is concerned with two major problems 
which demand prompt and vigorous action: (1) control of hemorrhage, and (2) control of shock. It is recommended that the hemorrhage be controlled with the use of large gauze pressure bandages. The wound should be filled with gauze and held under pressure with the use of elastic bandages. In some instances, it may be necessary to add a second pressure bandage before the bleeding is brought under control. Tourniquets are dangerous and impractical for the inexperienced to use. Because of blood loss, the victim may soon go into shock. Keep the patient warm. Intravenous fluids, such as Dextran and/or serum albumen should be administered as soon as possible. The administration of whole blood will be required later. Military personnel or persons having previously received tetanus toxoid inoculation should be given a booster dose, otherwise tetanus antitoxin should be administered. The use of antibiotics is suggested. The victim should be hospitalized as soon as possible.

As soon as feasible, the wound should be cleaned, dirt and dead tissue removed (debridement), and the injured vessels ligated. The wound should then be covered with a sterile dressing and left for 4-6 days. If there is no evidence of infection, advanced surgical procedures, such as primary closure and skin grafting, should be instituted. The procedure as outlined is done so with the hope of obtaining a clean wound and making a primary closure at the earliest possible date.

Prevention. The suggested methods of banging rocks together, screaming, blowing bubbles, shouting, splashing, etc. ad infinitum, are of questionable value if the shark really means business. Certain noises are definitely known to attract sharks. Movements should be slow and purposeful. In a number of instances it has been demonstrated that if the individual is not wounded, curious sharks may leave if one remains perfectly still. It may be necessary to shove the shark away with the use of a "shark billy"-a large stick that is carried for this purpose-or with some other object. Attempts to wound the shark are usually useless, and may even aggravate the situation. If possible, hit the shark on the snout, eyes, or gills. In general, dark-colored clothing and instruments are preferable to light-colored ones. The use of explosives can usually be expected to attract sharks in large numbers. When sharks are present, divers should not dangle arms or legs in the water from the surface, and should get in or out of boats quickly. An injured swimmer should get out of the water, if possible. 


\section{GIANT DEVIL RAY OR MANTA}

(Manta birostris Donndorff). (Fig. 6, Top).

This giant ray may attain a spread of more than $20 \mathrm{ft}$, and a weight of more than $3500 \mathrm{lbs}$. It does not possess a caudal sting. When harpooned, it is able to tow a small launch for several hours. The manta is not aggressive and is dangerous only because of its huge size. Several deaths have been reported of helmet divers whose airlines became fouled in the cephalic fins and "wings" of mantas that apparently came over to investigate the bubbles. Like
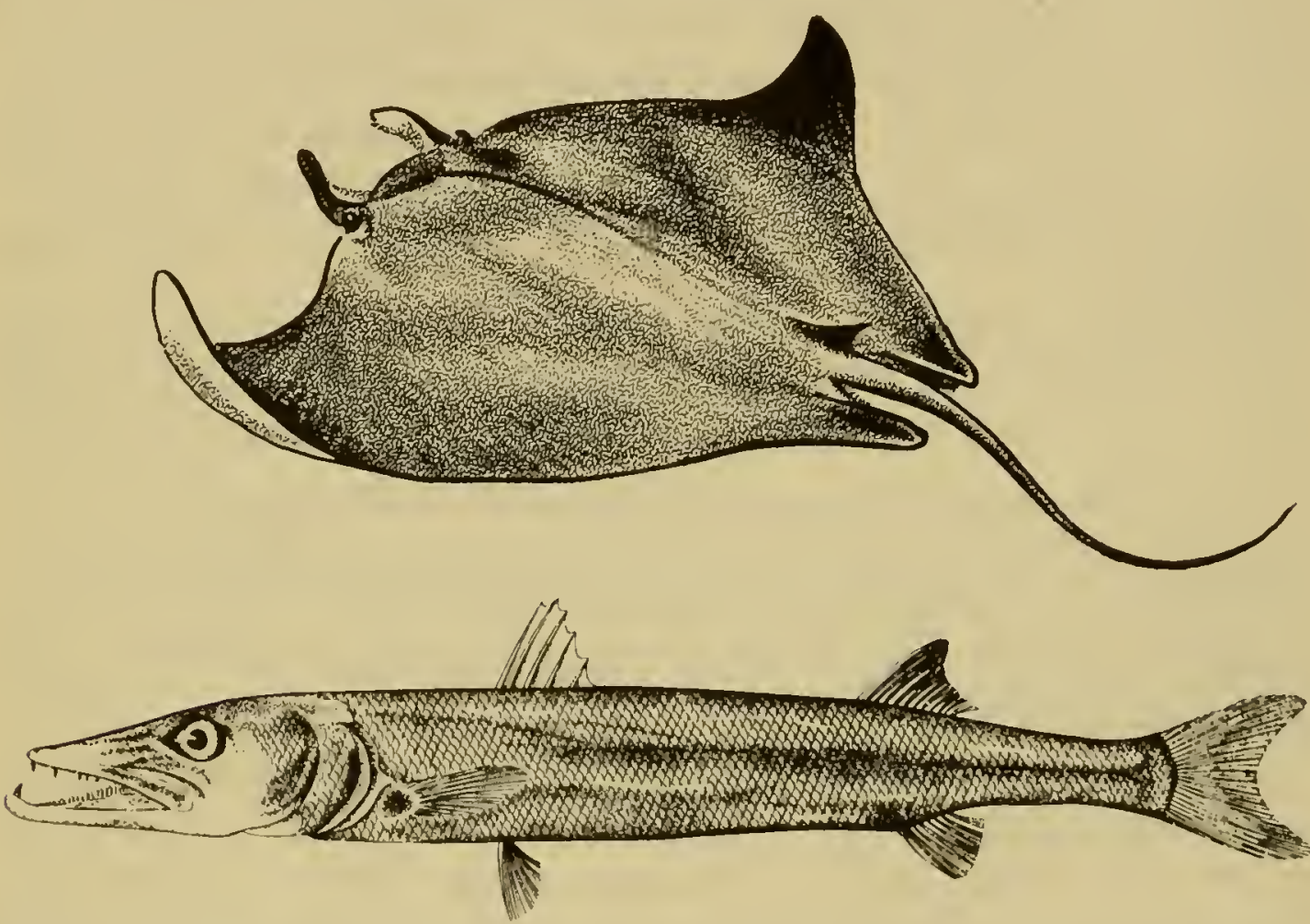

Fig. 6. Top: Giant Devil Ray or Manta, Manta birostris Donndorff. (Baergh) Bottom: Great Barracuda, Sphyraena barracuda (Walbaum). (Hon)

most sharks, their skin is covered by coarse dermal denticles which can inflict a severe abrasion of the skin if one were to brush up against them. They are generally seen swimming or basking near the surface of the water with the tips of their long pectoral fins curling above the surface. Occasionally, they are seen leaping out of the water and falling back into the water with a tremendous splash. Mantas are primarily plankton feeders, but may eat crustaceans and small fishes, at times. Their color is reddish or olivaceousbrown to black above, and light beneath. Mantas are found in tropical-subtropical belts in both hemispheres. Although some investigators believe that there may be as many as ten different 
species of mantas, they have been more recently grouped together under the single species $M$. birostris.

\section{BARRACUDA}

Reports concerning the danger of attacks from barracudas are conflicting, probably due to the fact that there are about 20 -odd species, which differ greatly in their aggressiveness. True barracuda are members of the family Sphyraenidae, and are all voracious carnivores. Some of the species are harmless because of their small size.. We found this to be true of a large school of Sphyraena chinensis Lacépède, in the Marshall Islands, where our divers consistently swam among them without concern, and in no instance did they attempt to attack, nor on the other hand, did the barracuda demonstrate undue fear of man. The same can be said for the Pacific barracuda, Sphyraena argentea Girard.

However, under the proper circumstances, the great barracuda, Sphyraena barracuda (Walbaum). (Fig. 6, Bottom) is said to be an exceedingly pugnacious and dangerous foe. According to Gudger (1918), who made an extensive study of the biology and habits of the great barracuda, this fish is feared more than sharks in some areas in the West Indies.

The great barracuda may attain a length of 6-8 $\mathrm{ft}$. The mouth is large and filled with enormous knife-like canine teeth (Fig. 7). They are swift swimmers, striking rapidly and fiercely. $S$. barracuda is found in the West Indies and Brazil, north to Florida, and in the Indo-Pacific from the Red Sea to the Hawaiian Islands. In general, species of barracuda are widely distributed throughout tropical and sub-tropical waters of the world.

Skin divers report that barracuda are attracted by anything which enters the water, particularly bright-colored objects. They will follow divers by the hour, but have been seldom known to attack an underwater swimmer.

Medical Aspects. Barracuda wounds can be differentiated from those of a shark since the former are straight cuts, whereas those made by the shark are curved like the shape of their jaws (Fig. 7, Top).

Treatment. Bites should be treated in the same manner as shark bites. See Page 22.

Prevention. Barracuda are attracted by bright-colored objects and will strike at any speared fish that a diver may be carrying. 
When swimming in waters inhabited by the great barracuda, precautions should be taken not to attract their interest unduly. When swimming in the company of the great barracuda, treat it with respect and caution-this may be that rare one that bites.
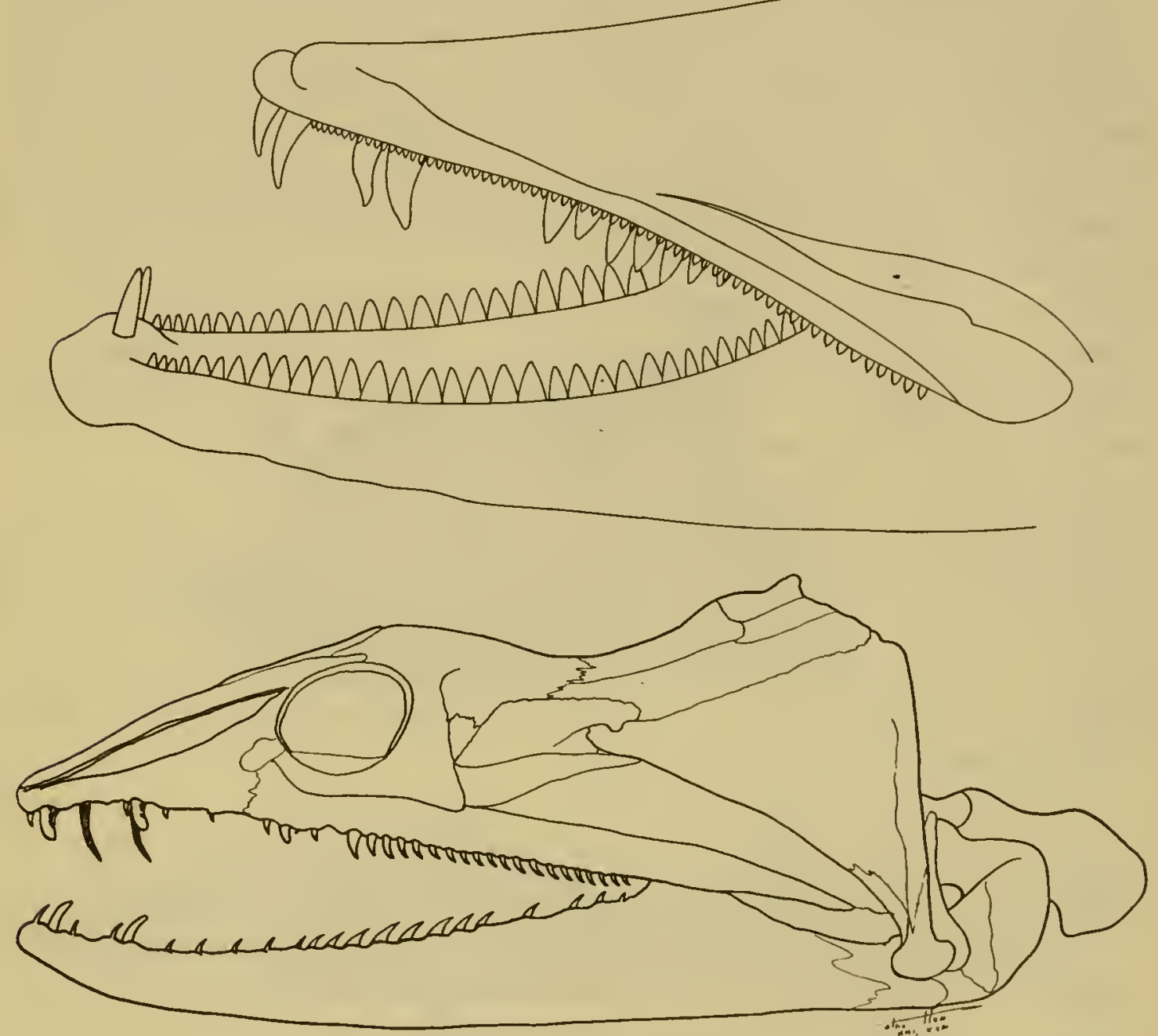

Fig. 7. Top: Jaws of the Great Barracuda, Sphyraena barracuda, showing the large knife-like canine teeth. (After Gudger) Bottom: Skull and jaws of a typical moray eel, Gymnothorax, showing the sharp canine teeth. (After Gregory)

\section{MORAY EELS}

Moray eels are members of the family Muraenidae, which contains some 20 or more species. (See Frontis.). They are largely confined to tropical and subtropical seas, although several temperate zone species are known. Gymnothorax mordax (Ayres), the moray eel of California and Muraena helena Linnaeus, of Europe, are examples of the latter group. Although moray eels are notoriously powerful and vicious biters, they seldom attack unless provoked. When wounded, they can inflict severe lacerations with their narrow muscular jaws, which are armed with strong, knifelike, or 

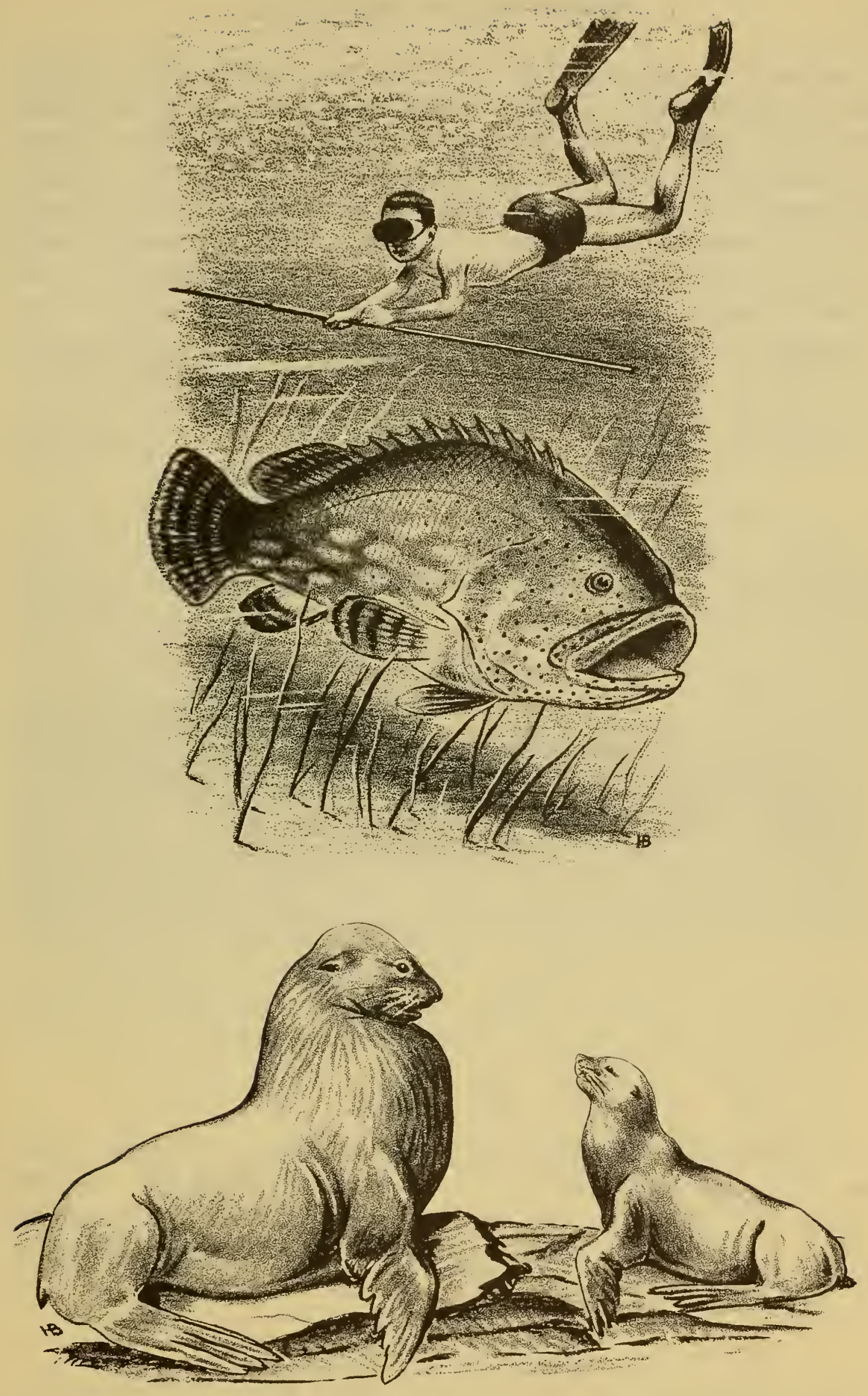

Fig. 8. Top: Diver swimming near a giant West Indian spotted grouper, Promicrops itaiara (Lichenstein). Bottom: California Sea Lion, Zalophus californianus (Lesson). (Baergh) 
crushing, teeth (Fig. 7, Bottom). They may retain their bulldoglike grip until death. Their powerful muscular bodies are covered by a tough leathery skin which is not readily penetrated by a knife. Morays are unbelievably slippery and difficult to grasp. Some of the larger species may attain a length of $10 \mathrm{ft}$., and better than a foot in diameter. Morays are bottom-dwellers, commonly found lurking in holes, and writhing snake-like through crevices, under rocks or corals.

Medical Aspects. Wounds produced by moray eels are usually of the tearing, jagged type.

Treatment. The principles involved in the treatment of shark bites are also applicable here. See page 22.

Prevention. Wounds from moray eels are most likely to be encountered when poking around crevices, in holes, or under coral or rocks inhabited by them. Poke your hand into a hole with caution!

\section{GIANT GROUPER, OR SEABASS}

Grouper, or seabass, as they are sometimes called, are members of the family Serranidae (Fig. 8, Top). Some of the larger species may attain a length of $12 \mathrm{ft}$, and a weight of more than $500 \mathrm{lbs}$. There are several records in which divers have encountered diffculty from these large creatures. Grouper tend to be unusually curious, bold, and voracious feeders. They are considered here as a potential hazard primarily because of their large size, cavernous jaws, and fearless attitudes. Certainly, they do not constitute a hazard in the sense that sharks do. Grouper are most frequently found lurking around rocks, caverns, old wrecks, etc.

\section{SEA LIONS}

Under ordinary circumstances, sea lions (Fig. 8, Bottom) cannot be considered as ferocious. However, during the breeding season, the large bulls may become irritable and have been known to nip at divers. Sea lions are generally curious, fast and magnificent swimmers.

\section{KILLER WHALES}

The killer whale, Grampus orca Linnaeus (Fig. 9) has a reputation of being a ruthless and ferocious beast. They are found in all oceans and seas, tropical and polar, alike, from Noraya Zemlya, 
Baffin Bay, and Bering Strait to beyond the Antarctic Circle in the Southern Hemisphere. The killer whale is characterized by the bluntly rounded snout, which merges imperceptibly with the forehead, the high black dorsal fin, the white patch just behind and above the eye, and the striking contrast of the jet-black color of the head and back with the snowy-white underparts. They have 10-14 large conical teeth on each side of the powerful jaws (Fig. 9), which interlock when the mouth is closed. Killer whales hunt in packs of 3-40 individuals, preying on other warm-blooded marine animals. They are fast swimmers and will attack anything that swims. They have been known to come up under ice floes and to knock seals and people into the water. If killer whales are spotted, the diver should get out of the water immediately.
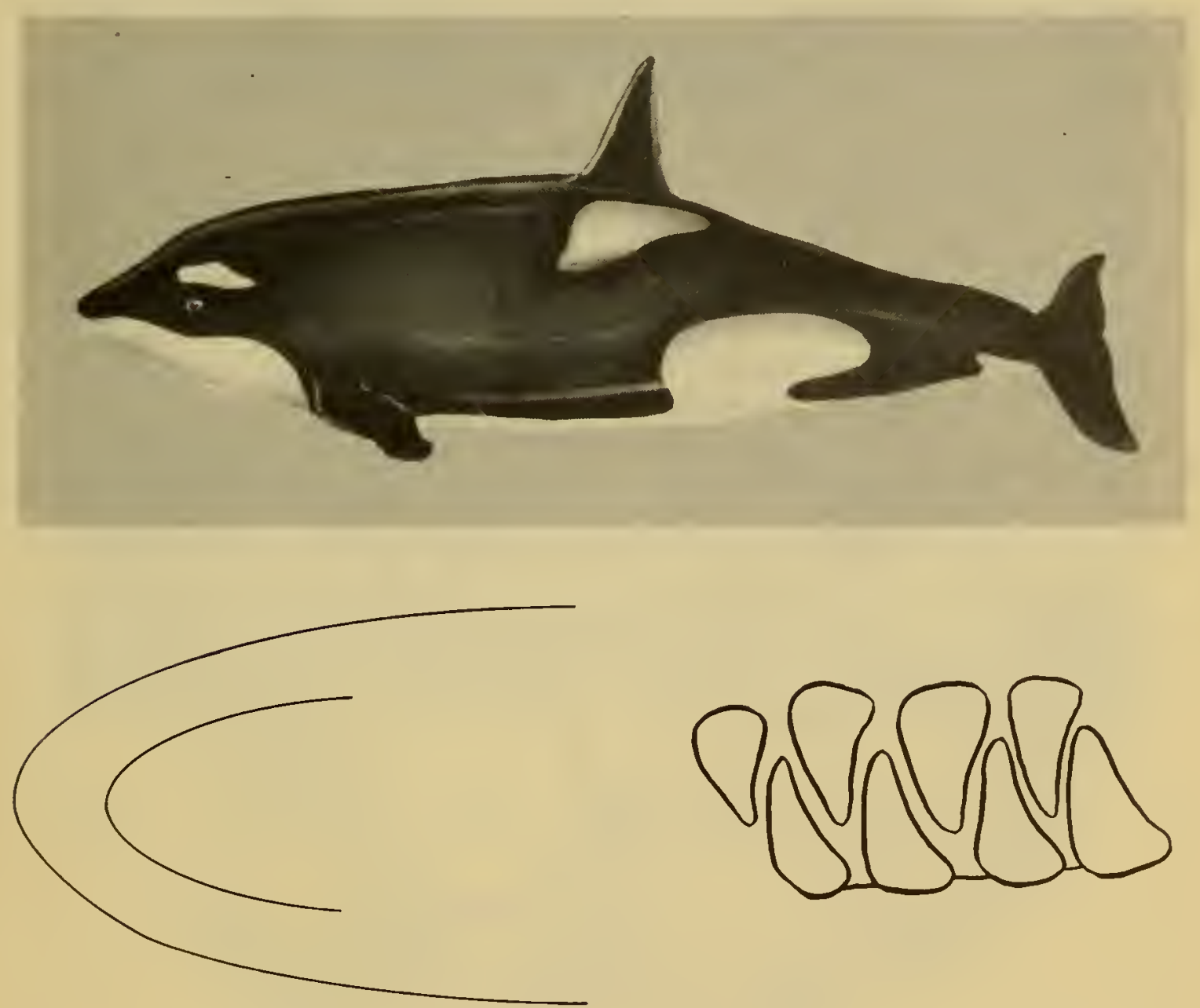

Fig. 9. Killer Whale, Grampus orca (Linnaeus). (Hon) 

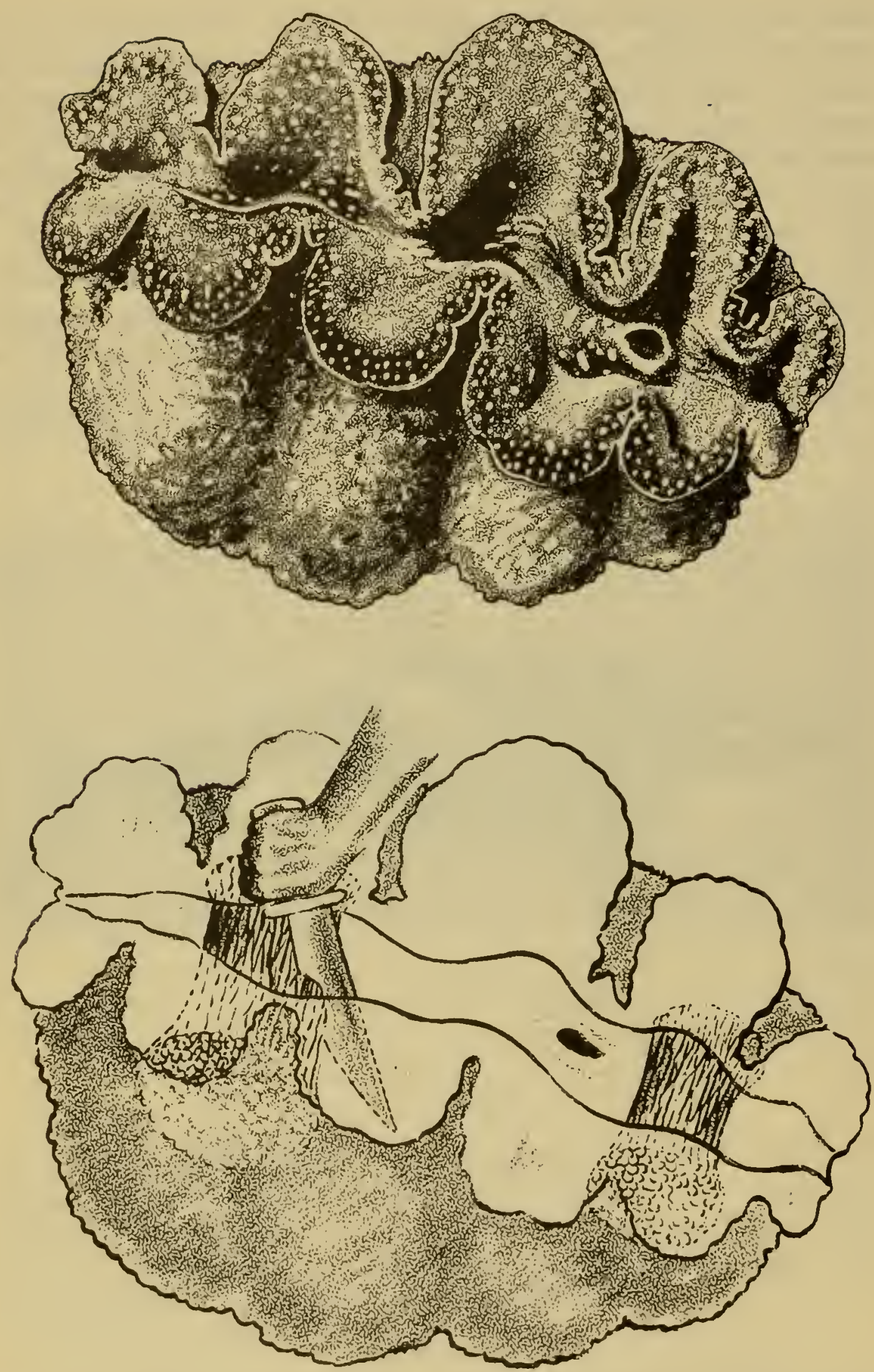

Fig. 10. Top: Giant Tridacna or Killer Clam, Tridacna gigas (Linnaeus). Bottom: Somidian showing approximate region to cut the lam in cut the clam in order to open the valves. 


\section{TRIDACNA CLAMS}

The so-called giant, or killer clams, (Fig. 10, Top) abound in tropical waters. Some of them attain huge proportions, weighing several hundred pounds (Fig. 11). Although accidents from them are rare, one should learn to recognize them and to avoid catching a foot or hand between the two valves. Drownings have occurred from divers accidentally stepping into the open valves and becoming trapped. Several such accidents are said to have taken place along the Great Barrier reef of Australia. In order to release the victim, a knife must be inserted between the valves and the adductor muscles must be severed (Fig. 10, Bottom).

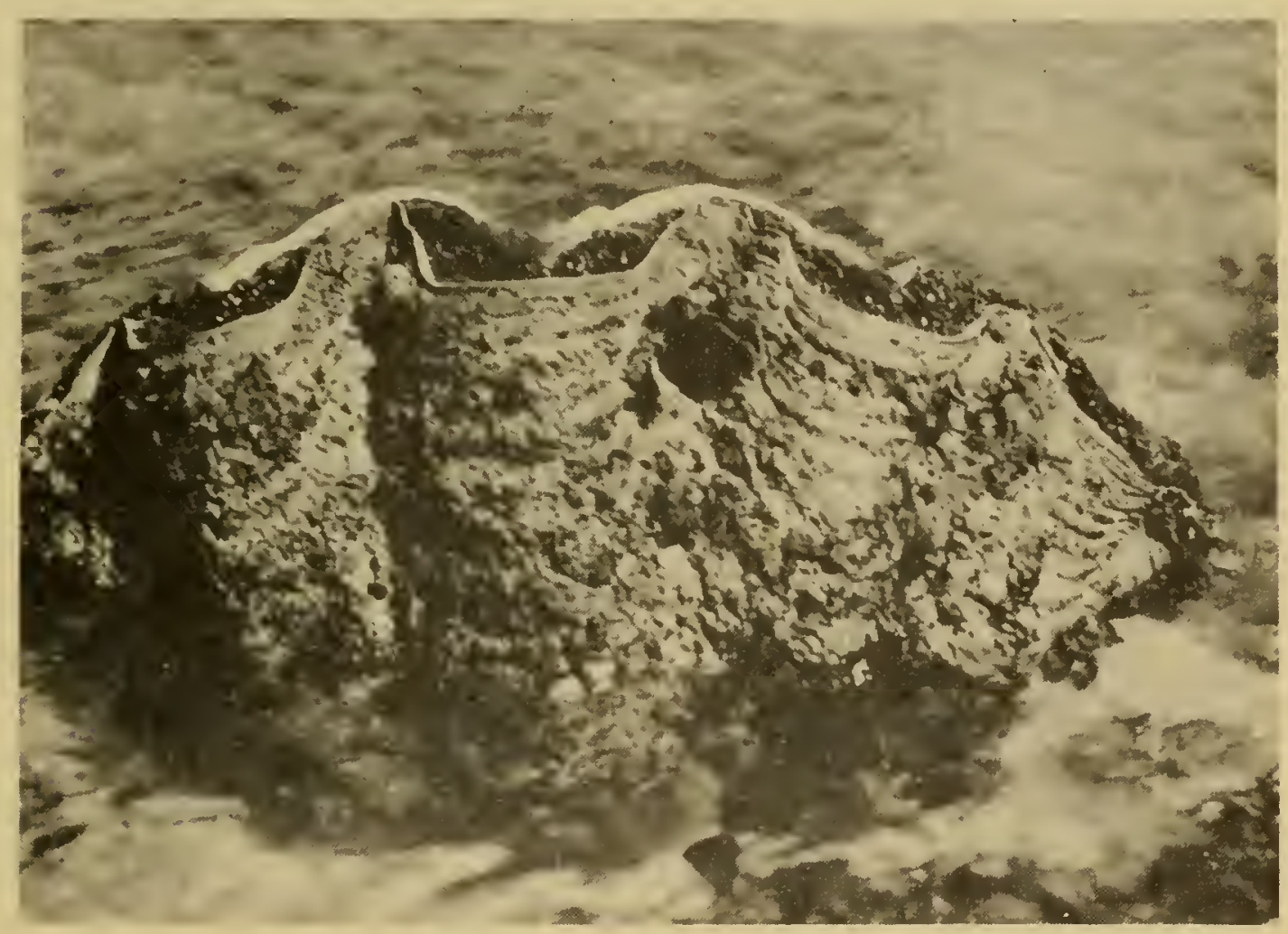

Fig. 11. Photograph of a large specimen of the giant tridacna clam in a tidal pool along the Great Barrier Reef of Australia. (From Yonge) 


\section{MARINE ANIMALS THAT STING}

\section{INVERTEBRATES}

Venomous marine invertebrates, or marine animals without backbones that inflict their injuries by stinging, can be grouped into four major categories:

1. Coelenterates -Hydroids, Jellyfishes, Coràls, and Sea Anemones

2. Molluscs

3. Annelid Worms

4. Echinoderms

-Univalve shellish, and Octopuses

- Stinging or Bristle Worms

-Sea Urchins

\section{COELENTERATES}

The coelenterates, which includes the hydroids, jellyfishes, corals, and sea anemones, are simple, many-celled organisms. In addition to a number of other technical characters, they all possess tentacles equipped with nematocysts or stinging cells. It is these stinging cells which make them of interest to the skin diver.

The coelenterates are divided into three principal classes:

I. Hydrozoa: the hydroids. To this class belong the hydroids which are commonly found growing in plume-like tufts on rocks, seaweeds and pilings. Some of the more common stinging members of this group are the following:

Stinging or Fire Coral, Millepora alcicornis Linnaeus (See Frontis.). This false coral is generally found living among true corals along reefs in the warm waters of the tropical Pacific, Indian Ocean, Red Sea, and Caribbean Sea.

Portuguese-Man-0'-War or Blue Bottle, Physalia physalis (Linnaeus) (Frontis). This hydroid is most commonly mistaken for a true jellyfish. Actually, it is a colonial hydroid. It is almost always found floating at the surface of the water. Suspended from the balloon-like floats are the stinging tentacles which may trail several feet down into the water. This particular species inhabits the tropical Atlantic, going as far north as the Bay of Fundy, the Hebrides, and the Mediterranean Sea. A closely allied species is found in the Indo-Pacific area, Hawaii, and southern Japan.

II. Scyphozoa: The true jellyfishes. This class includes the larger medusae, having eight notches in the margin of the bell. 
Many species of jellyfish are capable of stinging and producing mild skin irritations, but there are only a few which might be considered especially dangerous. They are:

Sea Wasp, Carybdea alta Reynaud. (Fig. 12). This species inhabits the tropical Pacific, Atlantic, and Indian Oceans.

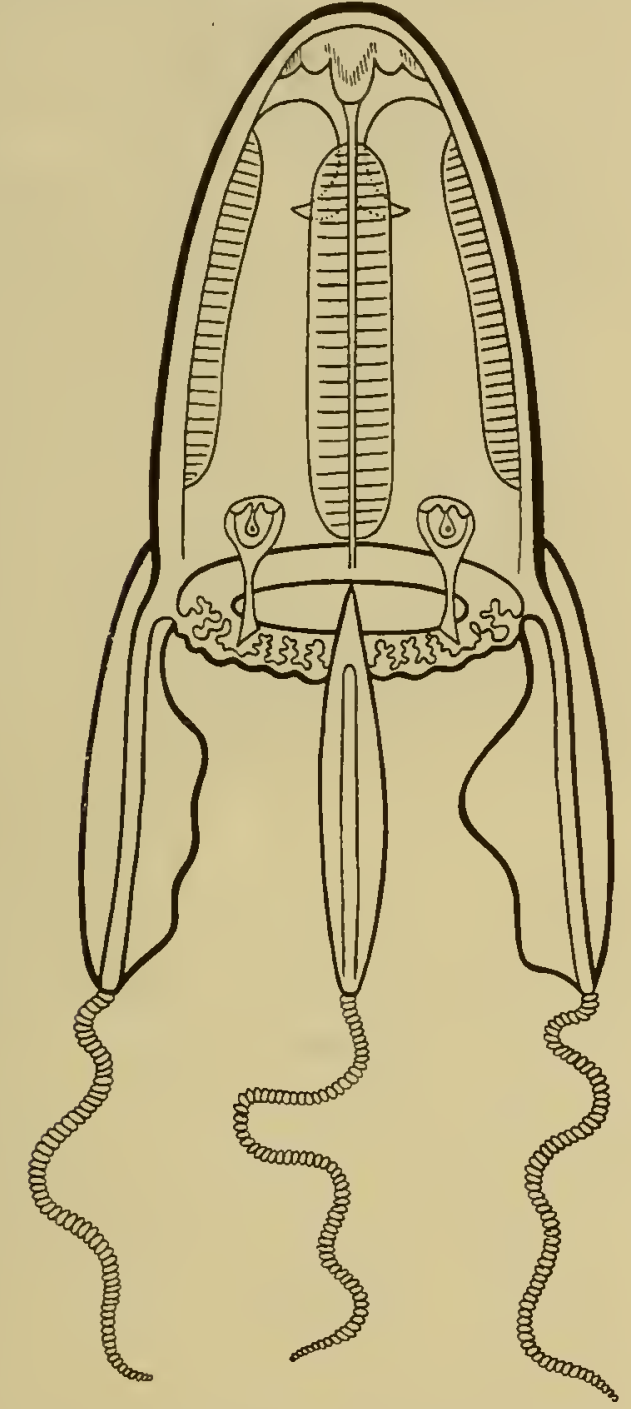

Fig. 12. Sea Wasp, Carybdea alata Reynaud. (After Mayer)

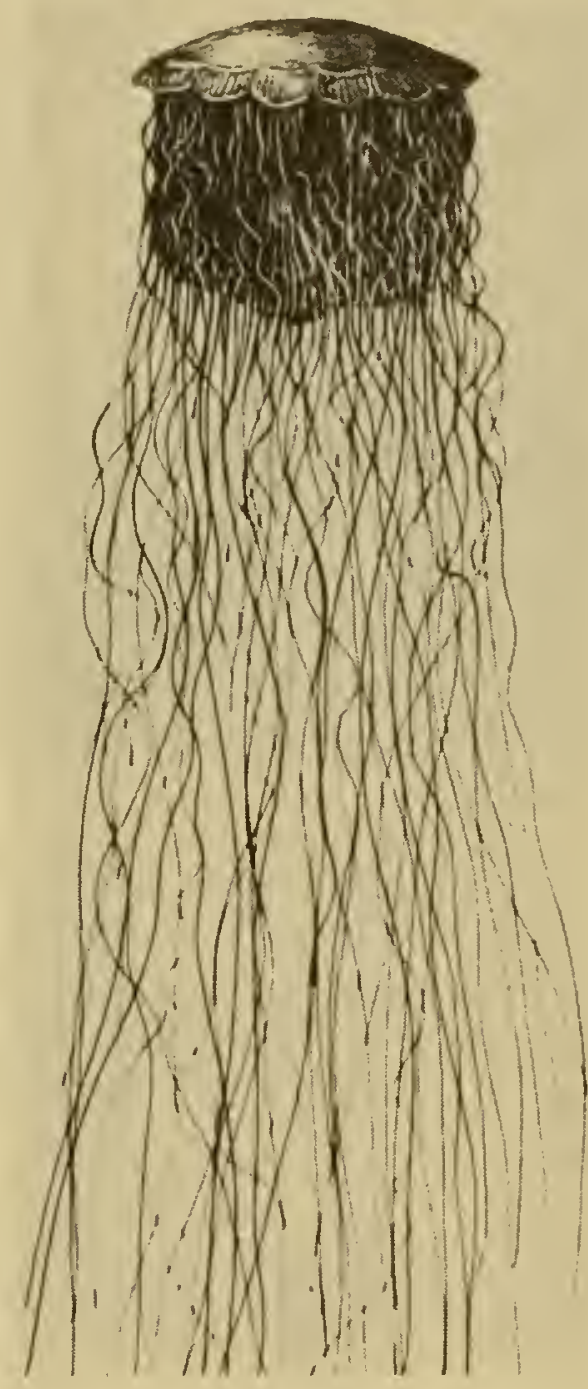

Fig. 13. Sea Blubber, Cyanea capillata Eschscholtz. (Shirao)

Sea Wasp, Chiropsalmus quadrigatus Haeckel (Frontis). This extremely dangerous jellyfish is an inhabitant of northern Australia, Philippines, and Indian Ocean. A closely related, but apparently less dangerous form occurs in the Atlantic, from Brazil to North Carolina, Indian Ocean, and northern Australia.

Sea Nettle, Dactylometra quinquecirrha Desor (Frontis). This is a widely distributed species occurring from the Azores and New England, to the tropics, West Africa, Indian Ocean, western Pacific, Malayan Archipelago to Japan and the Philippines. 
Sea Blubber, Cyanea capillata Eschscholtz. (Fig. 13). Inhabits the North Atlantic and Pacific, southern coast of New England to the Arctic Ocean; France to northern Russia, Baltic Sea; Alaska to Puget Sound, Japan, and China. Other stinging species of this genus are found in the tropical and temperate Pacific Ocean.

III. Anthozoa: The sea anemones and corals. Important venomous members of this group are:

Elk Horn Coral, Acropora palmata (Lamarck). (Fig. 14). Inhabits Florida Keys, Bahamas, and West Indies.

Sea Anemone, Actinia equina Linnaeus (Frontis). Inhabits the eastern Atlantic from the Arctic Ocean to the Gulf of Guinea, Mediterranean Sea, Black Sea, and the Sea of Azov.

Rosy Anemone, Sagartia elegans (Dalyell) (Frontis). Inhabits Iceland to Atlantic coast of France, Mediterranean Sea, and the coast of Africa.

Sea Anemone, Adamsia palliata (Bohadsch) (Frontis). Ranges from Norway to Spain, and the Mediterranean Sea.

Sea Anemone, Anemonia sulcata (Pennant) (Frontis). Eastern Atlantic, from Norway and Scotland to the Canaries, and the Mediterranean Sea.

Venom Apparatus of Coelenterates. The venom apparatus of coelenterates consists of the nematocysts or stinging cells which are largely located on their tentacles (Fig. 15). These nematocysts are situated within the outer layer of tissue of the tentacle. Each of the capsule-like nematocysts is contained within an outer capsule-like device called the cnidoblast. Projecting at one point on the outer surface of the cnidoblast is the trigger-like cnidocil. Contained within the fluid-filled capsular nematocyst is the hollow, coiled, thread tube. The opening through which the thread tube is everted is closed prior to discharge by a lid-like device called the operculum. The fluid within the capsule is the venom. Stimulation of the cnidocil appears to produce a change in the capsular wall of the nematocyst causing the operculum to spring open like a trap door, and the thread tube conveying the venom is everted. The sharp tip of the thread tube penetrates the skin of the victim and the venom is thereby injected. When a diver comes in contact with the tentacles of a coelenterate, he brushes up against the cnidocils of literally thousands of these minute stinging organs.

Medical Aspects. The symptoms produced by coelenterate stings vary according to the species, the site of the sting, and the person. In general, those caused by hydroids and hydroid corals (Mille- 

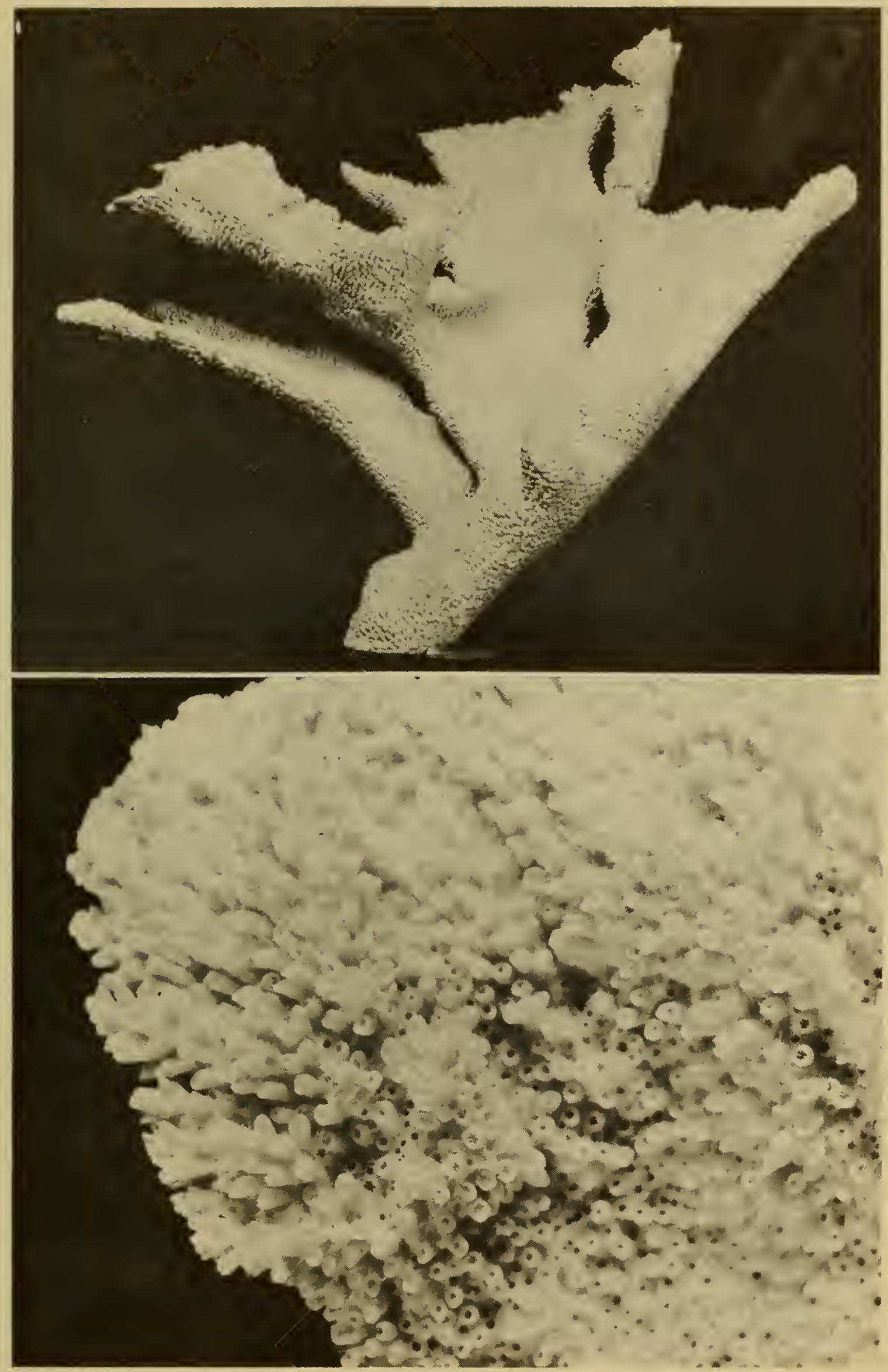

Fig. 14. Top: Elk Horn Coral, Acropora palmata (Lamarck). Large branch measuring about 18 ins. in height. Bottom: Close-up view of Acropora palmata. (Courtesy of Smithsonian Institution) 
pora), are primarily local skin irritations. Physalia stings may be very painful. Sea anemones and true corals produce a similar reaction, but may be accompanied by general symptoms. Ulcerations of the skin may be quite severe in lesions produced by Sagartia in the sponge fishermen's disease. Symptoms resulting from scyphozoans vary greatly. The sting of most scyphozoans is too mild to be noticeable, whereas Cyanea, Dactylometra, and Chiropsalmus. are capable of inflicting very painful local and generalized symptoms. Chiropsalmus is probably the most venomous marine organism known, and may produce death within 3 to 8 minutes in humans.

Symptoms most commonly encountered vary from an immediate mild prickly, or stinging sensation like that of a nettle sting, to a burning, throbbing or shooting pain which may render the victim unconscious. In some cases, the pain is restricted to an area within the immediate vicinity of the contact, or it may radiate to the groin, abdomen, or armpit. The area coming in contact with the tentacles usually becomes reddened, followed by a severe inflammatory rash, blistering, swelling and minute skin hemorrhages. In severe cases, in addition to shock, there may be muscular cramps, abdominal rigidity, diminished touch and temperature sensation, nausea, vomiting, severe backache, loss of speech, frothing at the mouth, sensation of constriction of the throat, respiratory difficulty, paralysis, delirium, convulsions, and death.

Treatment. Treatment must be directed toward accomplishing three objectives: relieving pain, alleviating effects of the poison, and controlling primary shock. Morphine is effective in relieving pain. Intravenous injections of calcium gluconate have been recommended for the control of muscular spasms. Oral histaminics and topical cream are useful in treating the rash. Dilute ammonium hydroxide, sodium bicarbonate, olive oil, sugar, ethyl alcohol and other types of soothing lotions have been used with varying degrees of success. Artificial respiration, cardiac and respiratory stimulants, and other forms of supportive measures may be required. There are no known specific antidotes.

Prevention. It should be kept in mind that the tentacles of some species of jellyfish may trail a great distance from the body of the animal-as much as 50 feet or more, in some instances. Consequently, jellyfish should be given a wide berth. Tight-fitting woolen underwear or rubber skin diving suits are useful in affording protection from attacks from these creatures. Jellyfish washed up on 


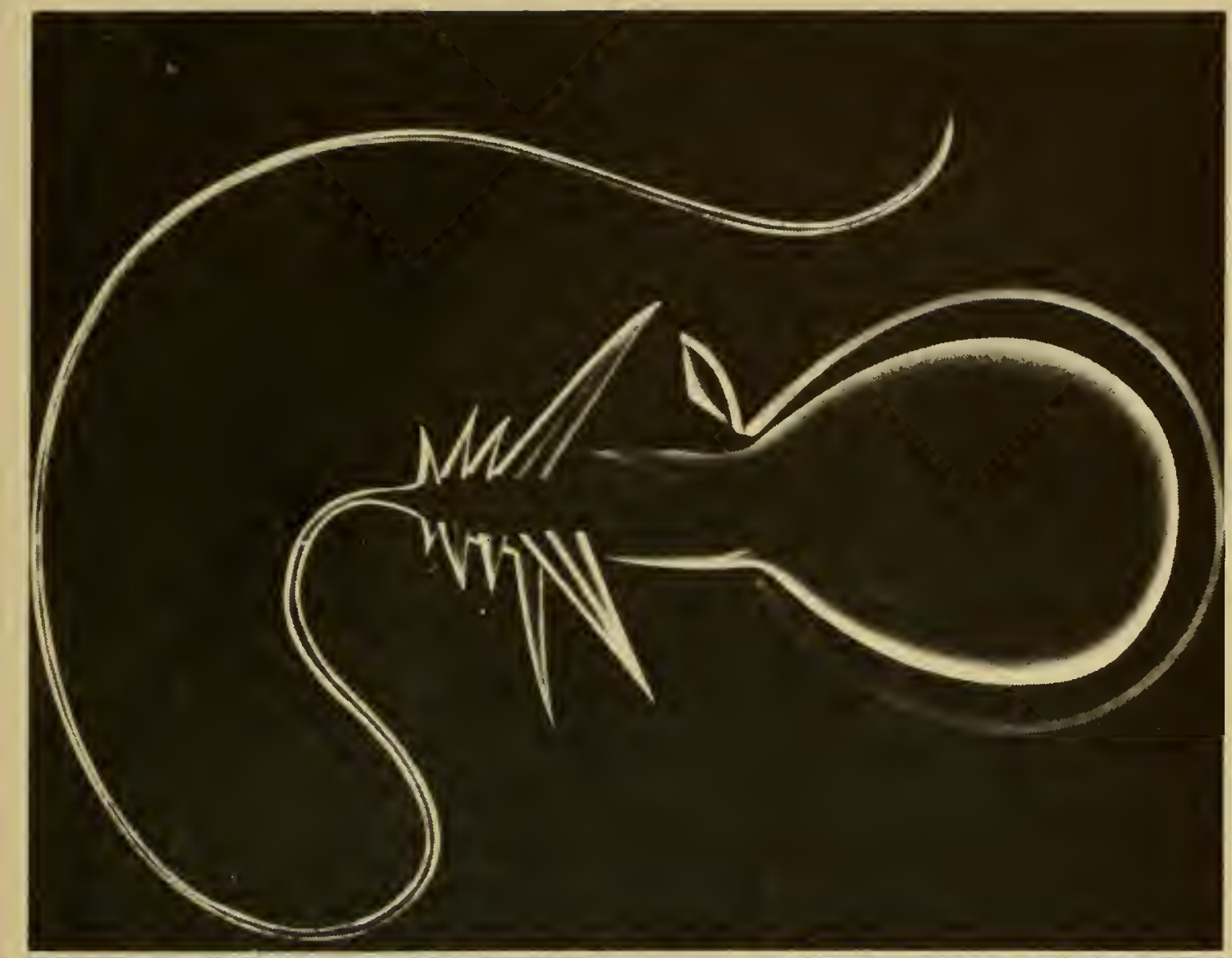

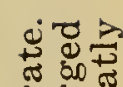

武

동

ฮิด

...

世隶

फ.

+ै की

崩

유을

屯 व

E $P$

क्ष

प

○ี

$=0$

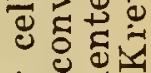
so

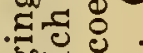

.

语

उ०

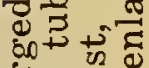

\%

들

क

च

吕氙

ið

प्

버웡

م.

म

$\dot{0} \stackrel{0}{\circ}$

开 
the beach, even though appearing dead, may be quite capable of inflicting a serious sting. The tentacles of some jellyfish may cling to the skin. Care should be exercised in the removal of the tentacles, or additional stings will be received. Use a towel, rag, seaweed, stick, or handful of sand. Swimming soon after a storm in tropical waters in which large numbers of jellyfish were previously present may result in multiple severe stings from remnants of damaged tentacles floating in the water. Upon being stung, the victim should make every effort to get out of the water as soon as possible because of the possible danger of drowning. Dilute ammonia and alcohol, which should be applied to the site of the stings as soon as possible. Rubbing the body with mineral oil, or baby oil, may help to prevent stings, to some extent.

\section{Coral Cuts}

The problem of coral cuts is deserving of special mention, since they represent an ever-present annoyance to the diver working in tropical areas. Stony corals, despite their delicate appearance, have calcareous outer skeletons with razor-sharp edges that are capable of inflicting nasty wounds. These injuries are generally superficial, but they are notoriously slow in healing, and often cause temporary disability.

Medical Aspects. Stinging corals produce their effects by stinging cells similar to those of jellyfish. However, a major consideration in the problem of coral cuts is the mechanical damage to the skin of the victim. The primary reaction to a coral cut, sometimes called "coral poisoning", is the appearance of red welts and itching, around the wound. If coral cuts are left untreated, a mere scratch, under adverse living conditions, may become within a few days, an ulcer with a septic sloughing base surrounded by a painful, reddened area.

Treatment. Prompt cleansing of the wound, removal of foreign particles, removal of dead tissue, and the application of antiseptic agents are recommended. In severe cases, it may be necessary to give the patient bedrest with elevation of the limb, kaolin poultices, magnesium sulfate in glycerin solution dressings, and antibiotics. Antihistaminic drugs given orally, or applied locally to the wound, afford relief of pain.

Prevention. When working in the vicinity of corals, one should take every precaution to avoid contact with them. Do not handle them with the bare hands. Wear leather or heavy cotton gloves, and rubber-soled canvas shoes, or a completely-soled flipper. The 
wearing of an outer garment over the body will help to prevent scratches over the body, which can develop into festering sores. Scratches should be painted with a mild antiseptic, such as zepherin* solution, upon getting out of the water.

\section{Molluscs}

Stinging or venomous molluscs of concern to the skin diver fall largely into two categories:

I. Gastropods or univalve molluscs.

II. Cephalopods-octopuses and squids.

\section{Gastropods}

The univalves include land, freshwater, and marine snails and slugs. Members of this class are characterized by a single shell, or lack of a shell. The body is usually asymmetrical in a spirally coiled shell (the slugs are an exception to this arrangement). There is typically a distinct head, with one to two pairs of tentacles, two eyes, and a large flattened fleshy foot. Only members of the genus Conus are of particular concern to the skin diver.

Species of Cone Shells: Univalve molluses of the genus Conus, or cone shells, as they are commonly called, because of their conelike shape, are favorites of shell collectors because of their ornate and attractive patterns. There are more than 400 species of cone shells, and all of them contain a highly-developed venom apparatus. Cone shells are usually found under rocks, coral, or crawling along the sand. Several of the tropical species have caused deaths. Some of the more dangerous species are listed below:

Court Cone, Conus aulicus Linnaeus (Fig. 16, Upper Left). Ranges from Polynesia westward to the Indian Ocean.

Geographer Cone, Conus geographus Linnaeus (Fig. 16, Upper Right). Inhabits the Indo-Pacific, from Polynesia to east Africa.

Marbled Cone, Conus marmoreus Linnaeus (Fig. 16, Center Left). Ranges from Polynesia westward to the Indian Ocean.

Striated Cone, Conus striatus Linnaeus (Fig. 16, Center Right). Inhabits the Indo-Pacific, from Australia to east Africa.

Textile Cone, Conus textile Linnaeus (Fig. 16, Lower Left). Ranges from Polynesia to the Red Sea.

Tulip Cone, Conus tulipa Linnaeus (Fig. 16, Lower Right). Ranges from Polynesia to the Red Sea.

* It is recommended that zepherin solution be used rather than merthiolate or iodine solution, since sensitivity reactions to these latter solutions are not uncommon in the tropics. 

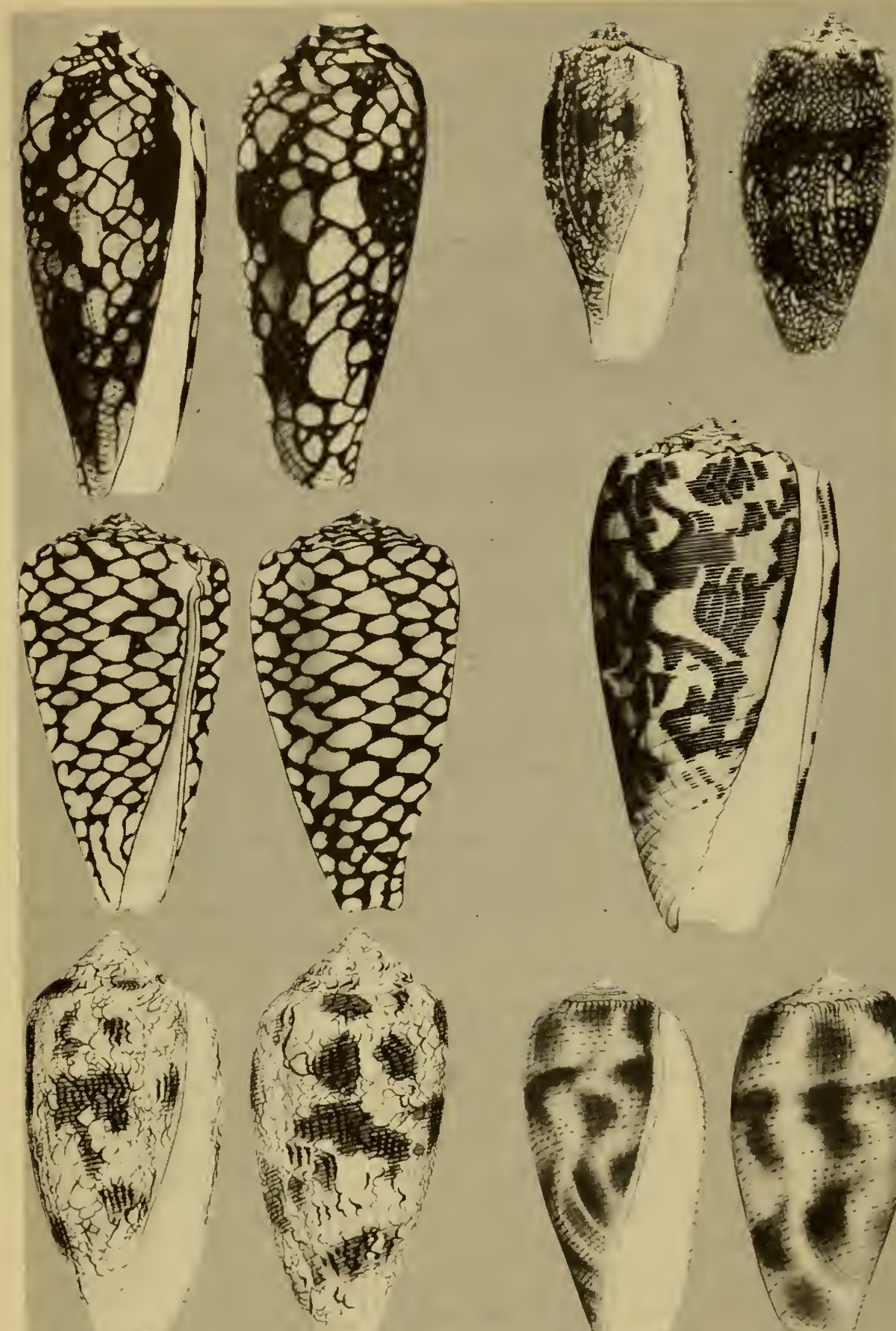

Fig. 16. Upper left: Court Cone, Conus aulicus Linnaeus. Upper right: Geographer Cone, Conus geographus Linnaeus. Center left: Marbled Cone, Comus mamoreus Linnaeus. Center right: Striated Cone, Comus striatus Linnaeus. Lower left: Textile Cone, Coms textile Linnaeus. Lower right: Tulip Cone, Conus tulipa Linnaeus. (From Hiyama) 

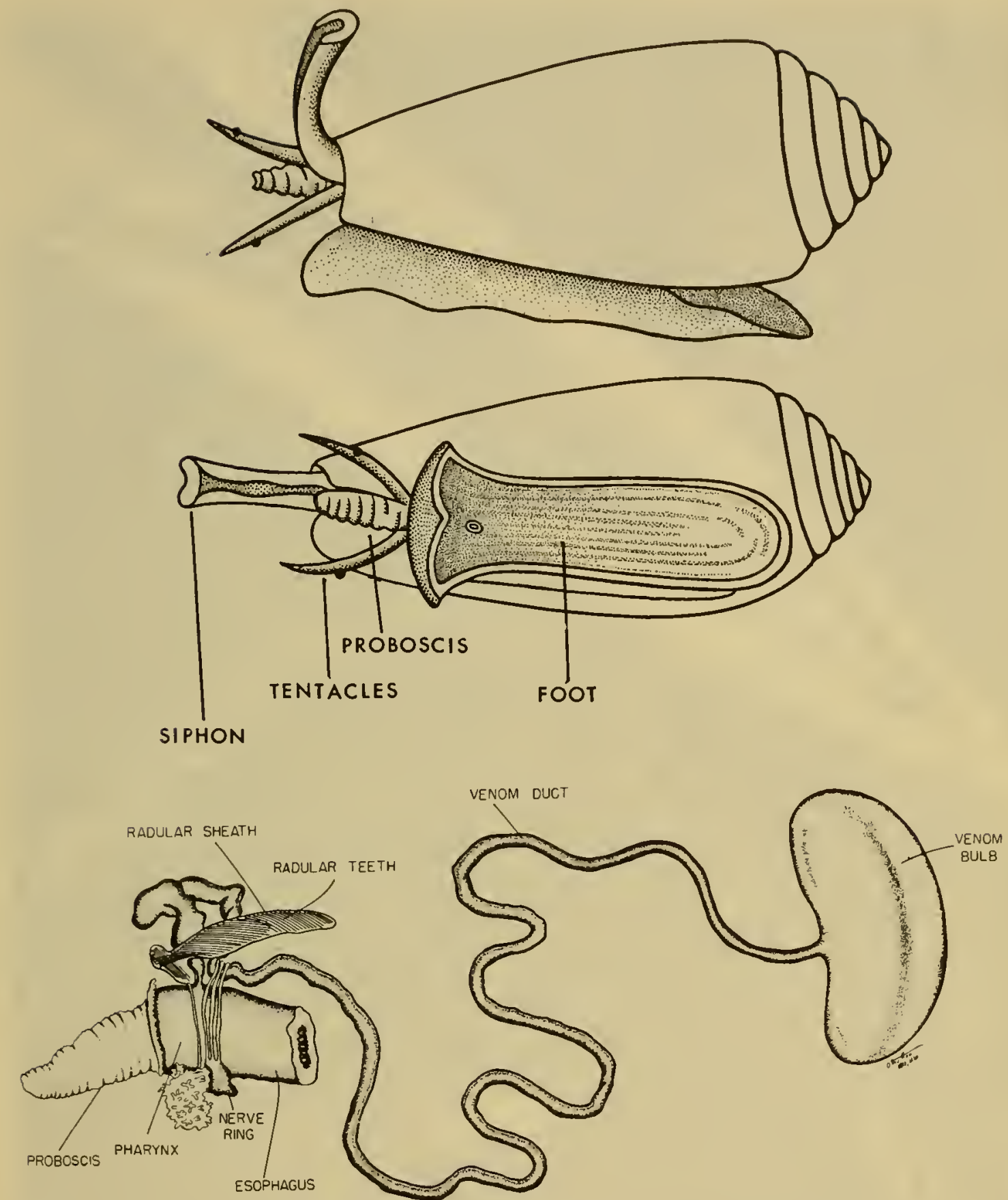

Fig. 17. Top: The external anatomy of a cone shell. (Kreuzinger) Bottom: Anatomy of the venom apparatus of Conus. (Hon)

Stinging or Venom Apparatus of Cone Shells. The venom apparatus consists of the venom bulb, venom duct, radular sheath, and radular teeth (Fig. 17). The pharynx and proboscis, which are a part of the digestive system, also play an important role as accessory organs. The venom apparatus lies in a cavity within the animal. It is believed that preparatory to stinging, the radular teeth which are housed in the radular sheath are released into the pharynx, and thence to the proboscis, where they are grasped for thrusting into the flesh of the victim. The venom, which is believed 


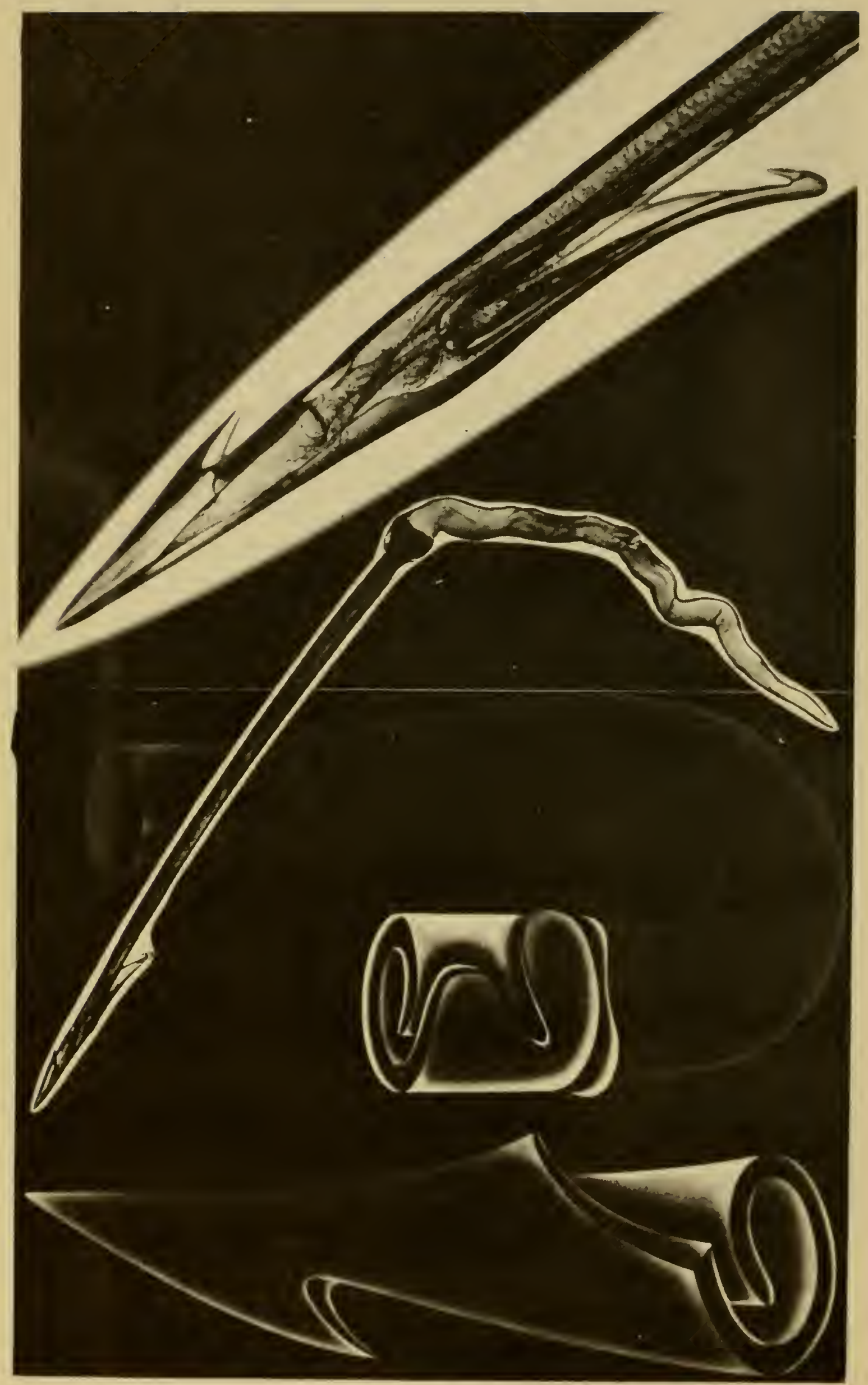

Fig. 18. See caption $\longrightarrow$ 
to be produced in the venom duct, is probably forced under pressure by contraction of the venom bulb and duct into the radular sheath, thereby being forced into the coiled radular teeth (Fig. 18).

Medical Aspects. Stings produced by Conus are of the puncture wound variety. Localized ischemia, cyanosis, numbness in the area about the wound, or a sharp stinging or burning sensation are

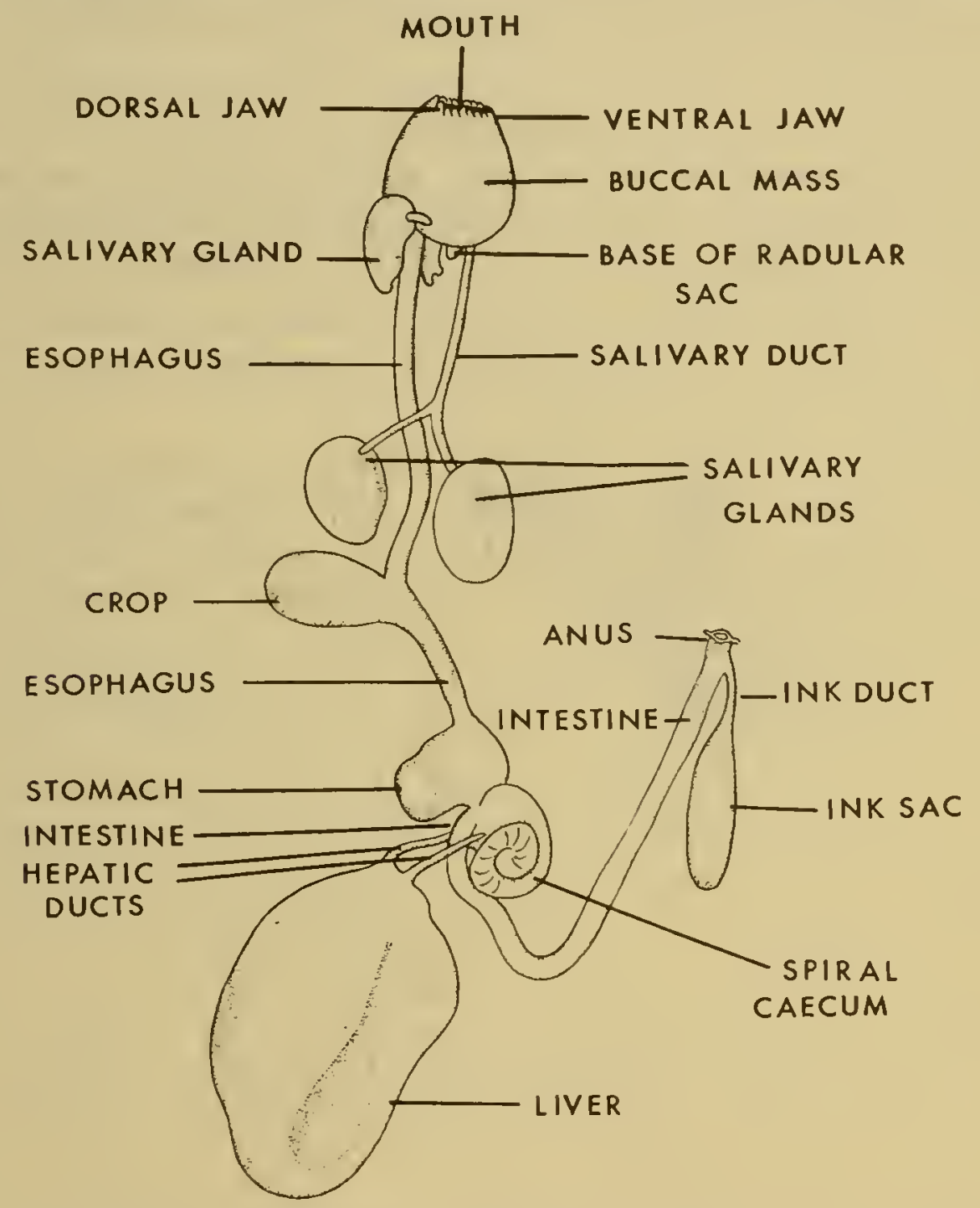

Fig. 19. Anatomy of the venom apparatus of the octopus. (Kreuzinger)

usually the initial symptoms. Numbness and tingling begin at the wound site and may spread rapidly, involving the entire body, but are particularly pronounced about the lips and mouth. In severe

Fig. 18. Top: Photomicrograph of the harpoon-like tip of the radular tooth of C. striatus. Center: Radular tooth of Conus striatus. Bottom: Semidiagrammatic drawing of a typical radular tooth of Conus. The radular teeth are comprised of a flat sheet of chitin rolled into a tube-like structure. The venom is contained within the lumen of the tooth. Upper picture illustrates base of tooth attached to ligament. Barbed tip of hollow tooth in lower drawing.

(Kreuzinger) 
cases, paralysis may be present. Respiratory distress is usually absent. Coma may ensue, and death is said to be the result of cardiac failure.

Treatment. There is no specific treatment. Cases of cone shell stings should be managed like venomous fish stings. See page 91 .

Prevention. Live cone shells should be handled with care, and effort should be made to avoid coming in contact with the soft parts of the animal.

\section{Cephalopods}

This group includes the nautilus, squid, cuttlefish, and octopus. The head is large and contains conspicuous and well-developed eyes. The mouth, armed with horny jaws and a radula, is surrounded by eight or ten tentacles equipped with numerous suckers or hooks. Rapid movements can be produced by expelling water from the mantle cavity through the siphon.

Few marine animals have received greater attention from fiction writers than has the octopus. Truly, it is a remarkable creature, but it is grossly overrated as a hazard to the diver. The octopus is a curious animal, but cautious, and can hardly be considered the demon of the seas that many writers make it out to be. Large specimens may exceed $25 \mathrm{ft}$. in span, but those encountered at diving depths are generally smaller. The giant squid that is commonly taken off the coast of South America may attain several times the length of the largest octopus, but are for the most part deep water inhabitants, and of little interest to skin divers. The nautilus and cuttlefish are not considered to be of medical importance. Octopuses tend to hide in holes, or underwater caves. Areas such as this should be avoided by the inexperienced diver. There is a danger, remote that it may be, of a diver being trapped underwater when entering such a cave, even by a relatively small specimen, if it can get a good grip on a smooth surface of the diver. A more practical danger comes from the careless handling of even small specimens of octopuses, since these animals possess a well-developed venom apparatus and produce their injurious effects by biting.

Species of Cephalopods. Since cephalopods can be identified only with difficulty by specialists, no attempt will be made to consider individual species. The colored Frontis shows the common octopus, Octopus vulgaris Lamarck, and the squid, Loligo vulgaris Lamarck, which are found in many parts of the world.

Venom Apparatus of the Octopus. The venom apparatus of the octopus is comprised of the so-called anterior and posterior sali- 
vary glands, the salivary ducts, the buccal mass, and the mandibles, or beak (Fig. 19). The mouth of the octopus is situated in the center of the oral and anterior surface of the arms, surrounded by a circular lip, fringed with finger-like papillae (Fig. 20). The mouth leads into a pharyngeal cavity having thick muscular walls. This entire muscular complex is known as the buccal mass, which is surrounded and concealed by the muscular bases of the arms. The buccal mass is furnished with two powerful dorsal and ventral chitinous jaws, whose shape resembles that of a parrot's beak. The arrangement of the jaws differs from the parrot in that the ventral one bites outside the dorsal, and is wider and larger. These jaws are able to bite vertically with great force, tearing the captured food which is held by the suckers before it is passed on to the rasping action of the radula. The duct from the posterior salivary

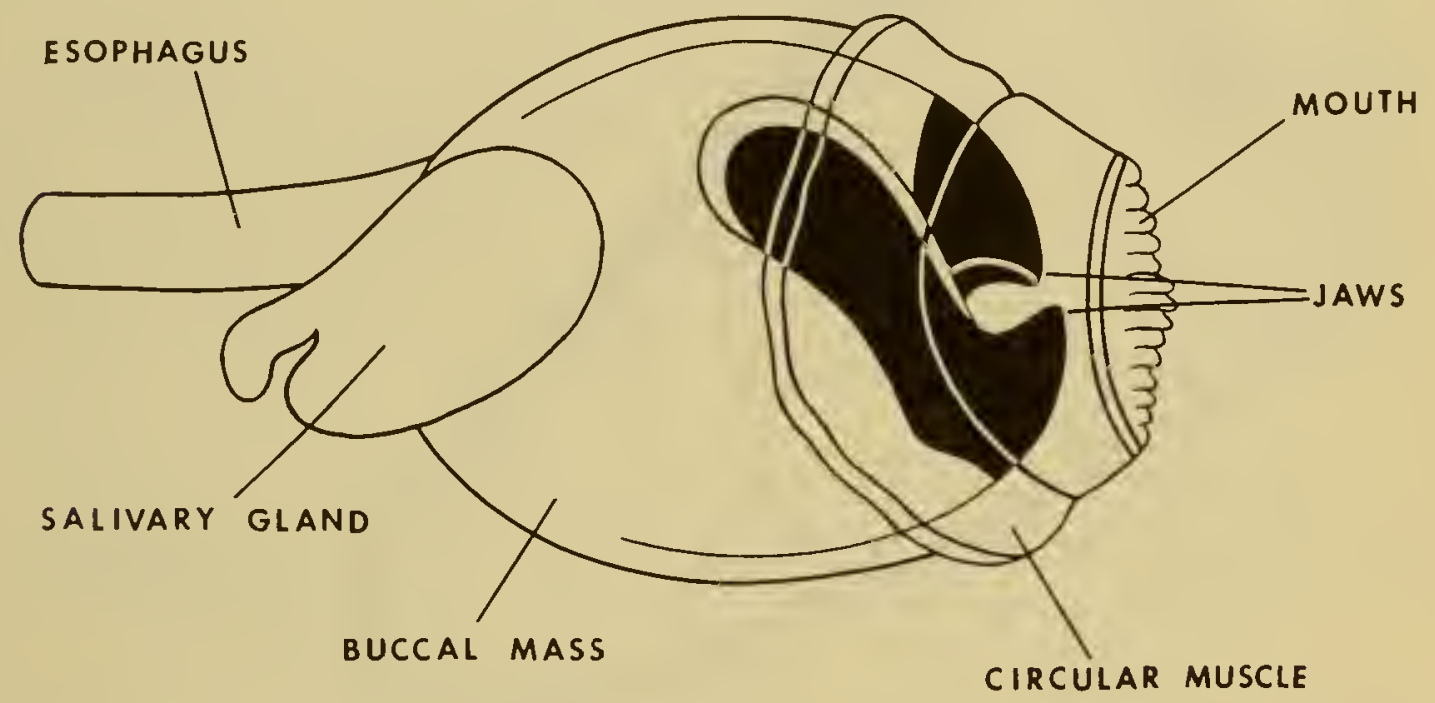

Fig. 20. Buccal mass of an octopus showing the mouth and jaws. (Kreuzinger)

glands opens on the tip of the sub-radular organ, which appears as an outgrowth in front of the tongue. The paired ducts from the anterior salivary glands open into the pharynx laterally and posteriorly. The venom is discharged from these ducts into the pharynx.

Medical Aspects. Octopus bites usually consist of two small puncture wounds which are produced by the sharp parrot-like chitinous jaws. A burning or tingling sensation is the usual initial symptom. At first, the discomfort is localized, but may later radiate to include the entire appendage. Bleeding is frequently profuse for the size of the bite, which may indicate that the clotting process of the blood is retarded. Swelling, redness, and heat commonly develop in the area about the wound. Recovery is generally uneventful. 
One fatality is reported resulting from an octopus bite. The incident took place near East Point, Darwin, Australia. According to the account, a diver captured a small octopus of unknown species which had a span of about $20 \mathrm{~cm}$. The diver permitted the octopus
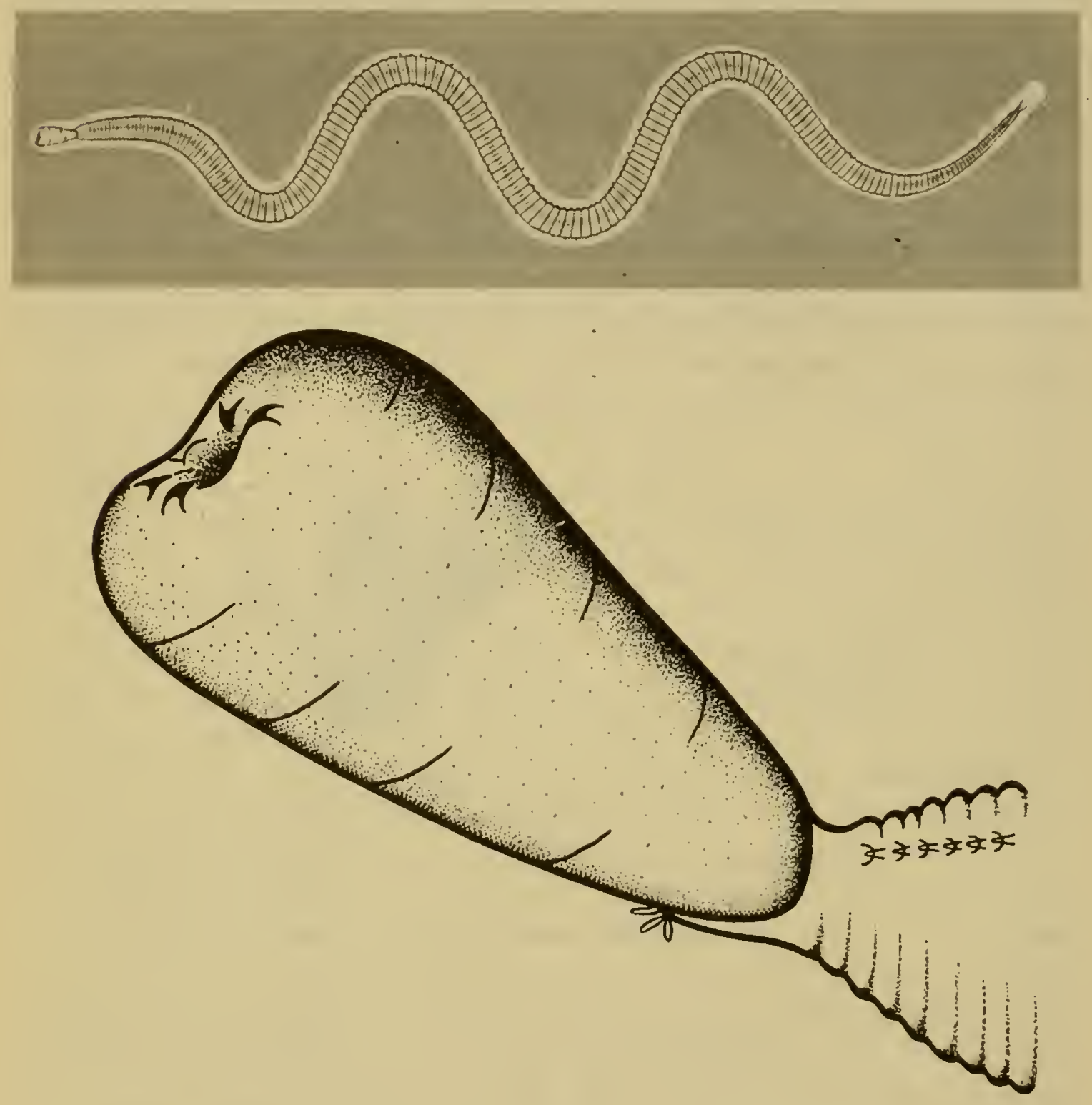

Fig. 21. Bloodworm, Glycera dibranchiata Ehlers, with head enlarged.

to crawl over his arms and shoulders, and finally to the back of his neck, where the animal remained for a few moments. During the period that the octopus was on his neck, a small bite was inflicted, producing a trickle of blood. A few minutes after the bite, the victim complained of a sensation of dryness in his mouth and of difficulty in swallowing. After walking a short distance up the beach from the scene of the accident, the victim began to vomit, developed a loss of muscular control, and finally suffered from respiratory dis- 
tress, and was unable to speak. The victim was rushed to a hospital and placed in a respirator, where he expired about two hours after being stung.

Treatment. Wounds from octopuses should be treated in the same manner as fish stings. (See Page 91).

Prevention: Underwater caves which are likely to be inhabited by octopuses should be avoided by the inexperienced diver. The wearing of an outer cloth garment makes it difficult for an octopus to adhere to the skin. Octopuses, regardless of their size, should be handled with gloves. Even some of the smaller species can inflict a painful bite, which in at least one case has been known to be fatal. Stabbing deep between the eyes is the method of choice for killing an octopus.

\section{ANNELID WORMS}

Segmented worms, or annelids, are organisms having an elongate body, which is usually segmented, each segment having paired setae, or bristle-like structures. In some species these setae are developed into a stinging mechanism. Still other species have tough chitinous jaws with which they can inflict a painful bite. Annelid worms are usually encountered when turning over rocks or coral boulders.

Species of Annelids. There are many species of annelid worms which might be listed, but the following species are representative of the two types: (1) those having biting jaws (Glycera), and (2) those having stinging setae (Eurythöe, Hermodice).

Bloodworm, Glycera dibranchiata Ehlers. (Fig. 21). Found along the coast of North Carolina to northeast Canada.

Bristleworm, Eurythöe complanata (Pallas). Found in the Gulf of Mexico, and throughout the tropical Pacific.

Bristleworm, Hermodice carunculata Pallas. (Fig. 22). Inhabits the Gulf of Mexico.

Medical Aspects. The chitinous jaws of Glycera are able to penetrate the skin and to produce a painful sensation 'similar to that of a bee sting. The marks from the jaws are oval-shaped, and are about as large as the inner circle of the following letter " $O$ ", in the center of which is a small reddish spot usually indicating where the jaws have pierced the skin, and bordered by a surrounding area of blanching. The wounded area may become hot and swollen, and may remain so for a day or two. The swelling may be followed by numbness and itching. 


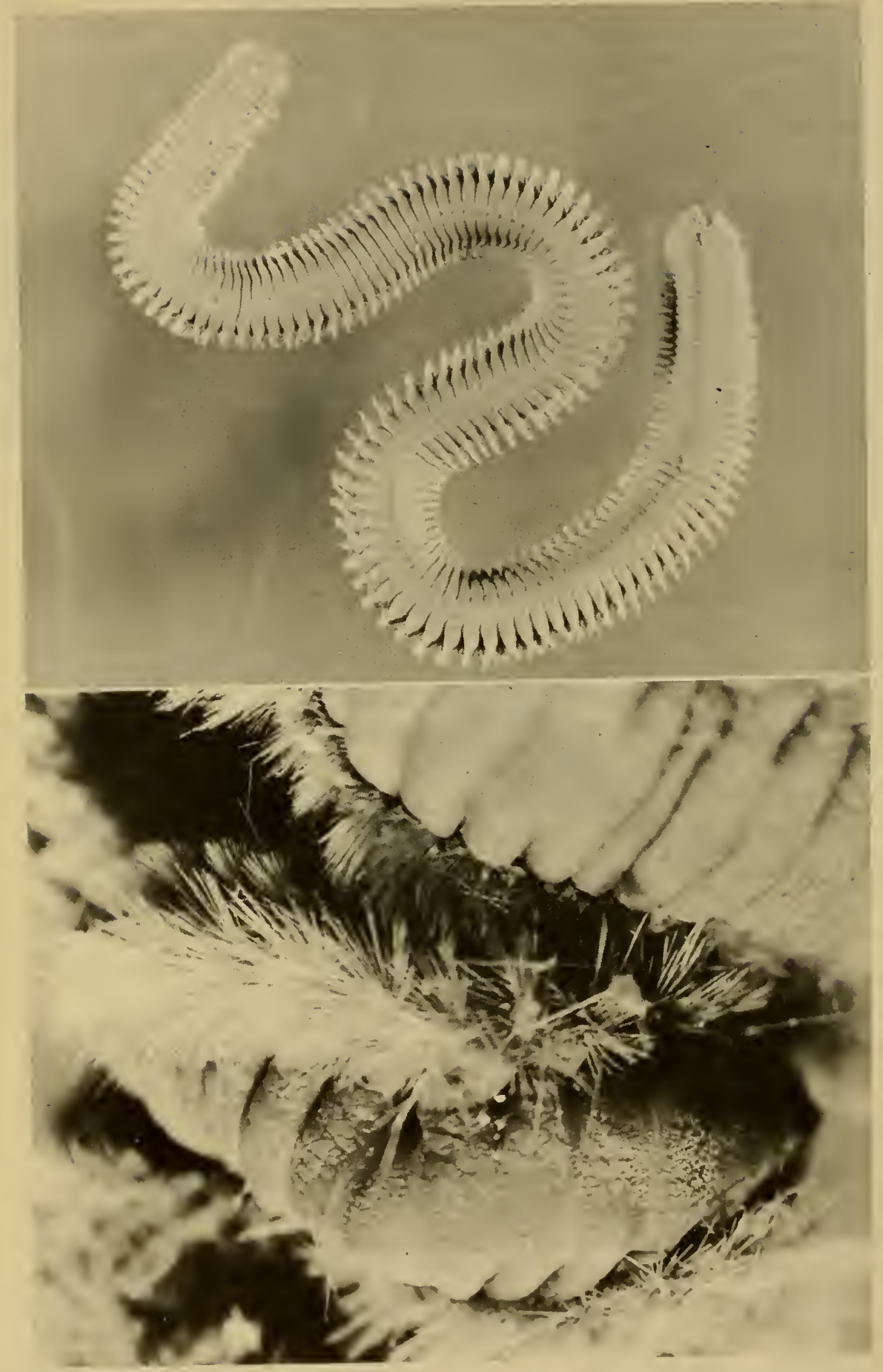

Fig. 22. Top: Bristleworm, Eurythoë complanata (Pallas). Bottom: Enlarged view of $E$. complanata, showing bristles fully extended. (Kreuzinger) 
Contact with the setae or bristles of the bristleworms may produce inflammation, swelling, and numbness, which may persist for several days. It is not definitely known whether a toxin is actually involved.

Treatment. There is no specific treatment for Glycera bites. They should be handled in the same manner as fish stings. (See Page 91).

Bristles can best be removed from the skin of the victim with the use of adhesive tape, and ammonia or alcohol applied to the area to alleviate the discomfort.

Prevention. Exercise care in the handling of Glycera and bristleworms. Cotton gloves will probably provide adequate protection from bloodworms, but rubber gloves are advisable when handling bristleworms.

\section{ECHINODERMS}

Echinoderms are characterized by having radial symmetry, with the body usually of five radii around an oral-suboral axis, comprised of calcareous plates which form a more or less rigid skeleton, or with plates and spicules embedded in the body wall. Starfishes or sea stars, sea cucumbers, and sea urchins are all members of this group. Some of the sea urchins are of primary concern to the skin divers. The long-spined tropical sea urchins may produce extremely painful wounds. Sea urchins are most commonly encountered under rocks, in sandy sheltered areas, in crevices or holes in rocks and coral.

Species of Sea Urchins. Because of the large number of sea urchins, only a few of the more representative ones will be listed.

Long-spined or Black Sea Urchin, Diadema setosum (Leske) (Fig. 23, Top). Widely distributed throughout the Indo-Pacific area, from East Africa to Polynesia, China, and Japan. Closely related species are found in the West Indies and the Hawaiian Islands.

Sea Urchin, Toxopneustes pileolus (Lamarck). Inhabits the IndoPacific area, from East Africa to Melanesia, and Japan. A comrnon and dangerous species.

Sea Urchin, Toxopneustes elegans Doderlein (Fig. 23, Bottom Left). Inhabits the waters about Japan.

(No common name), Asthenosoma ijimai Yoshiwara (Fig. 23, Bottom Right). Ranges from Southern Japan to the Molucca Sea. 
Venom Apparatus of Sea Urchins. The venom apparatus of sea urchins is believed to consist of their hollow venom-filled spines, and the globiferous pedicellariae. However, usually only one or the other is present within a single species of sea urchin.
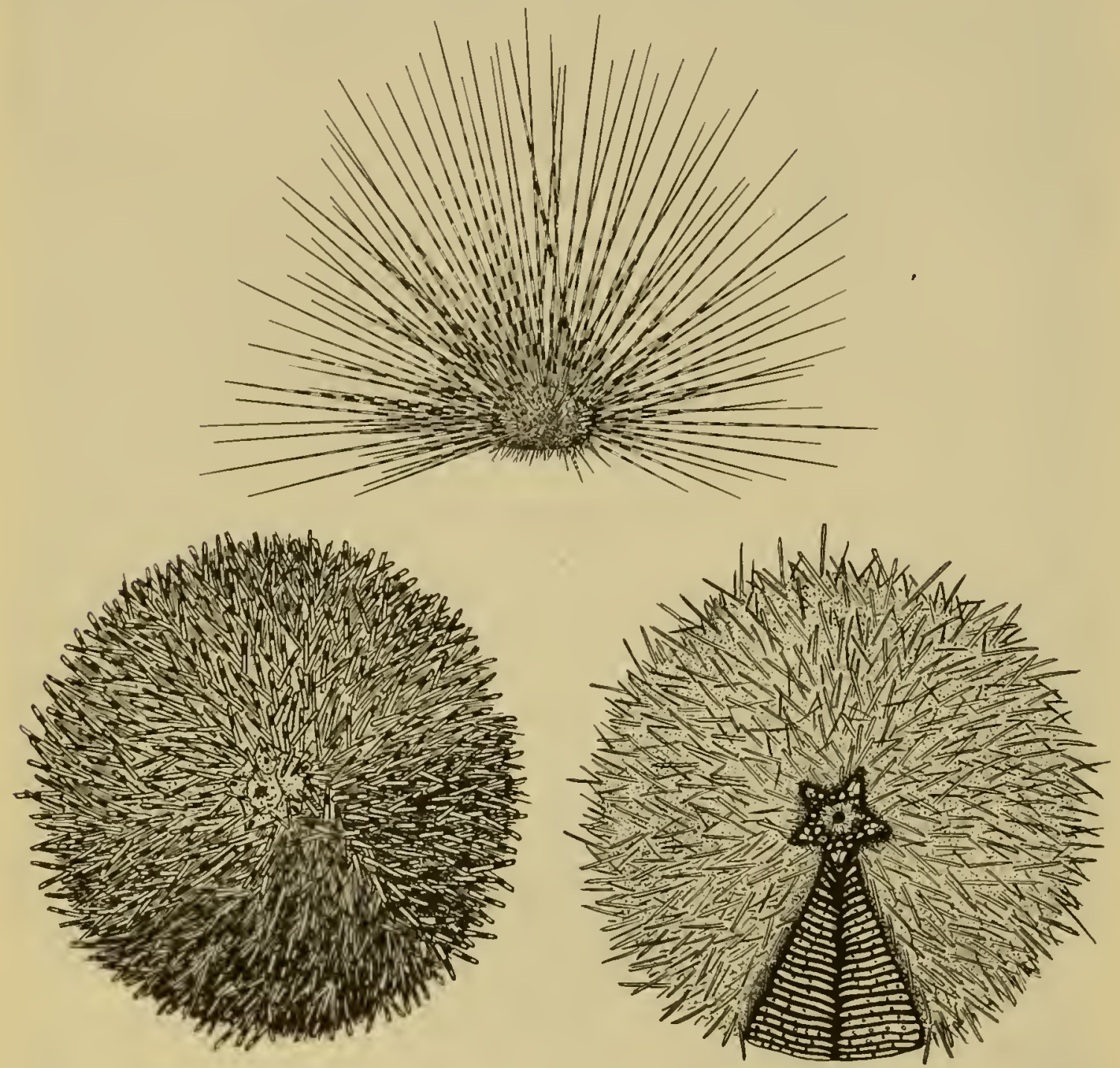

Fig. 23. Top: Black long-spined sea urchin, Diadema setosum (Leske). Bottom left: Sea Urchin, Toxopneustes elegans Doderlein. Bottom right: Sea Urchin, Asthenosoma ijimai Yoshiwara. Part of the outer covering has been removed to show the test beneath. (Kreuzinger)

Spines. The spines of sea urchins vary greatly from group to group. In most instances the spines are solid, have blunt, rounded tips, and do not constitute a venon organ. However, some species have long, slender, hollow, sharp spines, which are extremely dangerous to handle. The acute tips and the spinules permit ready entrance of the spines deep into the flesh, but because of their extreme brittleness, they break off readily in the wound and are very difficult to withdraw. The spines in Diadema may attain a length 
of a foot or more. It is believed that the spines of some of these species secrete a venom, but this has not been experimentally demonstrated. The aboral spines of Asthenosoma are developed into special venom organs carrying a single large gland. The point is sharp and serves as a means of introducing the venom (Fig. 24).

Pedicellariae. Pedicellariae are small, delicate, seizing organs which are found scattered among the spines of the shell. There are several different types of pedicellariae. One of these, because
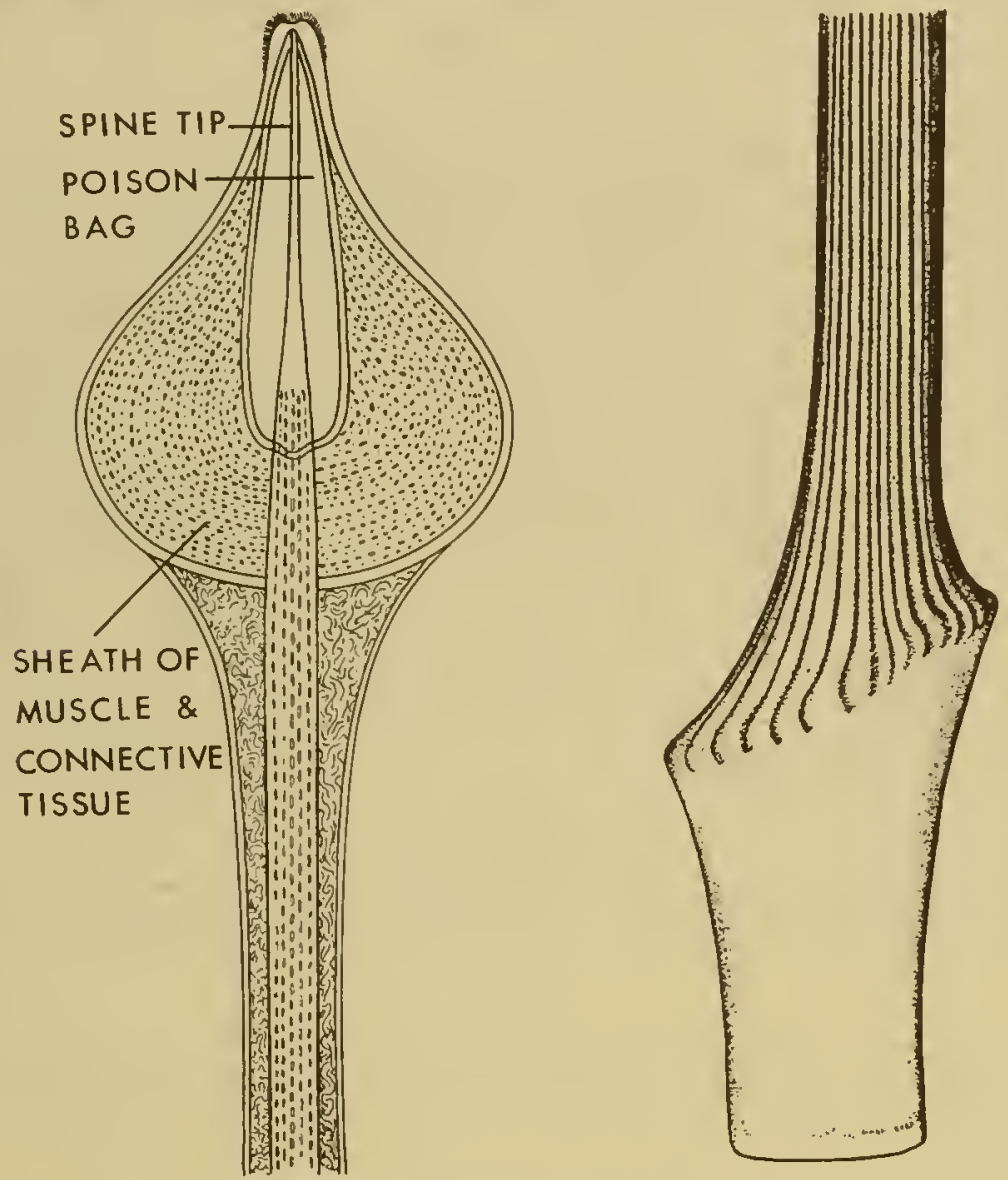

Fig. 24. A venomous aboral spine of the sea urchin, Asthenosoma ijimai. (After Mortensen)

of its globe-shaped head, is called the globiferous pedicellariae, and serves as a venom organ. They are comprised of two parts, a terminal, swollen, conical head, which is armed with a set of calcareous pincer-like valves or jaws, and a supporting stalk (Fig. 25). The head is attached to the stalk either directly by the muscles, or by a long flexible neck. On the inner side of each valve is found a small elevation provided with fine sensory hairs. Contact with these sensory hairs causes the valves to close instantly. The outer surface of each valve is covered by a large gland which in Toxopneustes has two ducts that empty in the vicinity of a small tooth-like pro- 
jection on the terminal fang of the valve. A sensory bristle is located on the inside of each valve. Contact with these bristles causes the small muscles at the base of the valve to contract, thus closing the valves and injecting the venom into the skin of the victim.

One of the primary functions of pedicellariae is that of defense. When the sea urchin is at rest in calm water, the valves are generally extended, moving slowly about, awaiting prey. When a foreign body comes in contact with them, it is immediately seized. The pedicellariae do not release their hold as long as the object moves,

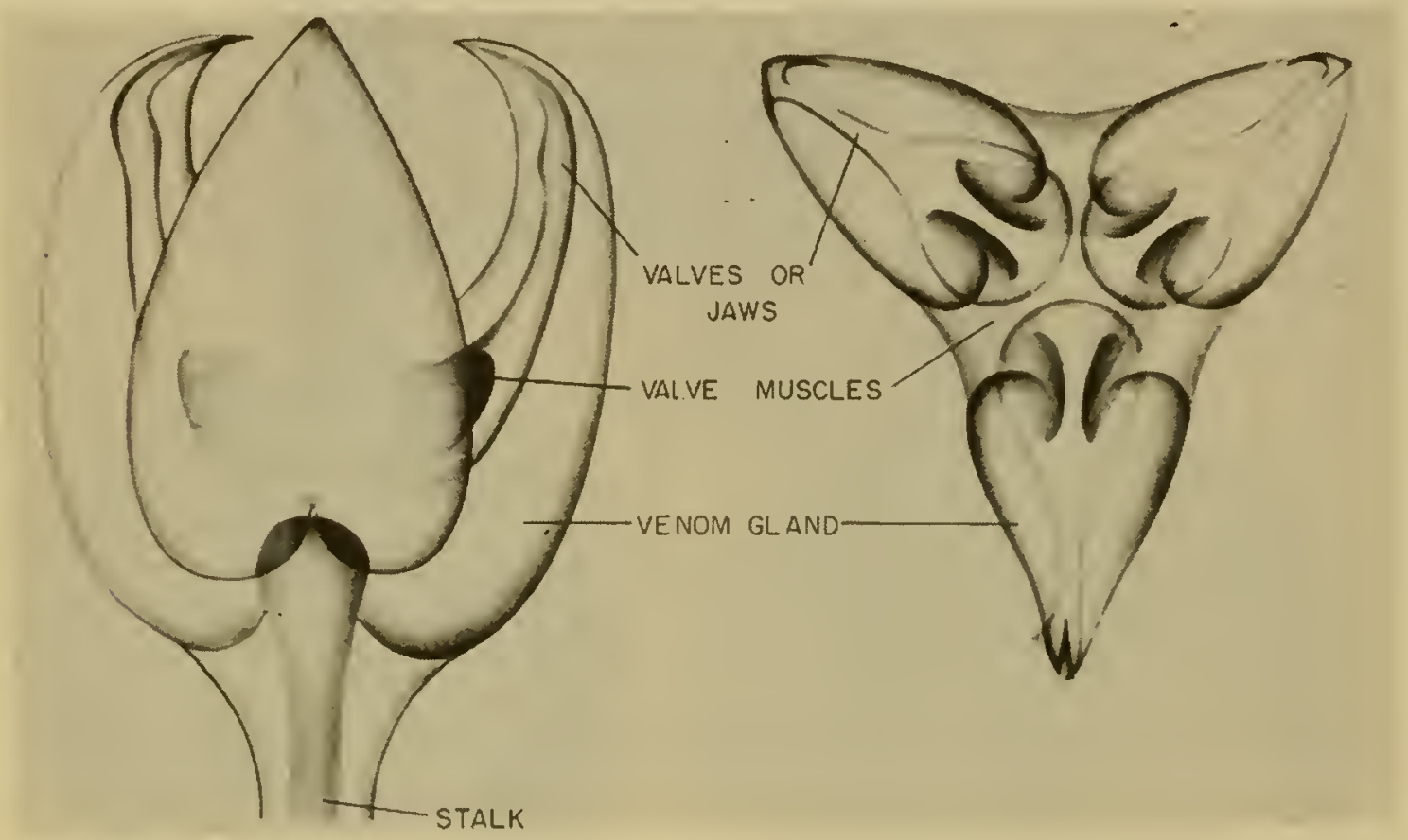

Fig. 25. Globiferous pedicellariae from the sea urchin, Salamacis bicolor Agassiz. This is representative of the venomous type of pedicellariae which are found in other species of sea urchins. (Kreuzinger)

and if it is too strong to be held, the pedicellariae are torn from the test, or shell, but continue to bite the object. Detached pedicellariae may remain alive for several hours after being removed from the sea urchin.

Medical Aspects. Penetration of the needle-sharp sea urchin spines may produce an immediate and intense burning sensation. The pain is soon followed by redness, swelling, and an aching sensation. Numbness and muscular paralysis have been reported. Secondary infections are not uncommon.

The sting from sea urchin pedicellariae may produce an immediate, intense, radiating pain, faintness, numbness, generalized muscular paralysis, loss of speech, respiratory distress, and in 
severe cases, death. The pain may diminish after about 15 minutes and completely disappear within an hour, but paralysis may continue for six hours or longer.

Treatment. Insofar as the venom is concerned, sea urchin stings should be handled in a manner similar to any other venomous sting. (See Page 91). However, attention is directed to the need of prompt removal of the pedicellariae from the wound. Pedicellariae are usually detached from the parent animal, and may continue to introduce venom into the wound. Sea urchin spines are extremely difficult to remove from the flesh because of their brittleness. The spines of some species will be readily absorbed within 24 to 48 hours, whereas others must be surgically removed. There may be some discoloration of the area about the wound due to the purple dye that is secreted by the animal, but this should not be disturbing.

Prevention. No sea urchin having elongate, needle-like spines should be handled. Moreover, leather and canvas gloves, shoes, and flippers do not afford protection. Care should be taken in handling any tropical species of short-spined sea urchin without gloves because of the pedicellariae. A diver working at night in coral areas must exercise extreme care because of the danger of coming in contact with sea urchins.

\section{VERTEBRATES}

Venomous marine vertebrates constitute a hazard to skin divers which, for the most part, can be easily avoided if a person is aware of them and knows something about their habits. Included within this chapter are those marine animals having a backbone, which inflict their injuries by stinging. Venomous marine vertebrates fall within two major groups: (1) fishes, and (2) reptiles. A remarkable and interesting variety of venomous fishes is found to exist, beginning with some of the lower forms and extending throughout the piscine group. Venomous marine reptiles, on the other hand, are limited to a relatively few species-the sea snakes, all of which have a similar type of venom apparatus.

\section{FISHES}

\section{HORNED OR SPINY SHARKS}

There are several species of horned sharks, but only one that has been incriminated to any extent as producing stings in humans. The spiny dogfish, Squalus acanthias Linnaeus, (Fig. 26), is found 
on both sides of the North Atlantic and North Pacific Oceans. Some of its close relatives are widely distributed throughout temperate and tropical seas. Dogfish are somewhat sluggish in their movements, and seem to prefer shallow, protected bays for their habitat.

Venom Apparatus. Wounds are inflicted by the dorsal stings which are located adjacent to the anterior margins of each of the two dorsal fins. The venom gland appears as a glistening, whitish substance situated in a shallow groove on the back of the upper portion of each spine. When the spine enters the skin, the venom gland is damaged and the venom enters the flesh of the victim.

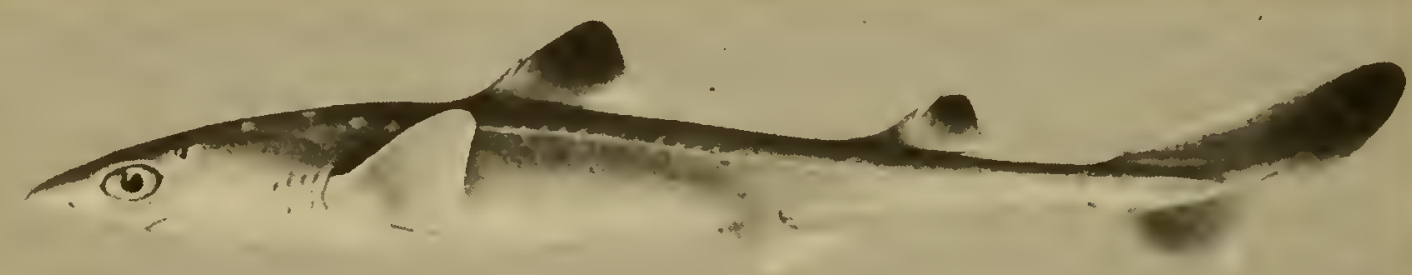

Fig. 26. Spiny Dogfish, Squalus acanthias Linnaeus. Note the single spine in front of each of the dorsal fins.

Medical Aspects. Symptoms consist of immediate, intense, stabbing pain, which may continue for a period of hours. The pain may be accompanied and followed by redness and severe swelling of the affected part. Tenderness about the wound may continue for several days. According to some authors, dogfish stings have been known to be fatal.

Treatment. Treat as any other fish sting. (See Page 91).

Prevention. Stings usually occur from the careless handling of dogfish. Be careful of the dorsal stings when removing the dogfish from a spear, hook, or net. They can give a sudden jerk and drive the sting deep into the flesh of a reckless fisherman.

\section{STINGRAYS}

Stingrays constitute one of the largest and most important groups of venomous marine organisms. There are said to be about 1500 stingray attacks reported in the United States each year. Stingrays are divided into seven families:

Dasyatidae-stingrays or whiprays Potamotrygonidac-river rays Gymnuridae-butterfly rays

Myliobatidac - eagle rays or bat rays

Rhinopteridae-cow-nosed rays

Mobulidae-devil rays or mantas

Urolophidac-round stingrays 
The species within these families are too numerous to list individually, so only a few representative species, which have been studied to a considerable extent by the venomologist, will be included. However, there are a few generalities which are pertinent to the group as a whole.

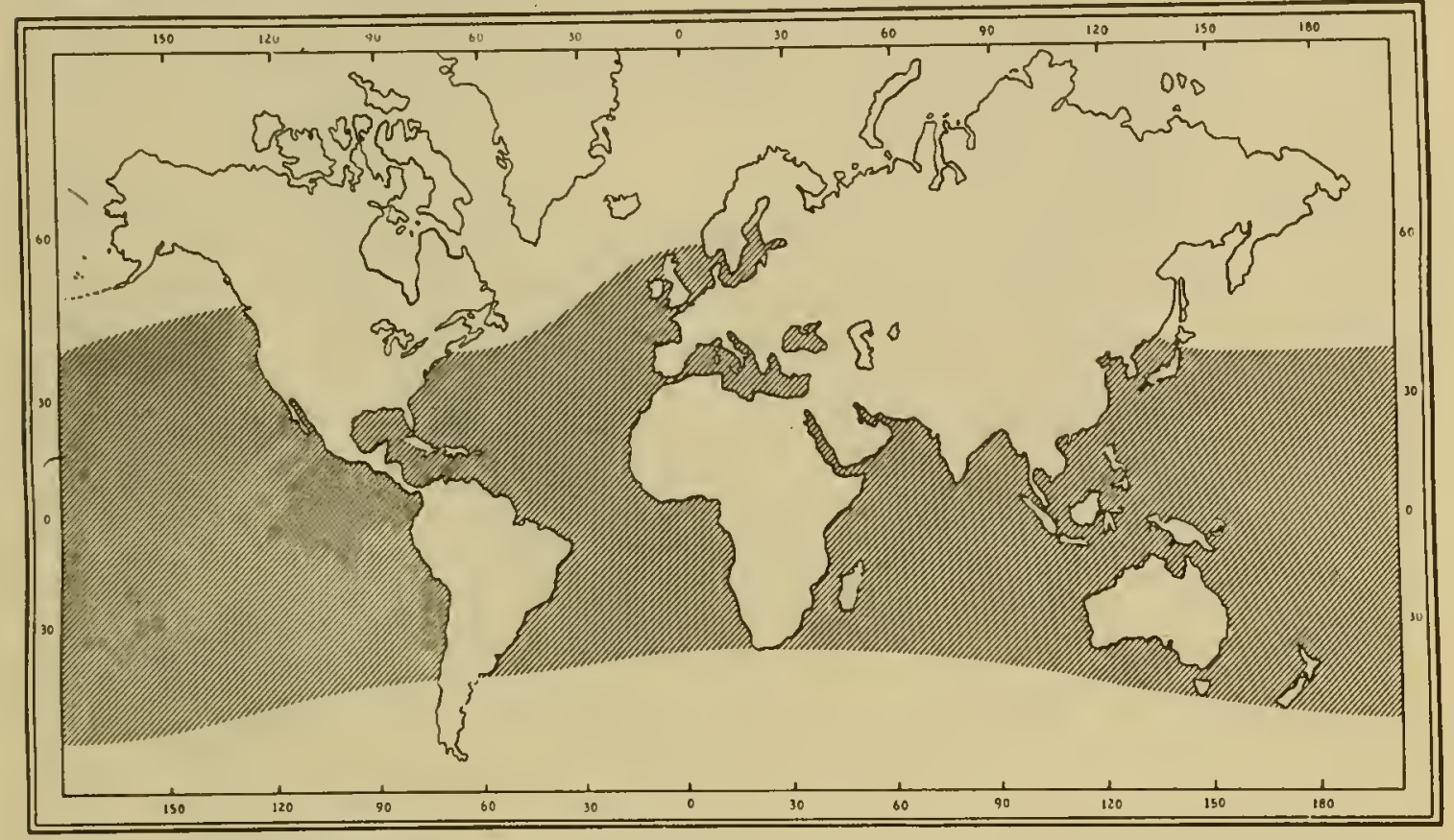

Fig. 27. Map showing the geographical distribution of stingrays. Although plagic and deep-water species are known to exist, stingrays are primarily shallow-water inhabitants, along coastal areas.

Rays are common inhabitants of tropical, subtropical, and warm temperate seas (Fig. 27). With the exception of the family Potamotrygonidae, which is confined to freshwater, rays are essentially marine forms, some of which may enter brackish, or freshwaters, freely. Rays are swimmers of moderate depths, and are most common in shallow water. A deep sea species has recently been reported from the Central Pacific Ocean. Sheltered bays, shoal lagoons, river mouths, and sandy areas between patch reefs are favorite habitats of rays. They may be observed lying on top of the sand, or partially submerged, with only their eyes, spiracles, and a portion of the tail exposed. Rays burrow into the sand and mud, and excavate the bottom with the use of their pectoral fins, by which means they obtain the worms, molluscs, and crustaceans upon which they feed.

RePRESENTATIVE STINGRAy SPECies:

Stingrays or Whiprays - Dasyatidae

Diamond Stingray, Dasyatis dipterurus (Jordan and Gilbert) (Fig. 28, Top). Occurs from British Columbia to Central America. 


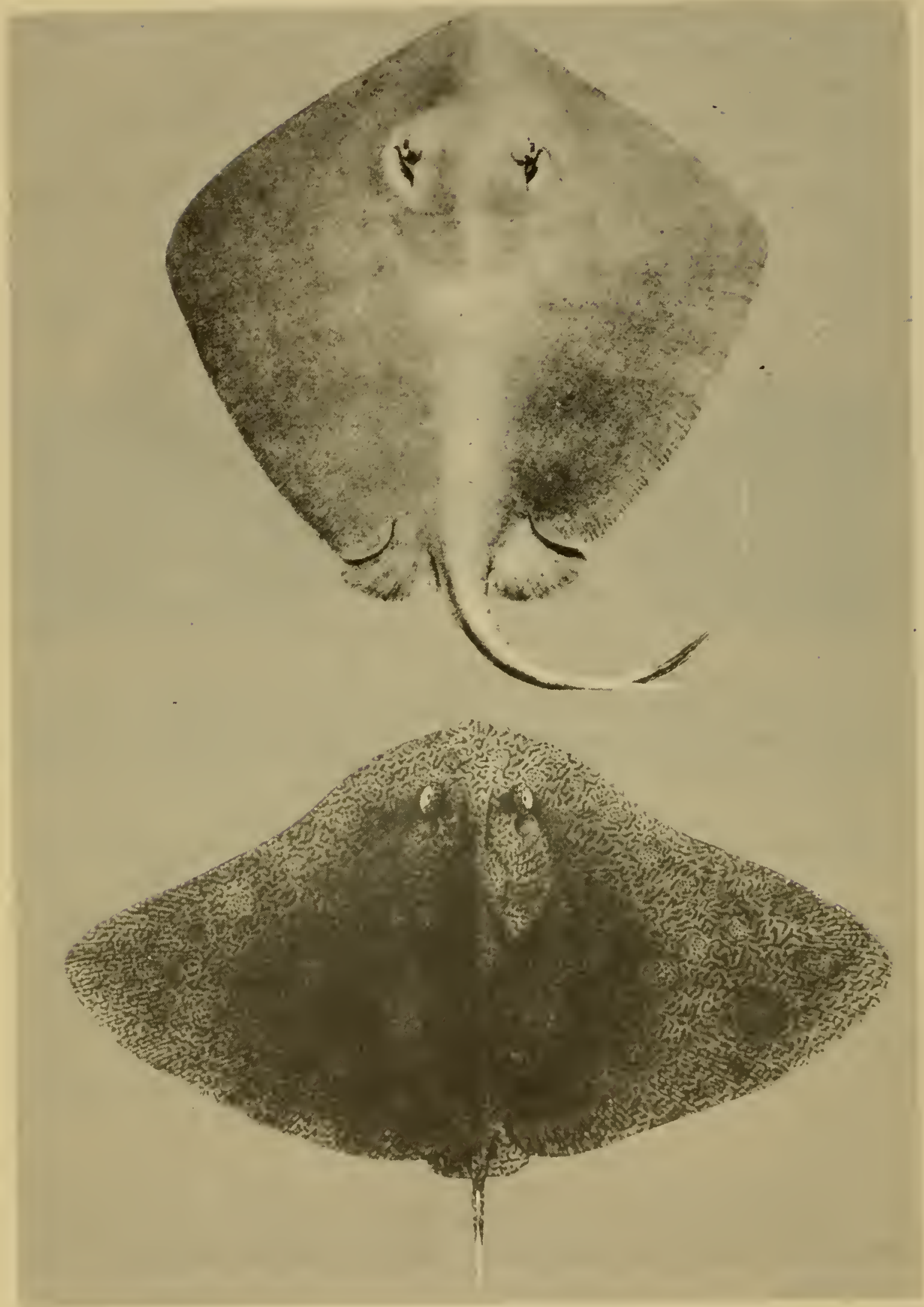

Fig. 28. Top: Diamond Stingray, Dasyatis dipterurus (Jordan and Gilbert). (From Walford) Bottom: Butterfly Ray, Gymnura marmorata (Cooper). (From Hiyama) 
Butterfly Rays - Gymnuridae.

Butterfly Ray, Gymnura marmorata (Cooper) (Fig. 28, Bottom). Found from Point Conception, California, south to Mazatlan, Mexico.

European Stingray, Dasyatis pastinaca (Linnaeus) (Fig. 29). Inhabits the northeastern Atlantic Ocean, Mediterranean Sea, and Indian Ocean. A very common species.

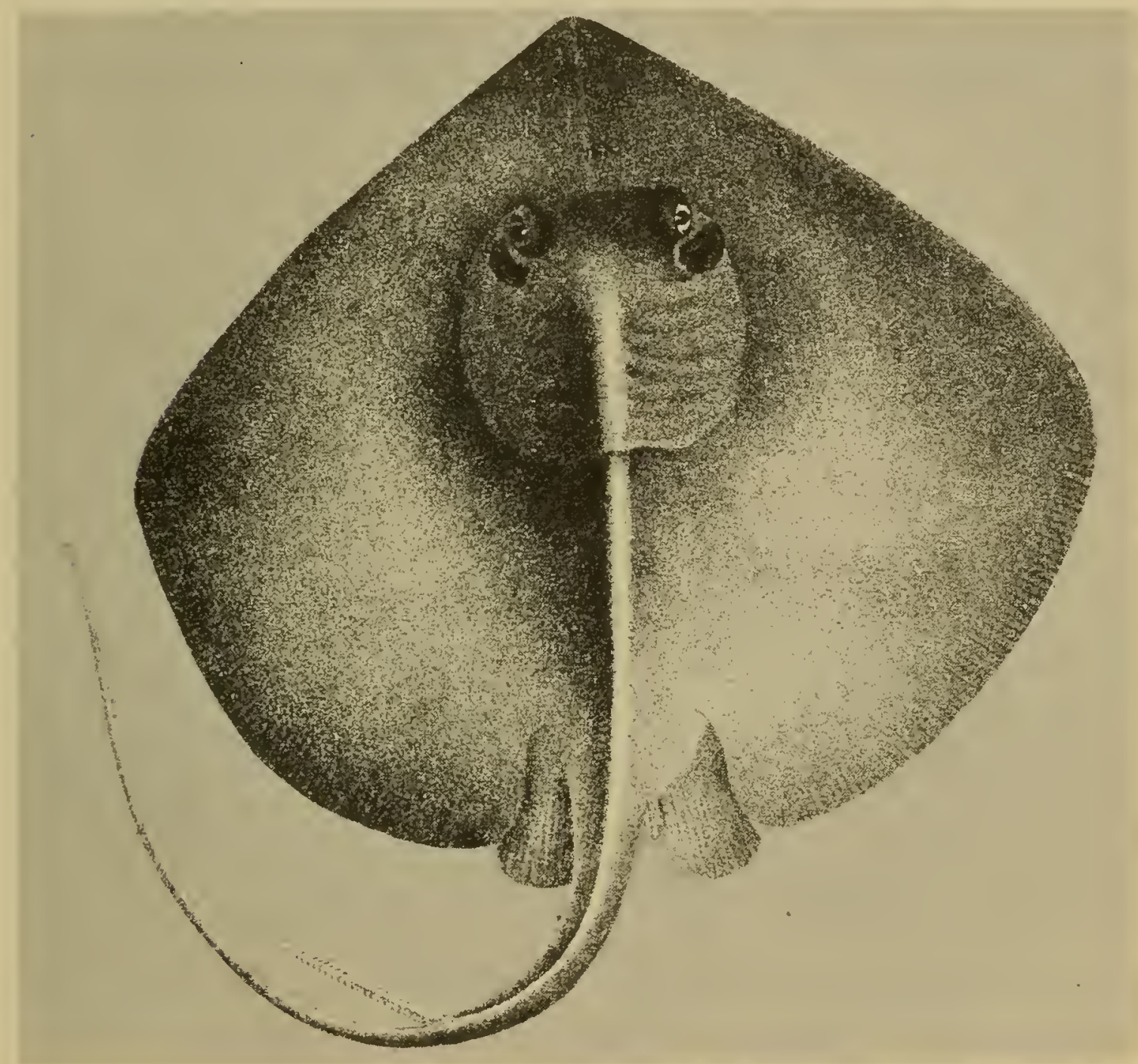

Fig. 29. European Stingray, Dasyatis pastinaca (Linnaeus).

Bat Rays or Eagle Rays - Myliobatidae

Bat Ray or Spotted Eagle Ray, Aetobatus narinari (Euphrasen) (Fig. 30, Top). Inhabits tropical and warm-temperate belts of the Atlantic, Red Sea, and Indo-Pacific Oceans.

California Bat Ray, Myliobatis californicus (Gill) (Fig. 30, Bottom). Found from Oregon to Magdalena Bay, Lower California. 


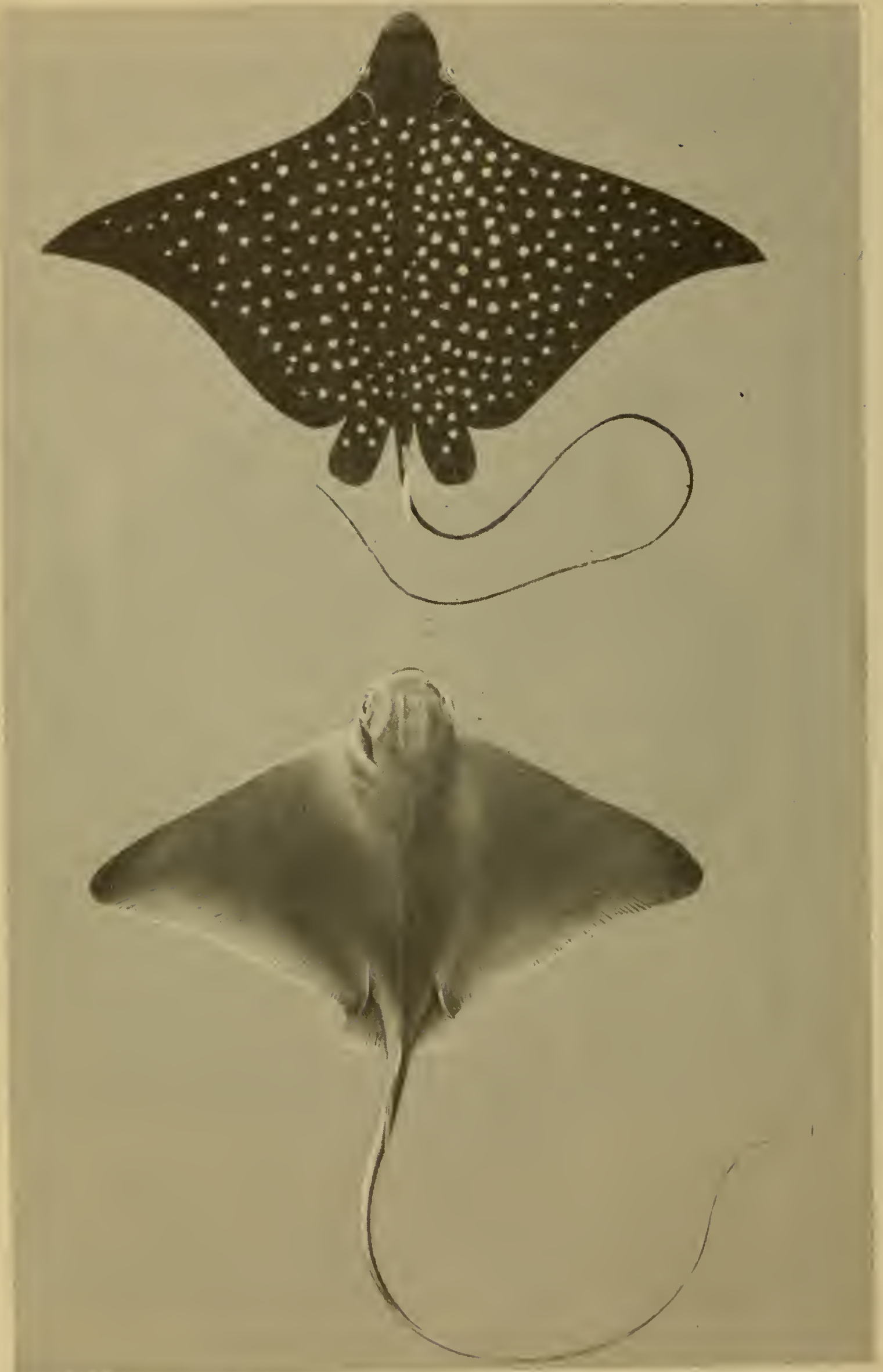

Fig. 30. Top: Bat Ray or Spotted Eagle Ray, Aetobatus narinari (Euphrasen). Bottom: California Bat Ray, Myliobatis Californicus (Gill). (Shirao) 


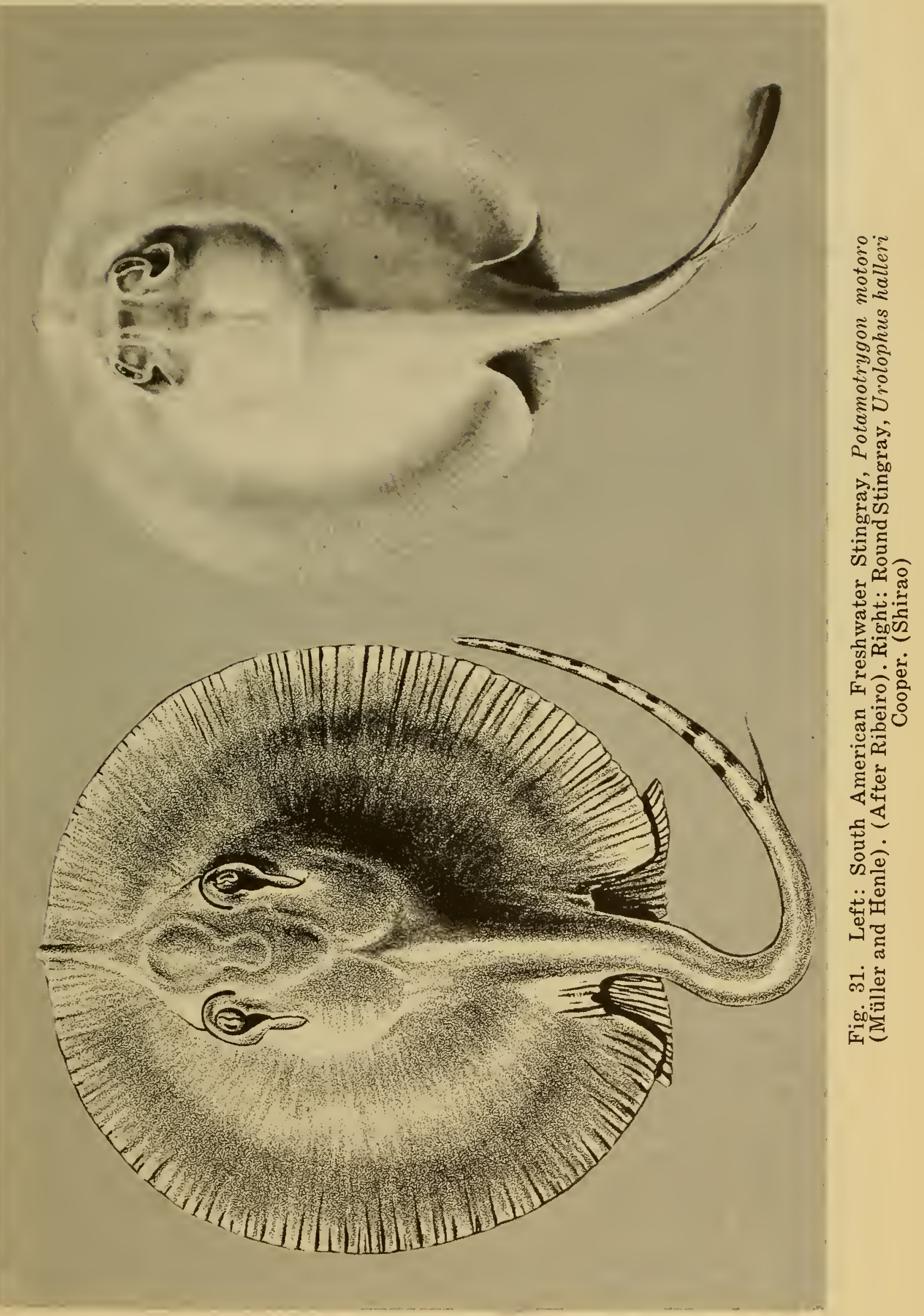


Freshwater Stingrays - Potamotrygonidae

South American Freshwater Stingray, Potamotrygon motoro (Müller and Henle). (Fig. 31, Left). Found in the freshwater rivers of Paraguay, and the Amazon River, south to Rio de Janeiro, Brazil. An extremely dangerous species.

\section{Round Stingrays - Urolophidae}

Round Stingray, Urolophus halleri (Cooper) (Fig. 31, Right). Found from Point Conception, California, south to Panama Bay.
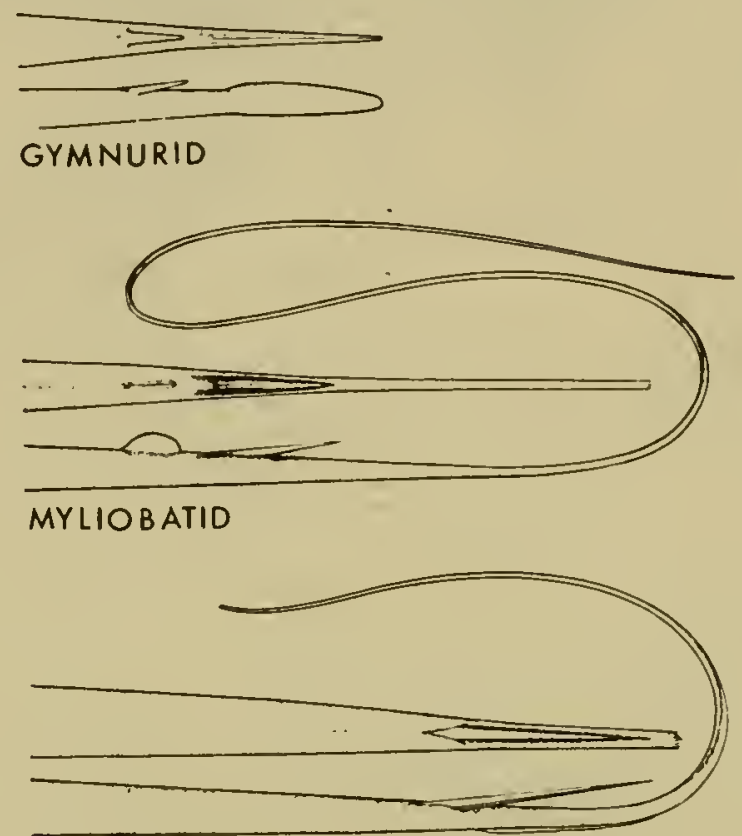

DASYATID

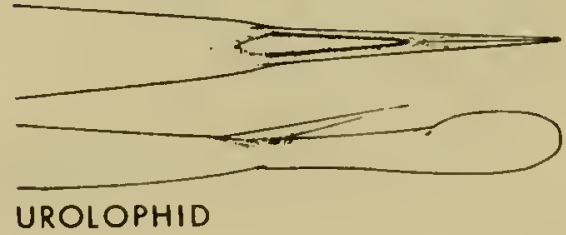

Fig. 32. Anatomical types of venom organs that are found in the various species of stingrays. (From Halstead and Bunker)

Venom Apparatus of Stingrays. The venom apparatus, or sting, of stingrays is an integral part of the caudal, or tail, appendage. A study of stingrays reveals that there are four general anatomical types of venom organs which vary somewhat in their effectiveness as a defensive weapon.

1. Gymnurid type (Fig. 32, Top). This type is found in the butterfly rays (Gymnura). The sting is small, poorly developed, and situated close to the base of a short tail, making it a relatively feeble striking organ. 
2. Myliobatid type (Fig. 32, Next to Top). This type is found in the bat, or eagle rays (Myliobatis, Aetobatis Rhinoptera). Their tails terminate in a long whip-like appendage. The sting in these rays are frequently large and well-developed, but situated near the base of the tail. Under the proper circumstances these rays can use their venom organs to good advantage.

3. Dasyatid type (Fig. 32, Next to Bottom). This type is found in the stingrays, proper, (Dasyatis and Potamotrygon). The sting is well-developed as in the previous type, but is frequently located out further from the base of the tail, making it a more effective striking organ. Stingrays possessing this type of venom apparatus are among the most dangerous kinds known. Their tails terminate in a long, whip-like appendage.

4. Urolophid type (Fig. 32, Bottom). This type is found among the round stingrays (Urolophus). The caudal appendage to which the sting is attached is short, muscular, and well-developed. Urolophid rays are also dangerous to man.

In general, the venom apparatus of stingrays consists of the serrate spine and an enveloping sheath of skin. Together they are termed the sting. Stingrays usually possess only a single spine at a time, but it is not unusual to find a specimen with two or more. Apparently, the spine remains until it is removed by injury. There is no evidence to support the idea that they are shed each year. As the young spine grows out from the tail, it takes with it a layer of skin, the so-called integumentary sheath, which continues to sheathe the spine until it is removed by injury or wear.

The spine is composed of a hard, bone-like material, called vasodentine. Along either side of the spine are a series of sharp recurved teeth. The spine is marked by a number of irregular, shallow furrows which run almost the length of the spine. Along either edge, on the underside of the spine, there will be found a deep groove; these are technically termed the ventrolateral-glandular grooves. If these grooves are carefully examined, it will be observed that they contain a strip of soft, spongy, grayish tissue extending throughout the length of the grooves. The bulk of the venom is produced by this tissue in the grooves, although lesser amounts are believed to be produced by other portions of the integumentary sheath, and in certain specialized areas of the skin on the tail which lies adjacent to the spine. These grooves serve to protect the soft delicate glandular tissue which lies within them, and even though all of the integumentary sheath may be worn away, the venom-producing tissue continues to remain within these 
grooves. Thus, a perfectly clean-looking spine can still be venomous. Fig. 33 illustrates the stingray sting in cross section. Fig. 34, Top shows the caudal spines of various species of stingrays.

Medical Aspects. Pain is the predominant symptom and usually develops immediately or within a period of ten minutes following the attack. The pain has been variously described as sharp, shoot-

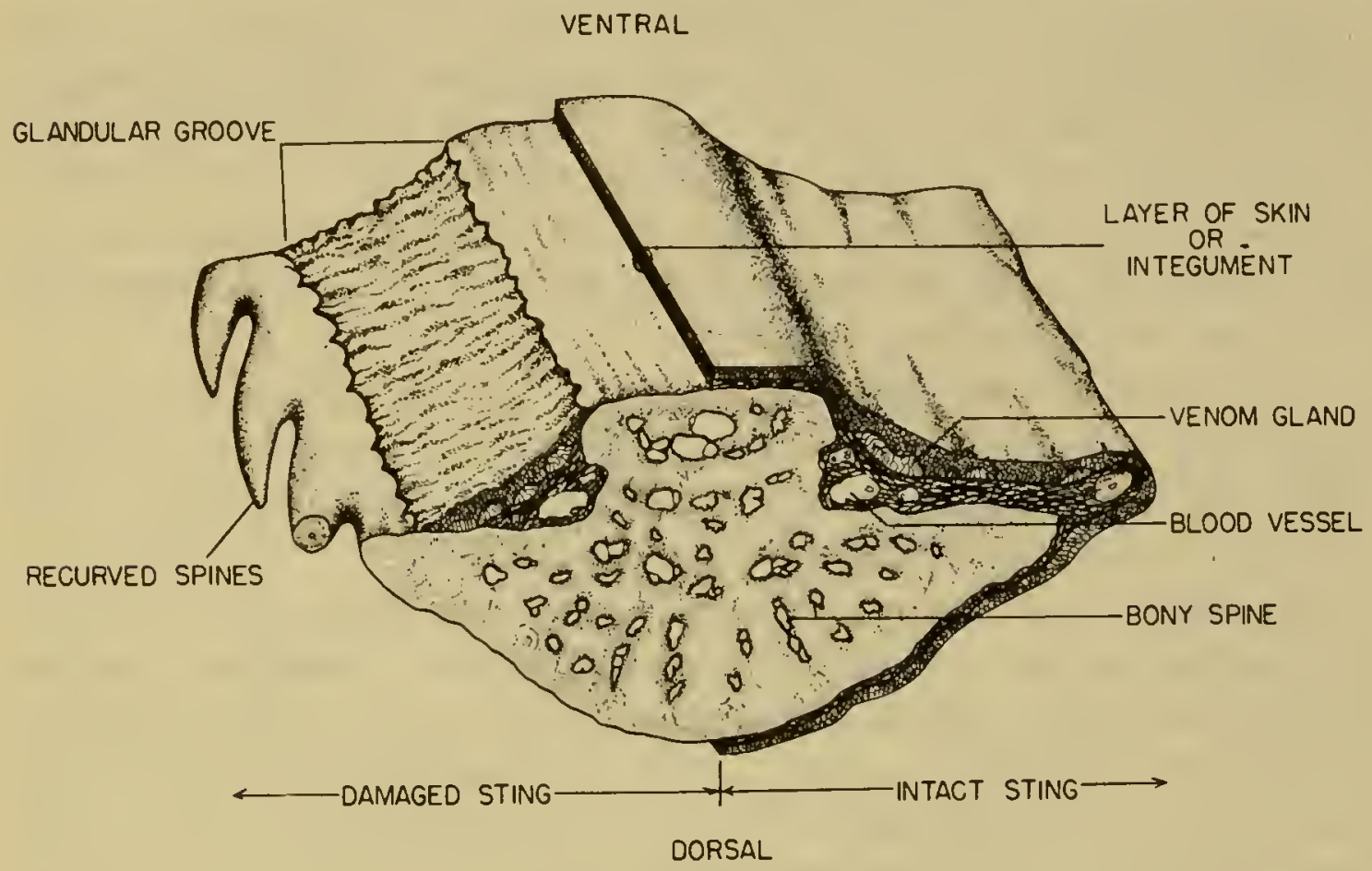

Fig. 33. Cross section of a stingray sting, showing both damaged and intact stings. Note that the bulk of the venom-producing tissue lies sheltered in the glandular grooves. Even damaged stings may retain sufficient glandular tissue in these grooves to produce intoxication.

ing, spasmodic or throbbing in character. The freshwater stingrays are reputed to cause extremely painful wounds. More generalized symptoms of fall in blood pressure, vomiting, diarrhea, sweating, rapid heart beat, muscular paralysis, and death have also been reported.

Stingray wounds are either of the laceration or puncture type (Fig. 34, Bottom). Penetration of the skin and underlying tissue is usually accomplished without serious damage to the surrounding structures, but withdrawal of the sting may result in extensive tissue damage due to the recurved spines. Swelling in the vicinity of the wound is a constant finding. The area about the wound at first has an ashy appearance, later becomes cyanotic and then reddened. Although stingray injuries occur most frequently about the ankle joint and foot as a result of stepping on the ray, instances have been reported in which the wounds were in the chest. 

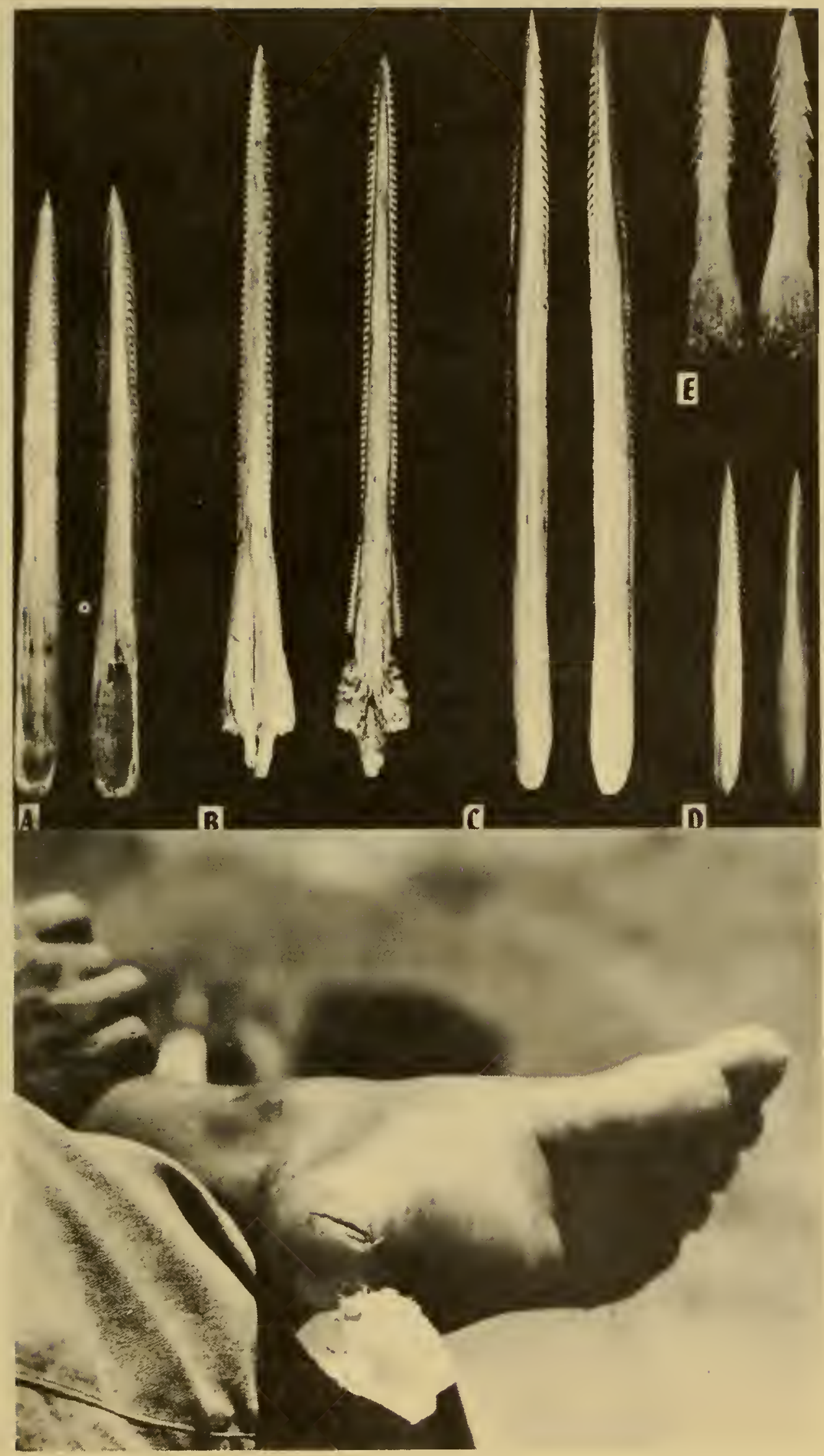

Fig. 34. Top: Caudal stings from various species of stingrays. a. Myliobatis californicus. b. Aetobatus narinari. c. Dasyatis dipterurus. d. Urolophus halleri. e. Gymnura marmorata. Dorsal and ventral views. All are mature spines except for G. marmorata. Bottom: Wound produced by the stingray, Aetobatus narinari. (From Halstead and Bunker) 
Treatment. There is no known specific antidote. See page 91 for the treatment of fish stings.

Prevention. It should be kept in mind that stingrays commonly lie almost completely buried in the upper layer of a sandy or muddy bottom. Stingrays are therefore a hazard to anyone wading in water inhabited by them. The chief danger is in stepping on one that is buried (Fig. 35). This danger can largely be eliminated by shuffling one's feet along the bottom. Usually the body of the ray

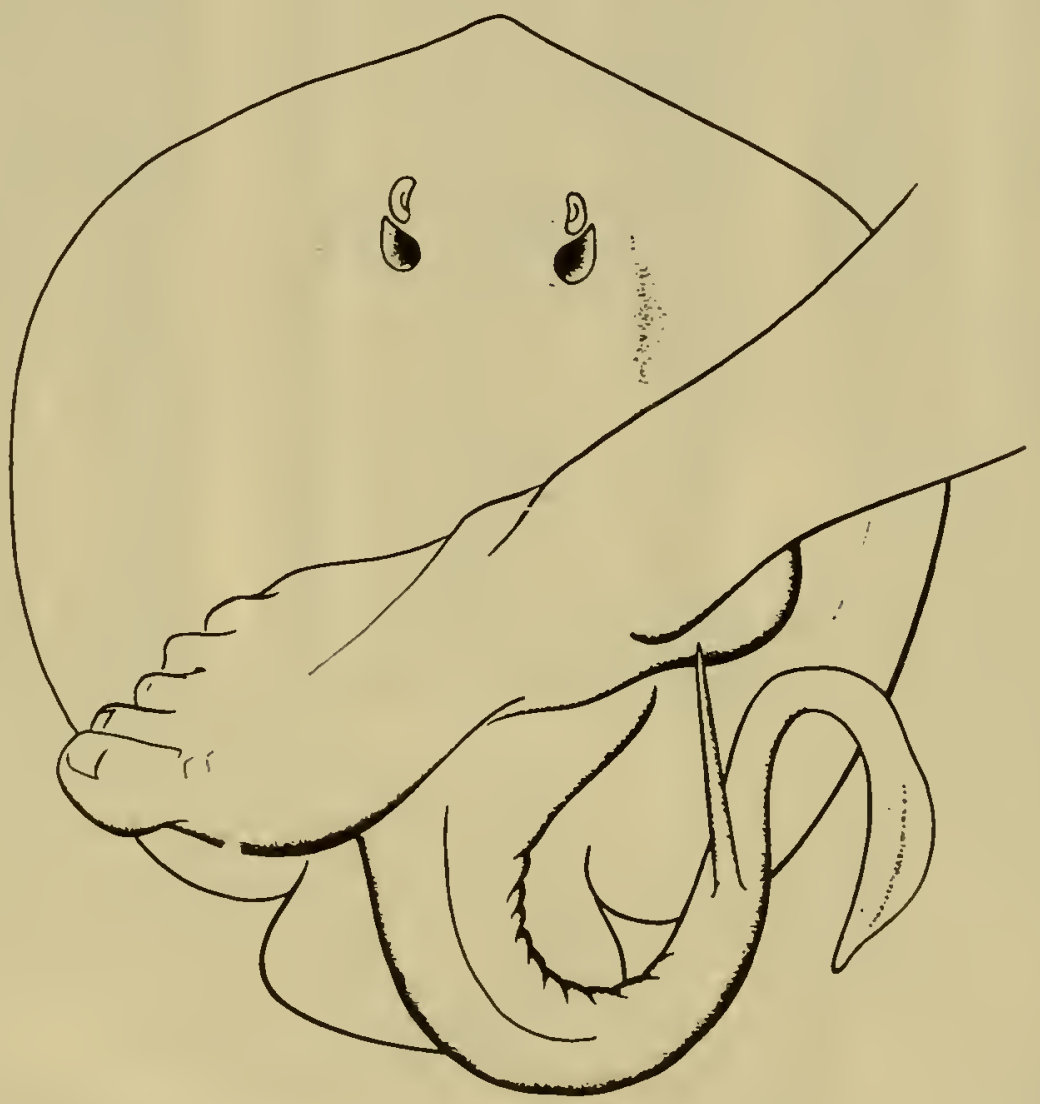

Fig. 35. Drawing showing how stingray wounds are most frequently encountered.

is pinned down by the weight of the victim, thereby permitting the beast to make a successful strike. Pushing one's feet along the bottom eliminates this danger and at the same time routes the stingray from its lair. It is also recommended that a stick be used to probe along the bottom in order to rid the area of hidden rays.

\section{(ELEPHANTFISHES AND RATFISHES}

Chimaeroids, elephantfish, or ratfish, as they are variously called, are a group of cartilaginous fishes having a single external gill opening on either side, covered over by a skin fold which leads 
to the gill chamber. Externally, ratfishes are more or less compressed laterally, tapering posteriorly to a slender tail. The snout is rounded, or cone-shaped, extended as a long pointed beak, or bears a curious hoe-shaped proboscis. There are two dorsal fins. The first fin is triangular, usually higher than the second, and edged anteriorly by a strong, sharp-pointed bony spine which serves as a venom organ (Fig. 36). Ratfishes have a preference for cooler

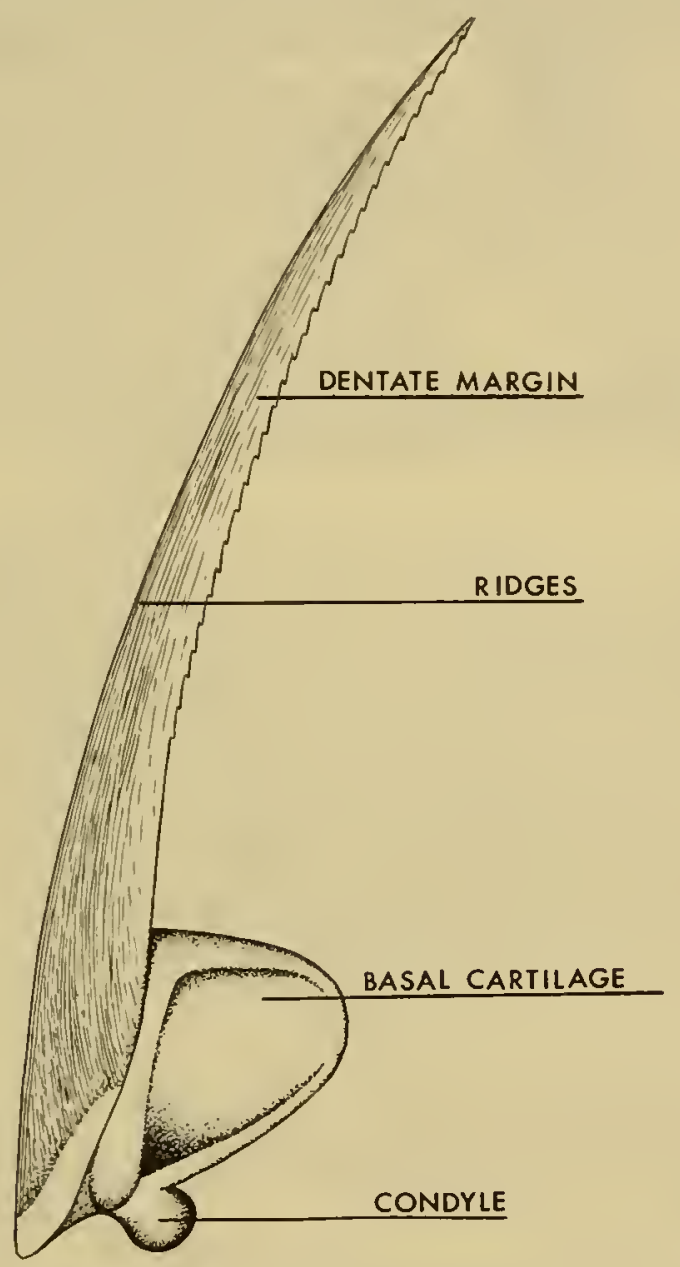

Fig. 36. Dorsal spine of the ratfish, Hydrolagus colliei (Lay and Bennett).

waters, and have a depth range from the surface down to 1400 fathoms. They are weak swimmers and die soon after being removed from the water. They have well-developed dental plates and can inflict a nasty bite. Only two species have been studied to any extent by venomologists.

\section{SPECIES OF RATFISHES :}

European Chimaera, Chimaera monstrosa Linnaeus (Fig. 37, Top). Inhabits the north Atlantic Ocean from Norway and Iceland to Cuba, the Azores, Morocco, Mediterranean Sea, and South Africa. 


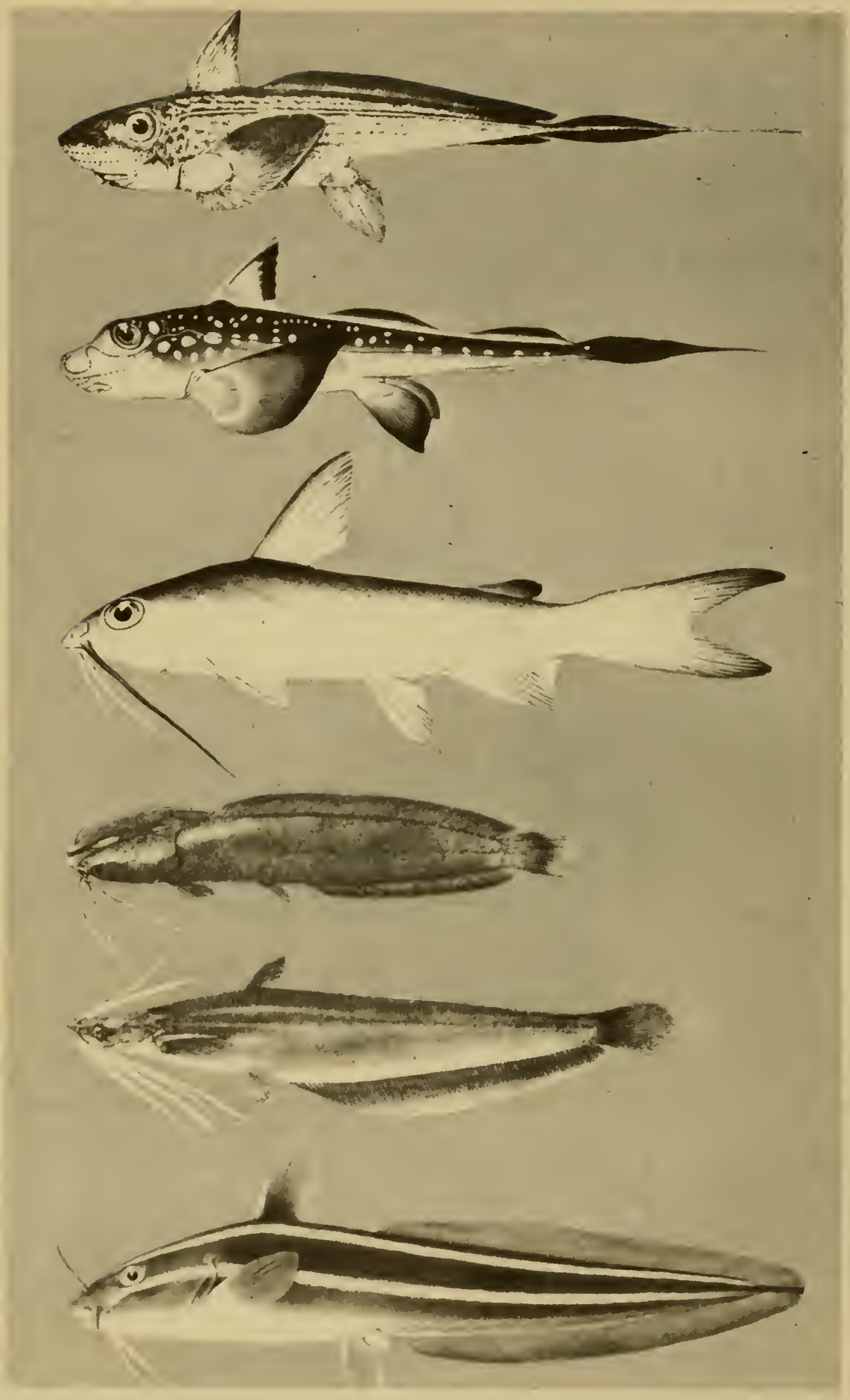

Fig. 37. Top to bottom: European Ratfish, Chimaera monstrosa Linnaeus. Pacific Ratfish, Hydrolagus collici (Lay and Bennett). Catfish, Galcichthys felis (Linnaeus). Catfish, Clarias batrachus (Linnaeus). Catfish, Heteropneustes fossilis (Bloch). Oriental Catfish, Plotosus lineatus (Thunberg). 
Pacific Ratfish, Hydrolagus colliei (Lay and Bennett) (Fig. 37, Next to Top). Found along the Pacific coast of North America.

Venom Apparatus of the Ratfish. The venom apparatus of ratfishes consists of the single dorsal sting which is situated along the anterior margin of the first dorsal fin. Along the back of the spine is a shallow. depression which contains a strip of soft, grayish tissue-the venom gland.

Medical Aspects. Ratfishes are said to inflict a very painful wound with their sharp dorsal stings. However, nothing is known about the symptoms produced. It is assumed that wounds from this fish are largely accidental since the fish is not reputed to be aggressive.

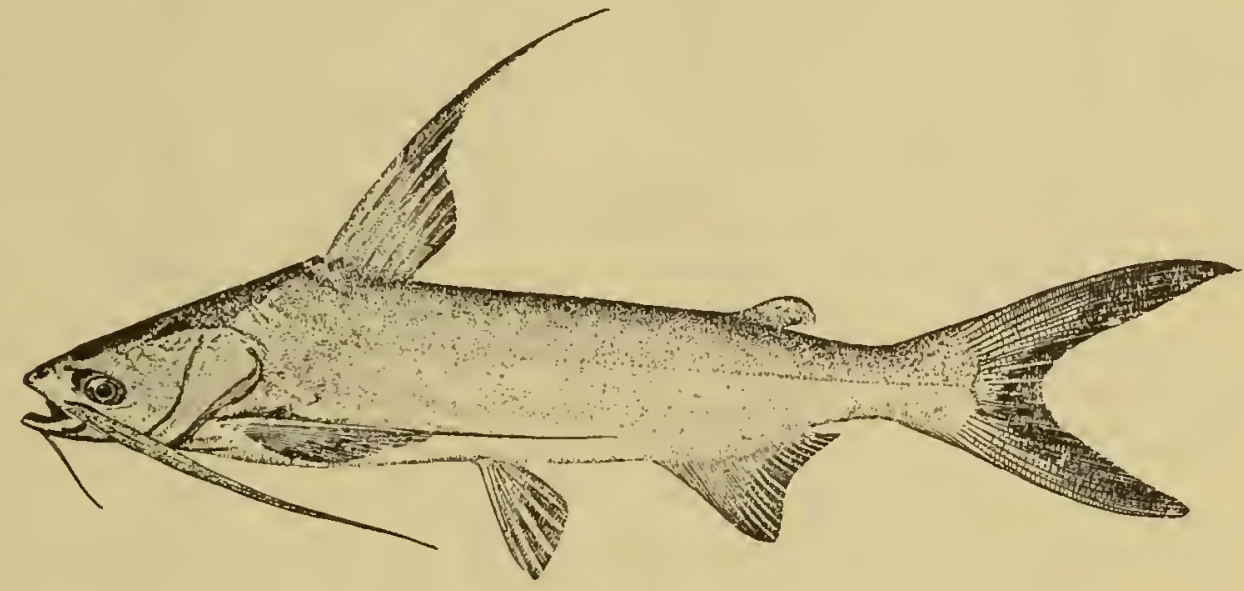

Fig. 38. Sea Catfish, Bagre marina (Mitchell).

\section{CATFISHES}

Catfishes come in a wide variety of sizes and shapes. Their body shape may vary from short to greatly elongate, or even eel-like. The head is extremely variable, sometimes very large, wide or depressed, or may be very small. The lips are usually equipped with long barbels. The skin of these fishes is thick and slimy, or may be covered with bony plates. No true scales are ever present. About one thousand species are included within this group, most of which are found in the freshwater streams of the tropics, but a few are marine. Only a few representative marine and brackish water species have been selected for the purposes of this manual.

\section{Representative SPECIES OF CatFishes:}

Catfish, Galeichthys felis (Linnaeus) (Fig. 37, Third from Top). Ranges from Cape Cod to the Gulf of Mexico.

Catfish, Clarias batrachus (Linnaeus) (Fig. 37, 4th from Top). India to the Netherlands Indies and Philippine Islands. 
Catfish, Heteropneustes fossilis (Bloch) (Fig. 37, Next to Bottom). Found along the coasts of India, Ceylon, and Viet Nam.

Oriental Catfish, Plotosus lineatus (Thunberg) (Fig. 37, Bottom). Occurs in the vicinity of river mouths throughout much of the Indo-Pacific area.

Sea Catfish, Bagre marina (Mitchell) (Fig. 38). Inhabits the east coast of America from Cape Cod to Rio de Janeiro, Brazil.

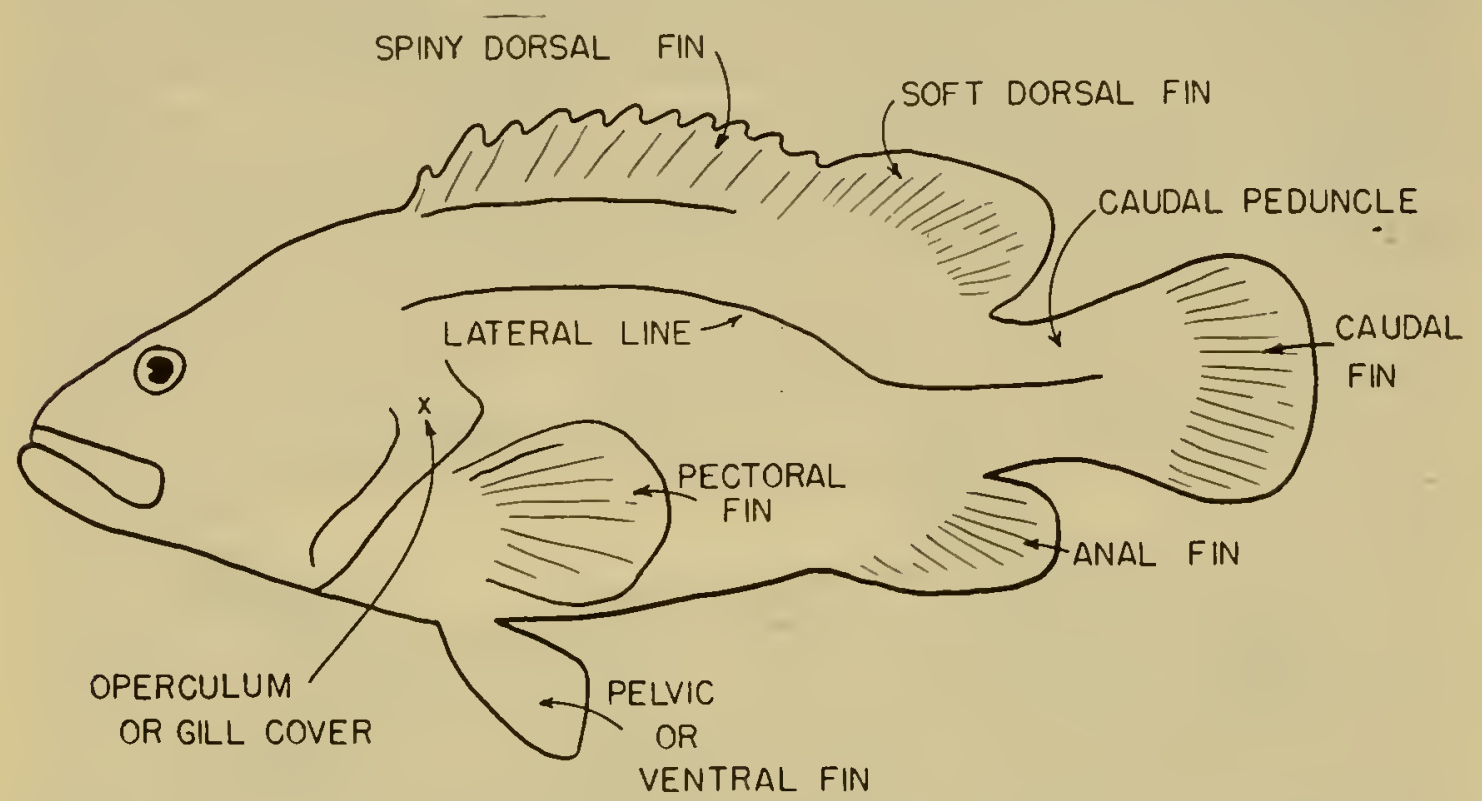

Fig. 39. Drawing showing the external anatomy of a true fish. Note the names of the various fins to which venom organs are sometimes attached.

Venom Apparatus of Catfishes. Venomous catfishes have a single, sharp, stout spine immediately in front of the soft-rayed portion of the dorsal and pectoral fins (Fig. 39). These spines are enveloped by a thin layer of skin, the integumentary sheath, which is continuous with that of the soft-rayed portion of the fin. There is no external evidence of the venom glands, which are located as a series of glandular cells within the outer, or epidermal, layer of the integumentary sheath. The venom, or glandular, cells are most concentrated at the anterolateral and posterolateral margins of the sting, where they are sometimes clumped two or three cells deep within the epidermal layer. The spines of some species are also equipped with a series of sharp, recurved teeth which are capable of producing a severe laceration of the victim's flesh, thus facilitating absorption of the venom and subsequent secondary infection (Fig. 40). The spines of the catfish are particularly dangerous because they can be locked into the extended position at the will of the fish.

Medical Aspects. The pain is generally described as an instan- 
taneous stinging, throbbing or scalding sensation which may be localized or may radiate up the affected limb. Some of the tropical species, such as Plotosus, are capable of producing violent pain, which may last for 48 hours or more. The area about the wound becomes pale immediately after being stung. The pallor is soon followed by a cyanotic appearance, and then by redness and swelling. In some cases the swelling may be very severe, accompanied by numbness and gangrene of the area about the wound. Shock
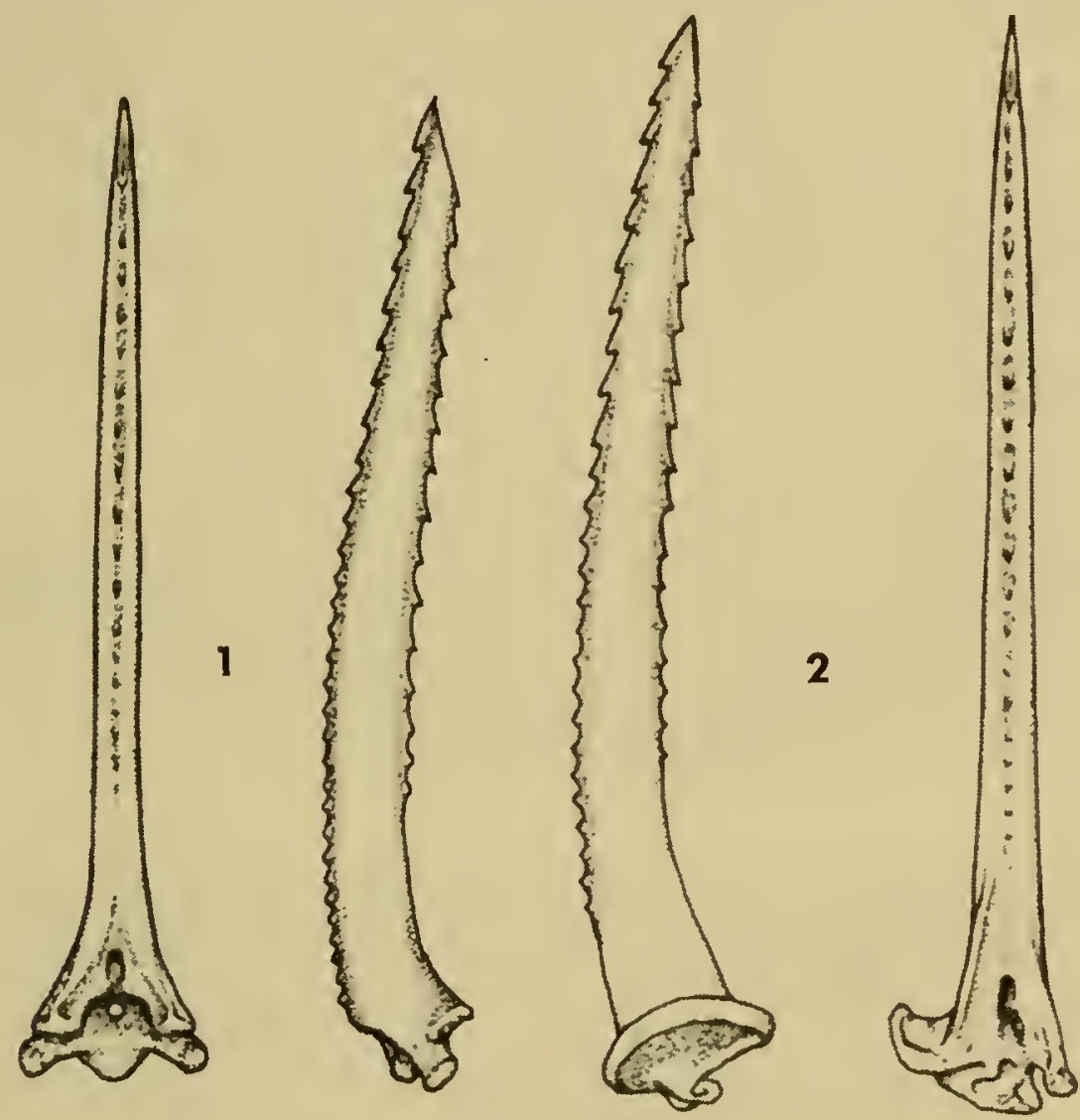

Fig. 40. Fin spines of the Mexican catfish, Galeichthys felis. (1). Dorsal spine, posterior and side views. (2). Pectoral spine, dorsal and posterior views.

may be present. Improperly treated cases frequently result in secondary bacterial infections of the wound. Some species of catfishes may produce wounds which may take weeks to heal, but in most instances the wounds are of minor consequence. Deaths have been reported from the stings of some of the tropical catfishes.

Treatment. There are no known specific antidotes. See Page 91 for the treatment of fish stings.

Prevention. Care should be exercised in the handling of catfishes because of their sharp rigid fin spines which can be readily driven into the flesh of the unwary victim. 


\section{MORAY EELS}

Moray eels are members of the family Muraenidae. The body of these fishes is scaleless, elongate, and rounded, or more or less compressed. The dorsal and anal fins are continuous with the caudal, and are generally covered by thick skin. The pectoral and pelvic fins are absent.

The meager amount of research that has been conducted on socalled "venomous eels" is concerned with the single European species, Muraena helena Linnaeus, which is distributed along coastal areas of the eastern Atlantic Ocean and Mediterranean Sea. Other species have been listed as venomous by modern authors, but their work is purely presumptive. The teeth of $M$. helena have been considered as constituting a venom apparatus from earliest times. However, recent anatomical studies fail to show any evidence of venom glands.
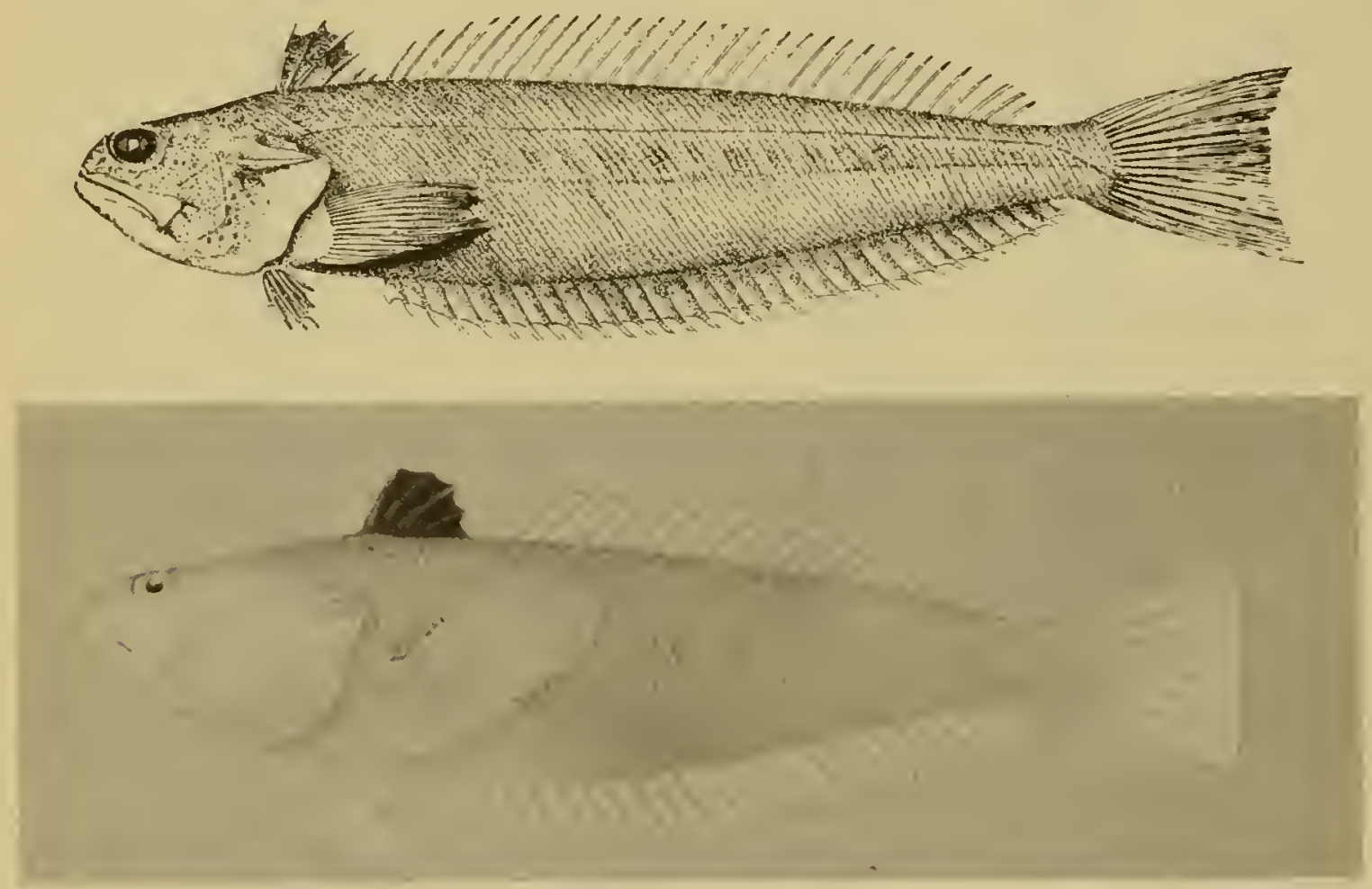

Fig. 41. Top: Great Weever, Trachinus draco Linnaeus. (Fron Joubin) Bottom: Lesser weever, Trachinus vipcra Cuvier. (Shirao)

\section{WEEVERFISHES}

Weevers are small marine fishes, all of which attain a maximum length of less than 18 inches. They are all members of the family, Trachinidae, and are among the more venomous fishes of the temperate zone. Weevers are primarily dwellers of flat, sandy, or 


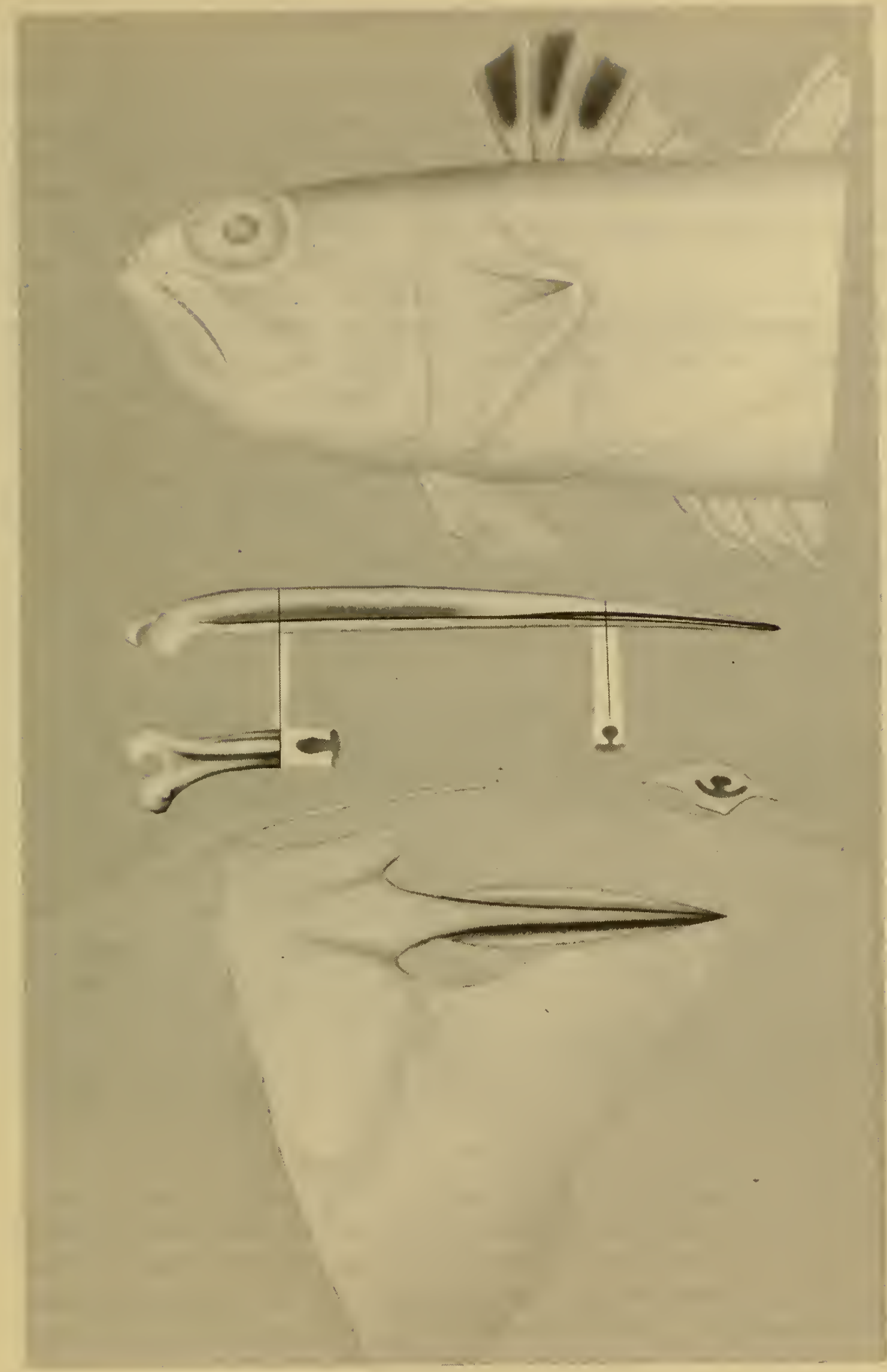

Fig. 42. Top: Head of Trachinus, showing the dorsal and opercular stings. Center: Dorsal Spine of Trachinus vipera, showing grooves in which the venom glands are located. Side and posterior views. Bottom: Operculum of $T$. vipera showing the dagger-like spine to which the venom gland is attached. Side view and cross section. 
muddy bays. They are commonly seen burying themselves in the soft sand or mud with only the head partially exposed. They may dart out rapidly, and may strike an object with unerring accuracy with their cheek spines. When a weever is provoked, the dorsal fin is instantly erected, and the gill covers expanded. Because of their habit of concealment, aggressive attitude, and highly-developed venom apparatus, they constitute a real danger to any skin diver working in their habitat. There are four species of weevers which are commonly recognized, but only two of them are included here.

\section{SPECIES OF WEEVERFISHES :}

Great Weever, Trachinus draco Linnaeus (Fig. 41, Top). Occurs from Norway, British Isles, southward to the Mediterranean Sea, and along the coast of North Africa.

Lesser Weever, Trachinus vipera Cuvier (Fig. 41, Bottom). Inhabits the North Sea, southward along the coast of Europe, and Mediterranean Sea.

Venom Apparatus of Weevers. The venom apparatus of the weeverfish consists of the dorsal and opercular spines and their associated glands (Fig. 42, Top). The dorsal spines vary from five to seven in number. Each of the spines is enclosed within a thinwalled sheath of skin from which protrudes a needle-sharp tip (Fig. 42, Center). Removal of the sheath reveals a thin, elongate, fusiform strip of whitish spongy tissue lying within the grooves, near the tips, of each spine. This spongy tissue is the venom-producing part of the spine. Removal of the skin covering the gill cover shows a broad, compressed, "dagger-like" opercular spine ending in a sharp tip (Fig. 42, Bottom). Attached to the upper and lower margins of the spine are the pear-shaped venom glands. Weever venom has been found to act as both a neurotoxin and hemotoxin, similar to some snake venoms.

Medical Aspects. Weever wounds usually produce instant pain, described as a burning, stabbing or "crushing" sensation-initially confined to the immediate area of the wound, then gradually spreading through the affected limb. The pain gets progressively worse until it reaches an excruciating peak, generally within 30 minutes. The severity is such that the victim may scream, thrash wildly about, and lose consciousness. In most instances, morphine fails to give relief. Untreated, the pain commonly subsides within 2 to 24 hours. Tingling, followed by numbness, finally develops about 
the wound. The skin about the wound at first is blanched, but soon becomes reddened, hot, and swollen. The swelling may be quite extensive and continue for ten days, or longer. Other symptoms and findings consist of headache, fever, chills, delirium, nausea, vomiting, dizziness, sweating, cyanosis, joint aches, loss of speech, slow heart beat, palpitation, mental depression, convulsions, difficulty in breathing, and death. Secondary infections are common in cases improperly treated. Gangrene has been known to develop as a complication. Recovery may take from several days to several months, depending upon the amount of venom received, condition of the patient, and other factors.

Treatment. There are no known antidotes. See Page 91, on the treatment of fish stings.

Prevention. Weeverfish stings are most commonly encountered while wading or swimming along sandy coastal areas of the eastern Atlantic or Mediterranean seas. Weevers are usually encountered partially buried in the sand or mud. Persons wading in waters where weevers abound should wear adequate footwear. Skin divers should attempt to avoid antagonizing these fishes since they are easily provoked into stinging. Never, under any circumstance, attempt to handle a living weever. Even when dead, weevers can inflict a nasty wound.

\section{SCORPIONFISHES}

Members of the family Scorpaenidae, the scorpionfishes, are widely distributed throughout all tropical and temperate seas. A few species are also found in arctic waters. Many scorpaenidae attain large size and are valuable food fishes, whereas others are relatively small and of no commercial value. Some species are extremely venomous.

Venomous scorpionfishes have been divided into three main groups on the basis of the structure of their venom organs, namely: 1) Zebrafish (Pterois);2) Scorpionfish proper (Scorpaena); and 3) the Stonefishes (Synanceja).

Zebrafish are among the most beautiful and ornate of coral reef fishes. They are generally found in shallow water, hovering about in a crevice or at times swimming unconcernedly in the open. They are also called turkeyfish because of their interesting habit of slowly swimming about, spreading their fan-like pectorals and lacy dorsal fins, like a turkey gobbler displaying its plumes. They are fre- 


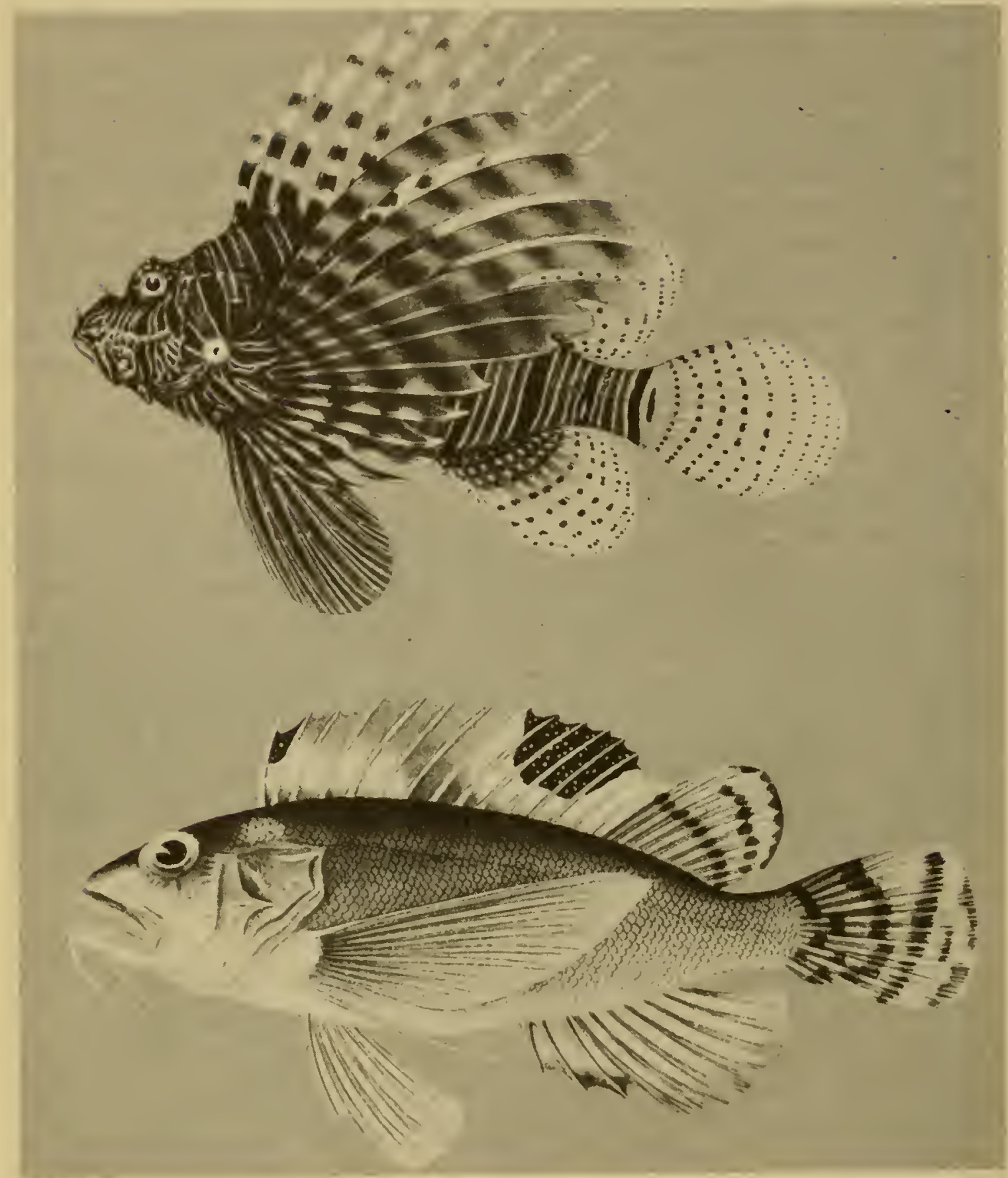

Fig. 43. Top: Zebrafish, Pterois volitans (Linnaeus). (From Hiyama) Bottom: Bullrout or Sulky, Apistus carinatus (Bloch and Schneider). (Shirao)

quently observed swimming in pairs, and apparently are fearless in their movements. Acceptance of the invitation to reach out and grab one of these fish results in an extremely painful experience, because hidden beneath the "lace" are the needlesharp fin stings. The fearlessness of the zebrafish makes it a particular menace to anyone working in the shallow water coral reef areas which it inhabits. 

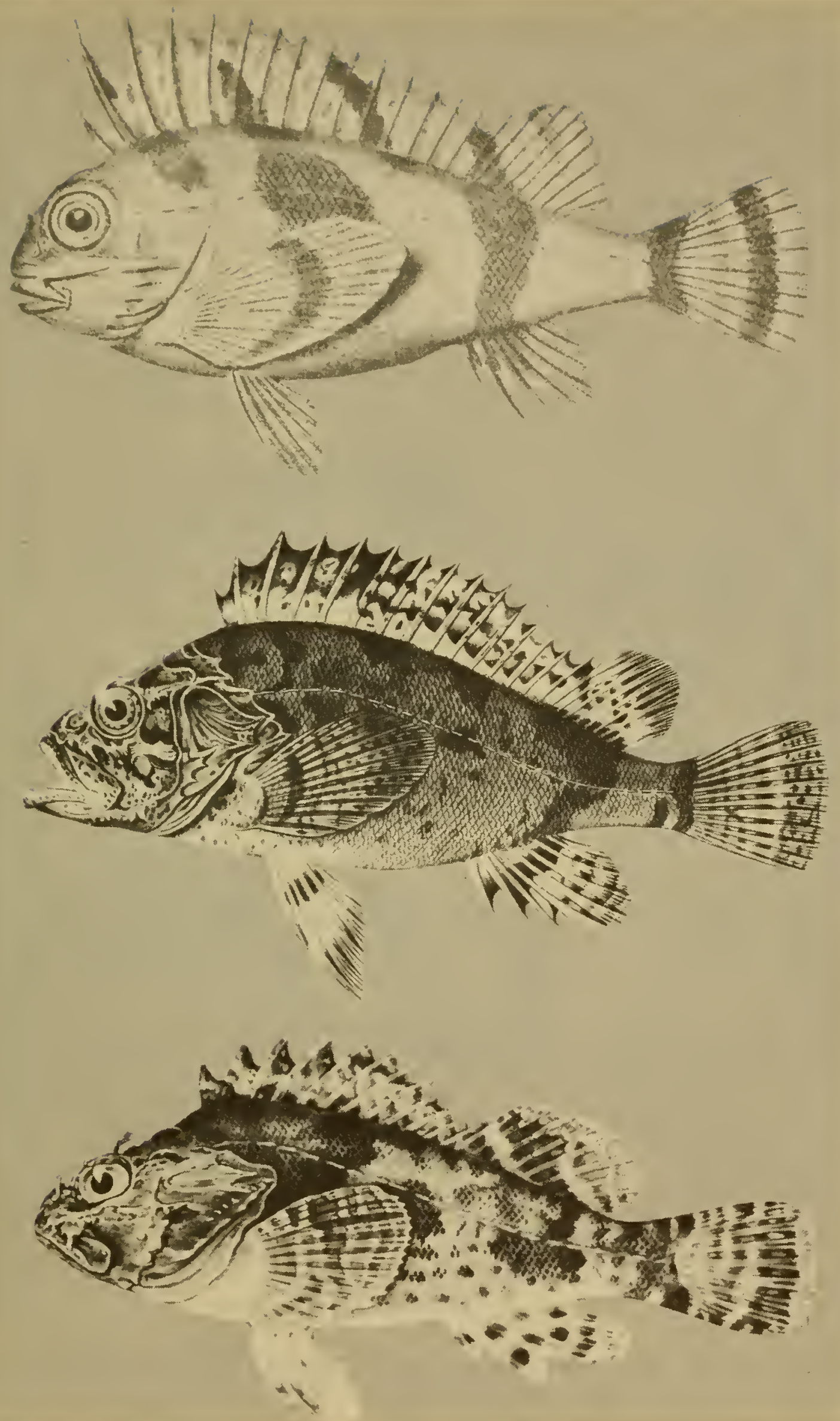

Fig. 44. Top: Waspfish or Fortescue, Centropogon australis (White). (From Whitley) Center: Bullrout, Notesthes robusta (Günther). (After Bleeker) Bottom: Scorpionfish, Scorpaena guttata Girard. (Shirao) 
Members of the genus Scorpaena are for the most part shallow water, bottom-dwellers, found in bays, along sandy beaches, rocky coastlines, or coral reefs, from the intertidal zone to depths of 50 fathoms or more. Their habit of concealing themselves in crevices, among debris, under rocks, or in seaweed, together with their protective coloration which blends them almost perfectly into their surrounding environment, makes them difficult to see. When they are removed from the water, they have the defensive habit of erecting their spinous dorsal fin and flaring out their armed gill covers, pectoral, pelvic and anal fins. The pectoral fins, although dangerous in appearance, are unarmed.

Stonefishes are largely shallow-water dwellers, commonly found in tidepools and shoal reef areas. Synanceja has the habit of lying motionless in coral crevices, under rocks, in holes, or buried in sand and mud. They appear to be fearless and completely disinterested in the careless intruder.

\section{SPECIES OF SCORPIONFISHES :}

Zelbrafish type: Zebrafish, Lionfish or Turkeyfish, Pterois volitans (Linnaeus) (Fig. 43, Top). Inhabits the Red Sea, Indian Ocean, China, Japan, Australia, Melanesia, Micronesia, and Polynesia. One of several closely allied species found around coral reefs.

Scorpionfish type: Bullrout or Sulky, Apistus carinatus (Bloch and Schneider) (Fig. 43, Bottom). Inhabits the coast of India, Netherlands Indies, Philippine Islands, China, Japan, and Australia.

Waspfish or Fortescue, Centropogon australis (White) (Fig. 44, Top). Inhabits New South Wales and Queensland, Australia.

Bullrout, Notesthes robusta (Günther) (Fig. 44, Center). Inhabits New South Wales and Queensland, Australia.

Scorpionfish, Scorpaena guttata Girard (Fig. 44, Bottom). Ranges from central California south into the Gulf of California.

Scorpionfish, Scorpaena plumieri Bloch (Fig. 45, Top). Inhabits the Atlantic coast from Massachusetts to the West Indies and Brazil. One of several closely related species found in this general region.

Scorpionfish, Rascasse, Sea Pig, etc, Scorpaena porcus (Linnaeus) (Frontis). Inhabits the Atlantic coast of Europe from the English Channel to the Canary Islands, French Morocco, Mediterranean and Black Seas.

Scorpionfish, Scorpaenopsis diabolus (Cuvier) (Fig. 45, Next to 


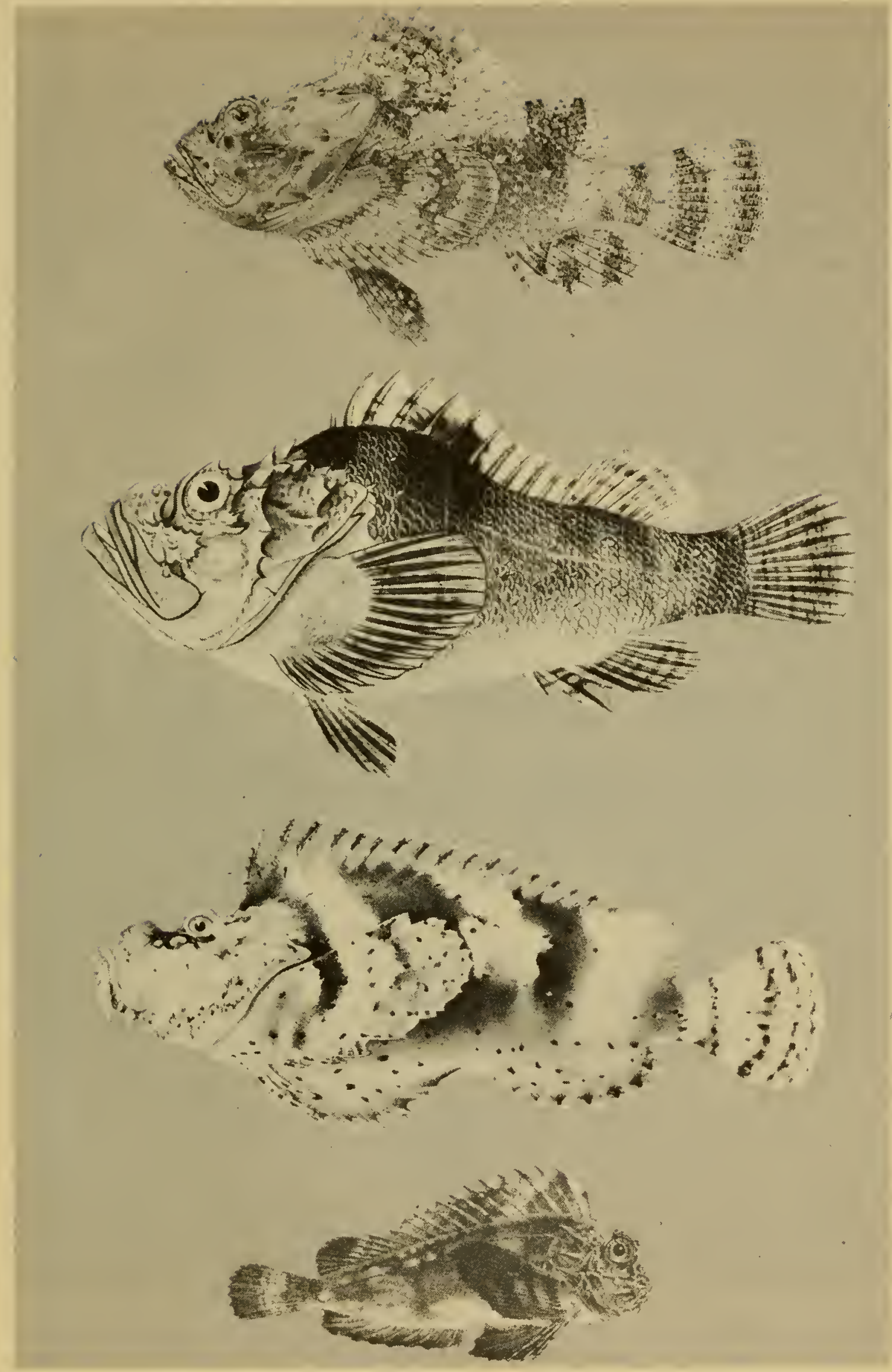

Fig. 45. Top to bottom: Scorpionfish, Scorpaena plumieri Bloch. (From Evermann and Seale) Scorpionfish, Scorpaenopsis diabolus (Cuvier). (From Hiyama) Lupo, Inimicus japonicus (Cuvier). (Shirao) No common name, Choridactylus multibarbis Richardson. (From Day) 
Top). Inhabits the Netherlands Indies, Australia, Melanesia, and Polynesia.

Lupo, Inimicus japonicus (Cuvier) (Fig. 45, Next to Bottom). Inhabits the coastal areas of Japan.

Stonefish type: Common Name Unknown, Choridactylus multibarbis Richardson (Fig. 45, Bottom). Found along coastal areas of India, China, Philippine Islands, and Polynesia.

Hime-Okoze, Minous monodactylus (Bloch and Schneider) (Fig. 46, Top). Inhabits the South Pacific Islands, China, and Japan.

Deadly Stonefish, Synanceja horrida (Linnaeus) (Fig. 46, Bottom). Inhabits India, East Indies, China, Philippine Islands, and Australia. The Stonefish is an extremely dangerous species.

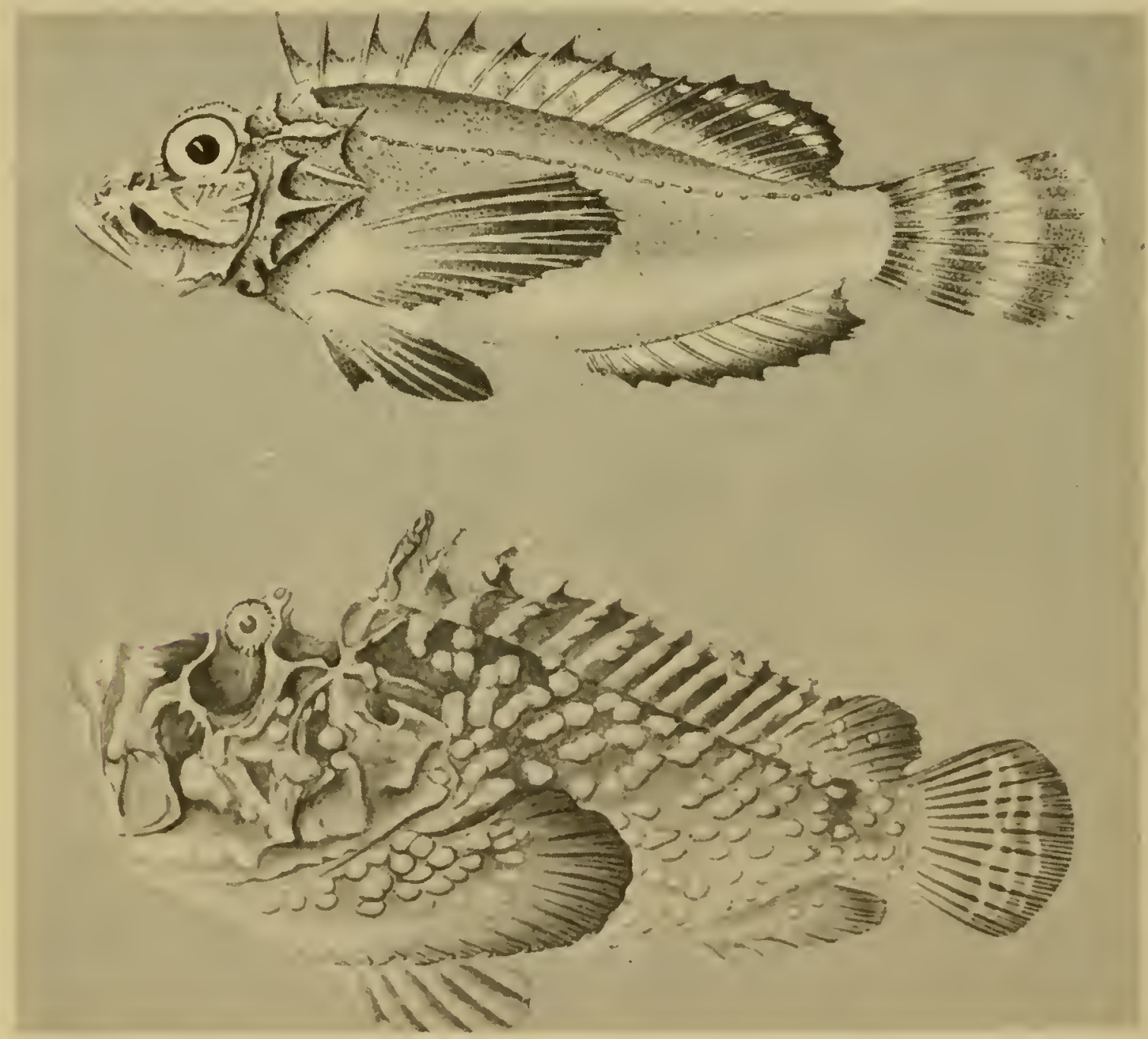

Fig. 46. Top: Hime-okoze, Minous monodactylus (Bloch and Schneider). (Shirao) Bottom: Deadly Stonefish, Synanccja horrida (Linnaeus). (Arita)

Venom Apparatus of Scorpionfishes: The venom organs of scorpionfishes vary markedly from one group to the next. A comparison of some of the more important differences appear's in the chart that follows. See also Fig. 47. 
COMPARISON OF THE VENOM ORGANS

OF PTEROIS, SCORPAENA, AND SYNANCEJA

\begin{tabular}{|c|c|c|c|}
\hline Structure & Pterois & Scorpaena & Synanceja \\
\hline Fin spines & Elongate, slender & $\begin{array}{l}\text { Moderately } \\
\text { long, heavy }\end{array}$ & Short, stout \\
\hline $\begin{array}{l}\text { Integumentary } \\
\text { sheath }\end{array}$ & Thin & $\begin{array}{l}\text { Moderately } \\
\text { thick }\end{array}$ & Very thick \\
\hline Venom glands & $\begin{array}{l}\text { Small-sized, well- } \\
\text { developed }\end{array}$ & $\begin{array}{l}\text { Moderate-sized, } \\
\text { very well-de- } \\
\text { veloped }\end{array}$ & $\begin{array}{l}\text { Very large, highly } \\
\text { developed }\end{array}$ \\
\hline Venom duct & Not evident & Not evident & Well-developed \\
\hline
\end{tabular}

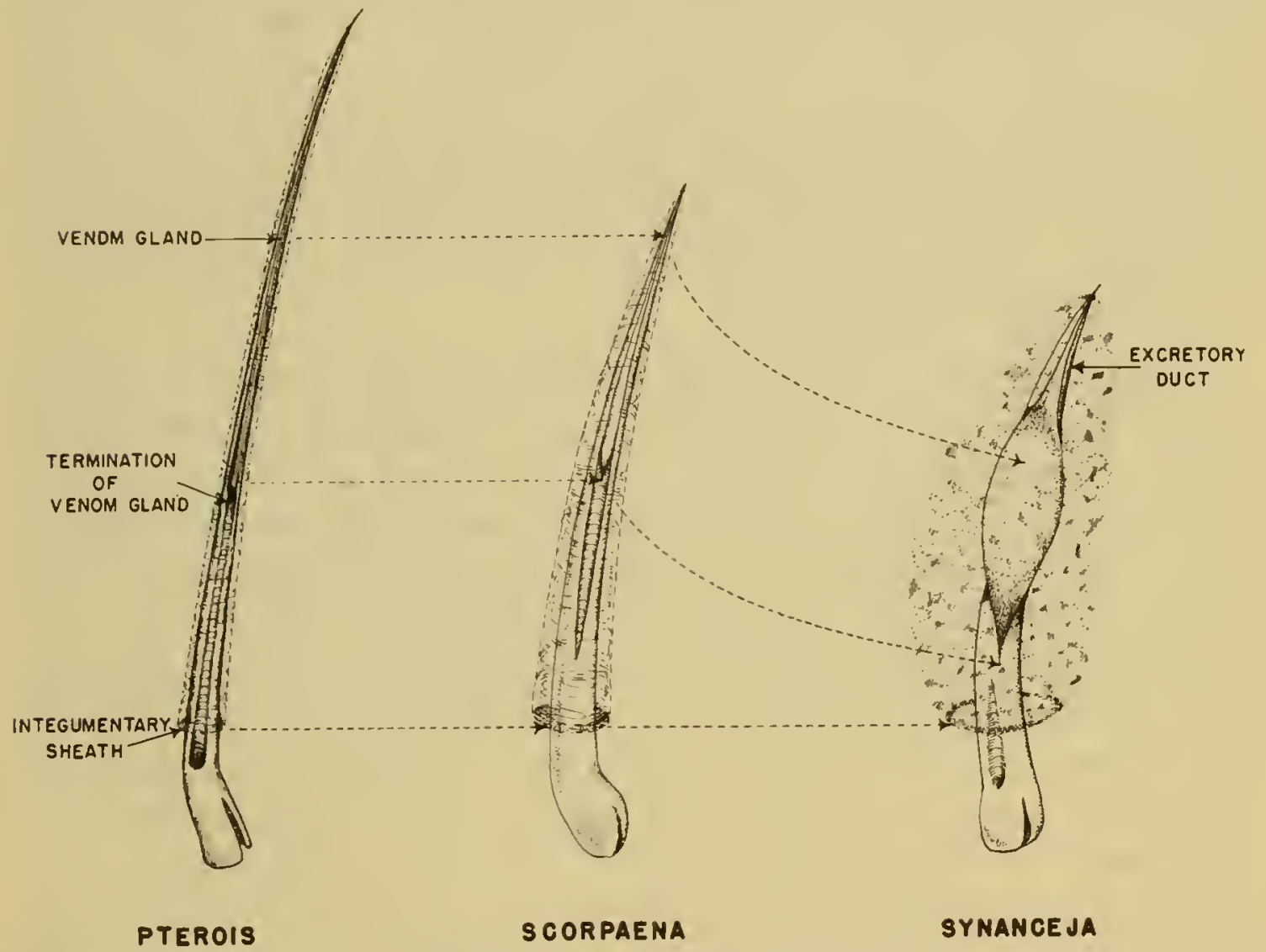

Fig. 47. Showing a comparison of the three types of scorpionfish dorsal stings. (Diagrammatic)

Zebrafish Type. The zebrafish, or Pterois type, have a venom apparatus consisting of 13 dorsal spines, 3 anal spines, 2 pelvic spines, and their associated venom glands. The spines are for the most part long, straight, slender, and camouflaged in delicate, lacyappearing fins. Located on the front side of each spine are the glandular grooves, open on either side, which appear as deep chan- 
nels extending the entire length of the shaft. Situated within these grooves are the venom glands. The glands are enveloped by a thin covering of skin--the integumentary sheath.

Scorpionfish Type. The scorpionfish, or Scorpaena type, have a variable number of dorsal spines, frequently 12, 3 anal and 2 pelvic spines, and their associated venom glands. The spines are shorter and heavier than those found in Pterois. The glandular grooves are restricted to about the distal two-thirds of the spine. The venom glands lie along the glandular grooves, but are limited to about the distal half of the spine. The enveloping integumentary sheath is moderately thick.

Stonefish Type. The stonefish, or Synanceja type, usually have 13 dorsal spines, 3 anal spines, 2 pelvic spines, and their associated venom glands. The venom organs of this fish differ from all of the others by the short, heavy spines and greatly enlarged venom glands, which are covered by a very thick layer of warty skin. This fish is particularly dangerous because of its camouflaged appearance-frequently resembling a large clump of mud or debris. The stings of this latter group are difficult to detect, because they are almost completely hidden.

Medical Aspects. The symptoms produced by the various species of scorpionfishes are essentially the same, varying in degree, rather than in quality. The pain is usually described as immediate, intense, sharp, shooting or throbbing, and radiates from the affected part. The area about the wound becomes ischemic, and then cyanotic. The pain produced by most scorpionfishes generally continues for only a few hours, but wounds produced by Synanceja may be extremely painful and may continue for a number of days. Pain caused by Synanceja is sometimes so severe as to cause the victim to thrash wildly about, to scream, and finally, to lose consciousness. The area in the immediate vicinity of the wound gradually becomes cyanotic, surrounded by a zone of redness, swelling, and heat. Subsequent sloughing of the tissues about the wound site may occur. In the case of Synanceja stings, the wound becomes numb and the skin, some distance from the site of injury becomes painful to touch. In some instances, complete paralysis of the limb may ensue. Swelling of the entire member that is affected may take place, frequently to such an extent that movement of the part is impaired. Other symptoms which may be present are: cardiac failure, delirium, convulsions, various nervous disturbances, nausea, vomiting, lymphangitis, swelling of the lymph nodes, joint aches, 
fever, respiratory distress, convulsions, and death. Complete recovery from a severe Synanceja sting may require many months, and may have an adverse effect on the general health of the victim.

Treatment. See Page 91 on the treatment of venomous fish stings.

Prevention. Zebrafish stings are usually contracted by individuals, who are attracted by their slow movements and lacy-appearing fins and who attempt to pick up the fish with their hands. Most scorpionfish stings result from the individual removing them from the hook, or nets, and being jabbed by their venomous spines. Stonefish are especially dangerous because of the difficulty of detecting them from their surroundings. Placing one's hands in crevices, or in holes inhabited by these fish, should be done with caution. Knowledge of the habits and appearance of these fishes is most important.

\section{TOADFISHES}

The toadfishes are all members of the family Batrachoididae. All of them are small, bottom fishes which inhabit the warmer waters of the coasts of America, Europe, Africa, and India. Toadfishes have broad, depressed heads, large mouths, and are somewhat repulsive in appearance. Most toadfishes are marine, but some are estuarine, or entirely freshwater, ascending rivers for great distances. They hide in crevices, in burrows, under rocks, debris, among seaweed, or lie almost completely buried under a few centimeters of sand or mud. Toadfishes tend to migrate to deeper water during the winter months, where they remain in a torpid state. They are experts at camouflage. Their ability to change their color to lighter or darker shades at will, and their mottled pattern make these fishes difficult to see.

SPECIES OF TOADFISHES :

Toadfish, Barchatus cirrhosus (Klunzinger) (Fig. 48, Top). Inhabits the Red Sea.

Toadfish, or Munda, Batrachoides grunniens (Linnaeus) (Fig. 48, Center). Inhabits the coasts of Ceylon, India, Burma, and Malaya.

Toadfish, Batrachoides didactylus (Bloch) (Fig. 48, Bottom). Inhabits the Mediterranean Sea and nearby Atlantic Coasts.

Toadfish, Oysterfish, Opsanus tau (Linnaeus) (Fig. 49, Top). Found along the Atlantic Coast of United States, from Massachusetts to the West Indies. 


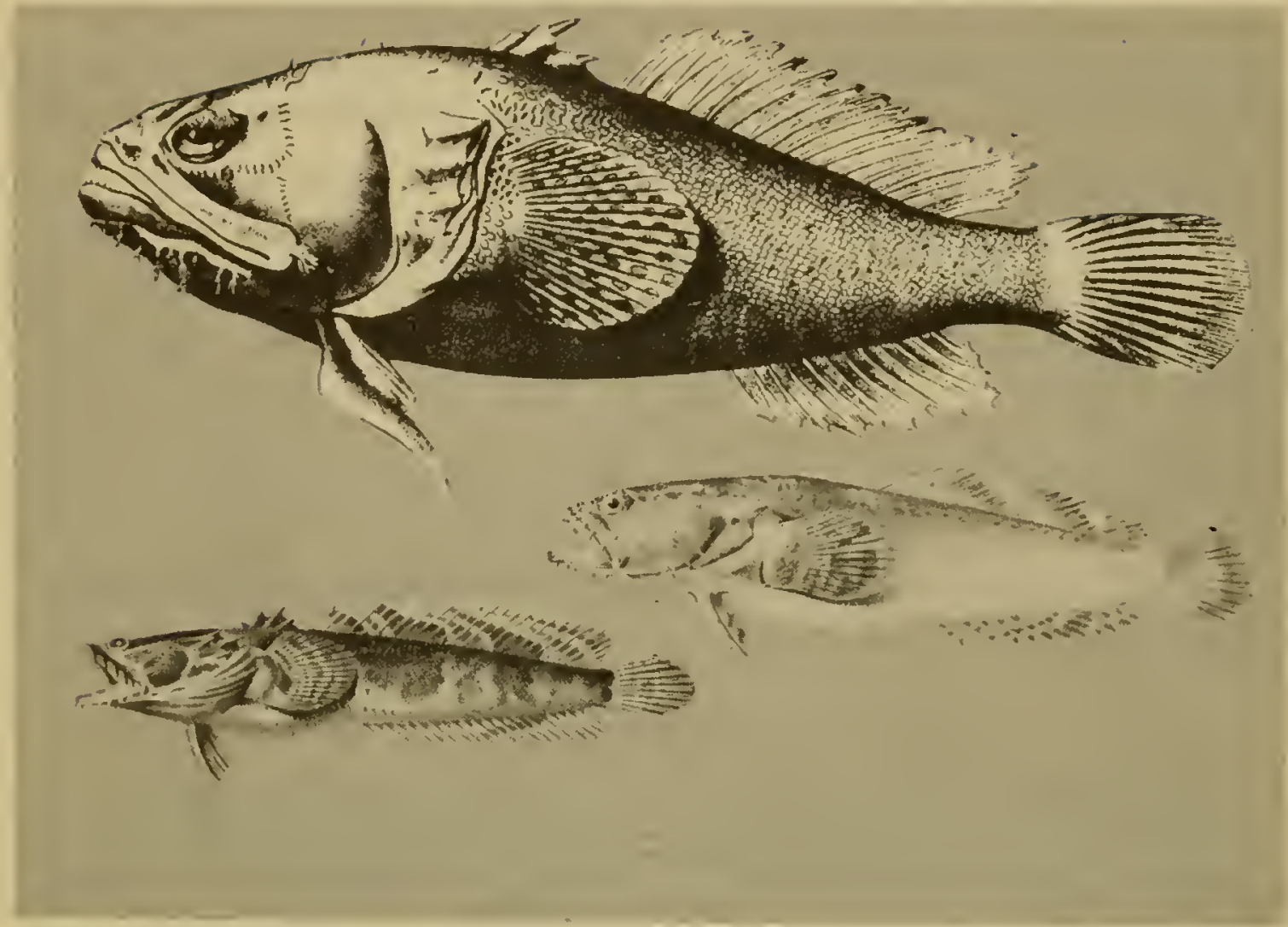

Fig. 48. Top: Toadfish, Barchatus eirhosus (Klunzinger). (From Klunzinger) Center: Toadfish, Batrachoides grunniens (Linnaeus). (From Sauvage) Bottom: Batrachoides didactylus (Bloch). (From Steindachner)

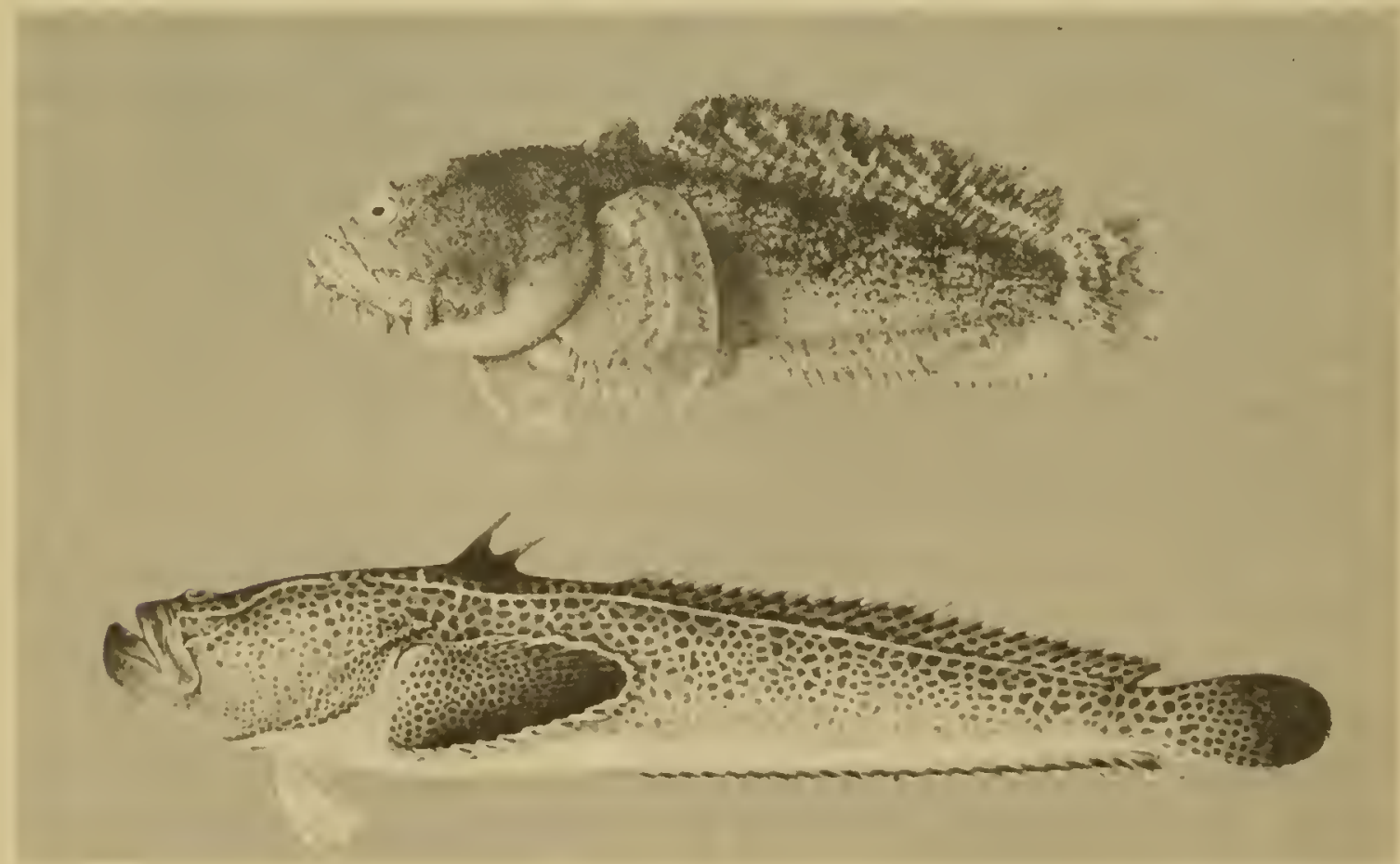

Fig. 49. Top: Toadfish, Opsanus tau (Linnaeus). (From Storer) Bottom: Toadfish, Thalassophryne reticulata Günther. (Shirao) 
Toadfish, Bagre Sapo, Sapo, Thalassophryne reticulata Günther (Fig. 49, Bottom). Inhabits the Pacific Coast of Central America. In addition to the above, there are several other closely related species inhabiting certain coastal areas of Central and South America.

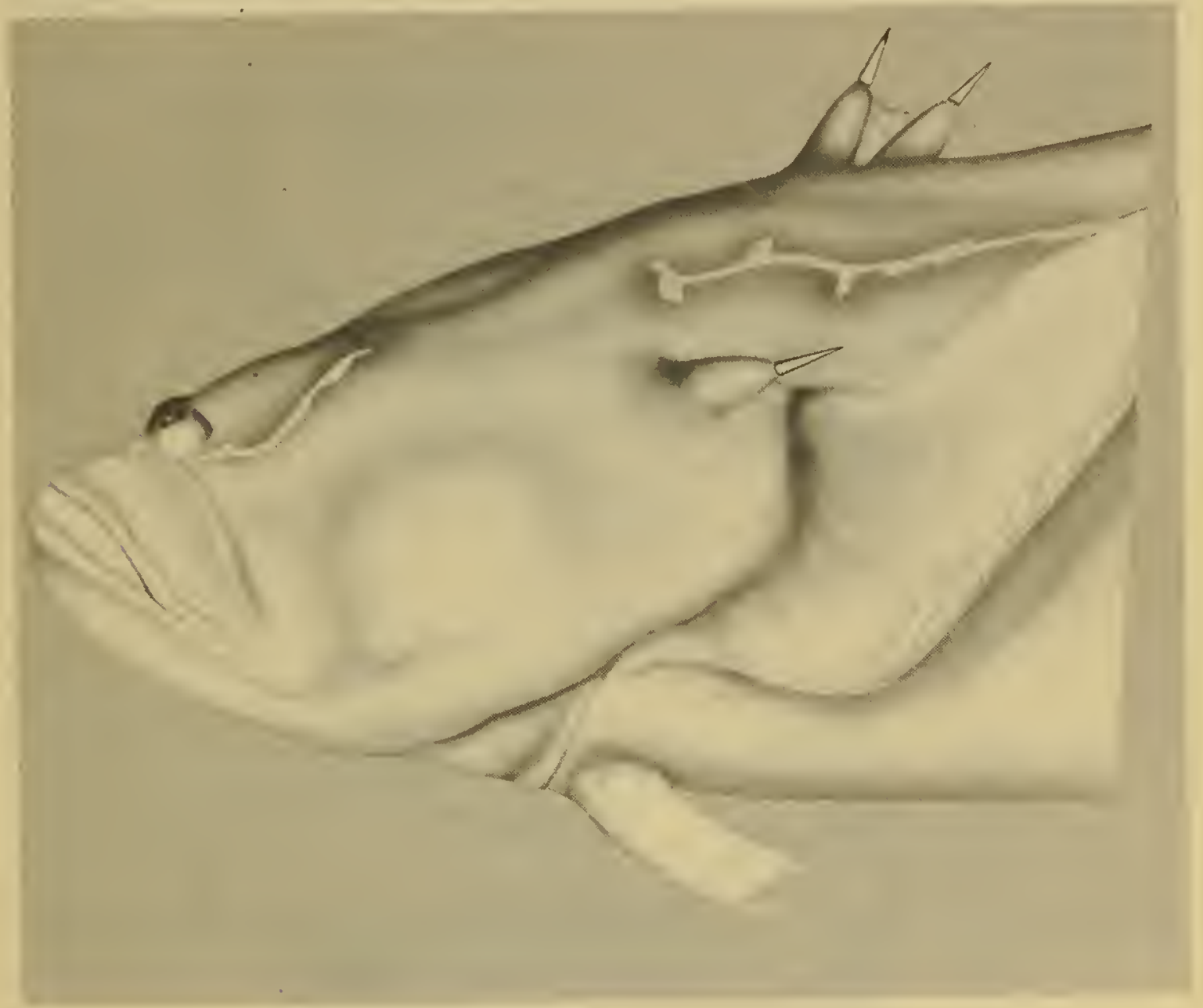

Fig. 50. Head of toadfish, Thalassophryne, showing the location of the dorsal and opercular stings.

Venom Apparatus. The venom apparatus of toadfishes consists of two dorsal fin spines, two gill cover spines, and their associated venom glands (Fig. 50). The dorsal spines are slender and hollow, slightly curved, and terminate in sharp, needle-like points. At the base and tip of each spine is an opening through which the venom passes. The base of each dorsal spine is surrounded by a glandular mass from which the venom is produced. Each gland empties into the base of its respective spine (Fig. 51, Top). The operculum is also highly specialized as a defensive organ for the introduction of venom. The horizontal limb of the operculum is a slender, hol- 

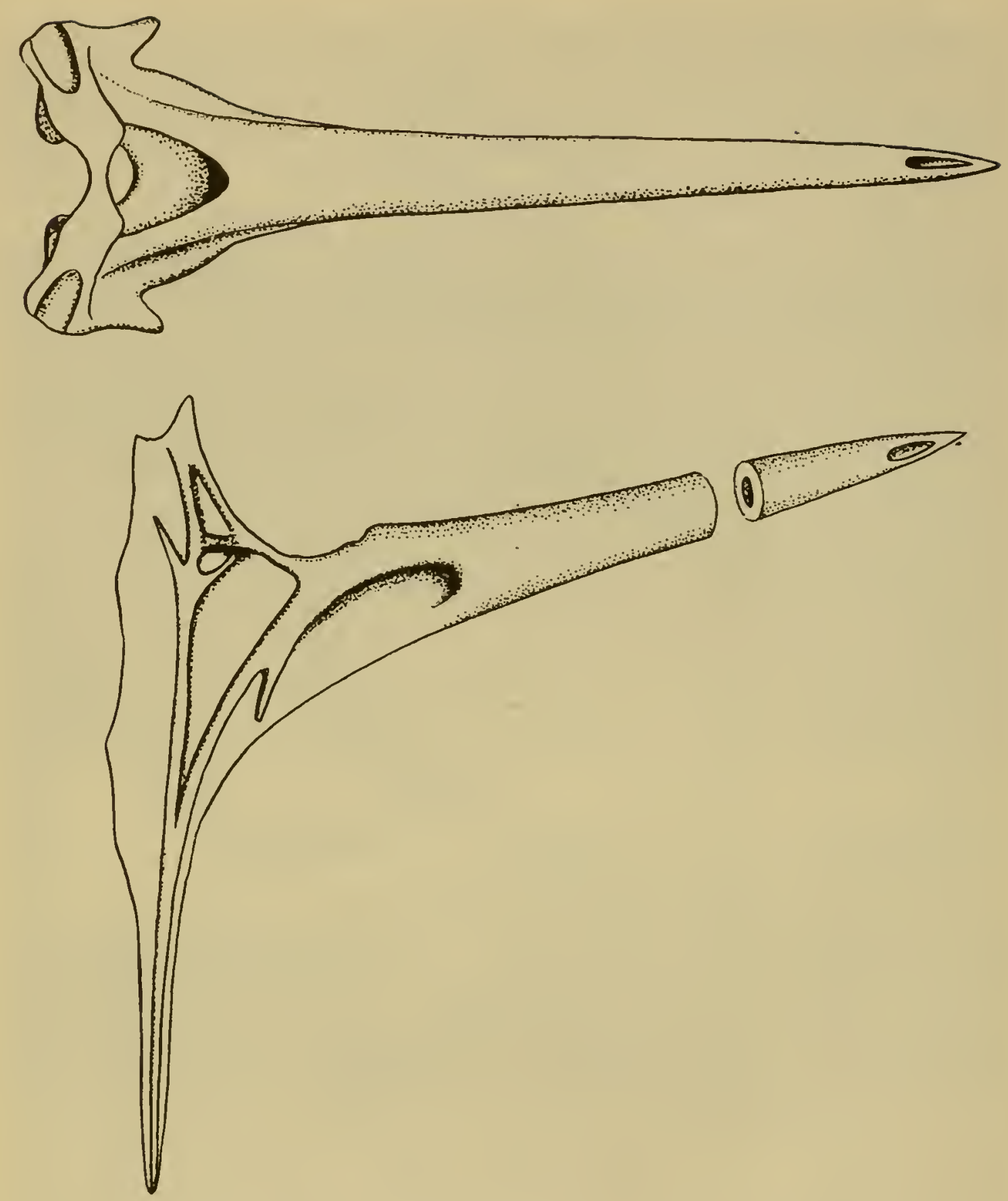

Fig. 51. Top: Dorsal sting of Thalassophryne. Bottom: Opercular sting of Thalassophryne.

low bone which curves slightly, and terminates in a sharp tip. Openings are present at each end of the spine for the passage of venom. With the exception of the outer tip, the entire gill spine is encased within a glistening, whitish, pear-shaped mass. The broad, rounded portion of this mass is situated at the base of the spine, and tapers rapidly as the tip of the spine is approached. This mass is the venom gland. The gland empties into the base of the hollow gill spine which serves as a duct (Fig. 51, Bottom). 
Medical Aspects. The pain from toadfish wounds develops rapidly, is radiating and intense. Some have described the pain as being similar to that of a scorpion sting. The pain is soon followed by swelling, redness, and heat. No fatalities have been recorded in the literature. Little else is known about the effects of toadfish venom.

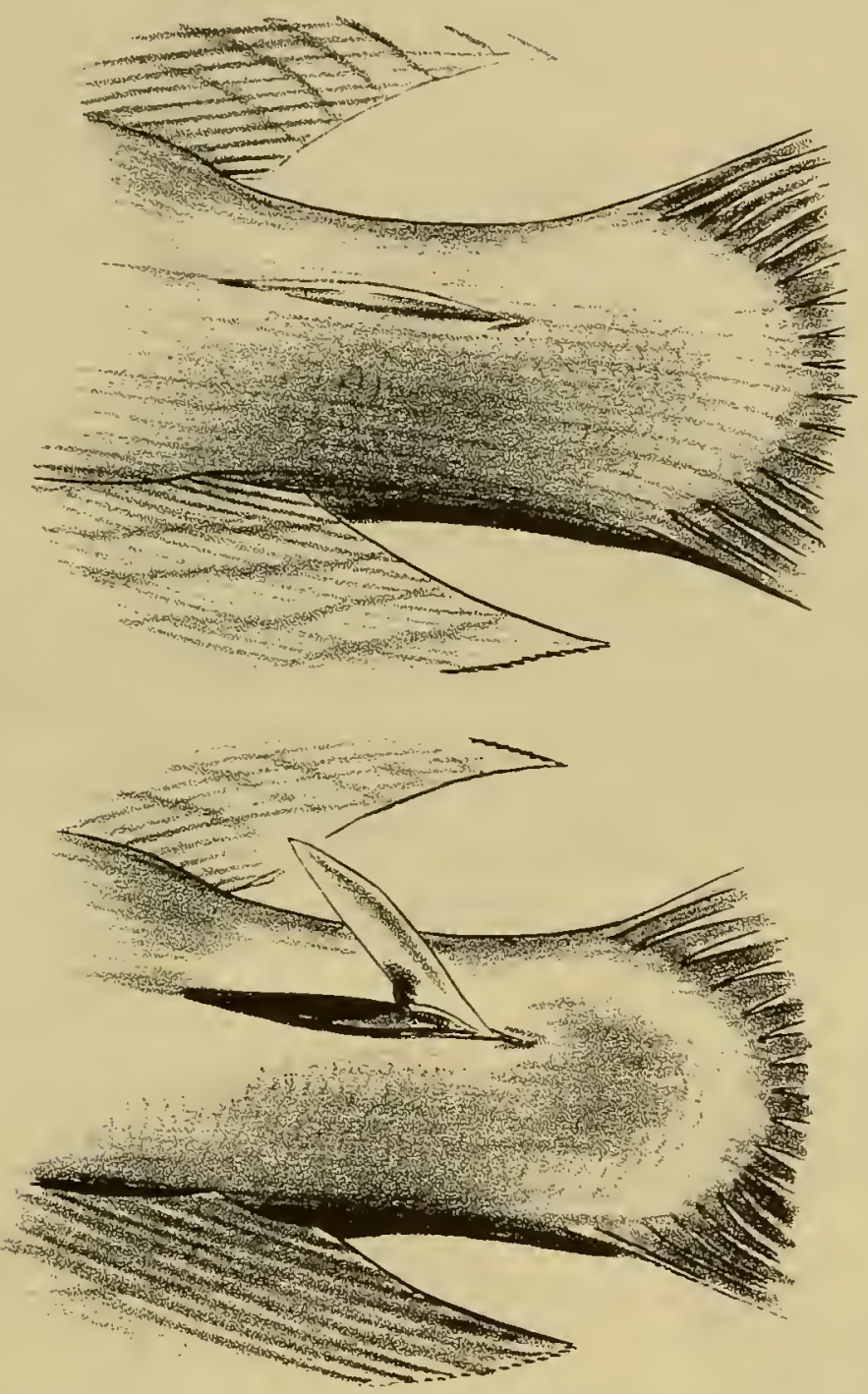

Fig. 52. Top: Tail of the surgeonfish, Acanthurus, showing the caudal spine in the contracted position. Bottom: Tail of Acanthurus, showing the caudal spine in the extended position. The fish can inflict a severe cut when the spine is extended.

Treatment. See Page 91 regarding the treatment of stings from venomous fishes.

Prevention. Persons wading in waters inhabited by toadfishes should take the precaution to shuffle their feet through the mud to avoid stepping on them. Removal of toadfishes from a hook or from nets should be done with care. 

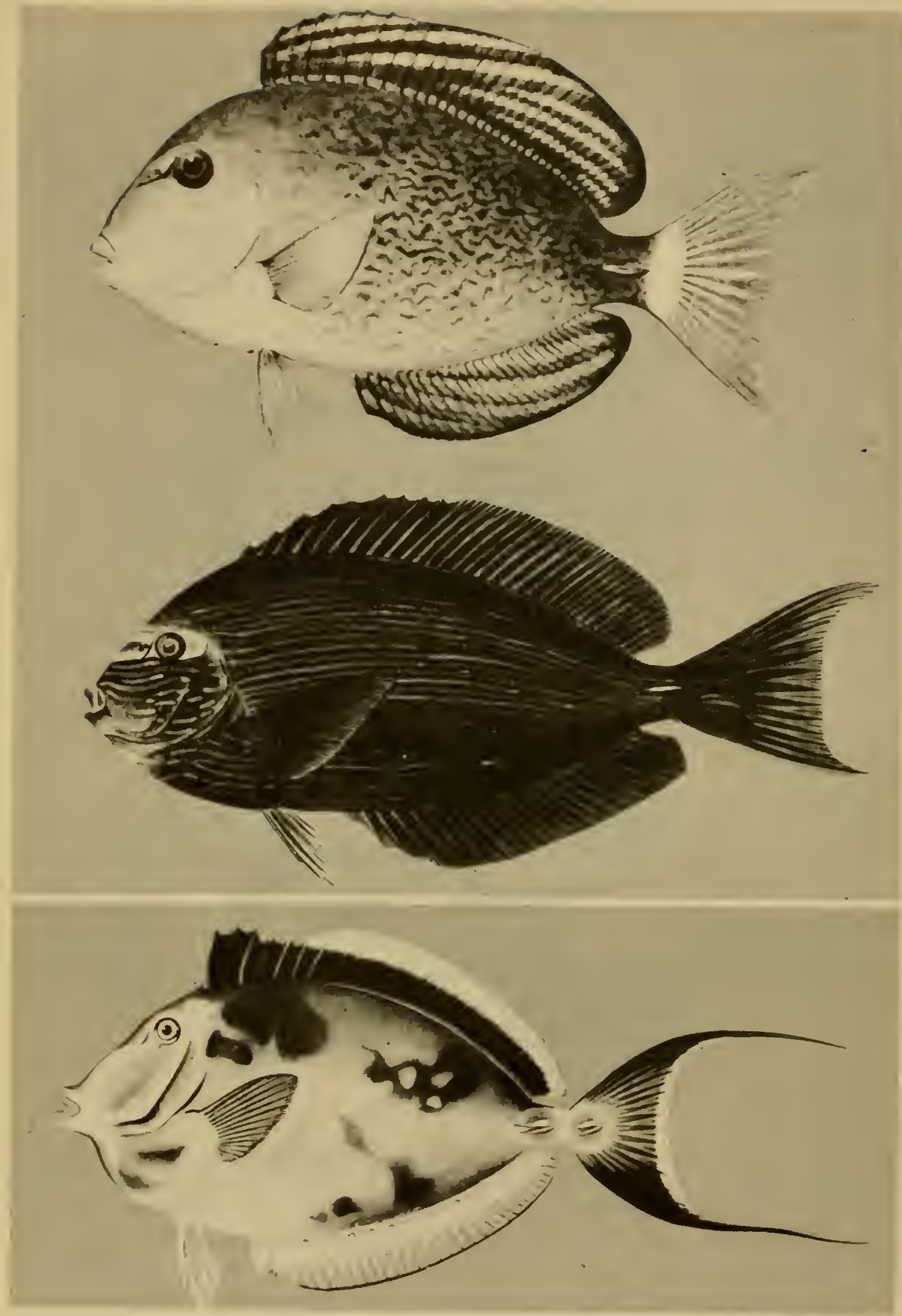

Fig. 53. Top: Surgeonfish, Acanthurus xanthopterus Cuvier and Valenciennes. (Coates) Center: Surgeonfish, Acanthurus bleekeri Günther. Bottom: Surgeonfish Naso lituratus (Bloch and Schneider). (Shirao) Three representative species of surgeonfishes. Note the sharp spines near the base of the tail. In the genus, Acanthurus, this spine can be extended, but Naso has spines which arise from plates and these are immovable. Both types can inflict serious wounds. 


\section{SURGEONFISHES}

Surgeonfishes are members of the family, Acanthuridae, and are reef-dwellers of warm seas. The principal genus of this family, Acanthurus, is characterized by the presence of a sharp, lance-like, movable spine on the side, at the base of the tail fin (Fig. 52). When the fish becomes excited, the spine, the point of which is directed forward, can be extended at right angles from the body of the fish. With a quick, lashing movement of the tail and the extended spine, large surgeonfishes are likely to inflict a deep and painful wound.

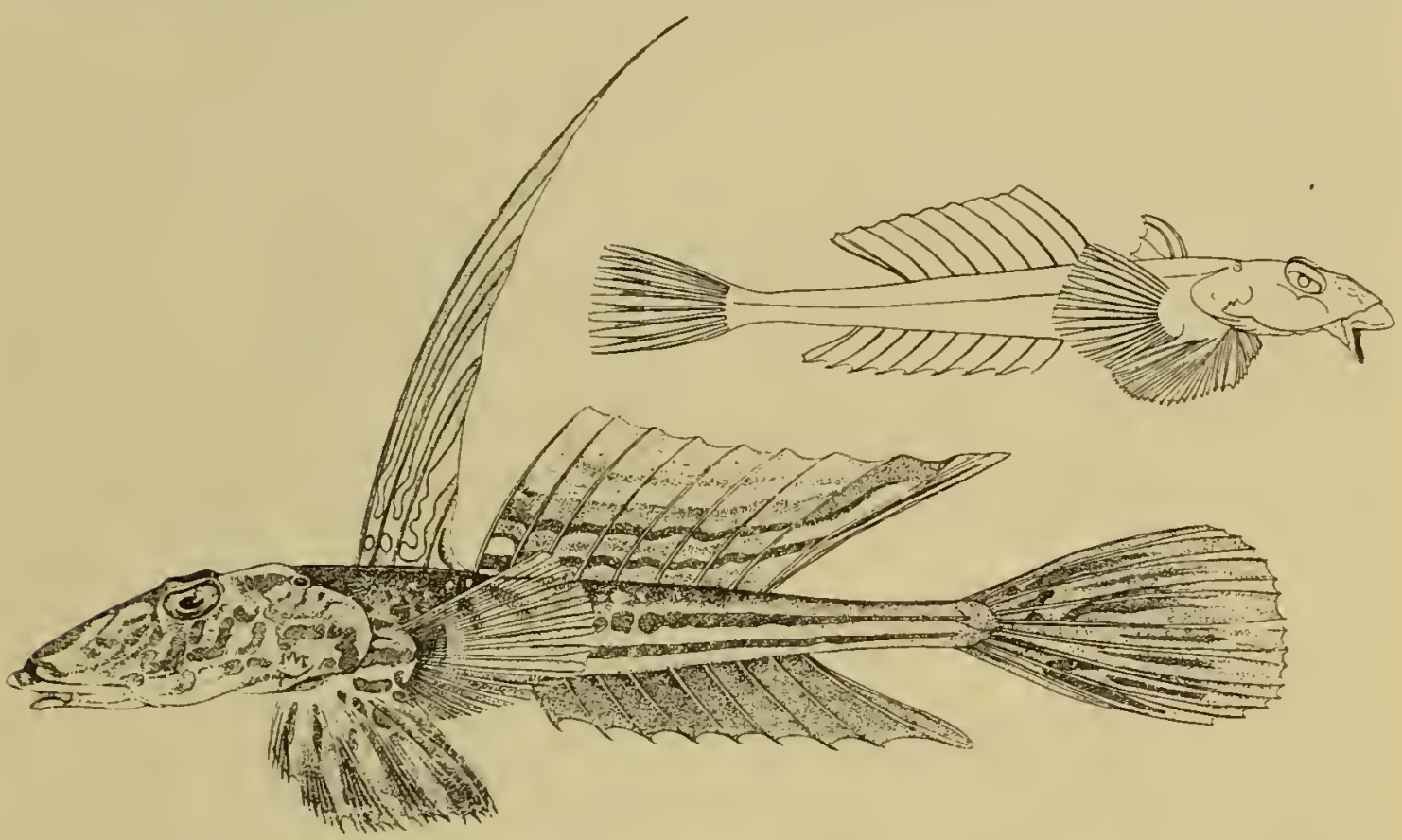

Fig. 54. Dragonet, Callionymus lyra Linnaeus. Male, lower left; female, upper right. (From Poll) Note the preopercular spines which are believed to be venomous.

Under normal circumstances, the spine remains adducted within a deep recess partially surrounded by an integumentary sheath. As to whether or not surgeonfishes' spines are venomous, this has not as yet been determined.

SPECIES OF SURGEONFISHES :

Yellow-Finned Surgeonfish, Acanthurus xanthopterus Cuvier and Valenciennes (Fig. 53, Top). Indo-Pacific area.

Bleeker's Surgeonfish, Acanthurus bleekeri Günther (Fig. 53, Center). Found throughout the Indo-Pacific area, with the exception of Hawaii.

Surgeonfish, Naso lituratus (Bloch and Schneider) (Fig. 53, Bottom). Ranges from Polynesia to east Africa and the Red Sea. 


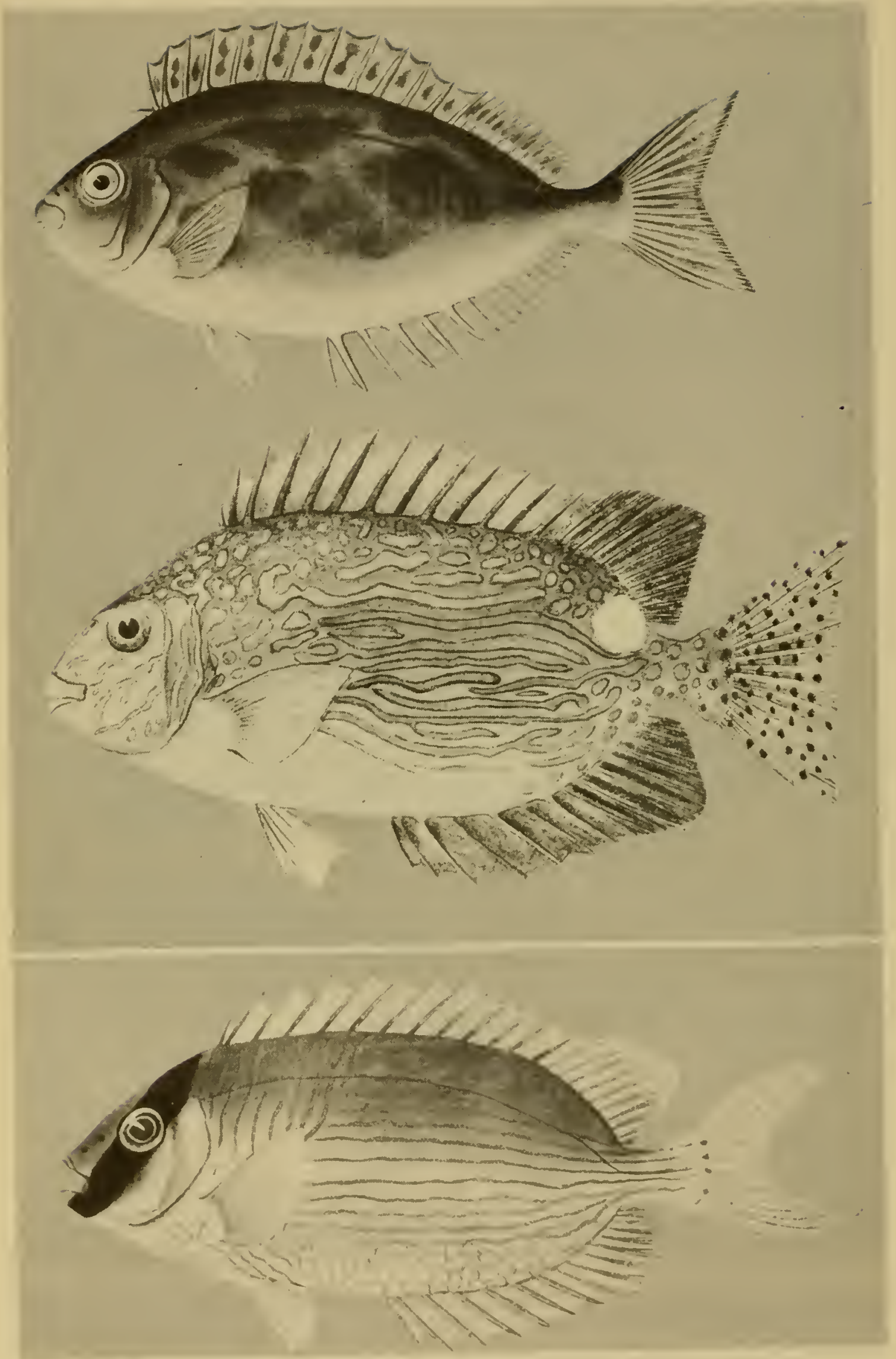

Fig. 55. Top: Rabbitfish, Siganus fuscescens (Houttuyn). (Shirao) Center: Rabbitfish, Siganus lineatus (Valenciennes). (Coates) Bottom: Rabbitfish, Siganus puellus (Schlegel). (From Hiyama) 


\section{DRAGONETS}

Dragonets are small, scaleless fishes with flat heads, bearing a preopercle that is armed with a strong spine. These fishes are brightly variegated in color, and have high, and often filamentous dorsal fins. Some species are found in deep water, whereas others are shore fishes inhabiting shallow bays and reefs. The gill spine of the European species, Callionymus lyra Linnaeus, (Fig. 54),
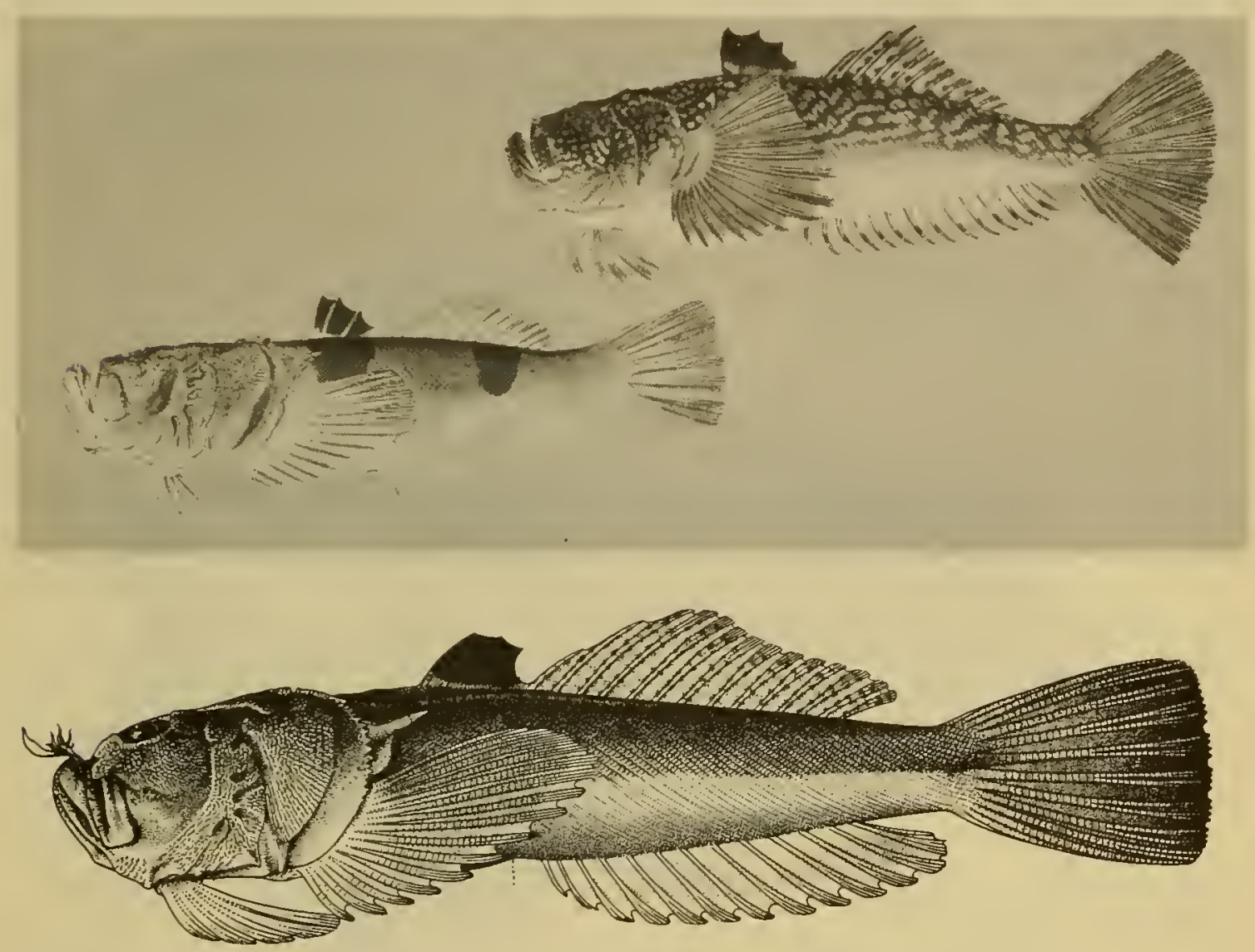

Fig. 56. Top: Star-gazer, Uranoscopus japonicus Houttuyn. (From Temminck and Schlegel) Center: Star-gazer, Uranoscopus bicinctus Temminck and Schlegel. (From Temminck and Schlegel) Bottom: Star-gazer, Uranoscopus scaber Linnaeus. (Smithsonian Institution)

which is distributed along the Atlantic coast of Europe and the Mediterranean Sea, is said to be venomous. They are said to be capable of inflicting serious wounds and should be handled with care.

\section{RABBITFISHES}

Rabbitfishes, which belong to the family Siganidae, are a group of spiny-rayed fishes which closely resemble the surgeonfishes. They differ from all other fishes in that the first and last rays of 
the pelvic fins are spinous. Rabbitfishes are of moderate size, usually valued as food, and abound about rocks and reefs from the Red Sea to Polynesia.

SPECIES OF RABBITFISHES :

Rabbitfish, Siganus fuscescens (Houttuyn) (Fig. 55, Top). Found throughout the Indo-Pacific region.

Rabbitfish, Siganus lineatus (Valenciennes) (Fig. 55, Center). Inhabits the Philippines, Santa Cruz Islands, New Guinea, Solomon Islands, Australia, Okinawa, and the Ryukyu Islands.

Rabbitfish, Siganus puellus (Schlegel) (Fig. 55, Bottom). Inhabits the East Indies, Philippines, Palau, Gilbert, Marshall, and Solomon Islands.

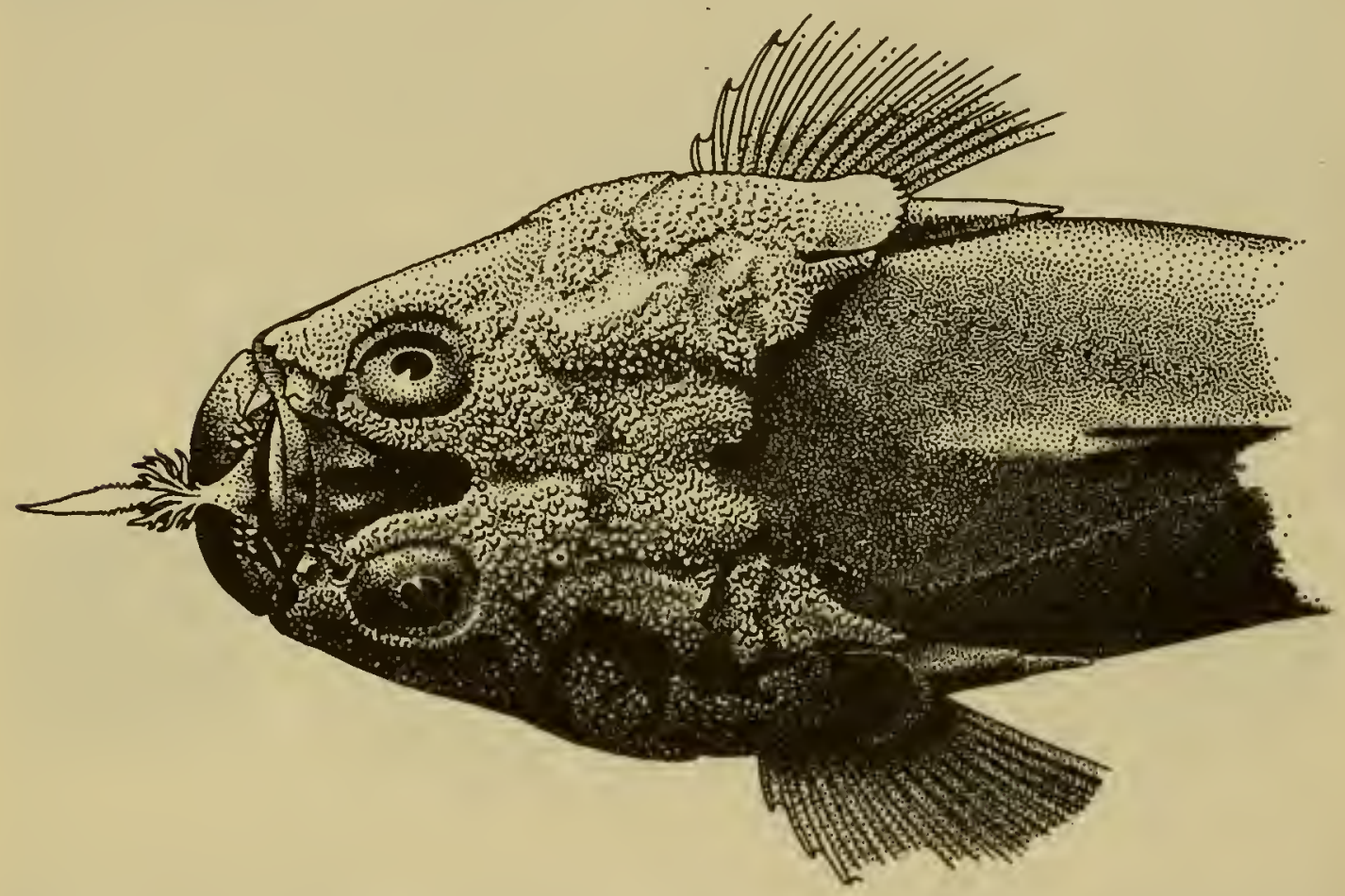

Fig. 57. Head of Uranoscopus scaber. Note the large spines protruding from the area just above the pectoral fins. Wounds from these spines can be fatal. (Smithsonian Institution)

Venom Apparatus. The venom apparatus of Siganus consists of 13 dorsal, 4 pelvic and 7 anal spines, and their associated venom glands. A groove extends along both sides of the midline of the spine for almost its entire length.. These grooves are generally deep and contain the venom glands, which are located in the outer one-third of the spine, near the tip.

Medical Aspects. The symptoms produced by rabbitfish stings are said to be the same as those produced by scorpionfishes. There is no information available regarding the nature of the venom. 
Treatment. See below for the treatment of venomous fish stings.

Prevention. In handling rabbitfishes, one should be careful to avoid being jabbed with the dorsal, pelvic or anal stings.

\section{STAR-GAZERS}

Star-gazers are bottom-dwelling marine fishes, members of the family Uranoscopidae, having a cuboid head, an almost vertical mouth with fringed lips, and eyes on the flat upper surface of the head. Uranoscopids spend a large part of their time buried in the mud or sand with only their eyes and a portion of the mouth protruding.

SPECIES OF STAR-GAZERS :

Star-Gazer or Mishmimaokoze, Uranoscopus japonicus Houttuyn (Fig. 56, Top). Inhabits southern Japan, southern Korea, China, Philippine Islands, and Singapore.

Star-Gazer, Uranoscopuś duvali (Bottard) (Fig. 56, Center). Inhabits the Indo-Pacific area.

Star-Gazer, Uranoscopus scaber (Linnaeus) (Fig. 56, Bottom). Inhabits the eastern Atlantic and Mediterranean Sea.

Venom Apparatus. The venom apparatus of Uranoscopus is said to consist of two shoulder spines, one on either side, each of which protrudes through a sheath of skin (Fig. 57). Venom glands are attached to these spines. The spine is said to have a double groove through which the venom flows.

Medical Aspects. There is no information available regarding the clinical characteristics of wounds produced by star-gazers. Wounds from the Mediterranean species, $U$. scaber, may be fatal.

Treatment. See below for the treatment of fish stings.

Prevention. Star-gazers should be handled with extreme care in order to avoid being jabbed by the shoulder spines.

\section{TREATMENT OF VENOMOUS FISH STINGS}

Efforts in treating venomous fish stings should be directed toward achieving three objectives: (1) alleviating pain, (2) combating effects of the venom, (3) preventing secondary infection. The pain results from the effects of the trauma produced by the fish spine, venom, and the introduction of slime and other irritating 
foreign substances into the wound. In the case of stingray and catfish stings, the retrorse barbs of the spine may produce severe lacerations with considerable trauma to the soft tissues. Wounds of this type should be promptly irrigated, or washed out with cold salt water or sterile saline if such is available. Fish stings of the puncture-wound variety are usually small in size, and removal of the poison is more difficult. It may be necessary to make a small incision across the wound, and then apply immediate suction, and possibly irrigation. At any rate, the wound should be sucked promptly in order to remove as much of the venom as possible. However, it should be kept in mind that fishes do not inject their venom in the manner employed by venomous snakes, so at best, results from suction will not be too satisfactory.

There is a division of opinion as to the advisability and efficacy of using a ligature in the treatment of fish stings. If used, the ligature should be placed at once between the site of the sting and the body, but as near the wound as possible. The ligature should be released every few minutes in order to maintain adequate circulation. Most doctors recommend soaking the injured member in hot water for 30 minutes to one hour. The water should be maintained at as high a temperature as the patient can tolerate without injury, and the treatment should be instituted as soon as possible. If the wound is on the face or body, hot moist compresses should be employed. The heat may have an attenuating effect on the venom since boiling readily destroys stingray venom in vitro. The addition of magnesium sulfate or epsom salts to the water is believed to be useful. Infiltration of the wound area with $0.5-2 \%$ procaine has been used with good results. If local measures fail to prove satisfactory, intramuscular or intravenous demerol will generally be efficacious. Following the soaking procedure, debridement and further cleansing of the wound may be desirable. Lacerated wounds should be closed with dermal sutures. If the wound is large, a small drain should be left in it for a day or two. The injured area should be covered with an antiseptic and sterile dressing.

Prompt institution of the recommended treatment usually eliminates the necessity of antibiotic therapy. If delay has resulted to any extent, the administration of antibiotics may be desirable. A course of tetanus antitoxin is an advisable precautionary measure.

The primary shock which follows immediately after the stinging generally responds to simple supportive measures. However, secondary shock resulting from the action of stingray venom on the cardiovascular system requires immediate and vigorous therapy. 
Treatment should be directed toward maintaining cardiovascular tone and the prevention of any further complications. Respiratory stimulants may also be required.

Another form of treatment is known as the L-C, or ligaturecryotherapy method. Immediately after being stung, the victim places a ligature between the site of the sting and the body at a point nearest the entrance of the venom, without making an incision. The hand or foot, as the case may be, including the ligature, is immersed in iced water. The ligature is removed after the member has been in iced water for not less than five, or more than ten, minutes, but the affected part must remain in the iced water for a minimum of two hours. There is said to be no danger of frostbite if iced water alone is used, but salt must not be added. This method has been employed several times in cases of stingray stings with reputedly good results.

\section{REPTILES}

\section{SEA SNAKES}

Much has been written regarding the subject of snakes, which are almost universally feared, particularly by those who lack knowledge concerning their habits. Sea snakes especially have been misunderstood by many persons and, unfortunately, very little factual information is available on their biology. However, it is known that all of them are highly venomous. Some species are said to contain a venom which is fifty times as potent as that of the king cobra, when tested upon laboratory animals. Fortunately, most sea snakes possess a rather poorly developed venom apparatus, and are fairly docile in their habits. Nevertheless, fatalities occur from time to time because of sea snake bites. Skin divers, working in areas inhabited by sea snakes, should be aware of the potential hazard and should take the necessary precautionary measures.

Sea snakes are highly specialized and maintain an exclusively aquatic life. They are members of the suborder Serpentes, and are, therefore, true snakes. Their bodies are covered by scales and have a complete absence of limbs, ear openings, sternum and urinary bladder. Their eyes are immobile, covered by transparent scales, and are without lids. The tongue is slender, forked, and protrusile. Sea snakes are further characterized by having a body more or less compressed posteriorly with a flat, paddle-shaped tail. Venom fangs are present and the maxillary teeth serve as hollow fangs. Most species seldom exceed a length of 3-4 ft., but some may attain a length of $9 \mathrm{ft}$., or more. 


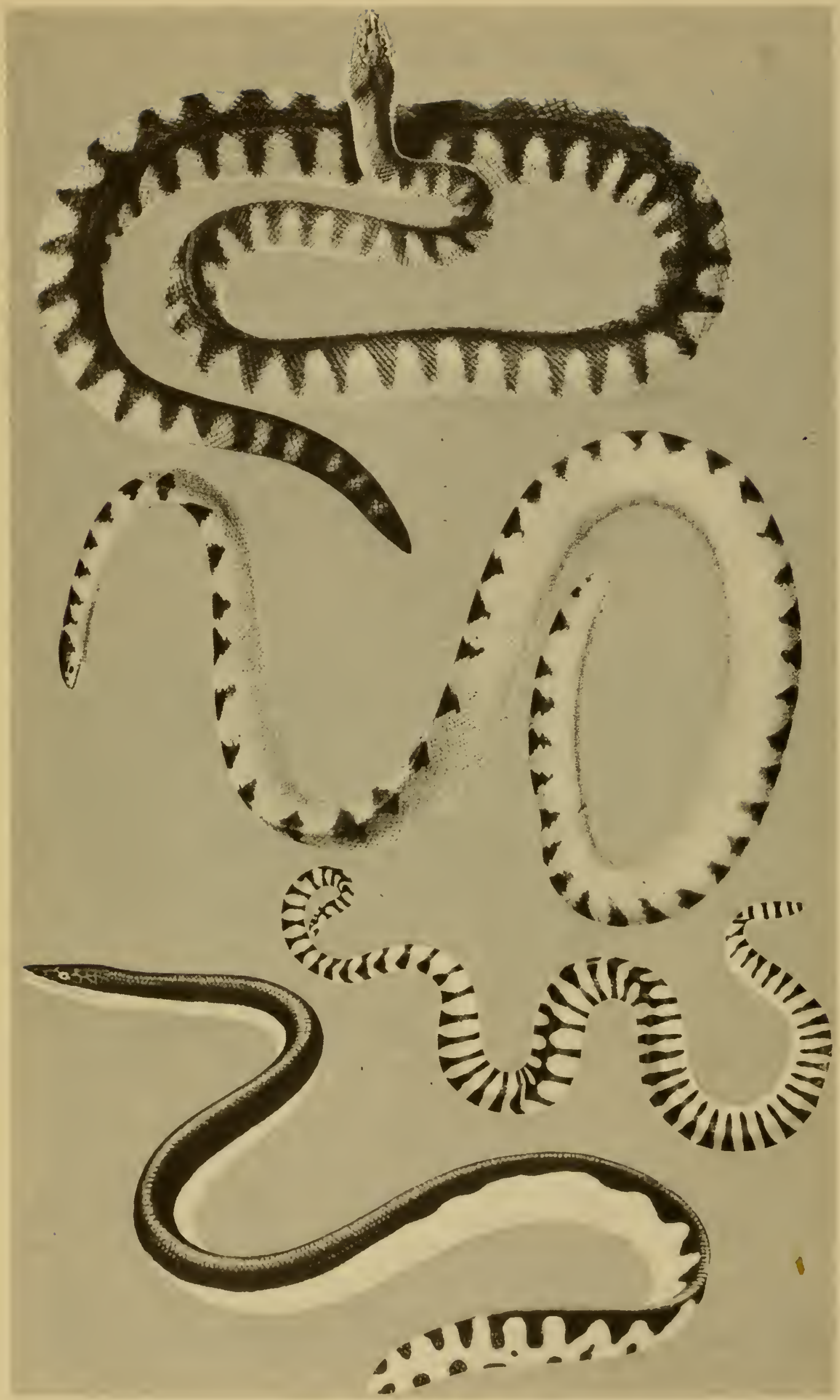

Fig. 58. See caption $\longrightarrow$ 
Habits of Sea Snakes. Sea snakes are primarily inhabitants of the tropical Pacific and Indian Oceans. With the exception of a single freshwater species, Hydrophis semperi Garman, which is found in the freshwater Lake Taal, Luzon, Philippine Islands, all are marine. Sea snakes are characteristically residents of sheltered coastal waters and are particularly fond of river mouths. However, some species of sea snakes have been observed from 100-150 miles from land. Pelamis platurus Linnaeus is the most widely distributed hydrophid species. Members of the genus Laticauda are said to be semi-terrestrial, and never venture far from the tide to which they return to feed. Sea snakes may sometimes appear swimming together, or breaking at the surface, in large numbers.

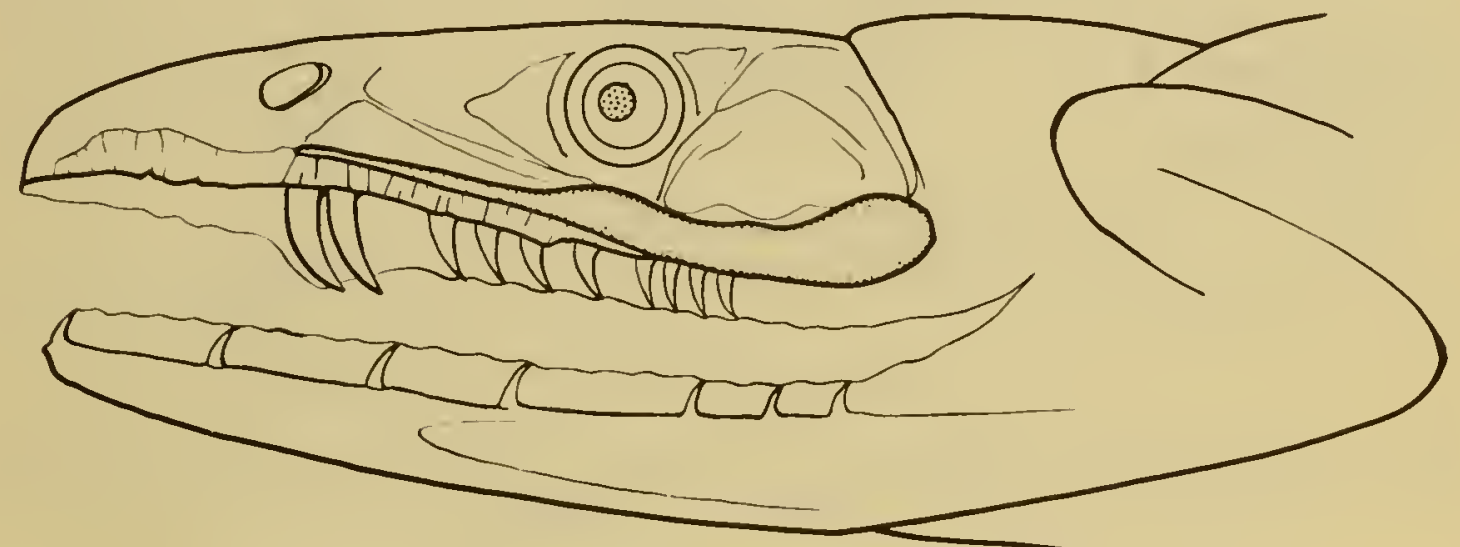

Fig. 59. Skull and fangs of the sea snake, Pelamis platurus. Note the venom gland, which is located just below the eye, emptying into the two anterior fangs.

With their compressed, oarlike tails, sea snakes are well adapted for locomotion in their marine environment. Instead of the imbricate position of the scales, such as is found in terrestrial snakes, most of the scales of hydrophids are juxtaposed and hexagonal in position, which further demonstrates an adaptation to an aquatic existence. Swimming is accomplished by lateral undulatory movements of the body. They have a remarkable ability to move backward or forward in the water with equal rapidity, but are awkward on land. Sea snakes are able to float on the surface of the ocean for long periods of time. It is reported that sea snakes are able to remain submerged for hours.

Sea snakes capture their food underwater, which consists almost entirely of fishes that are swallowed headfirst. A considerable portion of time is spent feeding on, or near, the bottom around rocks, in crevices where they capture eels and other small fishes, which they promptly kill with a vigorous bite of their venomous jaws.

Fig. 58. Top to bottom: Sea snake, Enhydrina schistosa (Daudin). Chittul or Banded Sea Snake, Hydrophis caerulescens (Shaw). Sea Snake, Hydrophis nigrocinctus Daudin. Yellow-bellied Sea Snake, Pelamis platurus (Linnaeus). 
There is disagreement regarding the disposition of sea snakes. Most persons reporting on the subject, and who have had first-hand experience with sea snakes, believe that they are generally docile. However, the aggressiveness varies somewhat from one species to the next. Enhydrina schistosa (Daudin) and Hydrophis cyanocinctus (Daudin) seem to be more pugnacious than some of the other species. In a series of 120 cases of sea snake bites that were studied, the largest number of attacks occurred while handling nets, sorting fishes, wading, washing, or accidentally stepping on the snake. Regardless of the reputed docility of sea snakes, it should be kept in mind that the venom is extremely potent and they should be handled with great care.

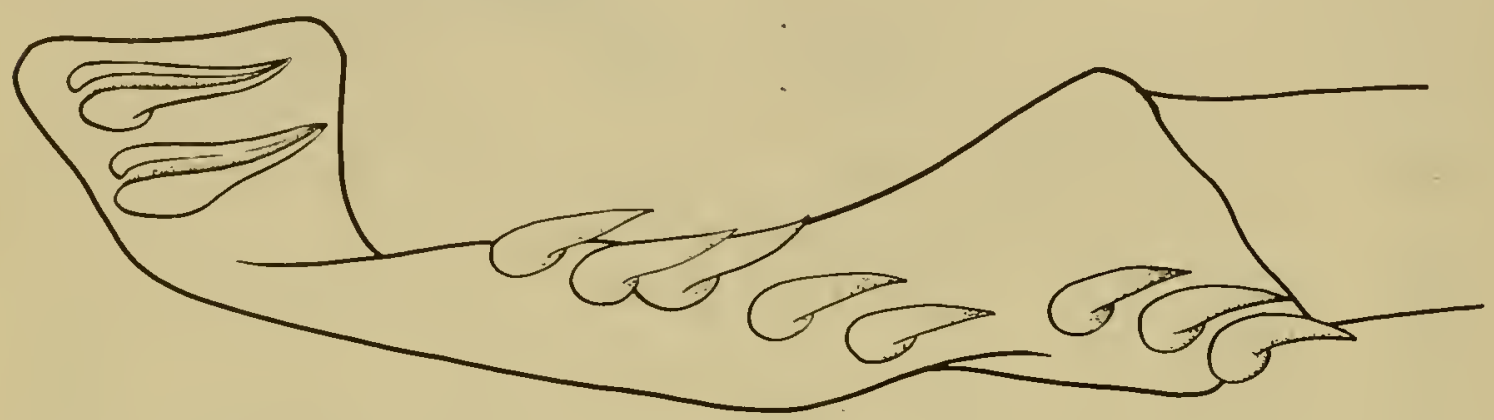

Fig. 60. Ventral view of front fangs of right upper jaw of the sea snake, Distira cyanocincta (Daudin).

\section{SPECIES OF SEA SNAKES :}

Sea Snake, Enhydrina schistosa (Daudin) (Fig. 58, Top). Inhabits the Persian Gulf to Cochin China and north coast of Australia.

Chittul, or Banded Sea Snake, Hydrophis caerulescens (Shaw) (Fig. 58, Next to Top). Ranges from the Persian Gulf to Japan, and the Netherlands Indies.

Sea Snake, Hydrophis nigrocinctus Daudin (Fig. 58, Next to Bottom). Inhabits the Bay of Bengal.

Yellow-Bellied Sea Snake, Pelamis platurus (Linnaeus) (Fig. 58, Bottom). This species has the greatest range of any sea snake, extending from East Africa, throughout the Indo-Australian area, eastward to the Gulf of Panama.

Although there are about 50 species of sea snakes, the ones listed are believed to be particularly dangerous to man.

Venom Apparatus. Sea snakes inflict their wounds with the use of fangs, which are reduced in size, but are of the cobra type (Fig. $59)$. In comparison with other venomous snakes, their dentition is relatively feeble but, nevertheless, fully developed for venom con- 
duction. The venom apparatus consists of the venom glands and fangs. The venom glands are situated, one on either side, behind and below the eye, and in front of the tympanic bones. They are ovate and have an elongate venom duct which terminates at the base of the fangs. Most sea snakes have two fangs on each side but some have only one. The venom duct enters at the base of the fang through a relatively broad, triangular opening of the canal (Fig. 60) and (Fig. 61).

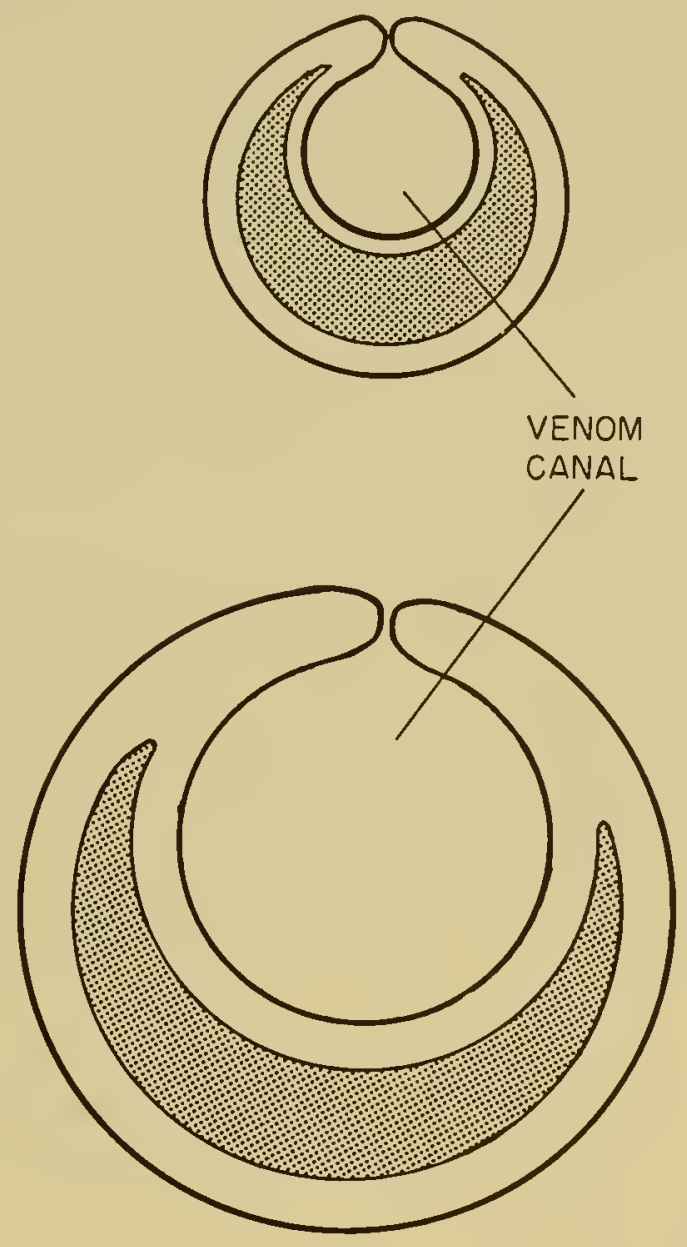

Fig. 61. Cross section through the fangs of the sea snake, Enhydris hardwicki. Note the canal through which the venom passes.

Medical Aspects. Symptoms caused by the bite of a sea snake characteristically develop rather slowly, taking from 20 minutes to several hours, but usually about one hour, before definite symptoms begin. Aside from the initial prick, there is no pain nor reaction at the site of the bite. The victim may even fail to connect the bite with his illness.

In some instances, the initial generalized symptoms are a mild euphoria, whereas in others, there is aching and anxiety. A sensation of thickening of the tongue and a generalized feeling of stiff- 
ness of the muscles gradually develops. Common complaints during the early stage are "aching", "stiffness", or pain upon movement. There may be little indication of actual weakness at this time. The paralysis which soon follows is usually generalized, but of the ascending type, beginning with the legs, and within an hour or two, involving the trunk, arm and neck muscles. Lockjaw is one of the outstanding symptoms. Drooping of the eyelids is an early and characteristic sign. The pulse becomes weak, irregular, and the pupils dilated. Speaking and swallowing become increasingly difficult. Thirst, burning, or dryness of the throat may also be present. Nausea and vomiting are not uncommon. Muscle twitchings, twisting movements, and spasms have been noted. Ocular and facial paralysis may later develop. In severe intoxication, the symptoms become progressively more intense, the skin of the patient is cold, clammy, cyanotic, convulsions begin, and are frequent, respiratory distress becomes very pronounced, and finally the victim succumbs in an unconscious state. The overall mortality rate has been estimated to be about 25 per cent.

Treatment. The routine incision and suction method as generally used in the treatment of snake bites is not recommended. The victim should avoid all possible exertion. Make the victim lie still. A tourniquet should be applied to the thigh in leg bites, or to the arm above the elbow in bites of the hand or wrist. The tourniquet should be released every 30 minutes. Keep in mind that you cannot cut off the blood supply to an appendage then just walk off and leave it. Transport the victim to the nearest first aid station or hospital as soon as possible. Do not make him walk. The snake should be captured and sent to the hospital for identification. This is a very important step in snake bite treatment. The snake may be a harmless water snake.

Antivenin therapy should be administered promptly upon arrival at the first aid station. A polyvalent antiserum containing a krait (Elapidae) fraction should be used. There is no specific antiserum for sea snake venom at the present time. The following may be of interest to the attending physician. Twenty $\mathrm{ml}$. of antiserum should be slowly injected intravenously. This should be preceded by cortisone to prevent serum reactions which are frequent, and may be severe. Epinephrine may be required if the cortisone fails to control the situation during the initial stages of a serum reaction. Supportive therapy should be given to prevent secondary shock.

Bed rest should continue until all indications of envenomation 
have passed. The patient should remain in the hospital for a minimum of 24 hours. Additional antiserum may be required. It is important that the patient be given continual reassurance. An adequate maintenance of fluid and electrolyte balance is required. Vomiting and increased sweating should be noted on the patient's chart. Antibiotic therapy may be required to control infection. If sedatives are required, a barbiturate or intramuscular paraldehyde is recommended. Because of their respiratory depressant effects, morphine and its derivatives are contraindicated. Feeding by gastric intubation, or intravenous fluids, may be required because of lockjaw. In the event of respiratory paralysis, the management of the case will be similar to that of bulbar poliomyelitis, and may require intubation, tracheotomy, and the aid of a respirator. Delayed effects from sea snake venom are unknown; if recovery occurs, it is rapid and complete.

Prevention. The bulk of recorded attacks have occurred among fishermen working with their nets in the vicinity of river mouths. In most instances, the attacks have resulted because of provocation of the snake. Individuals wading, and divers working, around rocky crevices, piers, and old tree roots inhabited by sea snakes should be aware of the danger. Despite the reputed docility of sea snakes, an attempt should be made to avoid handling or coming in contact with them. If bitten, try to exercise as little as possible and seek immediate medical help.

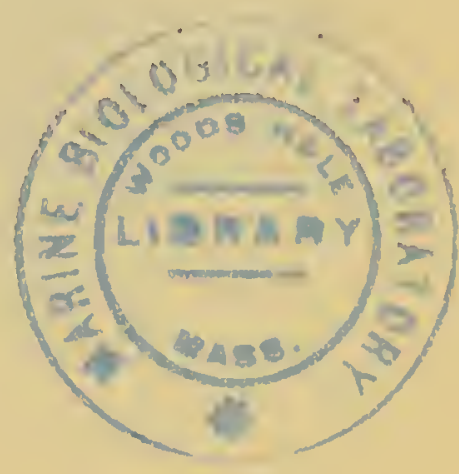




\section{MARINE ANIMALS THAT ARE POISONOUS TO EAT}

In the skin diver's quest for new adventures, many are finding that the "pastures on the other side of the fence" contain warmer and clearer water, and more abundant sea life. Venturing into strange tropical waters is not without some danger. In this chapter we are not concerned about what might hurt us from without, but rather the dangers from within-those sea foods likely to be eaten by the skin diver while in the field. Fortunately, most sea foods are. edible and nourishing, but there are those which are known to contain some of the most violent organic chemical poisons known to science. Note that we are not discussing illnesses due to bacterial food poisoning, but rather, a group of marine animals whose flesh, under certain circumstances, may contain poisonous chemical substances. It is to some of these toxic agents that we will direct our attention.

There are two major groups of marine organisms poisonous to eat. They are (1) molluscs, and (2) fishes. In rare instances, sea turtles and certain marine mammals have also caused serious poisonings.

\section{POISONOUS MOLLUSCS}

Under ordinary circumstances, most molluscs, or shellfish, are edible. However, at certain seasons of the year, bivalve molluscs may feed on poisonous microscopic marine animals, called dinoflagellates. The red tide phenomenon in which extensive areas of water take on a reddish hue and kill off large numbers of fishes, is a good example of some of these effects. The discoloration of the water is due to the presence of these minute creatures in great abundance. There are many different species of dinoflagellates, and several kinds of poisons are produced. The poison affecting fishes is probably a different one than that causing paralytic shellfish poisoning in man. Toxic dinoflagellates are ingested by the molluscs and the toxic materials are stored in various parts of the body of the shellfish. Strange to say, the poison is lethal to man, but does not seem to affect the mollusc. If a person should eat one of these molluscs containing a sufficient amount of the poison, violent intoxication, or death, may result. The toxicity of the shellfish is, therefore, dependent upon the food that it eats. 


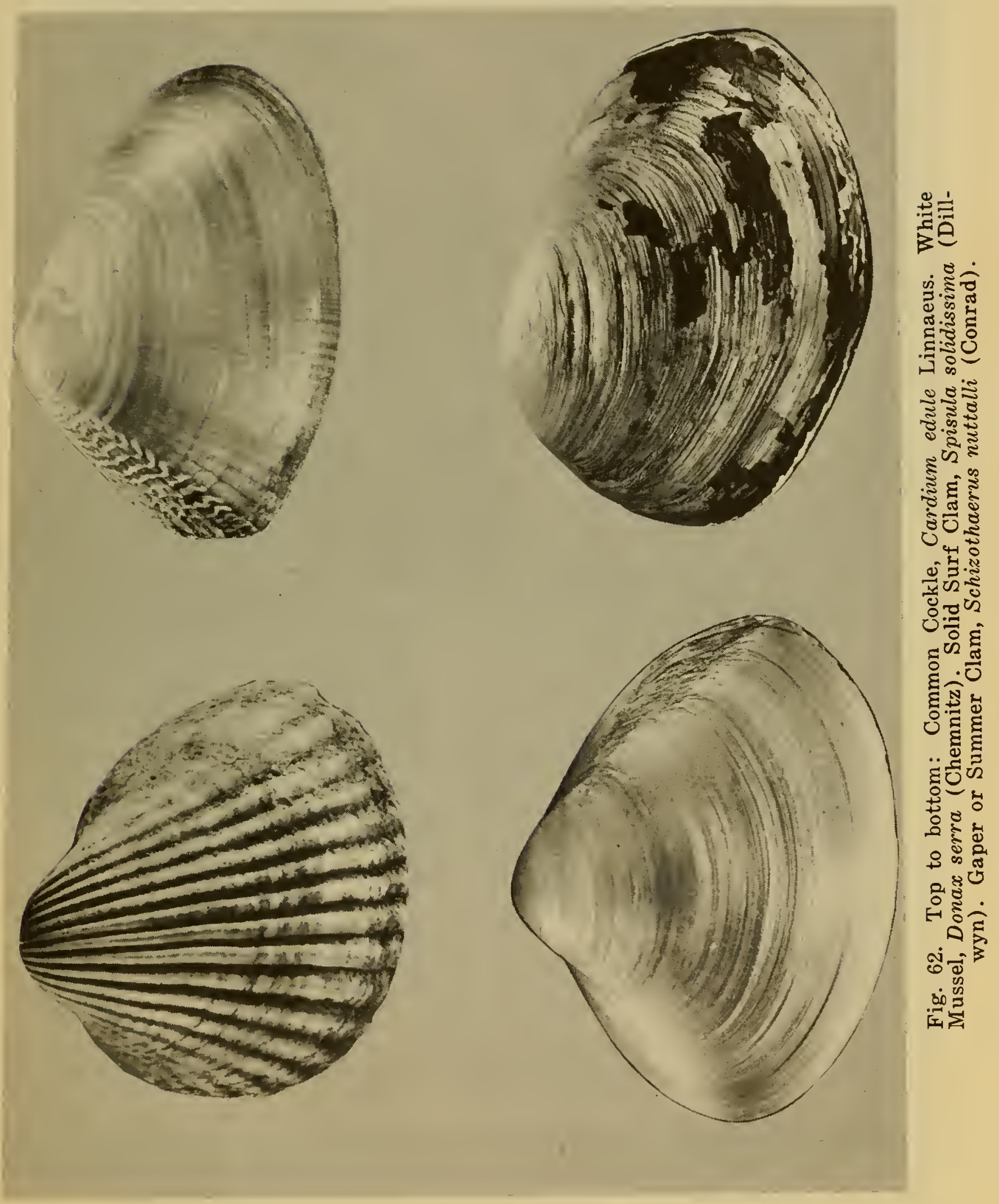




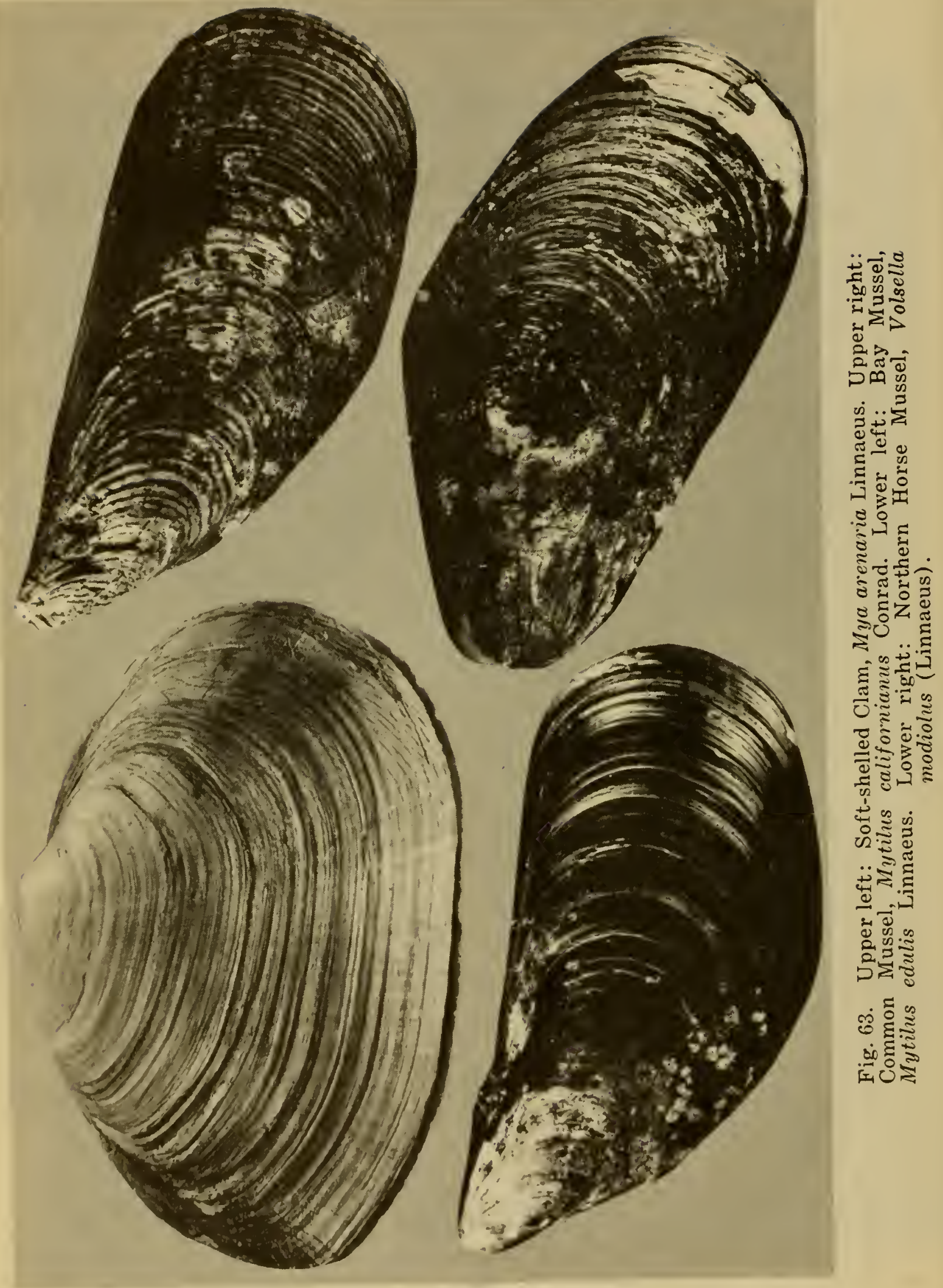




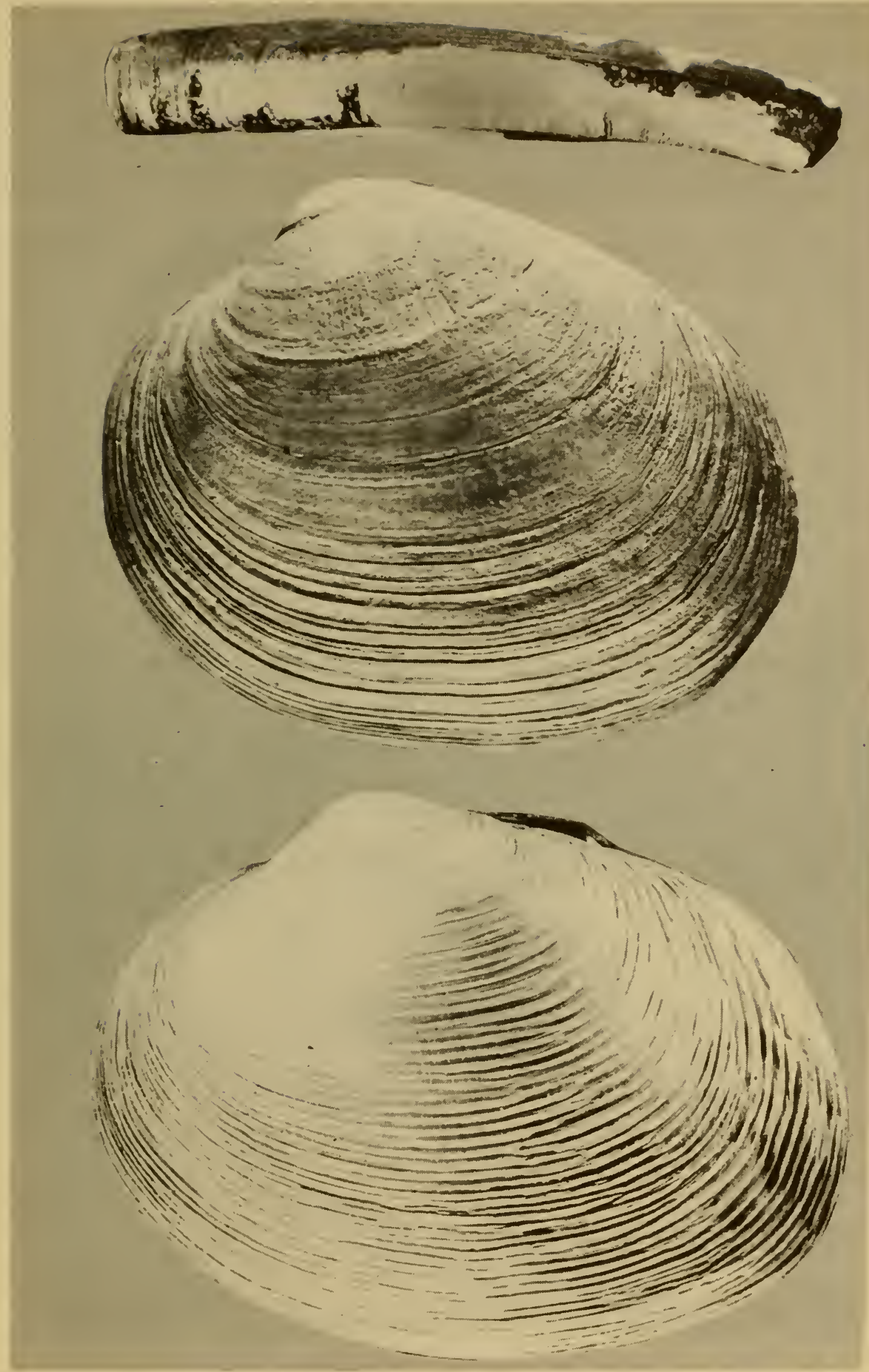

Fig. 64. Top: Atlantic Jackknife or Razor Clam, Ensis directus Conrad. Center: Smooth Washington or Butter Clam, Saxidomus giganteus (Deshayes). Bottom: Common Washington or Butter Clam, Saxidomus nuttalli Conrad. 


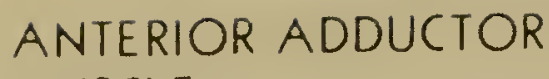
MUSCLE
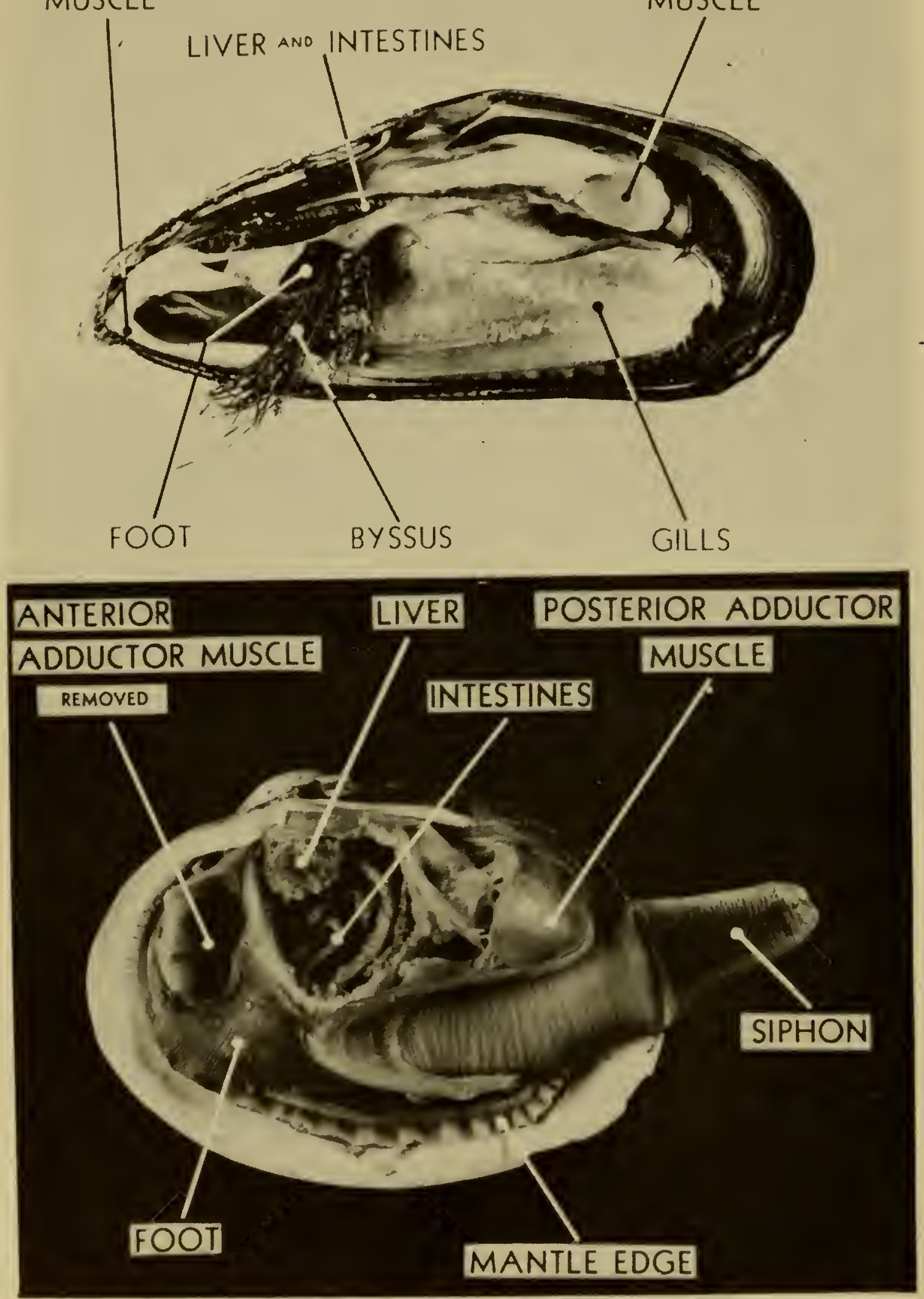

Fig. 65. Internal anatomy of shellfish, showing parts of the body likely to contain paralytic shellfish poison. Top: Mussel, Mytilus. Liver and intestines (dark meat) and gills are the most dangerous parts to eat. Bottom: Butter Clam, Saxidomus. The poison is concentrated primarily in the siphon. (Kreuzinger) 
The number of toxic dinoflagellates in the water varies according to the season of the year and the abundance of nutrient chemical substances that are available in the water. It has been observed over a period of time that the dangerous period of the year is during the warm season, which varies somewhat, but, in most instances, is from March to November. It is during the warm period of the year that dinoflagellates multiply. The Alaskan butter clam, Saxidomus giganteus (Deshayes), is somewhat of an exception to this rule, in that dangerous toxicity levels may occur at almost any time of the year.

Localities in which paralytic shellfish poisoning has occurred are: the Pacific coast of North America, from the Gulf of California to Alaska; New Brunswick and Nova Scotia, Canada; along the Coasts of Norway, England, Germany, Belgium, Netherlands, France; South Africa, and New Zealand.

SPECIES OF SHEllfish Most Commonly Involved in Human

POISONINGS :

Common Cockle, Cardium edule Linnaeus (Fig. 62, Top Left). Inhabits European Seas.

White Mussel, Donax serra (Chemnitz) (Fig. 62, Top Right). Inhabits South Africa.

Solid Surf Clam, Spisula solidissima (Dillwyn) (Fig. 62, Lower Left). Occurs from Labrador to North Carolina.

Gaper or Summer Clam, Schizothaerus nuttalli (Conrad) (Fig. 62, Lower Right). Found from Prince William Sound, Alaska, south to Scammons Lagoon, Baja California, and northern Japan.

Soft-Shelled Clam, Mya arenaria Linnaeus (Fig. 63, Top Left). Inhabits Britain, Scandinavia, Greenland, Atlantic coast of North America, south to Carolina; Alaska, south to Japan, and Vancouver, British Columbia; California and Oregon coasts.

Common Mussel, Mytilus californianus Conrad (Fig. 63, Top Right). Inhabits Unalaska, Aleutian Islands, eastward and southward to Socorro Island.

Bay Mussel, Mytilus edulis Linnaeus (Fig. 63, Lower Left). Ranges from the Arctic Ocean to South Carolina, Alaska to Cape San Lucas, Baja California; practically worldwide in temperate waters.

Northern Horse Mussel, Volsella modiolus (Linnaeus) (Fig. 63, Lower Right). Found along the Pacific Coast of America from the Arctic Ocean to San Ignacio Lagoon, Baja California; circumboreal.

Atlantic Jackknife, or Razor Clam, Ensis directus Conrad (Fig. 64, Top). Ranges from the Gulf of St. Lawrence River to Florida. 
Smooth Washington, or Butter Clam, Saxidomus giganteus (Deshayes) (Fig. 64, Center). Ranges from Sitka, Alaska, to San Francisco Bay, California.

Common Washington, or Butter Clam, Saxidomus'nuttalli Conrad (Fig. 64, Bottom). Ranges from Humbolt Bay, California to San Quentin Bay, Baja California.

Medical Aspects. There are three types of shellfish poisoning that are recognized by physicans, they are: (1) Gastrointestinal typecharacterized by such symptoms as nausea, vomiting, diarrhea, and abdominal pain. This type usually develops about 10-12 hours after eating the shellfish, and is believed to be caused by bacterial contamination; (2) Allergic type-characterized by redness of the skin, swelling, development of a hive-like rash, itching, headache, nasal congestion, abdominal pain, dryness of the throat, swelling of the tongue, palpitation of the heart, and difficulty in breathing. This type probably results from a sensitivity to shellfish on the part of the individual; (3) Paralytic type-this last type is caused specifically by the dinoflagellate poison present in shellfish. The disease has also been termed clam, mussel, or gonyaulax poisoning (after the scientific name of one of the causative dinoflagellates of the poisoning, namely, Gonyaulax catenella Whedon and Kofoid). The early symptoms are a tingling or burning sensation of the lips, gums, tongue, and face, which gradually spreads elsewhere to the body. The tingling areas later become numb, and movements of the muscles of the body may become very difficult. Other symptoms frequently present are weakness, dizziness, joint aches, increased salivation, intense thirst, difficulty in swallowing. Nausea, vomiting, diarrhea, and abdominal pain are relatively rare. The muscular paralysis may become increasingly severe until death ensues.

Treatment. There is no specific treatment available; no known antidotes. Evacuation of the gastrointestinal tract should be instituted as soon as possible. Vomiting can be stimulated by swallowing large quantities of salt water, egg white, or by merely placing one's finger down the throat. Alkaline fluids such as ordinary baking soda, are said to be of value since the poison is rapidly destroyed by that medium. Artificial respiration may be required. See a physician at once, if you are fortunate enough to be near a doctor.

Prevention. The extremely toxic nature of this poison cannot be over-emphasized. One should adhere strictly to local quarantine regulations-they are for your protection. Poisonous shellfish cannot be detected by their appearance, smell, or by discoloration 
of a silver object or garlic placed in the cooking water, etc. ad infinitum. It is only by careful scientific laboratory procedures that this poison can be determined with any degree of certainty.

The digestive organs, or dark meat, gills, and in some shellfish species, the siphon, contain the greatest concentration of the poison (Fig. 65). The musculature or white meat is generally harmless; however, it should be thoroughly washed before cooking. The broth, or bouillon, in which the shellfish is boiled is especially dangerous since the poison is water soluble, and should be discarded if there is the slightest doubt. The tidal location from which the shellfish were gathered cannot be used as a criterion as to whether the shellfish are safe to eat. Poisonous shellfish may be found in either low or high tidal zones. If in doubt-throw out!

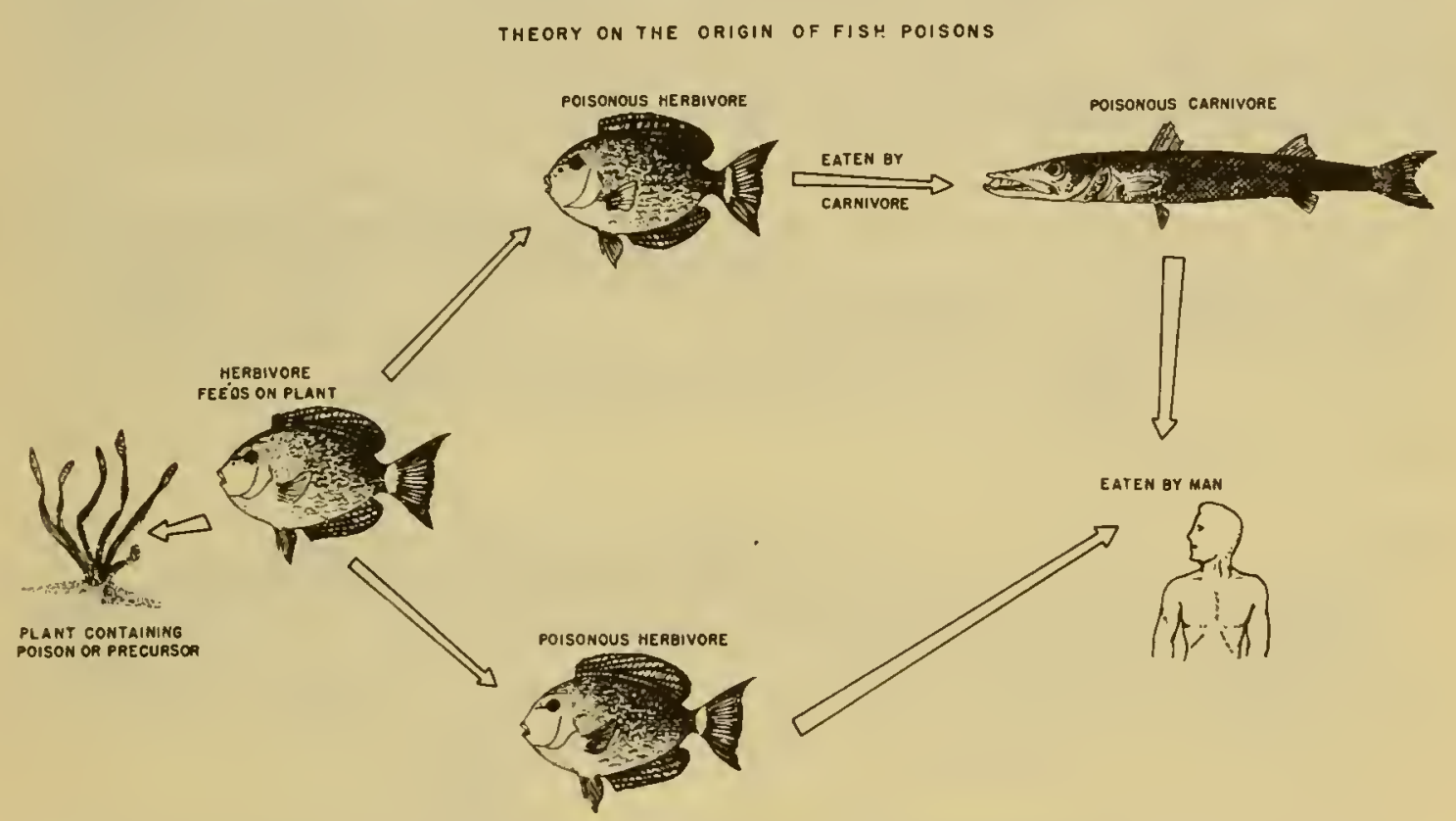

Fig. 66. Diagram illustrating theory as to the origin of fish poisons.

\section{POISONOUS FISHES}

The problem of poisonous fishes is an exceedingly complex one, and is quite mystifying to most persons encountering these organisms. One of the difficult things to understand is how a valuable food fish in one locality can be so poisonous in another. Nevertheless, this is the situation that exists. The dual personality of these fishes has caused much confusion both in medical literature and among laymen in the field. The fact that a person may have eaten a particular fish on hundreds of occasions and never found it to be poisonous is no guarantee that this same fish under slightly differ- 
ent circumstances, or in some other locality, will not produce violent intoxication and rapid death.

The big question is how do fish become poisonous, and what are the factors contributing to the condition? All of the details as to exactly how fishes become poisonous are not known at present. However, it is believed that in most instances fishes become poisonous because of their feeding habits. The poison is believed to originate in a marine plant. Plant-eating fishes feed on these plants containing the necessary chemical substances, and the poison is either accumulated or manufactured in the body of the fish. Carnivorous fishes feed on the plant-eating fishes, and the poison is thereby distributed to other groups of fishes. As in the case of paralytic shellfish poison the toxic materials do not affect the fish, but are lethal to man when sufficient quantity of the material is eaten (Fig. 66). Scombroid poison develops in an entirely different manner, and this will be discussed later in the chapter.

Poisonous fishes are widely distributed throughout the world, but occur in greatest number's in tropical waters, particularly in the West Indies and the tropical Pacific. Poisonous puffers, which are extremely toxic, may be found in temperate areas, and the Greenland shark, which under certain circumstances is poisonous, is found in Arctic seas.

\section{TYPES OF FISHES POISONOUS TO EAT}

There are currently recognized eight general categories of marine fishes'whose flesh is dangerous to eat. However, only five of them are of practical significance to the average person.

\section{POISONOUS SHARKS AND RAYS}

A number of deaths and many illnesses have been reported from the eating of sharks and rays. Most illnesses have been caused by tropical species, and the most severe poisonings have resulted from eating the livers of tropical sharks. However, the flesh of the Greenland shark, Somniosus microcephalus, Bloch and Schneider, which inhabits Arctic waters, has been observed on numerous occasions to cause intoxications in both humans and sled dogs. The chemical nature of these poisons is not known.

SPECIES REPORTED POISONOUS:

Black-Tipped Sand Shark Carcharhinus melanopterus (Quoy and Gaimard) (Fig. 67, Top). Indo-Pacific, South Africa to the East Indies, Hawaiian, Tuamotu, and Marianas Islands. 
Seven-Gilled Shark (Heptranchias perlo Bonnaterre) (Fig. 67, Next to Top). East and west Atlantic, Mediterranean, Cape of Good Hope, Japan.

Greenland Shark Somniosus microcephalus (Bloch and Schneider) (Fig. 67, Next to Bottom). Arctic Atlantic, North Sea east to the White Sea and west to the Gulf of St. Lawrence, Greenland.

Six-Gilled Shark Hexanchus grisseus (Bonnaterre) (Fig. 67, Bottom). Atlantic, Pacific coast of North America, Chile, Japan, Australia, Southern Indian Ocean and South Africa.
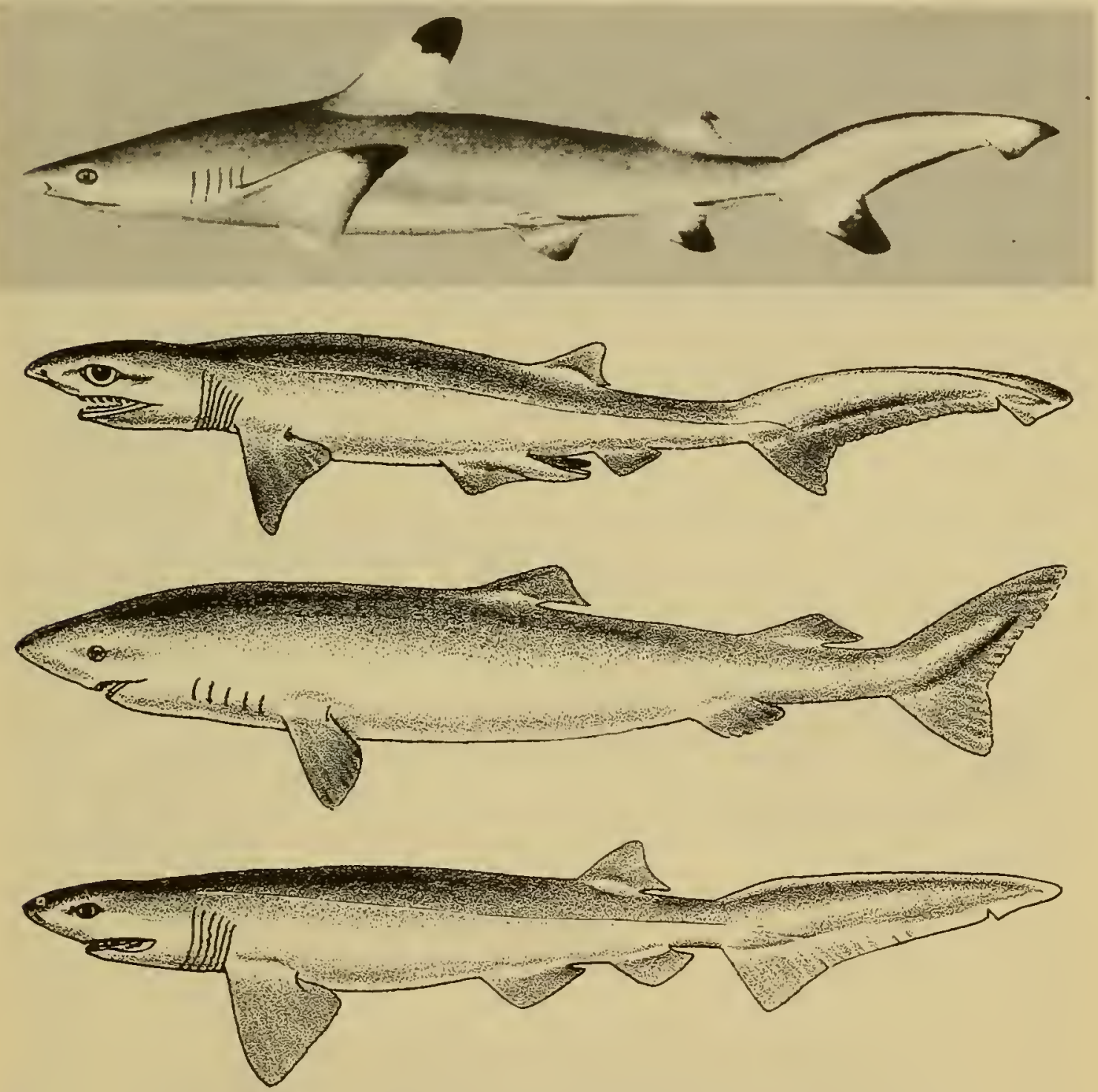

Fig. 67. Top to bottom: Black-tipped Sand Shark, Carcharhinus melanopterus (Quoy and Gaimard). Seven-gilled Shark, Heptranchias perlo (Bonnaterre). Greenland Shark, Somniosus microcephalus (Bloch and Schneider). Six-gilled Shark, Hexanchus grisseus (Bonnaterre). (Baergh)

White Shark Carcharodon carcharias (Linnaeus) (Fig. 2). Cosmopolitan, in tropical, subtropical and warm-temperate belts of all oceans. 


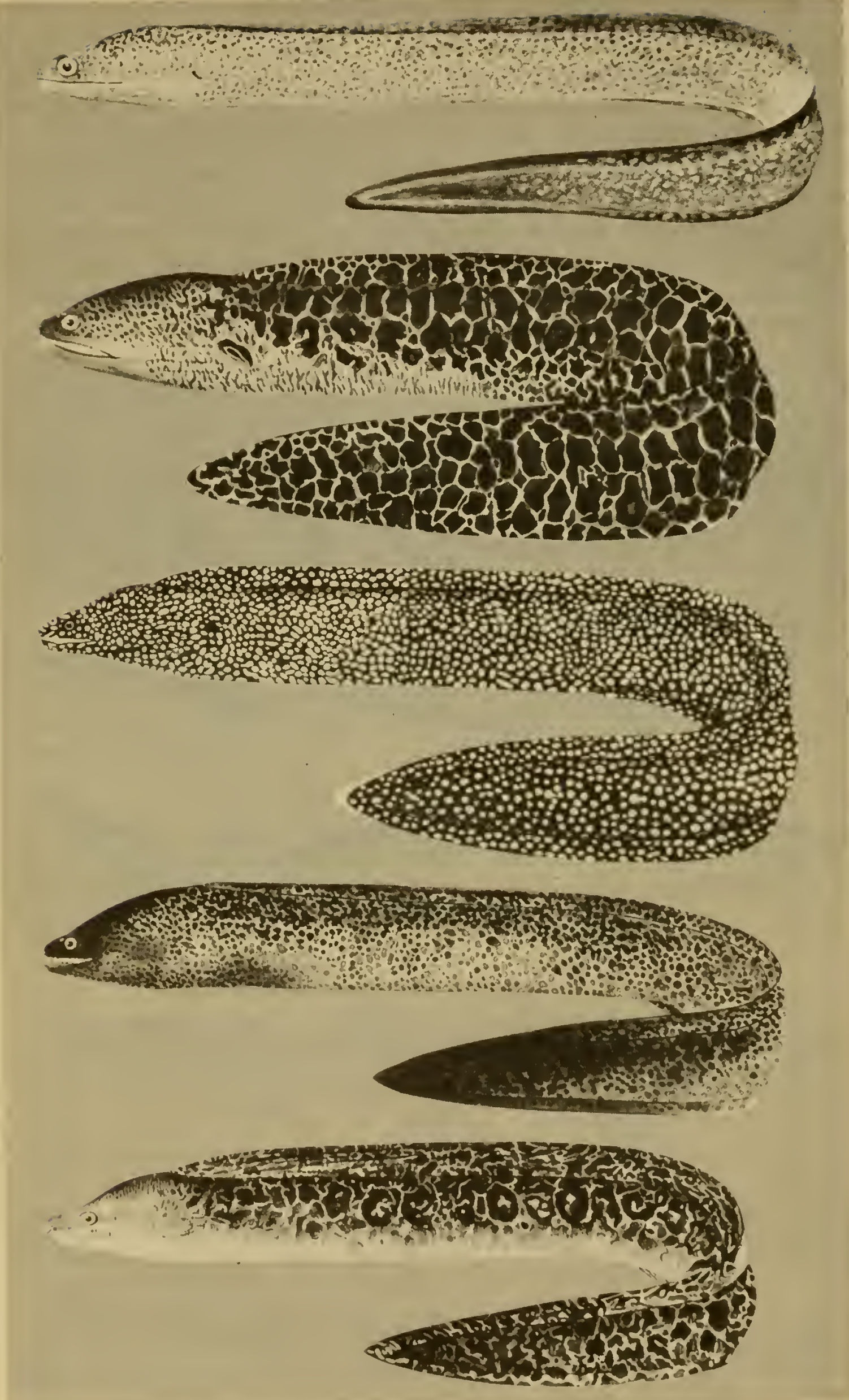

Fig. 68. See caption $\longrightarrow$ 
Hammerhead Shark (Sphyrna zygaena Linnaeus) (Similar to Fig. 4, Bottom). Tropical to warm-temperate belt of the Atlantic and Pacific Oceans.

Medical Aspects. The most severe forms of poisoning usually result from the eating of the liver. The musculature in most instances is only mildly toxic with the symptoms seldom more than that of a mild gastrointestinal upset, with a predominating diarrhea. Symptoms from liver poisoning usually develop within 30 minutes, and consist of nausea, vomiting, diarrhea, abdominal pain, headache, joint aches, tingling about the mouth, and a burning sensation of the tongue, throat, and esophagus. As time goes on, the nervous symptoms may become progressively severe, resulting in muscular incoordination and difficulty in breathing due to muscular paralysis, coma, and finally death.

Treatment. See Page 126 on the treatment of fish poisoning.

Prevention. Avoid eating the liver of any shark unless it is known with certainty to be edible. The livers of large tropical sharks are said to be especially dangerous. The flesh of tropical and arctic sharks should be indulged in only with caution.

\section{POISONOUS MORAY EELS}

The marine eels which have been reported in human intoxications have been largely members of the family Muraenidae, the moray eels. Some of these eels may attain a length of ten feet or more, and are heavy-bodied. All of the species involved in human poisonings are inhabitants of tropical reefs. Most of the reported poisonings have occurred from persons eating the flesh. Eel soup is a particularly dangerous form of preparing the fish, since the poison is readily water soluble.

SPECIES REPORTED POISONOUS:

Moray Eel, Gymnothorax flavimarginatus (Rüppell), (Fig. 68, Top). Hawaiian Islands, westward to East Africa.

Moray Eel, Gymnothorax javanicus (Bleeker) (Fig. 68, Next to Top). Hawaiian Islands, westward to East Africa.

Moray Eel, Gymnothorax meleagris (Shaw and Nodder) (Fig. 68, Center). Hawaiian Islands, westward to East Africa, Japan south to Australia.

Fig. 68. Top to bottom: Moray eel, Gymnothorax flavimarginatus (Rüppell). Moray Eel, Gymnothorax javanicus (Bleeker). Moray Eel, Gymnothorax meleagris (Shaw and Nodder). Moray Eel, Gymnothorax pictus (Ahl). Moray Eel, Gymnothorax undulatus (Lacépède). (Arita) 
Moray Eel, Gymnothorax pictus (Ahl) (Fig. 68, Next to Bottom). Polynesia to East Africa.

Moray Eel, Gymnothorax undulatus (Lacépède) (Fig. 68, Bottom). Hawaiian Islands to the Red Sea and East Africa.

Medical Aspects. The initial symptoms consist of tingling and numbness about the lips, tongue, hands, and feet, with a feeling of heaviness in the legs. This may be followed by nausea, vomiting, diarrhea, abdominal pain, joint aches, metallic taste, difficulty in swallowing, foaming at the mouth, intense sweating, muscular incoordination, lockjaw, violent convulsions and difficulty in breathing, due to muscular paralysis. About 10 per cent of the victims suffering from moray eel poisoning die. The recovery period in the mild cases extends over a long period of time.

Treatment. See Page 126 for the treatment of fish poisoning.

Prevention. Do not eat tropical moray eels. Even some of the socalled "safe" species may at times be violently poisonous.

\section{POISONOUS SCOMBROID FISHES}

Tuna, Bonito, Mackerel, Skipjack, etc.

This heading is somewhat misleading in that all of the fishes listed are, under most circumstances, edible. In this particular instance, the poisoning is due directly to inadequate preservation of the fish. This category of fishes is included, however, because of the danger that may come from eating stale scombroid fishesparticularly in tropical areas.

Fishes normally contain a chemical constituent in their flesh, called histidine. When histidine is acted upon by bacteria, this substance apparently changes into a histamine-like substance called saurine, which can cause illness in humans that resembles a severe allergy. This histamine-like substance is produced when scombroid fishes are left to stand at room temperature, or out in the sun for several hours. For some unknown reason, scombroid fishes seem to be more susceptible to becoming toxic by this means than most other types of fishes.

A list of the species will not be given, since any of the tuna, skipjack, bonito, mackerel, sierra, Spanish mackerel, etc. (Fig. 79, Next to Top) may be involved. Representatives of these fishes are world-wide in their distribution.

Medical Aspects. The symptoms of acute scombroid poisoning resemble those of a severe allergy. Frequently, poisonous scom- 
broid flesh can be detected immediately upon tasting it. Victims state that it has a "sharp, or peppery" taste. Symptoms develop within a few minutes after eating the fish, and consist of intense headache, dizziness, throbbing of the large blood vessels of the neck, feeling of dryness of the mouth, thirst, palpitation of the heart, difficulty in swallowing, nausea, vomiting, diarrhea, and abdominal pain. Within a short time, the victim develops massive red welts which are accompanied by intense itching. There is danger of shock, and deaths have been reported. Generally, the acute symptoms last only 8-12 hours, followed by rapid recovery.

Treatment. In addition to such routine procedures as evacuation of the stomach and catharsis, the use of any of the ordinary antihistaminic drugs will be found to be effective.

Prevention. Under most circumstances the eating of scombroid fishes is without danger as long as they are properly preserved. Commercially canned fish are without the slightest danger. Scombroids should be either promptly eaten soon after capture, or preserved by canning or by freezing as soon as possible. Fish left in the sun for longer than two hours should be discarded. Examine the fish before eating, if there is any evidence of staleness, such as pallor of the gills, or an off-odor, discard the fish.

\section{POISONOUS PUFFER-LIKE FISHES}

This group includes the puffer-like fishes, or members of the order Tetraodontoidea, which is comprised of ocean sunfishes, sharpnosed puffers, the puffers proper, and the porcupine fishes. The puffers proper, are our greatest offenders, and there are about 90 , or more, species of them. A characteristic of all puffers is their remarkable ability to inflate themselves by gulping in large quantities of water or air. Puffers make considerable noise during inflation by grinding their heavy jaw teeth together. Some of them can, and do, inflict nasty bites. Puffers have a distinctive offensive odor, which is particularly noticeable when they are being dressed.

These fishes are among the most poisonous of all marine creatures, and must be treated with respect. The liver, gonads, intestines, and skin usually contain a powerful nerve poison, which may produce rapid and violent death. The flesh, or musculature, of the flesh is generally edible. Strange to say, despite the great toxicity of this fish, it commands the highest prices in Japan as a food fish. Puffers, called fugu in Japan, are prepared and sold in special restaurants, which hire specially trained fugu cooks. The fugu is 
given careful treatment so as to eliminate the danger of eating it. Nevertheless, it is still the number one cause of fatal food poisoning in Japan-especially among the lower classes, who fail to take the necessary precautions. At best, eating puffer is a game of Russian roulette. Unless you feel that you are a professional fugu connoisseur, leave puffers alone-you will probably live longer.

Although puffers are most numerous in the tropics, many species do extend into temperate zones (Fig. 69). Puffers can be recognized by their characteristic shape and large teeth. The following list of species will serve to represent some of the more poisonous tetraodontoid fishes.

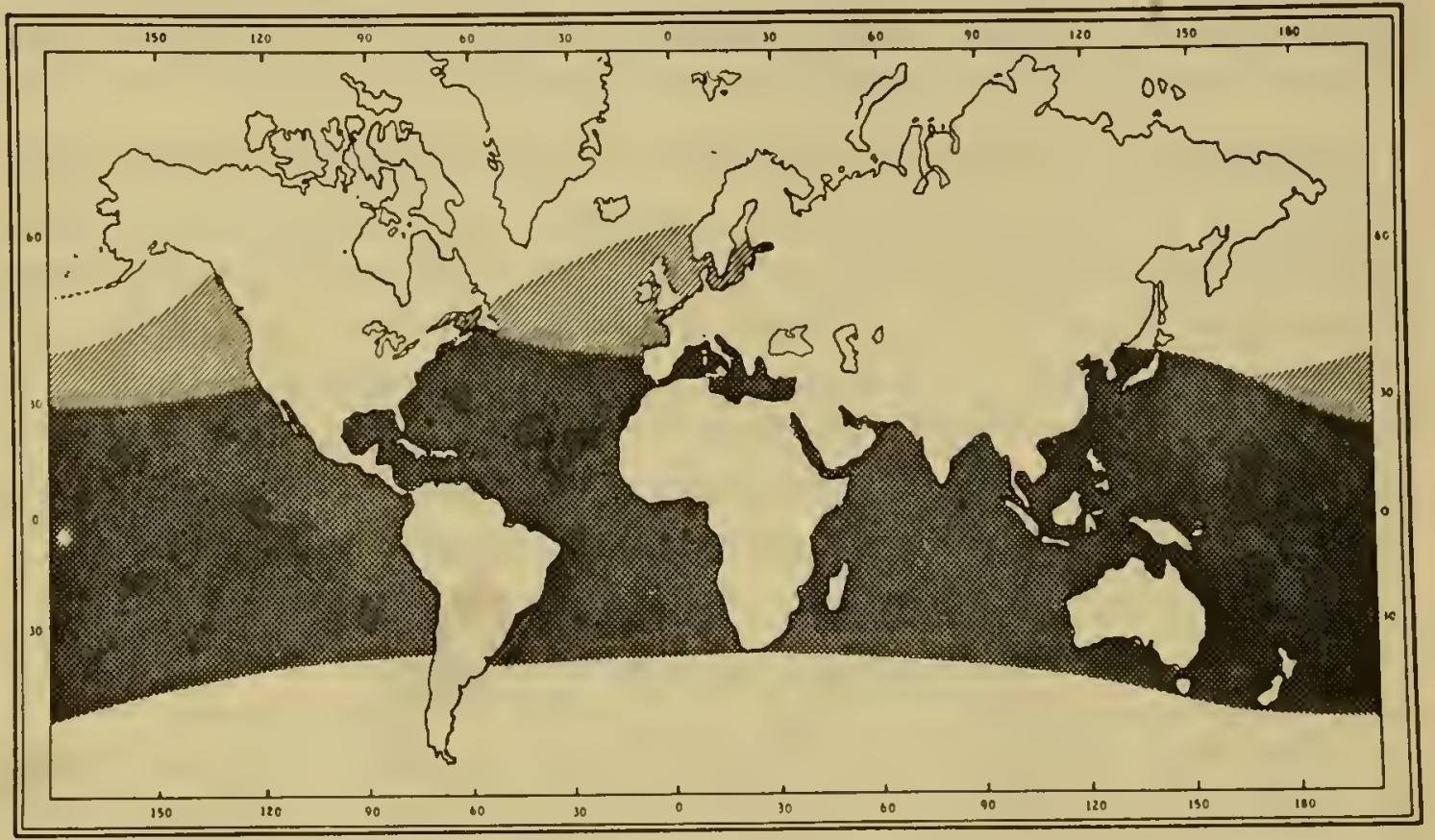

Fig. 69. Map showing the geographical distribution of puffers, and puffer-like fishes. The light striped areas in the upper portion of the map shows the range of the ocean sunfishes, or molas, which extend into temperate waters. Some of the molas are reportedly toxic at certain times.

\section{Representative Species of Poisonous Tetraodontoid Fishes:}

Maki-Maki, or Deadly Death Puffer, Arothron hispidus (Linnaeus) (Fig. 70, Top). Ranges from Panama throughout the tropical Pacific, Japan, to South Africa and the Red Sea.

White-Spotted Puffer, Arothron meleagris (Lacépède) (Fig. 70, Next to Top). Ranges from the west coast of Central America to Indonesia.

Black-Spotted Puffer, Arothron nigropunctatus (Bloch and Schneider) (Fig. 70, Center). Polynesia, tropical Indo-Pacific Japan, to east Africa and the Red Sea.

Fig. 70. Top to bottom: Maki-maki, or Deadly Death Puffer, Arothron hispidus (Linnaeus). White-spotted Puffer, Arothron meleagris (Lacépède). Blackspotted Puffer, Arothron nigropunctatus (Bloch and Schneider). Gulf Puffer,

Sphaeroides ammlatus (Jenyns). Porcupinefish, Diodon hystrix Linnaeus. 


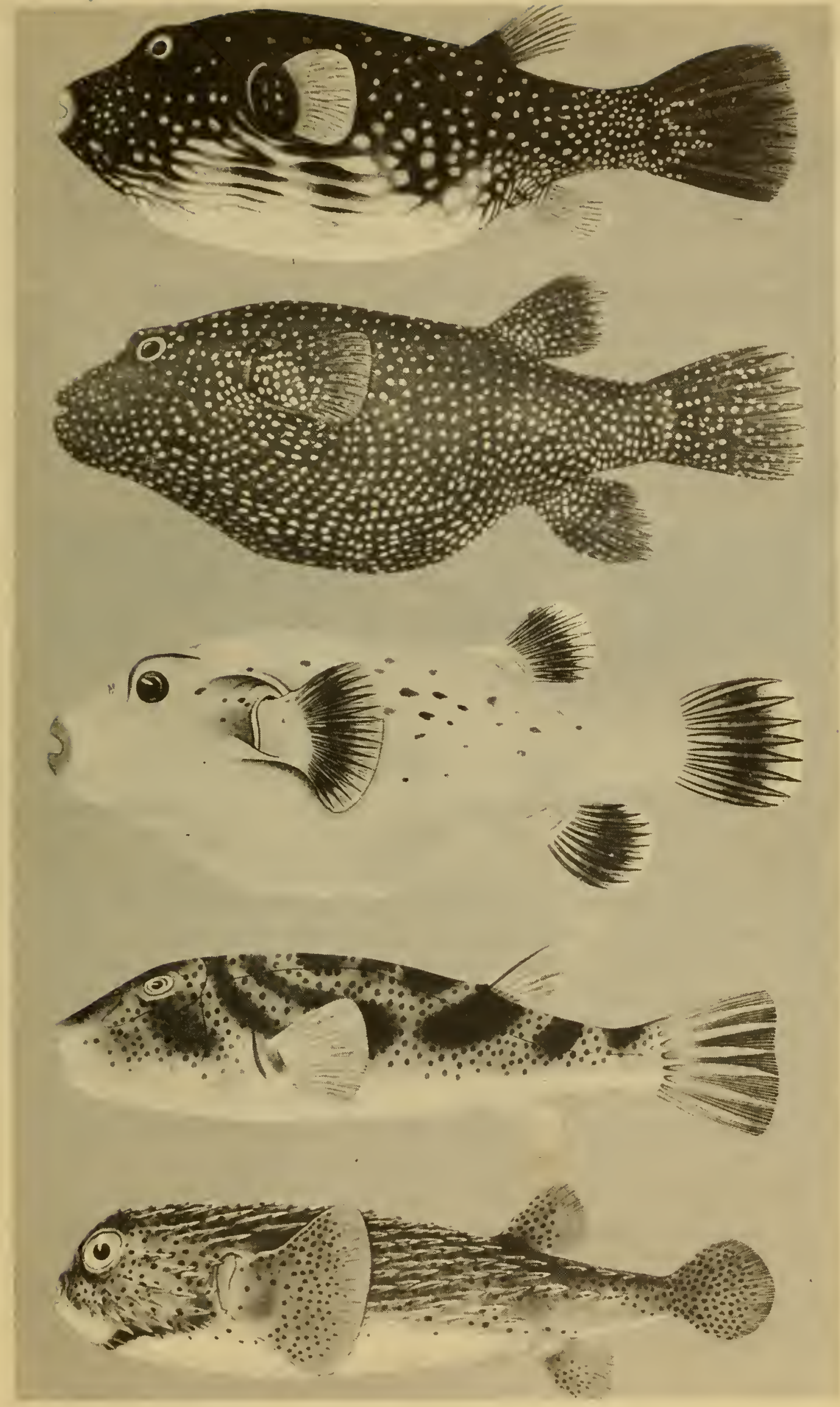

Fig. 70. See caption opposite. 
Gulf Puffer, Sphaeroides annulatus (Jenyns) (Fig. 70, Next to Bottom). Ranges from California to Peru, and the Galapagos Islands.

Porcupine Fish, Diodon hystrix Linnaeus (Fig. 70, Bottom). Circumtropical in its distribution, occasionally entering temperate areas.

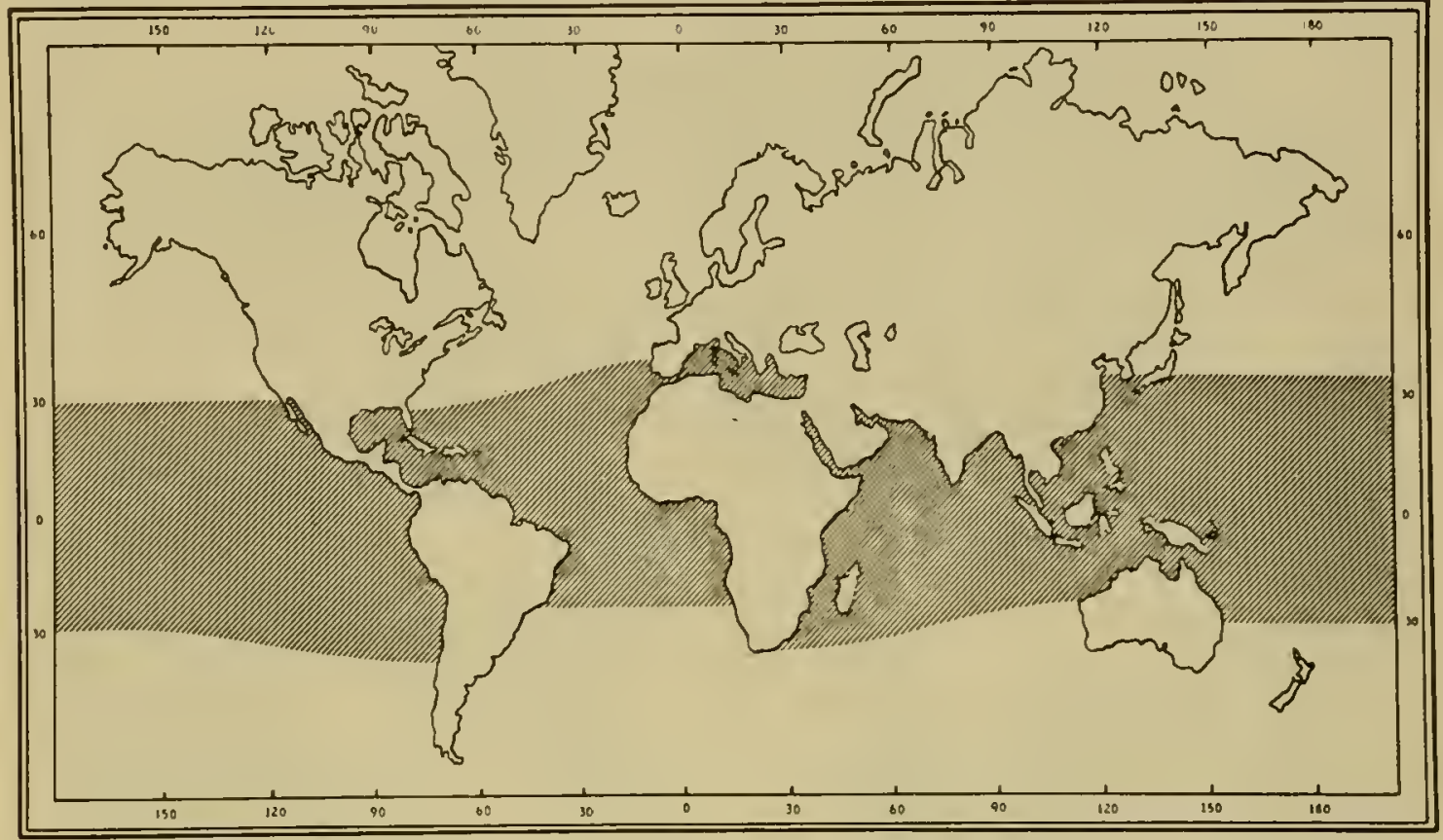

Fig. 71. Map showing the geographical distribution of Ciguatera-producing fishes.

Medical Aspects. Symptoms of tingling about the lips and tongue and motor incoordination usually develop within 10-45 minutes after ingestion of the fish. This tingling may later spread to other parts of the body. In some instances, the numbness may involve the entire body, in which instances the victim may feel as though he were "floating". Excessive salivation, extreme weakness, nausea, vomiting, diarrhea, abdominal pain may soon follow. Twitching of the muscles, paralysis, difficulty in swallowing, loss of voice, convulsions, and death by respiratory paralysis may ensue. More than 60 per cent of the victims poisoned by this fish die.

Treatment. See Page 126 on the treatment of fish poisoning. There is no specific treatment or antidote for puffer poisoning.

Prevention. Learn to recognize the puffer and leave it alone. It makes an excellent poisonous bait for stray cats, but a poor food for humans. 


\section{CIGUATERA-PRODUCING FISHES}

Ciguatera is a type of poisoning produced by a large variety of tropical marine reef or shore fishes. More than 300 different species have been incriminated, to date. Apparently, any marine fish, under the proper circumstances, may become involved with this type of poison since all of the species listed as poisonous are commonly eaten in some localities, and considered as good food fishes. It is, therefore, believed that these fishes become poisonous because of their food habits, as previously discussed.

Ciguatera is a serious problem in certain tropical areas such as the central and south Pacific Ocean and the West Indies (Fig. 71). It is unfortunately unpredictable, and therefore, exceedingly difficult to control. The edibility of fishes in an island area has been known to change suddenly. For example, ciguatera intoxications first began to appear in the islands of Midway, Johnston, Palmyra, Fanning, and Christmas about the year 1943, caused by eating fishes which had, previously, been known to be edible.

Representative Species of Ciguatera-Producing Fishes:

Surgeonfish, Acanthurus glaucopareius Cuvier (Fig. 72, Top). Indonesia, Philippine Islands, and tropical Pacific.

Ladyfish, Albula vulpes (Linnaeus) (Fig. 72, Next to Top). All warm seas.

Jack, Caranx hippos (Linnaeus) (Fig. 72, Center). Tropical Atlantic.

Herring, Clupanodon thrissa (Linnaeus) (Fig. 72, Next to Bottom). Tropical Pacific, Japan, China, Formosa, Korea, Indonesia, and India.

Surmullet, Parupeneus chryserydros (Lacépède) (Fig. 72, Bottom). Polynesia westward to east Africa.

Surmullet, Upeneus arge (Jordon and Evermann) (Fig. 73, Top). Polynesia and Micronesia.

Seabass, Grouper, Epinephelus fuscoguttatus (Forskål) (Fig. 73, Bottom). Indo-Pacific.

Seabass, Mycteroperca venenosa (Linnaeus) (Fig. 74, Bottom). Western tropical Atlantic.

Trunkfish, Lactoria cornutus (Linnaeus) (Fig. 73, Center Two). Tropical Pacific.

Trunkfish, Lactophrys trigonus (Linnaeus) (Fig. 74, Top \& Center). Atlantic coast of tropical America, northward to Cape Cod.

Porgie, Pagellus erythrinus (Linnaeus) (Fig. 75). Black Sea, 


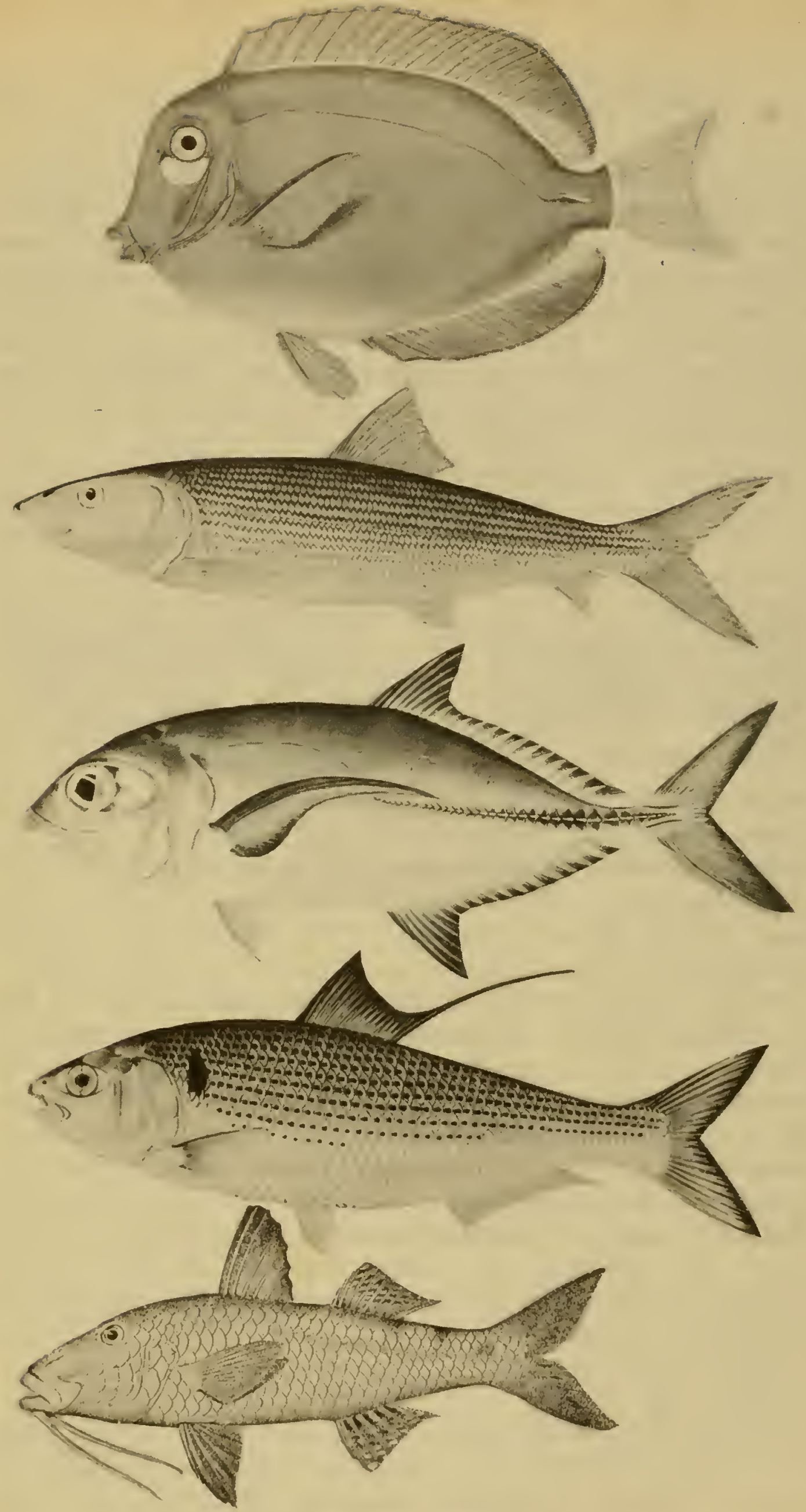

Fig. 72. See caption $\longrightarrow$ 


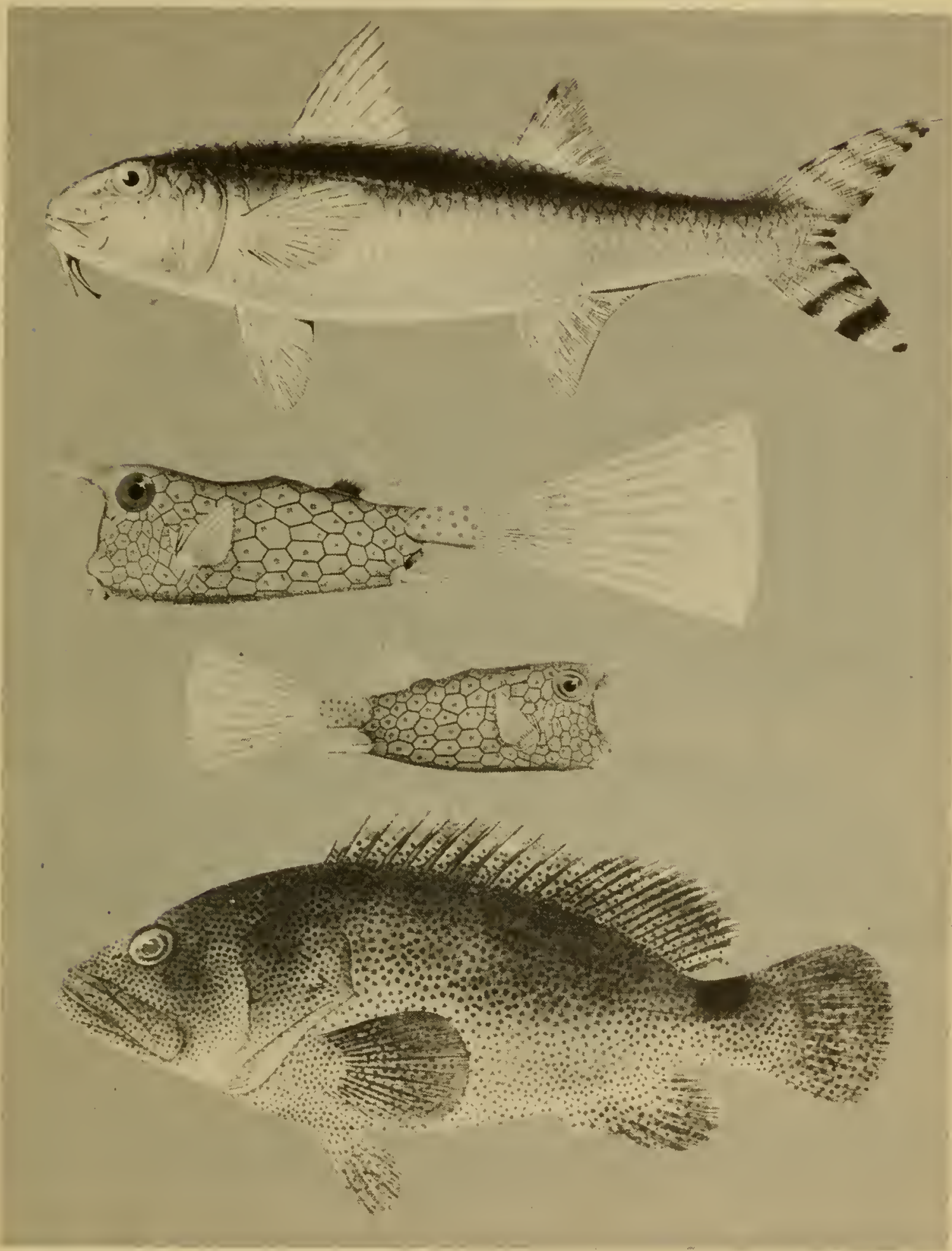

Fig. 73. Top to bottom: Surmullet, Upeneus arge (Jordan and Evermann). (From Jordan and Evermann, Retouched) Trunkfish, Lactoria cornutus (Linnaeus). (From Günther) Male, lower; female, upper. Seabass or Grouper, Epinephelus fuscoguttatus (Forskăl). (From Hiyama)

Fig. 72. Top to bottom: Surgeonfish, Acanthurus glaucopareius Cuvier. (From Günther) Ladyfish, Albula vulpes (Linnaeus). Jack, Caranx hippos (Linnaeus). (From Holbrook) Herring, Clupanodon thrissa (Linnaeus). Surmullet, Parupeneus chryserydros (Lacépède). (From Jordan and Evermann) 

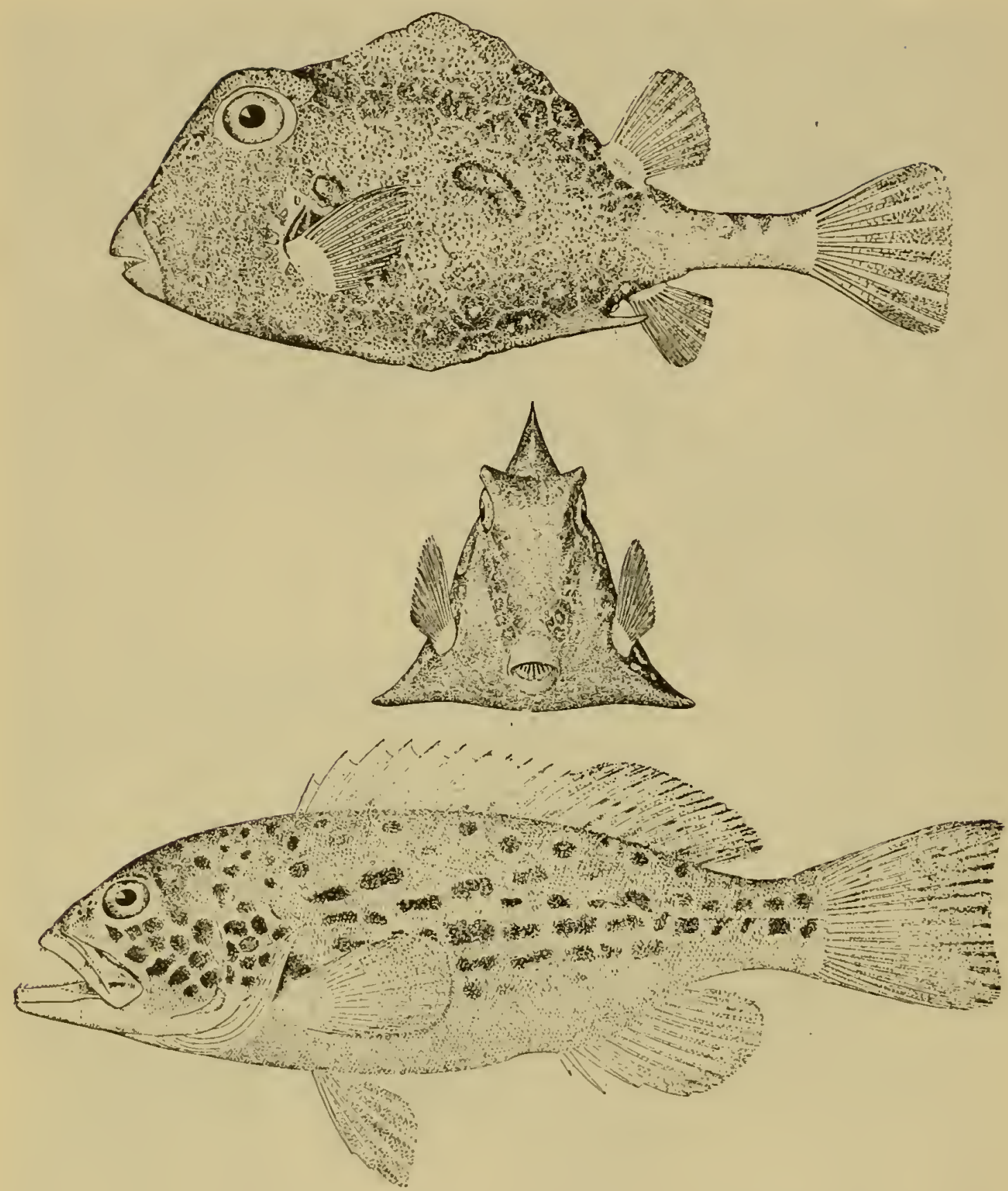

Fig. 74. Top and center: Trunkfish, Lactophrys trigonus (Linnaeus). (From Jordan and Evermann) Bottom: Seabass, Mycteroperca venenosa (Linnaeus). (From Jordan and Evermann)

Mediterranean, and east Atlantic, from the British Isles and Scandinavia to the Azores, Canaries, and Fernando Po.

Squaretail, Tetragonurus cuvieri (Risso) (Fig. 76). Temperate regions of the world.

Porgie, Pagrus pagrus (Linnaeus) Eastern Atlantic and Mediterranean Sea.

Surgeonfish, Acanthurus triostegus (Linnaeus) (Fig. 77, Top). Hawaiian and Johnston Islands. 
Filefish, Alutera scripta (Osbeck) (Fig. 77, Center). All warm seas.

Triggerfish, Balistoides niger (Bonnaterre) (Fig. 77, Bottom). Tropical Pacific, from Polynesia to Madagascar, China, and Japan. Jack, Caranx melampygus Cuvier (Fig. 78, Top). Tropical Pacific, north to Japan.

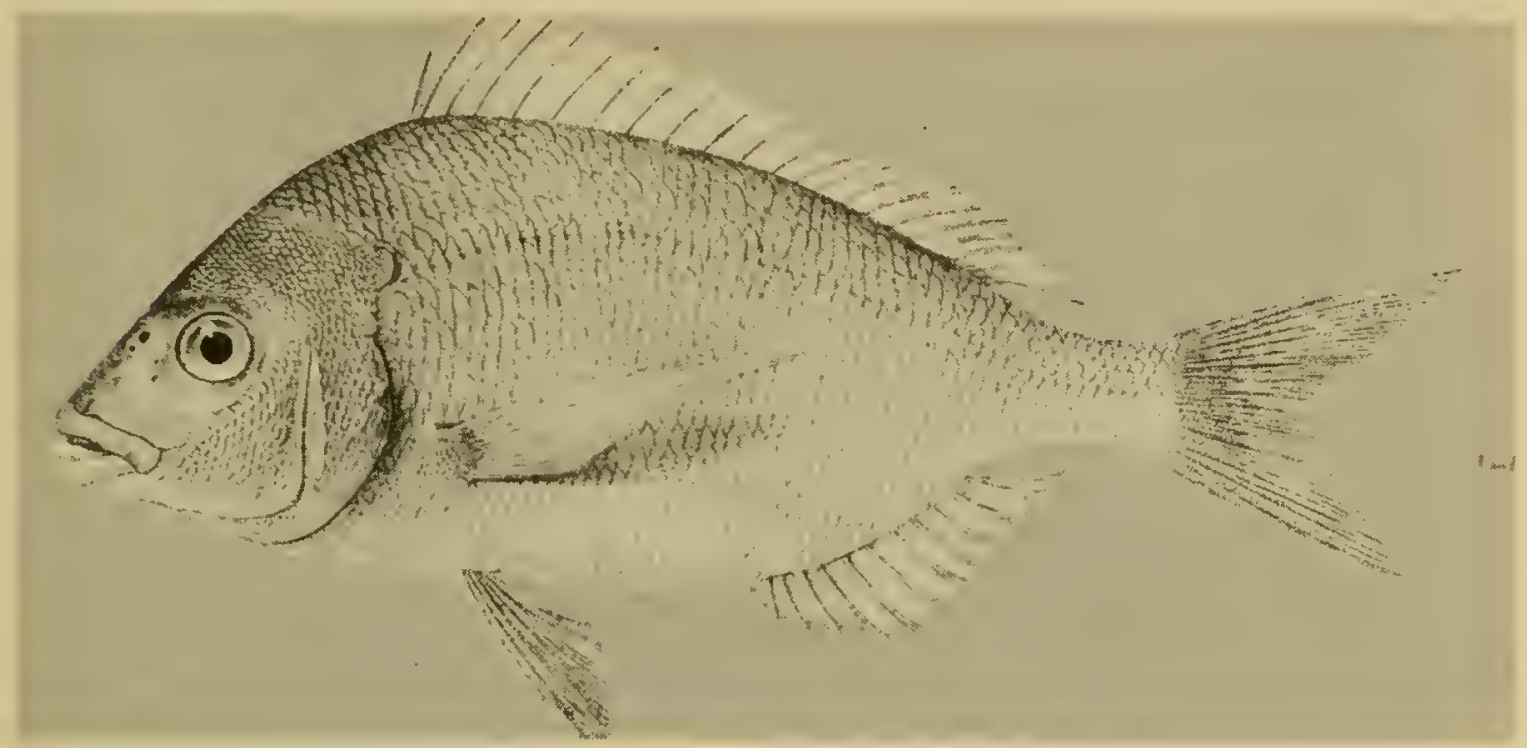

Fig. 75. Porgie, Pagellus erythrinus (Linnaeus). (From Day)

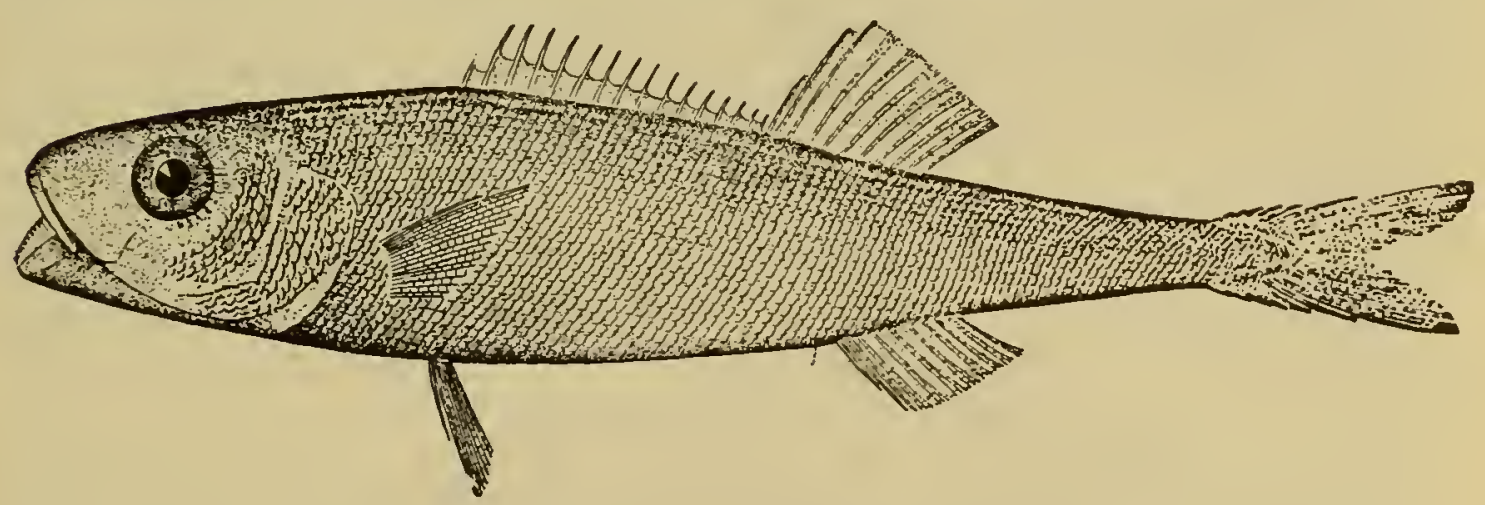

Fig. 76. Squaretail, Tetragonurus cuvieri (Risso). (From Jordan and Evermann)

Anchovy, Engraulis japonicus (Schlegel) (Fig. 78, Bottom). China, Japan, Korea, Formosa.

Squirrelfish, Myripristis murdjan (Forskål) (Fig. 79, Top). Indo-Pacific.

Oceanic Bonito, Katsuwonus pelamis (Linnaeus) (Fig. 79, Next to Top). Circumtropical. 


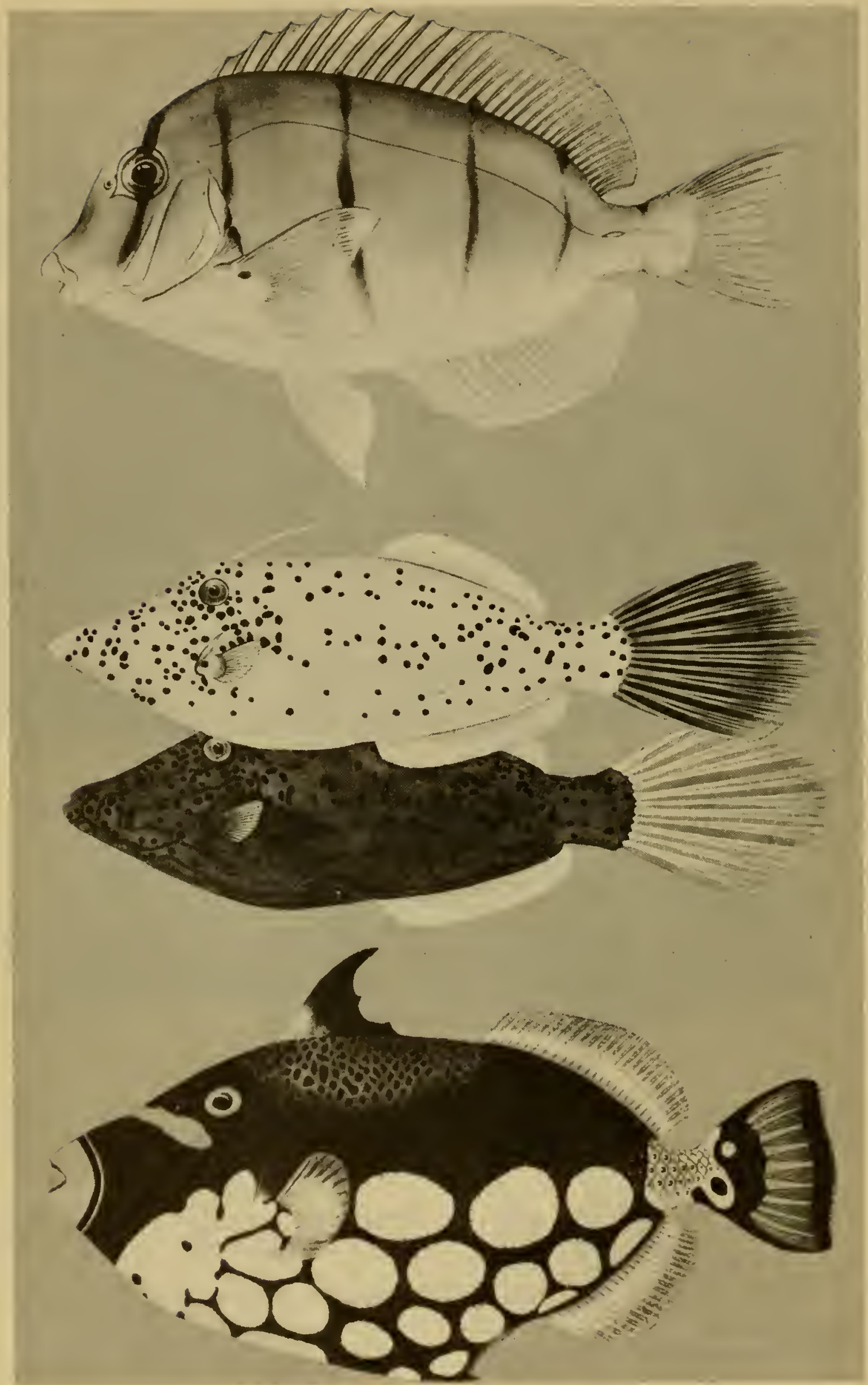

Fig. 77. Top: Surgeonfish, Acanthurus triostegus (Linnaeus). (From Hiyama) Center: Filefish, Alutera scripta (Osbeck). (From Hiyama) Bottom: Triggerfish, Balistoides niger (Bonnaterre). (From Hiyama) 
Wrasse, Epibulus insidiator (Pallas) (Fig. 79, Next to Bottom). Tropical Indo-Pacific.

Wrasse, Julis gaimardi (Quoy and Gainard) (Fig. 79, Bottom). Tropical Indo-Pacific area.

Snapper, Aprion vivescens Valenciennes (Fig. 80, Top). Tropical Indo-Pacific.

Snapper, Gnathodentex aureolineatus (Lacépède) (Fig. 80, Next to Top). Tuamotu Archipelago westward to East Africa.

Snapper, Lethrinus miniatus (Forster) (Fig. 80, Next to Bottom). Polynesia, westward to East Afríca.

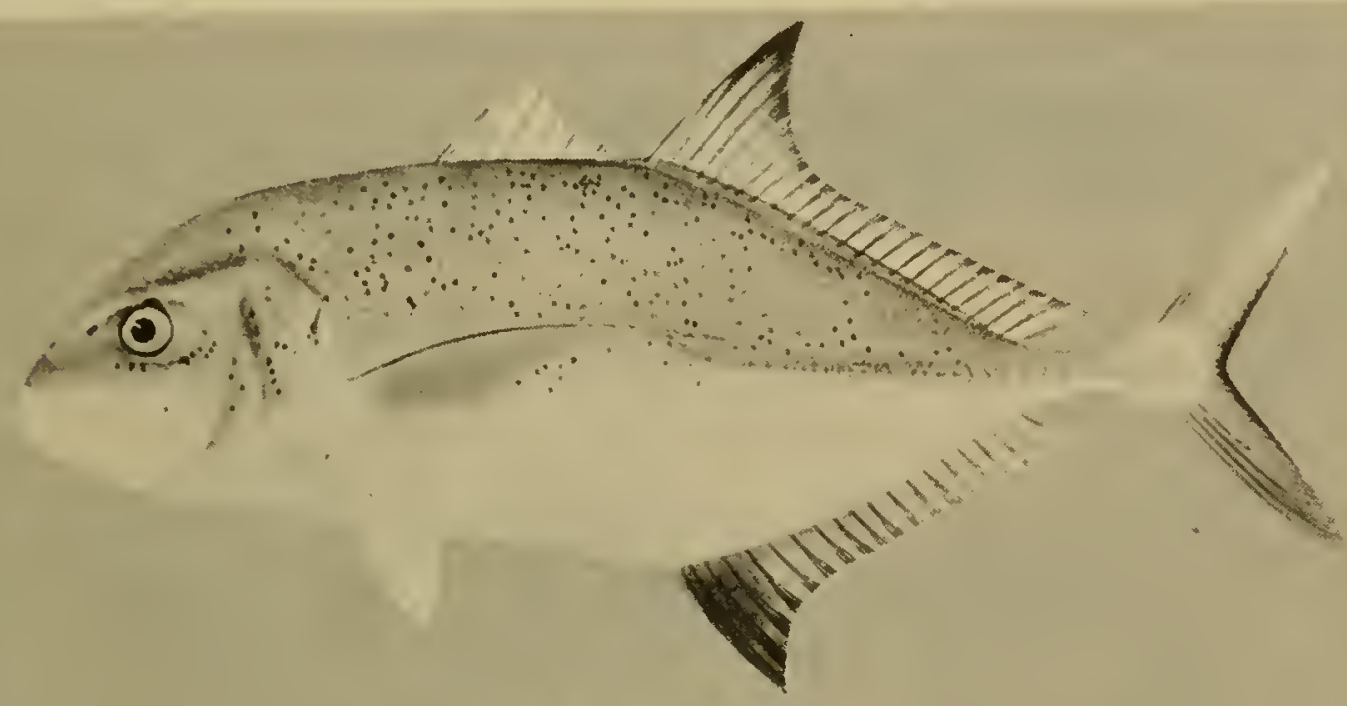

Fig. 78. Top: Jack, Caranx melampygus Cuvier. (From Hiyama) Bottom: Japanese Anchovy, Engraulis japonicus Schlegel.

Red Snapper, Lutjanus bohar (Forskål) (Fig. 80, Bottom). Tropical Pacific to east Africa and Red Sea.

Red Snapper, Lutjanus gibbus (Forskål) (Fig. 81, Top). Tropical Indo-Pacific.

Snapper, Lutjanus monostigma (Cuvier) (Fig. 81, Center). Polynesia, westward to the Red Sea, China.

Red Snapper, Lutjanus vaigiensis (Quoy and Gaimard) (Fig. 81, Bottom). Polynesia, westward to east Africa, Japan. 


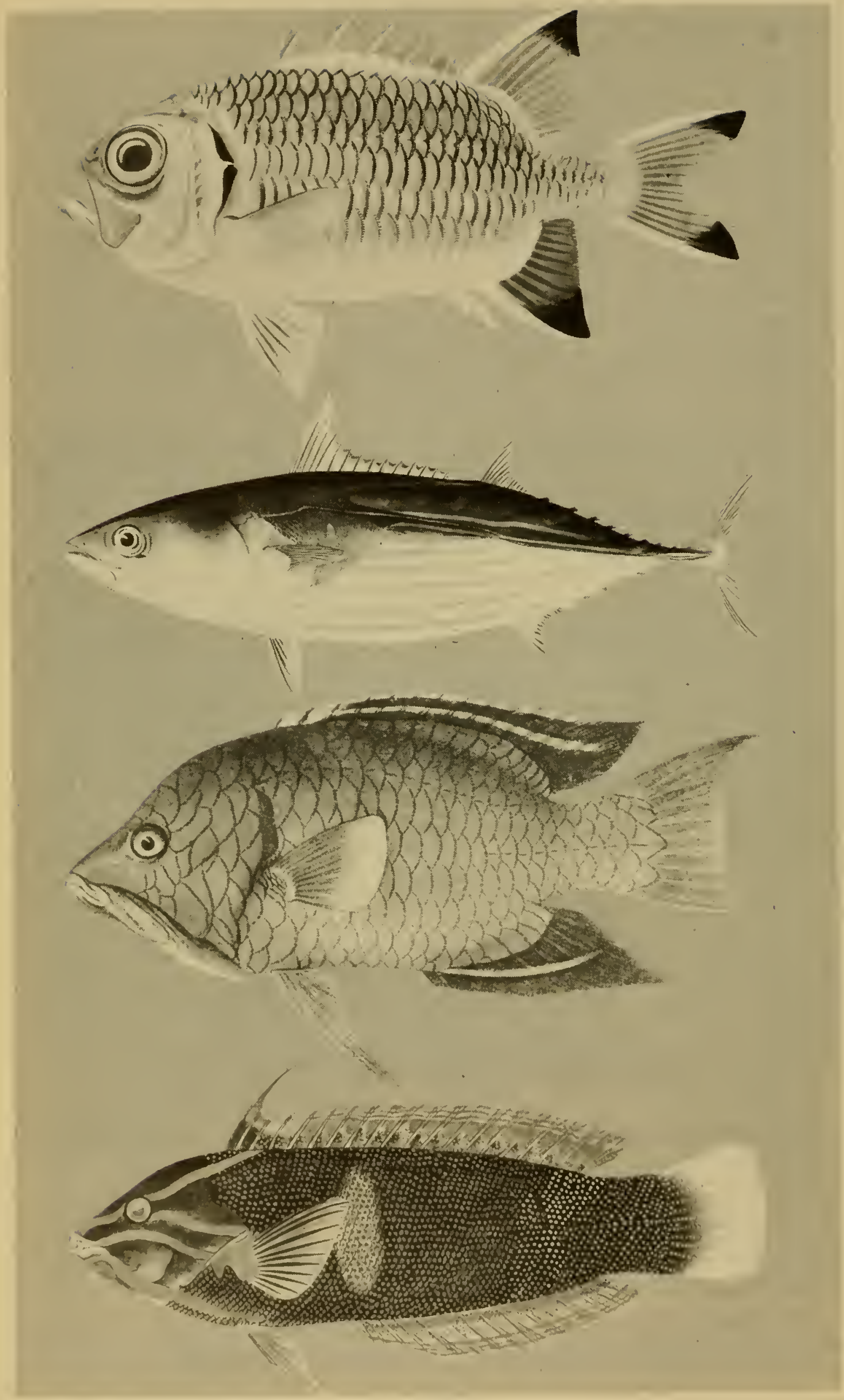

Fig. 79. See caption $\longrightarrow$ 
Snapper, Monotaxis grandoculis (Forskål) (Fig. 82, Top). Polynesia, westward to east Africa.

Chinaman Fish, Paradicichthys venenatus Whitley (Fig. 82, Center). Australia.

Parrotfish, Scarus caeruleus (Bloch) (Fig. 82, Bottom). Florida and West.Indies.

Parrotfish, Scarus microrhinos Bleeker (Fig. 83, Top). IndoPacific.

Seabass, Grouper, Cephalopholis argus Bloch and Schneider (Fig. 83, Next to Top). Tropical Indo-Pacific.

Seabass, Plectropomus oligacanthus Bleeker (Fig. 83, Next to Bottom). Indonesia, Philippine, Caroline and Marshall Islands.

Seabass, Plectropomus truncatus (Fowler) (Fig. 83, Bottom). Micronesia, Indonesia, Philippines.

Seabass, | Variola louti(Forskål) (Fig. 84, Top). Tropical IndoPacific.

Barracuda, Sphyraena barracuda (Walbaum) (Fig. 84, Bottom). Indo-Pacific; from Hawaii to the Red Sea; west Atlantic from Brazil to the West Indies, Florida and Bermuda.

Medical Aspects. Tingling about the lips, tongue, and throat, followed by numbness may develop immediately or any time within a period of 30 hours after ingestion of the fish. The tingling sensation may be accompanied by such other symptoms as nausea, vomiting, metallic taste, dryness of the mouth, abdominal cramps, and diarrhea. The muscles of the mouth, cheeks and jaws may become drawn and spastic, with a feeling of numbness. Headache, joint aches, nervousness, prostration, dizziness, pallor, cyanosis, inability to sleep, extreme weakness, and exhaustion are frequently present. The feeling of weakness may become progressively worse until the patient is unable to walk. Muscle pains are generally described as dull, heavy aches or cramping sensations, but may also be sharp, shooting, affecting particularly the arms and legs. Victims complain of their teeth feeling loose and painful in their sockets. Visual disturbances consisting of blurring, temporary blindness, sensitivity to light, and spots before the eyes are not uncommon. Skin disorders are frequently reported consisting of intense itching, red papular rash, blisters, extensive areas of loss of skin, especially of the hands and feet, and occasionally ulceration. There may also be loss of hair and nails.

In severe intoxication the nervous symptoms are particularly pronounced. The victim may interpret the feeling of cold as a

Fig. 79. Top to bottom: Squirrelfish, Myripristis murdjan (Forskăl). Oceanic Bonito, Katsuwonus pelamis (Linnaeus). Wrasse, Epibulus insidiator (Pallas). (From Hiyama) Wrasse, Julis gaimardi (Quoy and Gaimard). (Arita) 

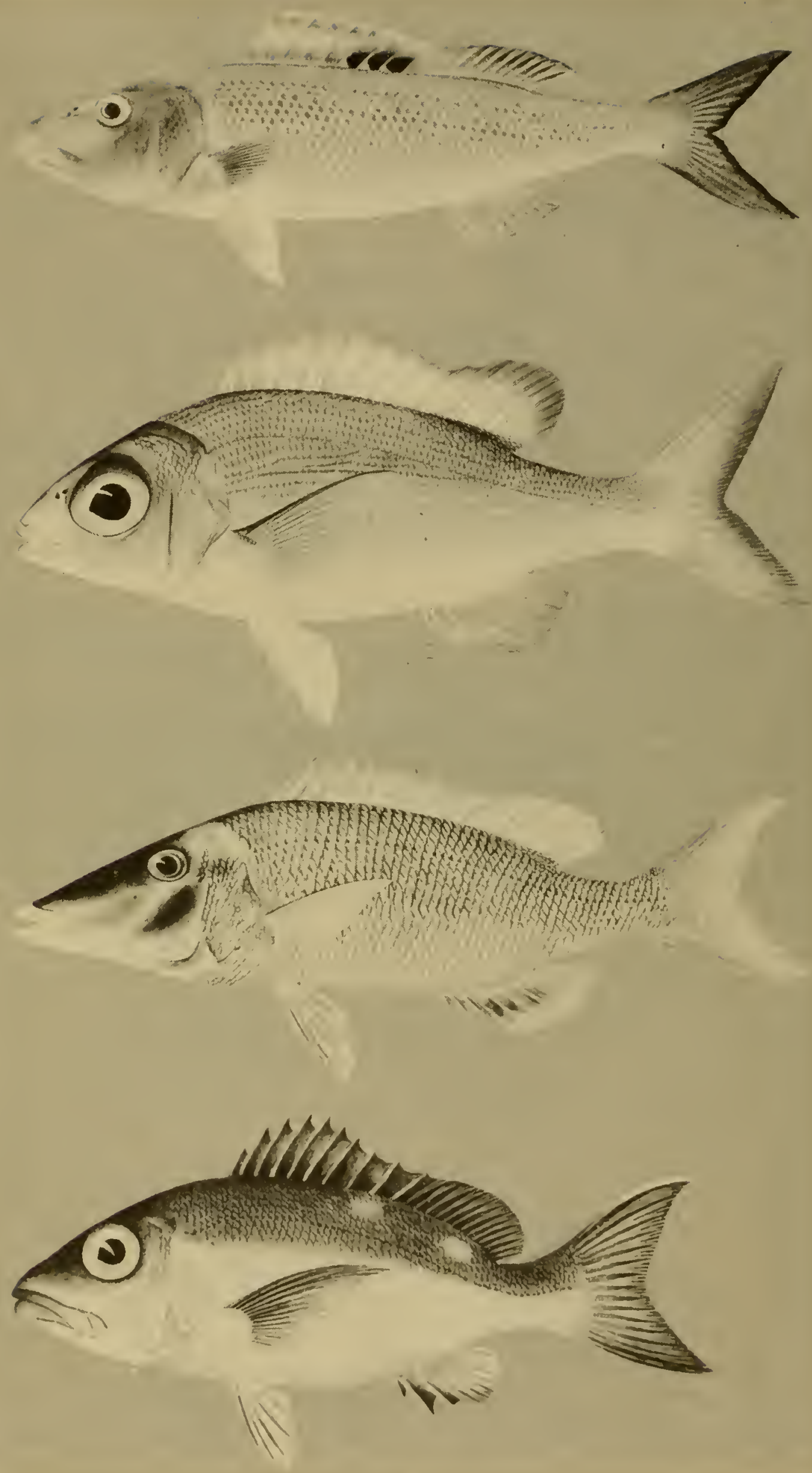

Fig. 80. See caption $\rightarrow$ 
tingling, burning, "dry ice or electric shock" sensation, or hot objects may give a feeling of cold. Difficulty in walking and generalized muscular incoordination may become progressively worse. Muscular paralysis, convulsions and death may ensue. The mortality rate in this type of fish poisoning is relatively low, about 7 percent of the persons poisoned die. In those instances in which the victim survives, recovery is extremely slow if the person has been severely poisoned. Complete recovery may require many months, and even years.

Treatment of Fish Poisoning. With the exception of scombroid poisoning in which the patient should be administered antihistaminic drugs, there is no specific treatment. However, a few general procedures have been of value in many instances.

'The stomach should be emptied at the earliest possible moment. Warm salt water, or egg white, will be found effective. If these ingredients are not available, stick a finger down the throat. A cathartic should be administered. In many instances, 10 percent calcium gluconate given intravenously has given prompt relief from some of the nervous symptoms, whereas in others, it has not. Paraldehyde and ether inhalations have been reported to be effective in controlling the convulsions. Nikethamide, or one of the other respiratory stimulants is advisable in cases of respiratory depression. In patients where excessive production of mucus is present, aspiration and constant turning are essential. Atropine has been found to make the mucus more viscid and difficult to aspirate and is not recommended. If laryngeal spasm is present, intubation and tracheotomy may be necessary. Oxygen inhalation and intravenous administration of fluids supplemented with vitamins given parenterally are usually beneficial. If the pain is severe, opiates will be required. Morphine is the drug of choice when given in small, divided doses. Cool showers have been found to be effective in relieving the severe itching. It should be kept in mind that in rare instances scombroid poisoning may be combined with other types of fish poisoning. Fluids given to patients suffering from disturbances of temperature sensation should be slightly warm, or at room temperature. Vitamin B complex supplements are advisable.

Prevention. One cannot detect a poisonous fish by its appearance. Moreover, there is no known simple chemical test to detect the poison. The most reliable methods involve the preparation of tissue extracts which are injected intraperitoneally into mice, or feeding

Fig. 80. Top to bottom: Snapper, Aprion virescens Valenciennes. (From Hiyama) Snapper, Gnathodentex aureolineatus (Lacépède). (From Hiyama) Snapper, Lethrinus miniatus (Forster). (From Hiyama) Snapper, Lutjanus bohar (Forskăl). (From Hiyama) 


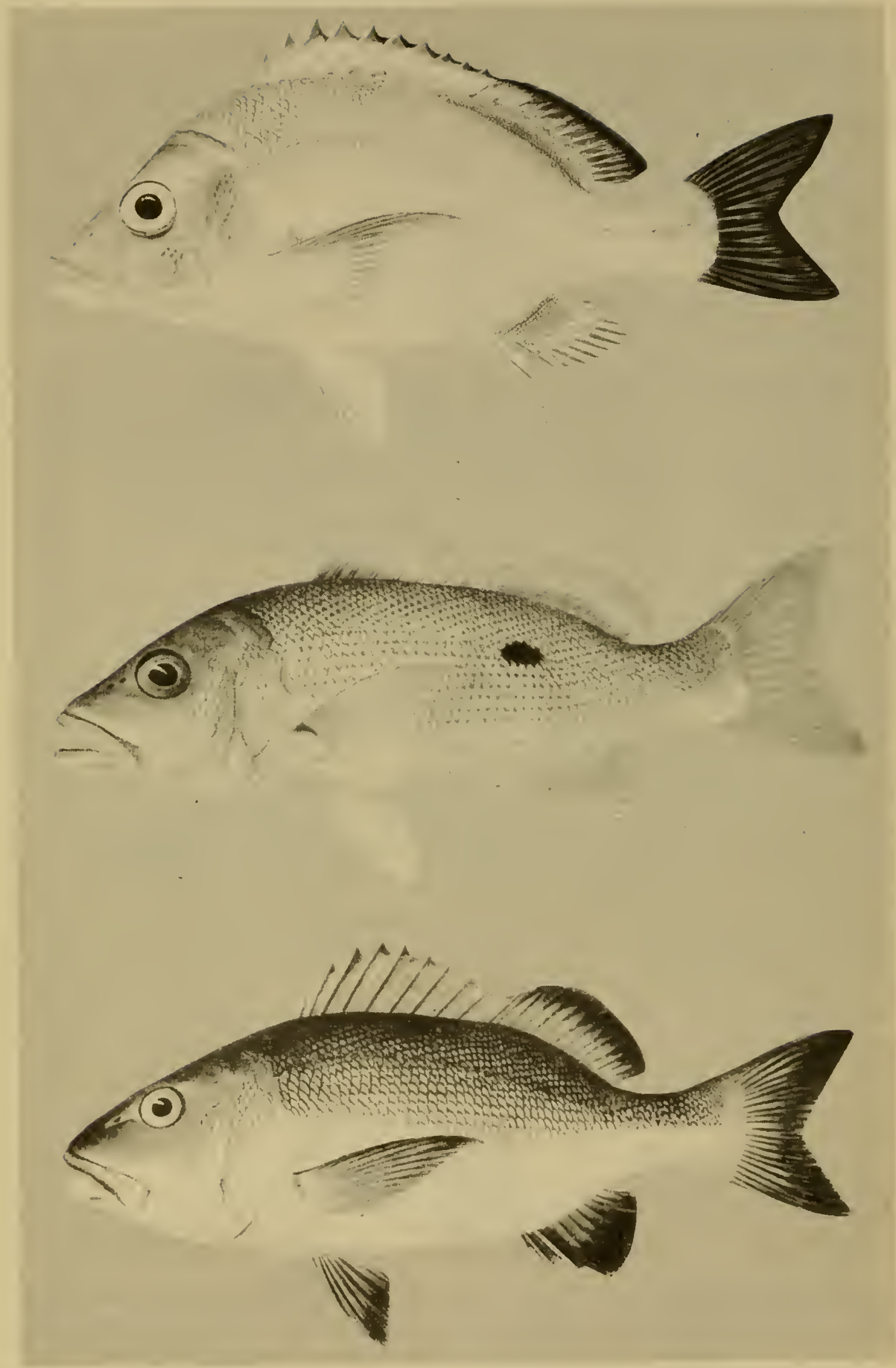

Fig. 81. Top: Snapper, Lutjanus gibbus (Forskăl). (From Hiyama) Center: Snapper, Lutjanus monostigma (Cuvier). (From Hiyama) Bottom: Red Snapper, Lutjanus vaigiensis (Quoy and Gaimard). (From Hiyama) 


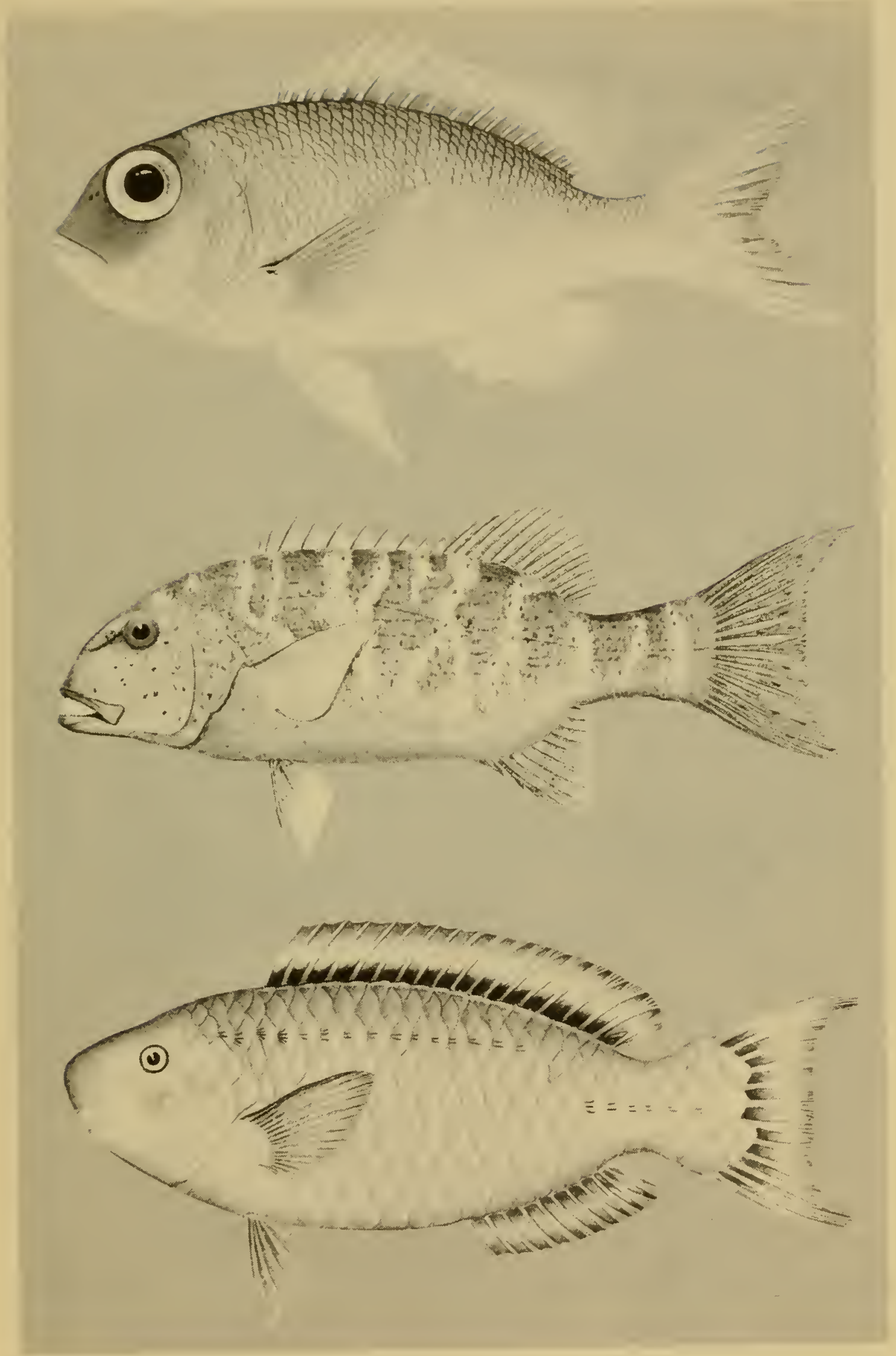

Fig. 82. Top: Snapper, Monotaxis grandoculis (Forskăl). (From Hiyama) Center: Chinaman Fish, Paradicichthys venenatus Whitley (Coates). Bottom: Blue Parrotfish, Scarus caeruleus (Bloch). 

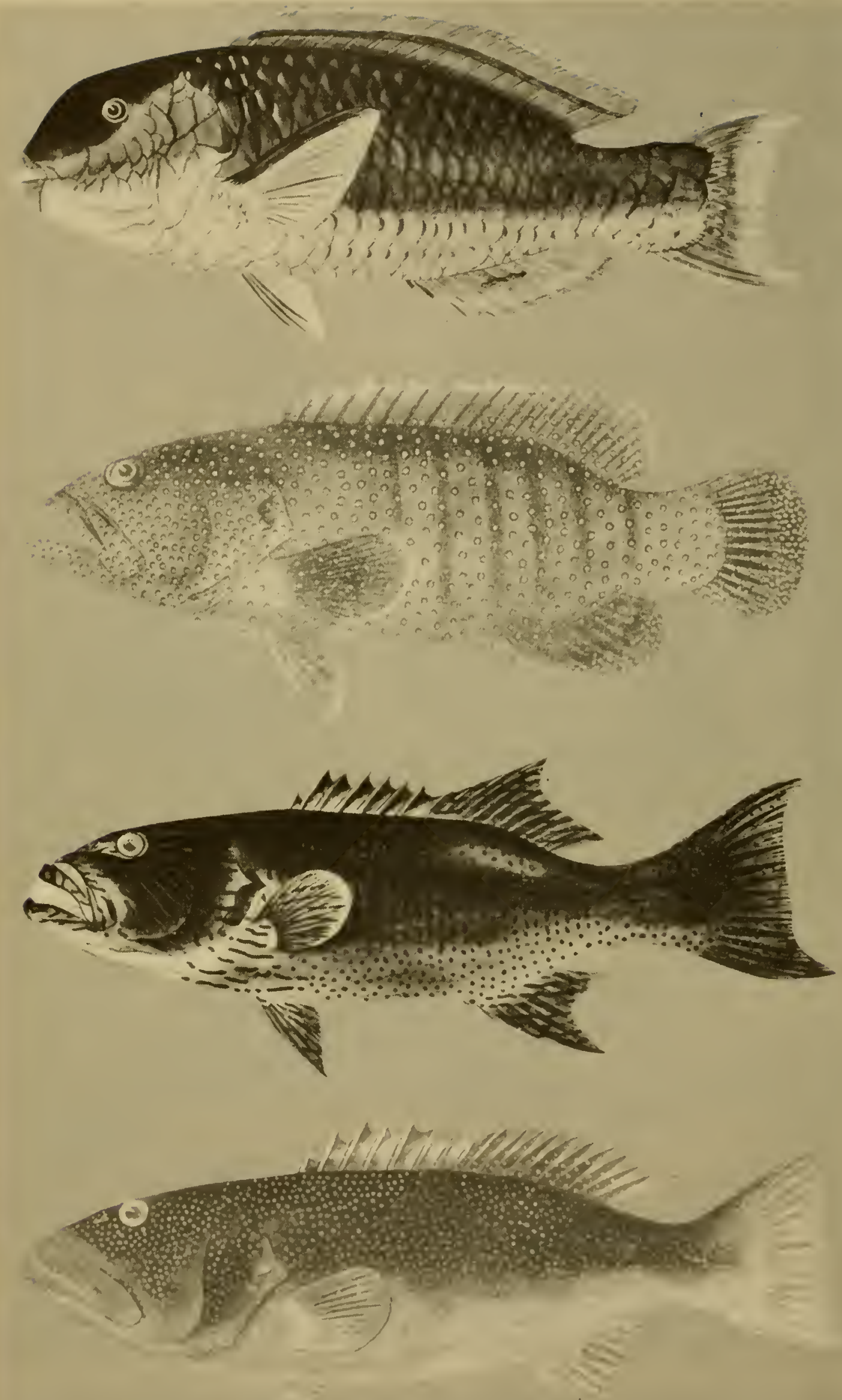

Fig. 83. See caption $\longrightarrow$ 
samples of the viscera and flesh to cats or dogs, and observing the animal for the developments of toxic symptoms. The visceraliver and intestines-of tropical marine fishes should never be eaten. Also, the roe of most marine fishes is potentially dangerous, and 'in some cases may produce rapid death. Fishes which are unusually large for their size should be eaten with caution. This is particularly true for barracuda (Sphyraena), jacks (Caranx), and grouper (Epinephelus) during their reproductive seasons.

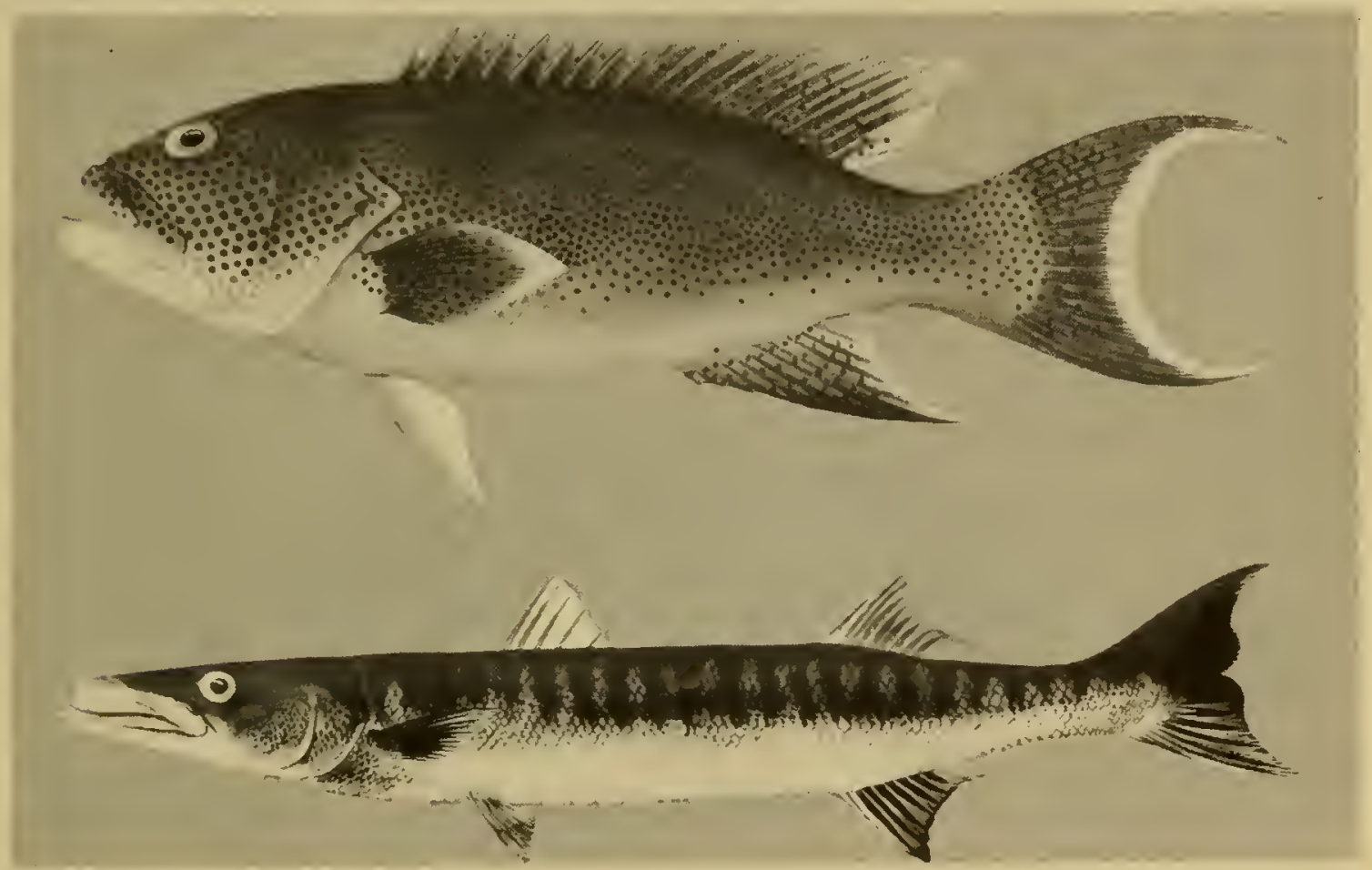

Fig. 84. Top: Seabass, Variola louti (Forskăl). (From Hiyama) Bottom Barracuda, Sphyraena barracuda (Walbaum). (From Hiyama)

If one is living under survival conditions, and questionable fishes must be eaten, it is advisable to cut the fish into thin fillets and to soak them in several changes of water-fresh or salt-for at least 30 minutes. (Do not use the rinse water for cooking purposes.) This will serve to leach out the poison which is somewhat water soluble. If a questionable species is cooked by boiling, the water should always be discarded. It must be emphasized that ordinary cooking procedures do not destroy or significantly weaken the poison. The advice of native people on eating tropical marine fishes is frequently conflicting and erroneous, particularly if they have not lived within a particular region over a period of time. Keep in mind that an edible fish in one region may kill you in another.

Fig. 83. Top to bottom: Parrotfish, Scarus microrhinos Bleeker. (From Hiyama) Seabass or Grouper, Cephalopholis argus Bloch and Schneider. (From Hiyama) Seabass, Plectropomus oligacanthus Bleeker. (From Hiyama) Seabass, Plectropomus truncatus (Fowler). (From Hiyama) 


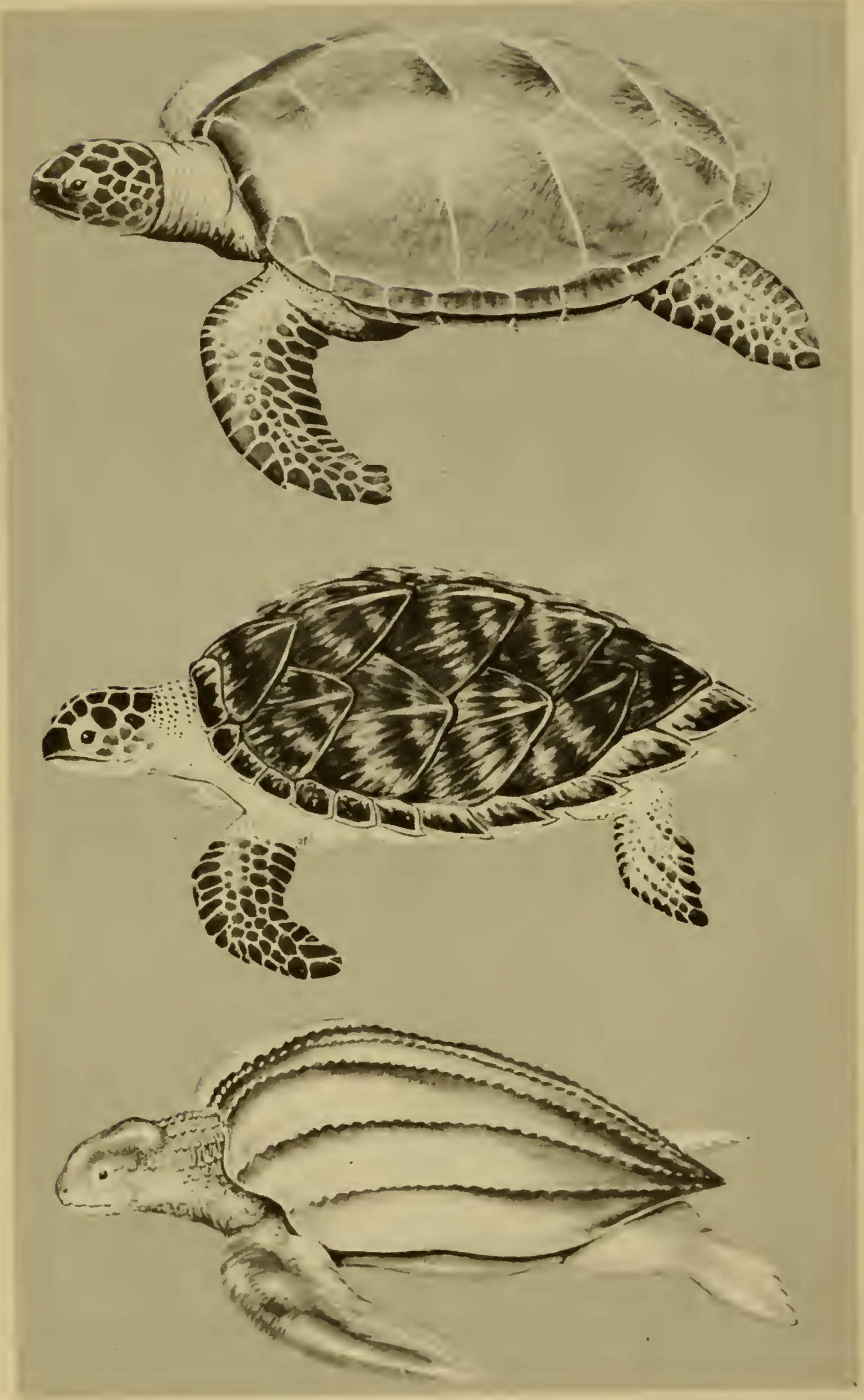

Fig. 85. See caption $\rightarrow$ 


\section{POISONOUS MARINE TURTLES}

Poisoning from marine turtles is one of the lesser known types of intoxications produced by marine organisms. The cáses that have been reported are sufficiently severe to be impressive. As in the case of fishes, most of these species are commonly eaten with impunity. For some unknown reason, certain species of marine turtles in the vicinity of the Philippine Islands, Ceylon, and Indonesia, under certain circumstances, may become extremely poisonous to eat.

\section{Species of Marine TURTles Reported as Poisonous to Eat:}

Green Sea Turtle, Chelonia mydas (Linnaeus) (Fig. 85, Top). Inhabits all tropical and subtropical seas.

Hawksbill Turtle, Eretmochelys imbricata (Linnaeus) (Fig. 85, Center). Inhabits all tropical and subtropical seas.

Leatherback Turtle, Dermochelys coriacea (Linnaeus) (Fig. 85, Bottom). Largely circumtropical, but occasionally taken in temperate waters.

Medical Aspects. Symptoms generally develop within a few hours to several days after ingestion of the flesh. The initial symptoms are usually nausea, vomiting, diarrhea, severe upper abdominal pain, dizziness, dry burning sensation of the lips, tongue, lining of the mouth and throat. S Swallowing becomes very difficult, and excessive salivation is pronounced. The disturbances of the mouth may take several days to develop, but become progressively severe as time goes on. The tongue develops a white coating, and the breath becomes very foul. Later, the tongue may become covered with multiple pinhead-sized, reddened papules, which may later break down into ulcers. If the victim has been severely poisoned, he tends to become very sleepy, and is difficult to keep awake. If this symptom develops, it is usually a bad sign, and death soon follows. Death is believed to be due to liver and kidney damage. About 44 percent of the victims poisoned by marine turtles die.

Treatment. There is no specific treatment. Some of the recommendations presented in fish poisoning are pertinent here.

Prevention. Marine turtles in the tropical Indo-Pacific region should be eaten with caution. If in doubt, check with local native groups and find out if they are safe to eat in that locality. Turtle liver is especially dangerous to eat.

Fig. 85. Top: Green Sea Turtle, Chelonia mydas (Linnaeus). Center: Hawksbill Turtle, Eretmochelys imbricata (Linnaeus). Bottom: Leatherback Turtle, Dermochelys coriacea (Linnaeus). 

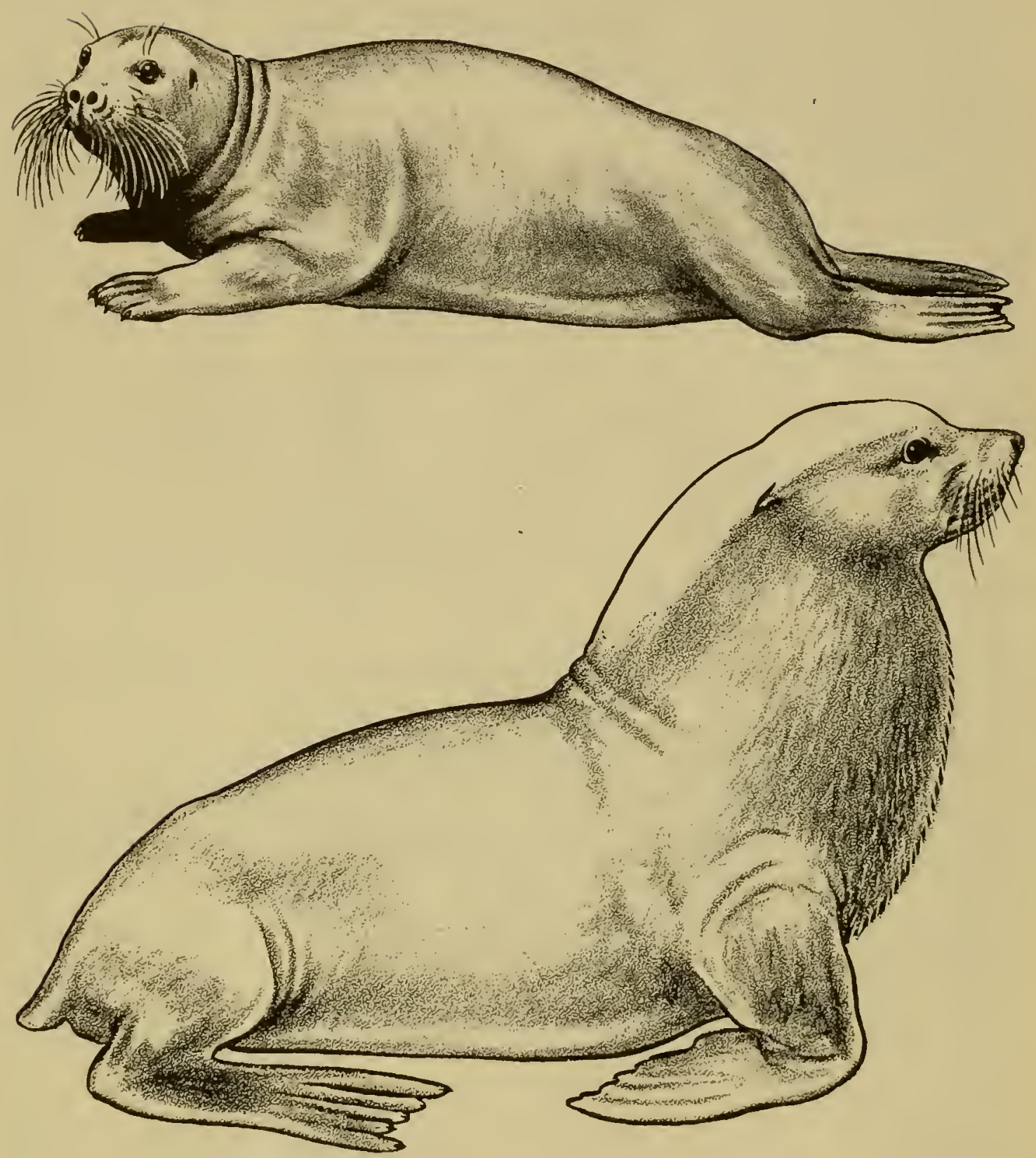

Fig. 86. Top: Bearded Seal, Erignathus barbatus (Erxleben). Bottom: Australian Sea Lion, Neophoca cinerea (Péron).

\section{MARINE MAMMALS}

Several species of marine mammals have been incriminated in human intoxications.

Polar Bear, Thalarctos maritimus Phipps. Ranges throughout the Arctic regions of the world. Numerous poisonings have resulted from eating the liver and kidneys of polar bears. The predominant symptoms are intense throbbing or dull frontal headaches, nausea, vomitfng, diarrhea, abdominal pain, dizziness, drowsiness, irritability, collapse, photophobia, and convulsions. Fatalities are rare. 
Recovery generally takes place within several days. It is believed by some that the primary cause of polar bear poisoning is due to Vitamin A, which is present in large concentrations in certain polar bear tissues.

Bearded Seal, Erignathus barbatus (Erxleben) (Fig. 86, Top). This species is circumboreal in its distribution, living at the edge of ice. The liver of this seal is said to contain a high concentration of Vitamin A, and may be as toxic as polar bear liver.

Australian Sea Lion, Neophoca cinerea (Péron) (Fig. 86, Bottom). This sea lion is confined to the coast of South Australia. The flesh of this animal is said to be toxic, but there is very little supporting data upon which to base any conclusions.

Whales and Dolphins. Several species of whales and dolphins are reported to have poisonous flesh, but data is too meager at this time to permit any definitive statements.

\section{MARINE ANIMALS THAT SHOCK}

Electric fishes constitute a relatively minor health hazard but, nevertheless, they are worthy of serious consideration. There are several different groups of fishes that possess electric organs: catfishes (Malopterurus), star-gazers (Astroscopus), electric eels (Electrophorus), and a number of genera of electric rays (Torpedo, Narcine, Hypnarce, Hypnos, Discopyge, etc.). Electric eels and catfishes are freshwater inhabitants, whereas star-gazers and rays are marine. The most important marine members are the electric rays, representatives of which are found in all temperate and tropical oceans. Electric rays are sluggish, feeble swimmers, spending most of their time lying on the bottom partially buried in the mud or sand, generally preferring shallow depths.

The electric organs, which constitute about one-sixth of the total body weight of the ray, are situated one on either side of the anterior part of the disc between the anterior extension of the pectoral fin and the head, extending from about the level of the eye backward past the gill region. Usually, outlines of the organs are externally visible on both the ventral and dorsal sides. The organs are comprised of columnar prism-like structures separated by loose connective tissue, forming a network similar to the cells of a honeycomb. The columns vary in number according to the species of ray. The ventral side of the ray is electrically negative whereas the dorsal side is positive. The production of an electrical discharge or shock is believed to be a simple reflex action-the result of tac- 


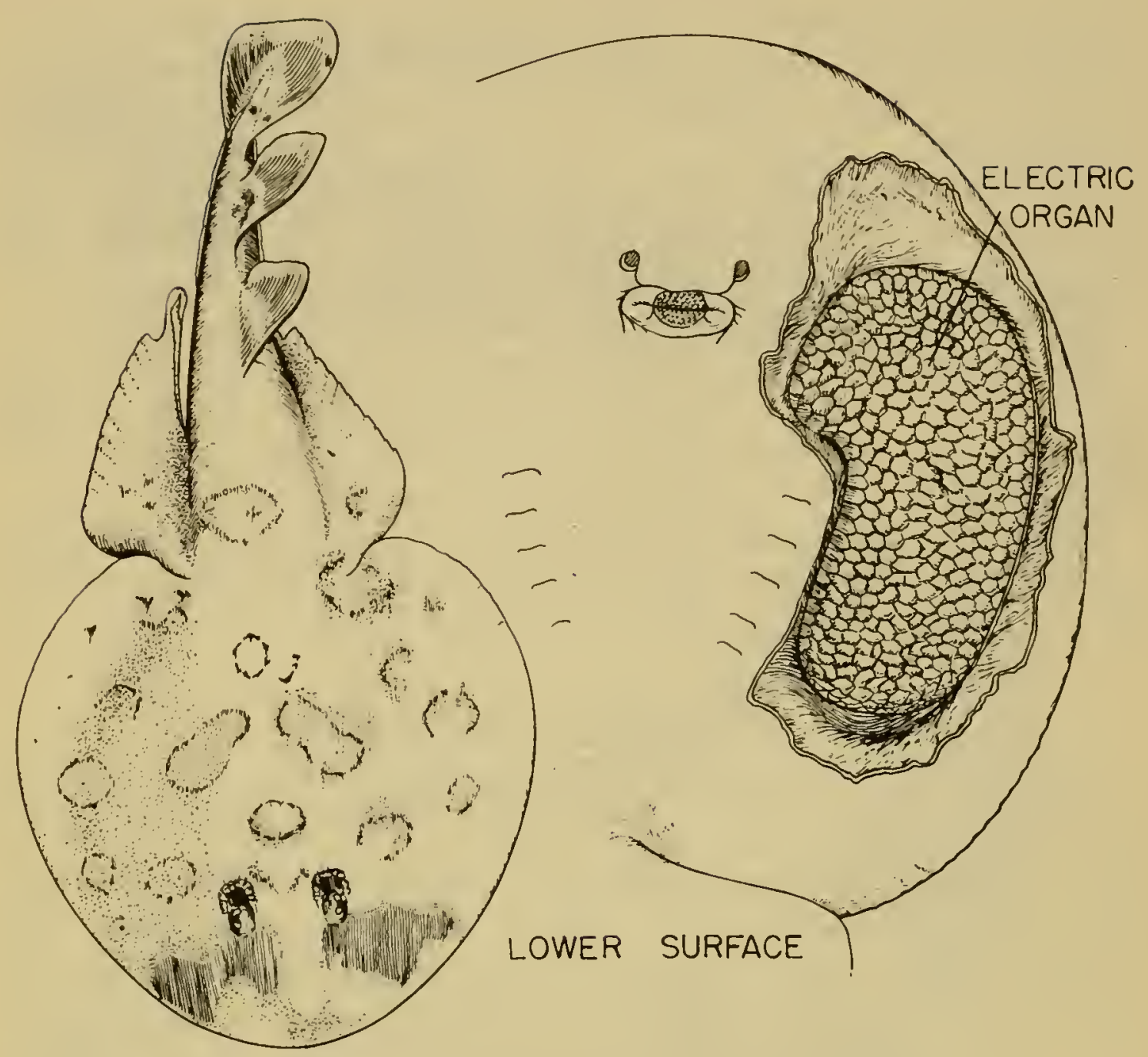

Fig. 87.

Fig. 88 .

Fig. 87. Lesser Electric Ray, Narcine brasiliensis (Olfers). A common electric ray which ranges from Florida and Texas south to Brazil. (After Bigelow and Schroeder)

Fig. 88. Showing the lower surface of the electric ray, Narcine brasiliensis. The skin is removed to reveal the electric organ. (After Bigelow and Schroeder)

tile stimulation. A ray can deliver a successive series of discharges, but he becomes progressively weaker, until finally exhausted. After a period of time, the fish recuperates and again is able to produce electrical discharges. The voltage delivered varies with the individual species, but it is said to range from 8 to 220 volts. Completion of the circuit by contacting the ray at two points is not necessary if the ray is in the water. Contact with a large ray may result in a shock sufficient to knock over and temporarily disable a man. Recovery is usually uneventful. 


\section{SELECTED BIBLIOGRAPHY}

BIGELOW, H. F. and SCHROEDER, W. C. 1948. Fishes of the western North Atlantic. Sharks. Sears Found. Mar. Res., Mem. No. 1, Pt. I:59546, figs. 7-106.

BOLIN, R. L. 1954. Report on a fatal attack by a shark. Pac. Sci. 8:105-108, 2 figs.

BOTTARD, A. 1889. Les poissons venimeux. Octave Doin, Paris: $198 \mathrm{pp}$.

BUDKER, P. 1947. La Vie des Requins. Gallimard, Villeneuve-Saint-Georges: 277 pp., 22 pls., 40 figs.

COPPLESON, V. M. 1950. A review of shark attacks in Australian waters since 1919. Med. Jour. Australia, 2:680-687, 7 figs.

COURVILLE, D. A., HALSTEAD, B. W. and HESSEL, D. W. 1958. A review of the literature concerning the chemistry of marine biotoxins. Chem. Rev. $58(2): 235-248$.

EVANS, H. M. 1943. Sting-fish and seafarer. Faber and Faber, Ltd., London: 180 pp., 7 pls., 30 figs.

FISH, C. J. and COBB, M. C. 1954. Noxious marine animals of the central and western Pacific Ocean. Fish and Wildlife Serv. Res. Rept. No. 36:3137,7 pls.

GUDGER, E. W. 1918. Sphyraena barracuda; its morphology, habits, and history. Pub. Carnegie Inst. Washington, 12(252):53-108, 2 figs., 7 pls.

HALSTEAD, B. W. (In preparation). Poisonous and venomous marine animals of the world.

HALSTEAD, B. W. 1956. Animal phyla known to contain poisonous marine animals. In "Venoms". Amer. Assoc. Adv. Sci., Symposium Ser. Pub. No. $44: 9-27$.

HALSTEAD, B W. 1957. Jellyfish stings and their medical management. Armed Forces Med. Jour. 8(11):1587-1602, 11 figs.

HALSTEAD, B. W. 1958. Poisonous fishes. Pub. Health Rept. 73 (4) :303-312, 12 figs.

HIYAMA, Y. 1950. Poisonous fishes of the South Seas. Spec. Sci. Rept., U. S. Fish and Wildlife Serv., No. 25: $188 \mathrm{pp}$.

KAISER, E. and MICHL, H. 1958. Die Biochemie der tierischen Gifte. Einzeldarstellungen aus dem Gesamtgebiet der Biochemie. Neue Folge. II Bd. Franz Deuticke, Wien: 258 pp., 23 abb., 57, Tb.

LLANO, G. A. 1957. Sharks v. men. Sci. Amer. 196(6) :54-61, illus.

PAWLOWSKY, E. N. 1927. Gifttiere und ihre Giftigkeit. Gustav Fischer, Jena: 516 pp., 176 figs.

PHISALIX, M. 1922. Animaux venimeux et venins. Masson et Cie., Paris, $1: 656$ pp.; $2: 864$ pp.; 17 pls., 521 figs.

RUSSELL, F. E. 1953. Stingray injuries: a review and discussion of their treatment. Amer. Jour. Med. Sci., 226:611-622, 3 figs.

SPRINGER, S. 1943. Sharks and their behavior, with particular reference to eight genera implicated in reports of attacks on man. Coord. Res. and Dev., U. S. Navy Emer. Resc. Equip. Sect., Dept. Navy. 31 pp.

SPRINGER, S. 1954. Laboratory experiments with shark repellents. Proc. Gulf and Caribbean Fish. Inst. 7th Ann. Sess. pp. 159-163.

WHITLEY, G. P. 1940. The fishes of Australia. Part 1. The sharks, rays, devil-fish, and other primitive fishes of Australia and New Zealand. Roy. Zool. Soc. New South Wales, Australian Zool. Handbook, 280 pp., 303 figs.

WHITLEY, G. P. and PAYNE, G. H. 1947. Testing a shark repellent. Australian Zool. $2(2)$ : 151-157, pls. 12-13, 1 fig. 



\section{INDEX}

acanthias, Squalus, 53

Acanthurus bleckeri, 87

glaucopareius, 117

triostegus, 120

xanthopteris, 87

Acropora palmata, 34

Actinia cquina, 34

Adamsia palliata, 34

Aetobatis, 61

A tobatus narinari, 57

Albula vulpes, 117

alcicornis, Millepora, 32

Alexander the Great, 6

alta, Carybdea, 33

Anemonia sulcata, 34

Annelid Worms, 32, 47

Annelid worm bites, 47

medical aspects, 47

prevention, 49

treatment, 49

annulatus, Sphaeroides, 115

Anthozoa, 34

A pistus carinatus, 76

A prion virescens, 123

arenaria, Mya, 105

arenarias, Carcharias, 22

arge, Upeneus, 117

argus, Cephalopholis, 125

Aristotle, 5

Arothron hispidus, 115

meleagris, 115

nigropunctatus, 115

Asthenosoma, 51

A sthenosoma ijimai, 49

Atlantic jackknife clam, 105

aulicus, Conus, 39

aureolineatus, Gnathodentex, 123

Australian sea lion, 135

australis, Centropogon, 76

Bagre marinus, 68 sapo, 81

barbatus, Evignathus, 135

Barchatus cirrhosus, 81

Barracuda, 25, 125, 131

Barracuda attacks, 25

medical aspects, 25

prevention, 25

treatment, 25

barracuda, Sphyraena, 25, 125

Batrachoides didactylus, 81 grunniens, 81

batrachus, Clarias, 67

Bat rays, 54, 57

Bay mussel, 105

Bearded seal, 135

Bibliography, 137

Bigelow and Schroeder, 4, 136

birostris, Manta, 24, 25
Diies from sea snakes, 97

medical aspects, 97

prevention, 99

treatment, 98

Biting marine animals, 9

Black sea urchin, 49

Black-tipped sand shark, 108

Bleeker's surgeonfish, 87

bleekeri, Acanthurus, 87

Bloodworm, 47

Blubber, Sea, 34

Blue Bottle, 32

bohar, Lutjanus, 123

Bonito, 112

Bottard, A., 5

brevirostris, Negaprion, 18

Bristle Worms, 32

Budker, Paul, 2, 3

Bullrout, 76

Butterfly rays, 54,57

caerulescens, Hydrophis, 96

caeruleus, Scarus, 125

California bat ray, 57

californianus, Mytilus, 105

Callionymus lyra, 89

capillata, Cyanea, 34

Caranx hippos, 117

Carcharhinidae, 14, 17

Carcharhinus melanopterus, 108 nicaraguensis, 18

obscurus, 18

carcharias, Carcharodon, 17, 109

Carcharias arenarius, 22 gangeticus, 22 taurus, 19

Carchariidae, 14, 19

Carcharodon carcharias, 14, 109

Cardium edule, 105

carinatus, A pistus, 76

Carstenszoon, 2

carunculata, Hermodice, 47

Carybdea alta, 33

catenella, Gonyaulax, 106

Catfishes, 67

Catfish stings, 68

medical aspects, 68

prevention, 68

treatment, 68

Centropogon australis, 76

Cephalopholis argus, 125

Cephalopods, 39,44

Cephalopod bites, 45

fatal octopus bite, 46

medical aspects, 45

prevention, 47

treatment, 47

Chimaera monstrosa, 65

Chimaeroids, 64 
Chinaman fish, 125

chinensis, Sphyraena, 25

Chiropsalmus quadrigatus, 33

Chiropsalmus stings, 36

Choridactylus multibarbis, 78

chryserydros, Parupeneus, 117

Ciguatera, 117, 125

medical aspects, 125

prevention, 127, 131

treatment, 125

Ciguatera-producing fishes, 117

cinera, Neophoca, 135

cirrhosus, Barchatus, 81

Clam, Atlantic jackknife, 105

common Washington, 106

razor, 105

smooth Washington, 106

soft-shelled, 105

solid surf, 105

summer, 105

Clarias batrachus, 67

Clupanodon thrissa, 117

Cnidoblast, 34

Cockle, Common, 105

Coelenterates, 32

Coelenterate stings, 34

medical aspects, 34,36

prevention, 36

treatment, 36

colliei, Hydrolagus, 67

Common cockle, 105

Common mussel, 105

Common Washington clam, 106

Comparison of the venom organs of Pterois, Scorpaena, and Synanceja, 79

complanata, Eurythöe, 47

Cone shell stings, 41

medical aspects, 41

prevention, 44

treatment, 44

Conus, 39,43

Conus aulicus, 39

geographus, 39

striatzes, 39

textile, 39

tulipa, 39

Cook, Captain, 6

Coppleson, V. M., 4

Corals, 32

Coral cuts, 38

medical aspects, 38

prevention, 38

treatment, 38

Coral, elk horn, 34

Coral poisoning, 38

Coral stings, 34,36

Cornutus, Lactoria, 117

Court cone, 39

Cousteau, J. Y., 1

Cow-nosed rays, 54

Cuttlefish, 44

cuvieri, Galcocerdo, 17 cuvieri, Tetragonurus, 120

Cyanea capillata, 34

Cyanea stings, 36

cyanocinctus, Hydrophis, 96

Dactylometra quinquecirrha, 33

Dactylometra stings, 36

Dangerous sharks, 9

Dasyatidae, 54,55

Dasyatis, 61

Dasyatis dipterurus, 55 pastinaca, 57

Deadly death puffer, 115

Decomposing shark meat, 3,4

Deuteronomy, 6

Devil rays, 54

diabolus, Scorpaenopsis, 76

Diadema, 50

Diadema setosum, 49

Diamond stingray, 55

dibranchiata, Glycera, 47

didactylus, Batrachoides, 81

Dinoflagellates, 100

Diodon hystrix, 116

diplana, Sphyma, 22

dipterurus, Dasyatis, 55

directus, Ensis, 105

Dogfish, 1

Dolphins, 135

Donax serra, 105

draco, Trachinus, 72

Dragonets, 89

Dusky shark, 18

duvali, Uranoscopus, 91

Eagle rays, 54, 57

Echinoderms, 32, 49

edule, Cardium, 105

edulis, Mytilus, 105

Eels, poisonous moray, 111

Electric fishes, 135, 136

clegans, Sagartia, 34

clegans, Toxopneustes, 49

Elephantfish, 64

Elk horn coral, 34

Enhydrina schistosa, 96

Ensis directus, 105

Epinephelus, 131

Epinephelus fuscoguttatus, 117

Epibulus insidiator, 123

cquina, Actinia, 34

Erignathus barbatus, 135

erythrinus, Pagellus, 117

European ratfish, 65

European stingray, 57

Eurythöe, 47

Eurythöe complanata, 47

Evans, H. Muir, 5

fclis, Galcichthys, 67

Fire Coral, 32

Fish poisoning, ciguatera type, 125

medical aspects, 125

prevention, 127,131

treatment, 127 
favimarginatus, Gymnothorax, 111

Fortescue, 76

fossilis, Hetcropneustes, 68

Freshwater stingrays, 60

Fugu, 113

fuscesccns, Siganus, 90

fuscoguttatus, Epinephelus, 117

gaimardi, Julis, 123

Galcichthys fclis, 67

Galeocerdo cuvieri, 17

Ganges River Shark, 22

gangeticus, Car'charias, 22

Gaper clam, 105

Gastropods, 39

Geographer Cone, 39

geographus, Conus, 39

Giant devil ray, 24

Giant grouper, 28

Giant killer clams, 31

Giant squid, 44

gibbus, Lutjanus, 123

giganteus, Saxidomus, 106

glaucopareius, Acanthurus, 117

glaucus, Isurus, 17

Globiferous pedicellariae, 50,51

Glycera , 47, 49

Glycera dibranchiata, 47

Gnathodentex aureolineatus, 123

Gonyaulax catenella, 106

Grampa orca, 28

grandoculis, Monotaxis, 125

Gray nurse shark, 22

Great barracuda, 25

Great weever, 70

Greenland shark, 109

Green sea turtle, 133

Grouper, 117, 131

grunniens, Batrachoides, 81

guntheri, Isurus, 17

guttata, Scorpaena, 76

Gymnothorax flavimarginatus, 111 javanicus, 111

meleagris, 111

mordax, 26

pictus, 112

undulatus, 112

Gymnura, 60

Gymnura marmorata, 57

Gymnuridae, 54

Habits of sea snakes, 95

halleri, Urolophus, 60

Hammerhead, 14

Hammerhead shark, 22, 111

Hawksbill turtle, 133

helena, Muraenophis, 26, 70

Heptranchias perlo, 109

Hermodice carunculata, 47

Herring, 117

Heteropneustes fossilis, 68

Hime-Okoze, 78

hippos, Caranx, 117 hispidus, Arothron, 115

Hiyama, Yoshio, 6, 7

Horned sharks, 53

Horned shark stings, 54

horrida, Synanceja, 78

Hydroids, 32

Hydroid stings, 34

Hydrolagus colliei, 67

Hydrophis caerulescens, 96

cyanocinctus, 96

nigrocinctus, 96

semperi, 95

Hydrozoa, 32

hystrix, Diodon, 116

ijimai, Asthenosoma, 49

Inimicus japonicus, 78

insidiator, Epibulus, 123

Invertebrates, 32

Isuridae, 14

Isurus glaucus, 17

guntheri, 17

oxyrinchus, 17

Jacks, 117, 131

japonicus, Inimicus, 78

japonicus, Uranoscopus, 91

javanicus, Gymnothorax, 111

Jellyfish, 32, 33

Jonah, 2

Julis gaimardi, 123

Killer clams, 31

Killer whales, 28

Lacépède, Bernard, 2

Lactophrys trigonus, 117

Lactoria cornutus, 117

Ladyfish, 117

Lake Nicaragua Shark, 18

Lamna nasus, 17

Laticauda, 95

Leatherback turtle, 133

Lemon shark, 18

Lesser weever, 72

Lethrinus miniatus, 123

Ligature-cryotherapy treatment, 93

lineatus, Siganus, 90

Lionfish, 76

lituratus, Naso, 87

Llano, George, 4

Loligo vulgaris, 44

longimanus Pterolamiops, 18

Long-spined sea urchin, 49

louti, Variola, 125

Lupo, 78

Lutjanus bohar, 123

gibbus, 123

monostigma, 123

vaigiensis, 123

lyra, Callionymus, 89 
Mackerel, 112

Mackerel shark, 14, 17

Magnus, Olaus, 2

Maki-maki, 115

Mammals, poisonous marine, 134

Manchineel berries, 6

Man-eater, 14

Manta birostris, 24

Mantas, 24, 54

Marbled cone, 39

Marine animals, poisonous to eat, 100 History of, 6

Marine animals that sting, 32

Marine mammals, 133

marinus, Bagre, 68

maritimus, Thalarctos, 134

marmorata, Gymnura, 57

Martyr, Peter, 6

melanopterus, Carcharhinus, 108

meleagris, Gymnothorax, 111

microcephalus, Somniosus, 108, 109

microrhinos, Scarus, 125

Millepora alcicornis, 32

miniatus, Lethrinus, 123

Minous monodactylus, 78

Mishmimaokoze, 91

Mobulidae, 54

modiolus, Volsella, 105

Molluses, 32, 39

monodactylus, Minous, 78

monostigma, Lutjanus, 123

Monotaxis grandoculis, 125

monstrosa, Chimaera, 65

Moray eels, '26, 70

Moray eel bites, 26

medical aspects, 28

prevention, 28

treatment, 28

Moray eels, poisonous, 111

Moray eel poisoning, 112

medical aspects, 112

prevention, 112

treatment, 112

mordax, Gymnothorax, 26

Moses, 6

motoro, Potamotrygon, 60

multibarbis, Choridactylus, 78

Munda, 81

Muraenidae, 26, 70

Muraena helena, 26, 70

Mussel, Bay, 105

Mussel, Common, 105

Northern horse, 105

White, 105

Mya arenaria, 105

Mycteroperca venenosa, 117

Myliobatidae, 54, 57

Myliobatis, 61

Mytilus californianus, 105

Mytilus edulis, 105 narinari, Aetobatus, 57

Naso lituratus, 87

nasus, Lamna, 17

Nautilus, 44

Negaprion brevirostris, 18

Nematocyst, 34

Neophoca cinerea, 135

Nettle, Sea, 33

nicaraguensis, Carcharhinus, 18

nigrocinctus, Hydrophis, 96

nigropunctatus, Arothron, 115

Nigrosine dye, 4

Northern horse mussel, 105

Notesthes robusta, 76

muttalli, Saxidomus, 106

nuttalli, Schizothaerus, 105

obscurus, Carcharhinus, 18

Octopus, 32, 39, 44

bites, 45

medical aspects, 45

prevention, 47

trea tment, 47

habits, 44

venom apparatus, 44

oligacanthus, Plectropomus, 125

Opsanus tau, 81

orca, Grampa, 28

oxyrinchus, Isurus, 17

Oysterfish, 81

Pacific ratfish, 67

Pagellus erythrinus, 117

Pagrus pagrus, 120

palliata, Adamsia, 34

palmata, Acropora, 34

Paradicichthys venenatus, 125

Paralytic shellfish poisoning, 100, 105

Parrotfish, 125

Parupeneus chryserydros, 117

pastinaca, Dasyatis, 57

Pawlowsky, E. N., 6

Pedicellariae, $50,51,52$

Pelamis platurus, 95,96

perlo, Heptranchias, 109

Peron, François, 2

Pharaohs, 6

Phisalix, Marie, 6

Physalia physalis, 32

physalis, Physalia, 32

pictus, Gymnothorax, 112

pileolus, Toxopneustes, 49

platurus, Pelamis, 95, 96

Plectropomus oligacanthus, 125 truncatus, 125

Poisoning from moray eels, 112

medical aspects, 112

prevention, 112

treatment, 112

Poisoning from puffers, 116

medical aspects, 116

prevention, 116

treatment, 116 
Poisoning from scombroid fishes, 112 medical aspects, 112 prevention, 113 treatment, 113

Poisoning from shark liver, 111 medical aspects, 111 prevention, 111 treatment, 111

Poisoning from turtles, 133 medical aspects, 133 prevention, 133 treatment, 133

Poisonous fishes, 107, 108 marine animals, 100 marine mammals, 134 marine turtles, 133 molluscs, 100 moray eels, 111 puffer-like fishes, 113 scombroid fishes, 112 sharks and rays, 108

Polar bear, 134

Porbeagle shark, 17

Porcupine fish, 116 porcus, Scorpaena, 76 Porgie, 120

Portuguese Man-O'-War, 32

Potamotrygon, 61

Potamotrygonidae, 54, 60

Prevention of anemone stings, 36 barracuda bites, 25 bristleworm stings, 49 catfish stings, 69 ciguatera, 127 coelenterate stings, 36 cone shell stings, 44 coral cuts, 38 coral stings, 36 dogfish stings, 54 horned sharks, 54 jellyfish stings, 36 moray eel bites, 28 moray eel poisoning, 112 octopus bites, 47 paralytic shellfish poisoning, 106 puffer poisoning, 116 rabbitfish stings, 91 scombroid poisoning, 113 scorpionfish stings, 81 sea snake bites, 99 sea urchin stings, 53 shark attacks, 23 shark poisoning, 111 shellfish poisoning, 106 star-gazer stings, 91 stingray stings, 64 stonefish stings, 81 tetraodon poisoning, 116 toadfish stings, 86 turtle poisoning, 133 weeverfish stings, 73 worm bites, 49

zebrafish stings, 81

Ptcrois, 73, 79

Pterois volitans, 76

Pterolamiops longimanus, 18

puellus, Siganus, 90

Puffers, 6, 113

Puffer, deadly death, 115

Puffer-like fishes, poisonous, 113

Puffer poisoning, 116

medical aspects, 116

prevention, 116

treatment, 116

quadrigatus, Chiropsalmus, 33

quinquecirrha, Dactylometra, 33

Rabbitfishes, 89

Rabbitfish stings, 90

medical aspects, 90

prevention, 90

treatment, 90

Rascasse, 76

Ratfishes, 64, 65

Ratfish stings, 67 medical aspects, 67

Razor clam, 105

Red snapper, 123

Red tide phenomenon, 100

Reptiles, 93

Requiem sharks, 14, 17

reticulata, Thalassophryne, 83

Rhinoptera, 61

Rhinopteridae, 54

River rays, 54

robusta, Notesthes, 76

Rondelet, 2

Rosy Anemone, 34

Round stingrays, 54, 60

Sagartia elegans, 34

Sagartia stings, 36

Sand sharks, 13, 19

Sapo, 81

Saurine, 112

Saxidomus giganteus, 106

Saxidomus nuttalli, 106 scaber, Uranoscopus, 91

Scarus caeruleus, 125

Scarus microrhinos, 125

schistosa, Enhydrina, 96

Schizothaerus nuttalli, 105

Scombroid fishes, poisonous, 112

Scombroid poisoning, 112

medical aspects, 112

prevention, 113

treatment, 113

Scorpaena, 73, 76, 78

Scorpaena guttata, 76

Scorpaena plumieri, 76

Scorpaena porcus, 76

Scorpaenidae, 73

Scorpaenopsis diabolus, 76 
Scorpionfishes, 73

Scorpionfish stings, 80

medical aspects, 80

prevention, 81

treatment, 81

Scorpionfish venom organs, 80

Scyliorhinid sharks, 9

Scyphozoa, 32, 36

Sea Anemone, 32, 34

Sea Anemone stings, 34,36

medical aspects, 34,36

prevention, 36

treatment, 36

Seabass, 28, 117

Sea blubber, 34

Sea catfish, 68

Sea cucumbers, 49

Seals, 9 bearded, 135

Sea lions, 28 Australian, 135

Sea nettle, 33

Sea pig, 76

Sea snakes, $53,93,96$

bites, 97

medical aspects, 97

prevention, 99

treatment, 98

habits, 95

Sea stars, 32,49

Sea urchins, 32,49

stings, 52

medical aspects, 52

Sea Wasp, 33

Segmented worms, 47

semperi, Hydrophis, 95

Serpentes, 93

serra, Donax, 105

Serranidae, 28

setosum, Diadema, 49

Seven-gilled shark, 109

Shark billy, 22

Shark chaser, 4

Shark Menace Advisory Committee, 4

Sharks, 1, 9

attacks upon man by, 14

fatality rate, 22

first aid management, 22

medical aspects, 22

prevention, 23

treatment, 22

auditory nerves of, 11

black-tipped sand, 108

blood and food in water with, 9

cannibalism in, 11

carcharhinid, 11

detection of food of, 10

diet of, 9

feeding pattern of, 11

individual, 11

mob, 11

geographical location of attacks, 14

Greenland, 109 gustatory organs of, 11

history of shark attacks, 1-4

incidence of shark attacks, 14

intelligence of, 11

lateral line of, 11

liver of, 111

migration of, 14

noise, effect upon, 11

olfactory organs, 11

poisoning by, 111

poisonous, 108

repellants, testing of, 3

seasonal incidence of shark attacks, 14

seven-gilled, 109

sharp-nosed Mackerel Shark, 17

six-gilled, 109

species dangerous to man, 14

swimming behavior, 11

teeth of, 9,10

visual acuity, 11

white, 109

Shellfish poisoning, 106

gastrointestinal type, 106

allergic type, 106

paralytic type, 106

medical aspects, 106

prevention, 106

treatment, 106

Siganidae, 89,90

Siganus fuscescens, 90

lineatus, 90

puellus, 90

Skipjack, 112

Smooth Washington clam, 106

Snapper, 123, 125

red, 123

Soft-shelled clam, 105

solidissima, Spisula, 105

Solid surf clam, 105

Somniosus microcephalus, 108, 109

Sphaeroides anmulatus, 115

Sphyraena, 131

barracuda, 25, 125

chinensis, 25

Sphyma diplana, 22

zygaena, 111

Sphyrnidae, 14

Spines of sea urchins, 50

Spisula solidissima, 105

Sponge fishermen's disease, 36

Spotted eagle ray, 57

Springer, Stewart, 4

Squalus acanthias, 53

Squaretail, 120

Squids, 39,44

Star-gazers, 91

stings, 91

medical aspects, 91

prevention, 91

treatment, 91

Stinging cells, 34

coral, 32 
history of, 5 marine animals, 32

Stinging worms, 32

Stingrays, 5, 60 attacks by, 62 medical aspects, 62 prevention, 64 treatment, 64 freshwater, 60

Stings from anemones, 34 annelid wol'ms, 47

bloodworm, 47

blue bottle, 34 catfishes, 68 cone shells, 43 corals, 34

dragonets, 89 horned sharks, 54 hydroids, 34 jellyfishes, 34 octopuses, 45 Portuguese-Man-O'-War, 32 rabbitfishes, 90 ratfishes, 67 scorpionfishes, 73 sea blubber, 34 sea nettles, 34 sea stars, 49 sea urchins, 52 sea wasp, 34 star-gazers, 91 stingrays, 54,55 stonefishes, 73 surgeonfishes, 87 toadfishes, 86 weeverfishes, 70 zebrafishes, 79

Stonefish, 78 stings, 80 medical aspects, 80 prevention, 81 treatment, 80 venom organs, 80

Striated cone, 39 striatus, Conus, 39 Sugar, 36 sulcata, anemonia, 34 Sulky, 76

Summer clam, 105

Surgeonfishes, 87, 117, 120 Bleeker's, 87 yellow-finned, 87

Surmullet, 117

Synanceja, 73,76

Synanceja horrida, 78

tau, Opsanus, 81 taurus, Carcharias, 19 Tench, 2

Tetragonurus cuvieri, 120 Tetraodontoidea, 113
Tetraodontoid fishes, 113,115

Textile cone, 39

textile, Conus, 39

Thalarctos maritimus, 134

Thalassophryne reticulata, 83

thrissa, Chupanodon, 117

Tiger shark, 18

Toadfishes, 81

stings, 86

medical aspects, 86

prevention, 86

treatment, 86

Toltecs, 6

Toxopneustes, 51

elegans, 49

pileolus, 49

Trachinus draco, 72 vipera, 72

Treatment of anemone stings, 36 barracuda bites, 25 bristleworm stings, 49 catfish stings, 69 ciguatera, 127 coelenterate stings, 36 cone shell stings, 44 coral cuts, 38 coral stings, 36 dogfish stings, 54 horned sharks, 54 jellyfish stings, 36 moray eel bites, 28 moray eel poisoning, 112 octopus bites, 47 paralytic shellfish poisoning, 106 puffer poisoning, 116 rabbitfish stings, 91 scombroid poisoning, 113 scorpionfish stings, 81 sea snake bites, 98 sea urchin stings, 53 shark attacks, 22 shark poisoning, 111 shellfish poisoning, 106 star-gazer stings, 91 stingray stings, 64 stonefish stings, 81 tetraodon poisoning, 116 toadfish stings, 86 turtle poisoning, 133 venomous fish stings, 91 weeverfish stings, 73 worm bites, 49 zebrafish stings, 81

Triakid sharks, 9

Tridacna clams, 31

trigonus, Lactophrys, 117

triostegus, Acanthurus, 120

truncatus, Plectropomus, 125

Trunkfish, 117

Trygon, 5

Tulip cone, 39

tulipa, Conus, 39 
Tuna, 112

Turkeyfish, 73, 76

Turtle, green sea, 133 hawksbill, 133 leatherback, 133

Turtle poisoning, 133 medical aspects, 133 prevention, 133 treatment, 133

Turtles, poisonous marine, 133

undulatus, Gymnothorax, 112

Univalve shellfish, 32,39

Upeneus arge, 117

Uranoscopus duvali, 91 japonicus, 91 scaber, 91

Urolophidae, 54, 60

Urolophus, 61 halleri, 60

vaigiensis, Lutjanus, 123

Variola louti, 125

venenatus, Paradicichthys, 125 veneosa, Mycteroperca, 117

Venom apparatus of anemones, 34 catfishes, 68 cone shells, 41 corals, 34 dogfish, 54 horned sharks, 54 jelly fish, 34 moray eels, 70 octopus, 44 Pterois, 79 rabbitfishes, 90 ratfish, 67

Scorpacna, 79

Scorpionfishes, 79

sea snakes, 96 sea urchin, 50 stingrays, 60 dasyatid type, 61 gymnurid type, 60 myliobatid type, 61 urolophid type, 61 stonefish, 79

surgeonfishes, 87

Synanceja, 79

toadfish, 83

weevers, 72

Venomous

fishes, 53

invertebrates, 32

reptiles, 53

vertebrates, 53

vipera, Trachinus, 72

virescens, A prion, 123

volitans, Pterois, 76

Volsella modiolus, 105

vulgaris, Loligo, 44

vulpes, Albula, 117

Wasp, sea, 33

Waspfish, 76

Weever, great, 72

lesser, 72

stings, 72

medical aspects, 72

prevention, 73

treatment, 73

Weeverfishes, 70

Whales, 135

Whale shark, 9

Whiprays, 54,55

White mussel, 105

White shark, 14, 109

White-tipped shark, 18

Whitley, Gilbert P., 3

Wrasse, 123

xanthopterus, Acanthurus, 87

Yellow-finned surgeonfish, 87

Zebrafish, 1, 73, 74, 79

stings, 80

venom organs, 79

Zephiran, 39

Zervos, S. G., 5

zygaena, Sphyrna, 111 



